KARIN KIRCHGATTER

\title{
Análise de seqüências varde populações naturais de Plasmodium falciparum da Amazônia Brasileira
}


Candidato(a): Karin Kirchgatter.

Título da Tese: Análise de seqüências var de populações naturais de Plasmodium falciparum da Amazônia Brasileira.

A Comissão Julgadora dos trabalhos de Defesa da Tese de Doutorado, em sessão pública realizada a considerou o(a) candidato(a):

1) Examinador(a)

2) Examinador(a)

3) Examinador(a)

4) Examinador(a)

5) Presidente 


\title{
Análise de seqüências varde populações naturais de Plasmodium falciparum da Amazônia Brasileira
}

\author{
Tese apresentada ao \\ Instituto de Ciências Biomédicas \\ da Universidade de São Paulo, \\ para obtenção do título de \\ Doutor em Ciências
}

\begin{abstract}
Área de concentração: Biologia da Relação Patógeno Hospedeiro
\end{abstract}

Orientador: Prof. Dr. Hernando Antonio del Portillo 
DADOS DE CATALOGAÇÃO NA PUBLICAÇÃO (CIP)

Serviço de Biblioteca e Informação Biomédica do

Instituto de Ciências Biomédicas da Universidade de São Paulo

Kirchgatter, Karin.

Análise de seqüências var de populações naturais de Plasmodium falciparum da Amazônia Brasileira / Karin Kirchgatter. -- São Paulo, 2001.

Tese (Doutorado) -- Instituto de Ciências Biomédicas da Universidade de São Paulo.

Departamento de Parasitologia.

Área de concentração: Biologia da Relação Patógeno-Hospedeiro.

Linha de pesquisa: Malária.

Orientador: del Portillo, Hernando Antonio.

Versão do título para o inglês: Analysis of var sequences from natural parasite populations of Plasmodium falciparum in the Brazilian Amazon.

\footnotetext{
Descritores: 1. Malária $\quad$ 2. Plasmodium falciparum $\quad 3$. Malária grave $\quad 4$. Genes var 5 . Proteína PfEMP1 6. DBL1 $\alpha$
} 
Às minhas duas famílias (Kirchgatter \& Hildebrand) e aos meus amigos, pelo estímulo, compreensão e apoio que sempre me deram. 
Ao Nilton, pelo carinho e

paciência nas horas difíceis. 
Aos pacientes com malária, em especial àqueles que fizeram este estudo possível. 


\section{AGRADECIMENTOS}

Ao Prof. Dr. Hernando Antonio del Portillo, pela orientação, pelo esforço na obtenção dos recursos necessários e pela confiança que depositou em mim.

Ao Dr. Luiz Jacintho da Silva, Superintendente da SUCEN, e ao PqC José Carlos Rehder de Andrade, Diretor da Divisão de Programas Especiais, pelo apoio e incentivo à pesquisa.

Ao Prof. Dr. Erney Plessman Camargo, por disponibilizar a infra-estrutura do departamento.

À PqC Silvia Maria Di Santi, pelos momentos difíceis que passou no Laboratório de Malária da SUCEN para que eu pudesse realizar este trabalho e pela amizade com que sempre pude contar.

Ao Prof. Dr. Marcelo Urbano Ferreira, pelo fornecimento de amostras de Rondônia, Acre e Tanzânia e ao Dr. Crispim Cerutti Jr., pelo fornecimento de amostras de Mato Grosso.

Aos Drs. Cris Newbold e Alister Craig, por compartilharem protocolos de PCR e "primers" antes de sua publicação.

À Profa. Dra. Marta Teixeira e aos membros de seu laboratório, por facilitarem a utilização do Seqüenciador Automático.

Ao Prof. Dr. Carlos Winter, pela co-orientação e auxílio nas análises das seqüências e ao Prof. Dr. Marcos Boulos, pela ajuda na análise de dados laboratoriais de pacientes graves.

Aos Drs. Anamaria Aranha Camargo, Alex Fiorini Carvalho e Luiz Fernando Lima Reis, do Instituto Ludwig, pela utilização dos robôs Hydra e Flexys.

À Dra. Emília Kimura, pelo anticorpo anti-eritrócitos humanos e à Dra. Silvia Reni Uliana, pela proteína Meta1-His.

Aos Drs. Camila Indiani de Oliveira, Gerhard Wunderlich e Carmem Fernandez Becerra, pela discussão no dia a dia para solução dos problemas.

Aos Drs. Myrna Garcia Serrano e João Marcelo Pereira Alves, e à Flávia Maia, Rogéria Ventura e Adriana Fuzato, pelo auxílio nos programas de análise de seqüências e pelo convívio diário sempre alegre.

Às minhas alunas, bolsistas da FUNDAP, Veruska Marques e Priscilla Avila, pela colaboração na triagem dos clones e no descongelamento e manutenção dos isolados em cultura.

Aos colegas que participaram de alguma forma deste trabalho, pela colaboração valiosa e aos demais colegas do Departamento de Parasitologia do Instituto de Ciências Biomédicas da USP e do Laboratório de Malária da SUCEN, pela colaboração de todos os dias. 
Este estudo contou com apoio financeiro INCO-DC Programme (IC18-CT98-0364) e Superintendência de Controle de Endemias (SUCEN). 


\section{ÍNDICE}

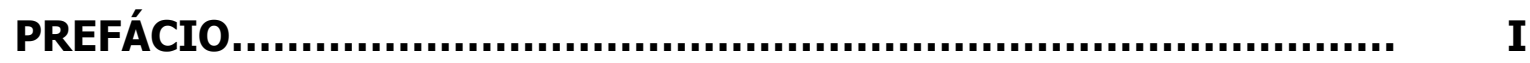

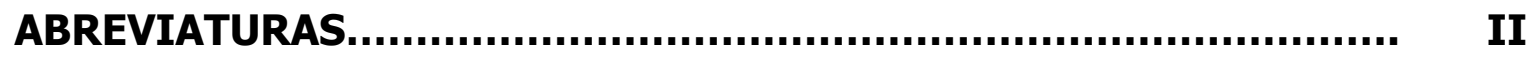

RESUMO

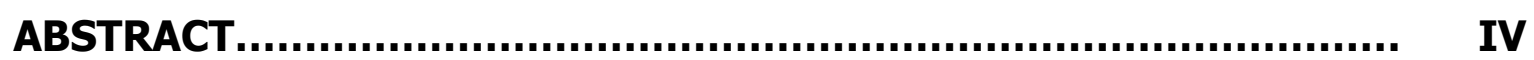

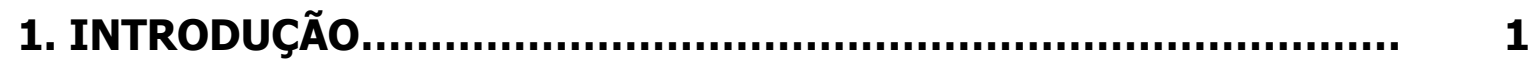

1.1. Ciclo de Vida do Plasmodium................................................................... 2

1.2. Situação da Malária...............................................................................

1.2.1. No Mundo......................................................................................

1.2.2. No Brasil...............................................................................

1.2.3. No Estado de São Paulo.....................................................................

1.3. Aspectos Clínicos e Laboratoriais da Malária Grave.................................. 8

1.4. Aspectos Moleculares da Malária Grave.................................................. 12

1.4.1. Seqüestramento e Citoaderência....................................................... 12

1.4.1.1. Receptores do hospedeiro envolvidos em citoaderência................... 13

1.4.1.2. Ligantes do parasita envolvidos em citoaderência............................ 18

1.4.2. Autoaglutinação e "Rosetting".............................................................. 20

1.4.2.1. Receptores do hospedeiro envolvidos em "rosetting"....................... 21

1.4.2.2. Ligantes do parasita envolvidos em "rosetting"............................... 24

1.4.3. Variação Antigênica....................................................................... 25

1.4.3.1. Proteína de Membrana do Eritrócito 1 (PfEMP1) e Reconhecimento Imune

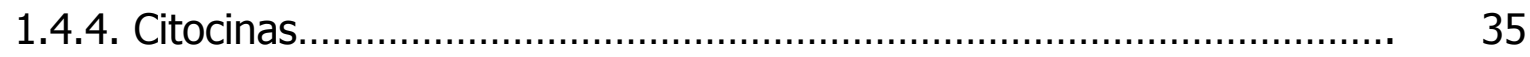




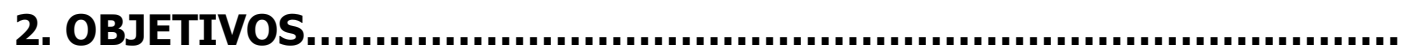

2.1. Objetivo Geral................................................................................ 38

2.2. Objetivos Específicos.................................................................... 38

3. PACIENTES, MATERIAL E MÉTODOS...................................... 40

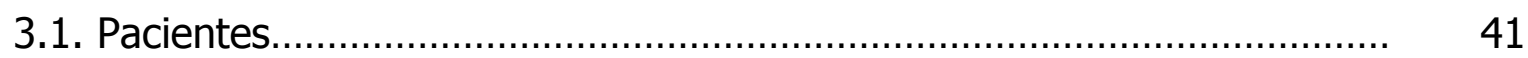

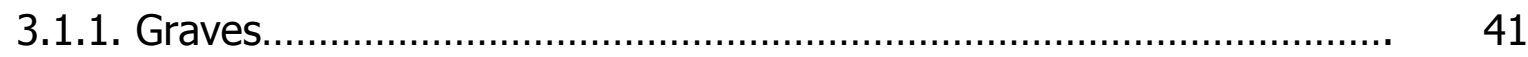

3.1.2. Não Graves.................................................................................... 42

3.2. Descongelamento, cultivo e purificação de parasitas maduros............... 42

3.3. Extração do DNA genômico.................................................................... 43

3.4. Extração de RNA............................................................................... 43

3.5. Tratamento com DNase e Síntese de cDNA.......................................... 44

3.6. Amplificação de DNA ..........................................................................

3.7. Gel de Agarose e Purificação dos Fragmentos........................................ 45

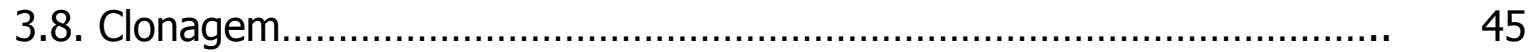

3.9. Análise das Seqüências..................................................................... 46

3.10. Southern Blot.................................................................................... 47

3.10.1. Preparo de Sondas Radioativas...................................................... 47

3.10.2. Preparo, Hibridação e Lavagem das Membranas............................... 47

3.11. PCR Multiplex................................................................................ 48

3.12. Expressão de Proteínas....................................................................... 49

3.13. Imunofluorescência..................................................................... 50 
4.1. Análise do repertório de seqüências $\mathrm{DBL} 1 \alpha$ de genes var de isolados de campo de P. falciparum dos Estados de Mato Grosso e Rondônia, Brasil

4.2. Análise de seqüências DBL1 $\alpha$ de genes var expressos em isolados de campo de $P$. falciparum obtidos de pacientes com malária grave infectados na Região Amazônica Brasileira.

5. CONCLUSÕES.

7. ANEXO 1

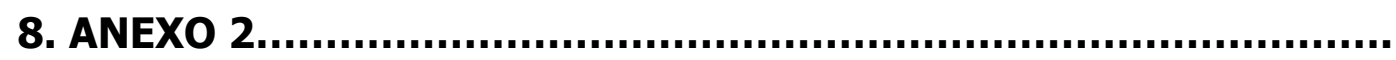

9. ANEXO 3 


\section{PREFÁCIO}

"Esta tese foi elaborada de acordo com as Normas da CPG/ICB relativas a outras formas de elaboração de tese de doutorado que permitem a inclusão, como Anexos, de resultados já publicados em periódicos internacionais indexados em língua inglesa. Permite ainda, que detalhes metodológicos e resultados obtidos sejam aqueles contidos nos artigos anexados ao corpo da tese".

Artigos que compõe o corpo da tese:

Anexo 1 - "Plasmodium falciparum: DBL-1 Var Sequence Analysis in Field Isolates from Central Brazil". 2000. Kirchgatter, K.; Mosbach, R. \& del Portillo, H.A. Experimental Parasitology 95: 154-7.

Anexo 2 - "Association of severe non-cerebral Plasmodium falciparum malaria in Brazil with expressed PfEMP1 DBL1 $\alpha$ sequences lacking cysteine residues". Karin Kirchgatter e Hernando A. del Portillo. Molecular Medicine. Submetido.

Este trabalho foi desenvolvido segundo os aspectos éticos de pesquisas envolvendo seres humanos e foi aprovado em 08/07/1998 pela Comissão de Ética em Pesquisa com Seres Humanos do Instituto de Ciências Biomédicas da USP (Parecer 013/CEP Anexo 4). 


\section{ABREVIATURAS}

aa - aminoácidos

amp - ampicilina

ATS - "acidic terminal segment"

CD - "cluster of differentiation"

CIDR - "cysteine-rich interdomain region"

CLAG - "cytoadherence-linked asexual gene"

CR1 - receptor de complemento 1

CSA - sulfato de condroitina A

CSP - Proteína Circumsporozoíta

dATP - desoxiadenosinatrifosfato

DBL - "Duffy-binding-like domain"

DMSO - dimetilsulfóxido

DNA - ácido desoxirribonucleico

DNase - desoxirribonuclease

DO - densidade óptica

DP - desvio padrão

EBA - "erythrocyte-binding antigens"

EDTA - ácido etileno-diamino-tetra-acético

GST - glutationa-s-transferase

HA - ácido hialurônico

HS - "heparan sulphate"

ICAM-1 - "intercellular adhesion molecule 1"

IFA - Ensaio de imunofluorescência indireta

IgG - Imunoglobulina $G$

IgM - Imunoglobulina $M$

IPTG - isopropil 2-D-tiogalactopiranosídeo

KAHRP - "knob-associated His-rich protein"

$\mathrm{kb}$ - kilobase

kDa - kiloDalton

LB - meio de cultura Lúria - Bertani

PCR - Reação de Polimerização em Cadeia

PECAM-1 - "platelet-endothelial cell adhesion molecule 1"

PfEMP1 - "Plasmodium falciparum erythrocyte membrane protein 1"

RNAse - ribonuclease

SDS - dodecil sulfato de sódio

SDS-PAGE - eletroforese em gel de poliacrilamida com SDS

TEMED - N,N, $\mathrm{N}^{\prime}, \mathrm{N}^{\prime}$ - tetrametil-etilenodiamina

tet - tetraciclina

Tris - Tris -(hidroximetil) - aminometano

TSP - trombospondina

UV - luz ultravioleta

VCAM-1 - "vascular cell adhesion molecule 1" 


\section{RESUMO}

Os genes var de Plasmodium falciparum codificam a proteína PfEMP1 expressa na superfície de eritrócitos infectados e que medeia os fenômenos de citoaderência e "rosetting". Ambos os fenômenos estão diretamente associados à malária grave, e seu domínio mais N-terminal, DBL1 $\alpha$, media especificamente "rosetting". Análise de seqüências DBL1 $\alpha$ de isolados brasileiros e de outros países revelou que a similaridade entre elas não pode predizer origem geográfica. Com o objetivo de determinar se existem seqüências $\mathrm{DBL} 1 \alpha$ associadas à malária grave, analisamos as seqüências DBL1 $\alpha$ expressas em parasitas obtidos de pacientes brasileiros com esta manifestação clínica e encontramos que as seqüências predominantemente expressas apresentavam uma ou duas deleções de cisteínas. Significativamente, apesar de freqüentes no genoma de parasitas de pacientes com malária não grave, essas seqüências foram raramente expressas. Esses dados demonstram a primeira associação de seqüências PfEMP1 expressas e malária grave em pacientes da Amazônia Brasileira. 
ABSTRACT

Plasmodium falciparum var genes code for PfEMP1, a protein expressed on the surface of infected erythrocytes, and which mediates cytoadherence and rosetting. Both phenomena are directly associated with severe malaria and the most $\mathrm{N}$-terminal domain, DBL1 $\alpha$, specifically mediates rosetting. DBL1 $\alpha$ sequence analysis from Brazilian and worldwide isolates revealed that sequence similarities cannot predict geographical origin. To determine whether there are DBL1 $\alpha$ sequences associated with severe malaria, we examined expressed var DBL1 $\alpha$ sequences in patients with severe malaria from the Brazilian Amazon and found that the predominantly expressed DBL1 $\alpha$ sequences from these parasites lacked 1-2 cysteine residues. Significantly, these sequences were amply found on the genomic repertoire of parasites from patients with mild malaria and yet they were rarely expressed. These data demonstrate the first association of particular PfEMP1 expressed sequences and severe malaria in patients from the Brazilian Amazon. 
1. INTRODUÇÃO 


\subsection{Ciclo de Vida do Plasmodium}

A malária é uma doença parasitária transmitida na natureza pela picada de fêmeas de mosquitos do gênero Anopheles infectadas por protozoários do gênero Plasmodium, e caracteriza-se por acessos de febre com intervalos determinados, dependendo da espécie de Plasmodium envolvida. Quatro espécies causam a doença no homem: Plasmodium vivax, P. falciparum, P. malariae e P. ovale. No Brasil, somente três espécies de Plasmodium são encontradas: $P$. vivax e $P$. falciparum, agentes da febre terçã, cujos acessos ocorrem a cada 48 horas e $P$. malariae, responsável pela febre quartã, com acessos a cada 72 horas (revisado em Bruce-Chwatt, 1985).

O ciclo de vida do Plasmodium inicia-se quando o mosquito ingere sangue de um hospedeiro humano contendo formas sexuadas maduras, denominadas gametócitos femininos e masculinos. No estômago do mosquito os gametócitos masculinos sofrem exflagelação, originando gametas masculinos (microgametas), enquanto que os gametócitos femininos sofrem maturação para gametas femininos (macrogametas). O microgameta então, fertiliza o macrogameta, e a fusão destes dois forma o zigoto, que após tornar-se móvel é chamado de oocineto. 0 oocineto fixa-se na parede do estômago, entre as células epiteliais, sendo denominado oocisto. Dentro do oocisto formam-se muitos esporozoítas, células alongadas e móveis, com um núcleo central, que após a liberação na cavidade corpórea do mosquito, alcançam as glândulas salivares tornando-o infectivo. Quando o mosquito alimenta-se novamente de sangue, os esporozoítas são injetados na corrente circulatória. Após um máximo de 30 minutos, os esporozoítas entram nos 
hepatócitos e sofrem processo de desenvolvimento conhecido como esquizogonia pré-eritrocítica. Interessante notar que os esporozoítas podem entrar e sair de muitos hepatócitos, através de penetração direta na membrana plasmática, provavelmente buscando hepatócitos específicos que sejam suscetíveis à infecção (Mota e cols., 2001). Os esquizontes que se formam após a esquizogonia préeritrocítica rompem a célula e liberam merozoítas na circulação, que por sua vez invadem as células vermelhas do sangue e transformam-se em trofozoítas jovens ou anéis. Quando começam a crescer e seu citoplasma torna-se mais irregular, são denominados trofozoítas maduros, e após o processo de divisão assexual, são chamados de esquizontes, contendo vários merozoítas em seu interior. Após o término do processo de divisão os esquizontes rompem as hemácias e os merozoítas liberados na corrente circulatória invadem novas hemácias, iniciando novo ciclo eritrocítico. Esta liberação de parasitas na circulação é responsável pelo aparecimento dos sintomas e portanto, a duração do ciclo eritrocítico determina a

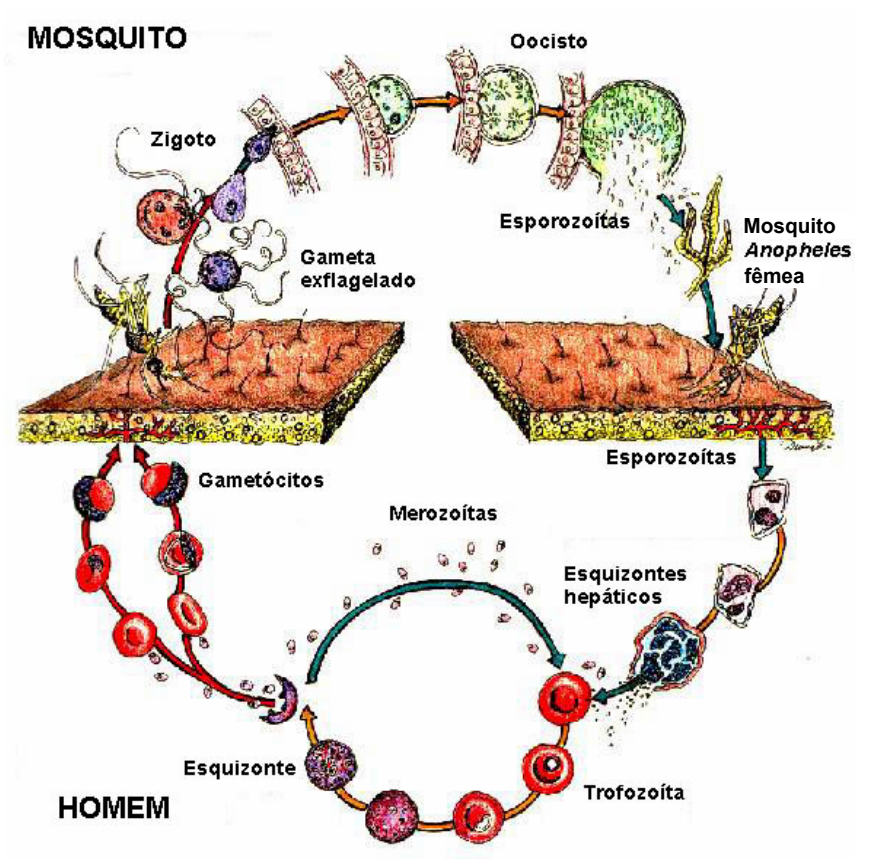

Figura 1. Ciclo de vida do Plasmodium falciparum (modificado de www.malariatest.com). periodicidade destes sintomas, variando entre as espécies de Plasmodium. Após algumas gerações de merozoítas, alguns se diferenciam em formas sexuadas (gametócitos), sofrem maturação e são ingeridos por fêmeas de anofelinos durante 0 repasto sangüíneo, fechando o ciclo (Figura 1). 


\subsection{Situação da Malária}

\subsubsection{No Mundo}

A malária é a doença parasitária tropical mais importante, causando a morte de mais pessoas que qualquer outra doença transmissível, exceto tuberculose. Ocorre principalmente nas regiões tropicais e subtropicais, sendo que $40 \%$ da população mundial vive em áreas de risco. Anualmente, estima-se que ocorram 300 a 500 milhões de casos clínicos e 1,5 a 2,7 milhões de pessoas morrem devido a complicações decorrentes da malária, principalmente no continente africano (Figura 2), sendo 1 milhão de crianças menores de 5 anos de idade. Outros grupos de alto risco são mulheres durante a gestação e viajantes não imunes. Epidemias de malária relacionadas a dificuldades econômicas e problemas ambientais também contribuem para as taxas de mortalidade. P. falciparum é o responsável pela maioria das infecções e quase a totalidade dos óbitos, ocorrendo em muitos países, porém, principalmente no continente africano (revisado em Breman, 2001).

Figura 2.

Taxas de mortalidade da malária

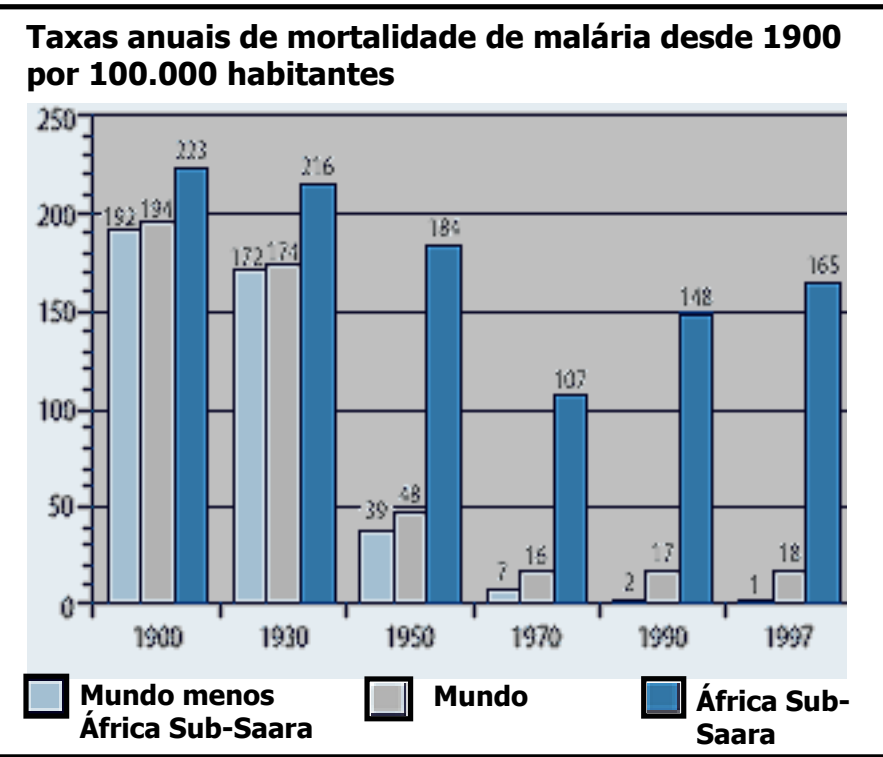

(modificado de http://mosquito.who.int/docs/whr99.htm)

A Organização Mundial de Saúde listou 101 países ou territórios como endêmicos para a malária: 45 países africanos, 21 americanos, 4 europeus, 14 no 
leste mediterrâneo, 8 no sudeste asiático e 9 na região oeste do Pacífico. Entretanto, mais de $90 \%$ de todos os casos de malária estão na África Sub-Saara. Fora do continente africano, 2/3 da malária se concentram em apenas 6 países. Por ordem crescente de incidência estes países são: Ilhas Salomão, Colômbia, Vietnã, Sri Lanka, Brasil e Índia (WHO, 1996).

\subsubsection{No Brasil}

O Brasil é responsável por $50,6 \%$ dos casos de malária registrados nas Américas, sendo que 99,7\% concentram-se na Região Amazônica, principalmente no Pará, Amazonas e Rondônia, responsáveis por quase $80 \%$ dos casos (Figura 3). Em três anos consecutivos (1996, 1997 e 1998), o número de casos notificados no Brasil foi inferior a 500 mil. Entretanto, em 1999, o número oficial chegou a 632.813, registrando um aumento de $34 \%$, com $15 \%$ de acréscimo nas infecções por $P$.

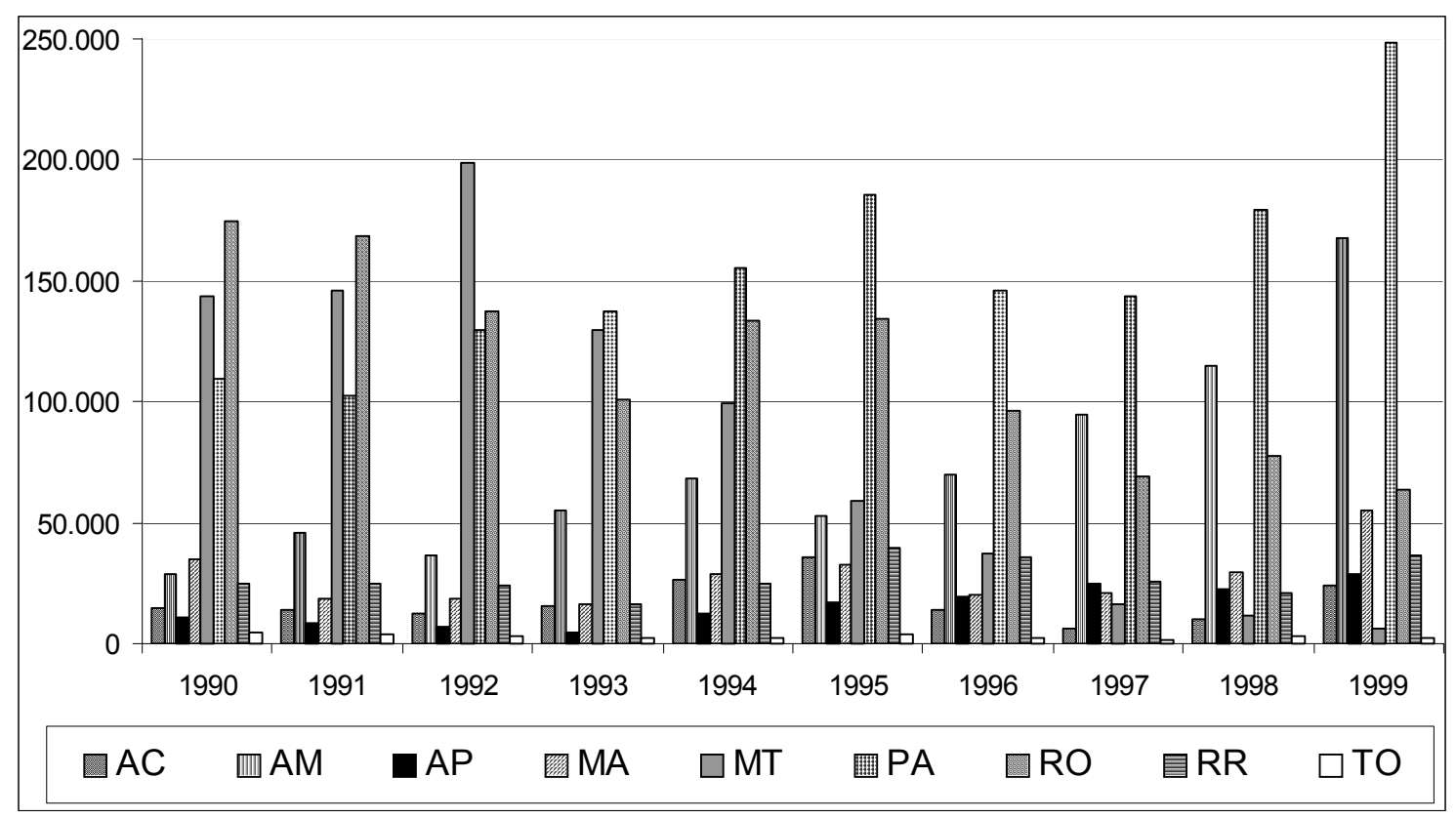

Figura 3. Exames positivos de malária, registrados nos estados da Amazônia Legal. Brasil, 1990 a 1999. Fonte: GT/Malária e Coordenações Regionais da FUNASA. 
falciparum. Já em 2000, houve um pequeno decréscimo, sendo notificados 611.042 casos (www.funasa.gov.br/epi/pdfs/casos_conf_por_uf_1980_2000.pdf). O número de óbitos devido à malária varia de estado para estado, é impreciso e provavelmente subnotificado. Em 1998, 151 óbitos devido à malária foram registrados, contra 137 de 1997, o que significa $10 \%$ de aumento (www.funasa.gov.br/epi/malaria/pdfs/resumo_exec_pcim.pdf).

Segundo a Organização Mundial de Saúde, o risco de se adquirir malária na Amazônia Brasileira (incidência por 1000 habitantes) é de 30,3, o 3o índice do continente. Porém, os países endêmicos do continente africano têm uma média de 120, variando de 0,01 (Argélia) a 501 (Malaui). O Brasil também responde pela maioria das infecções causadas por $P$. falciparum no continente americano, mas possui um índice de risco de 10,3, menor que o observado para as Guianas (WHO, 1997).

No que diz respeito à espécie de plasmódio detectada, até 1983 o $P$. vivax teve maior freqüência relativa. Entretanto, por motivos ainda pouco esclarecidos, de 1984 a 1988 o P. falciparum apresentou ligeiro predomínio, sendo detectado em mais de 50\% das lâminas positivas. Então, desde 1988, quando ocorreu nova inversão da fórmula parasitária, o $P$. vivax tem sido a espécie predominante no Brasil. Em 1999 e 2000, somente 18,6\% e 20,5\% dos casos foram causados por $P$. falciparum, respectivamente (fontes SUCEN, Gerência Técnica de Malária e Coordenações Regionais da FUNASA).

Acredita-se que a expansão da rede de laboratórios, aliada ao uso da mefloquina e de testes imunocromatográficos nas áreas de difícil acesso, tenha contribuído para a diminuição do número de $P$. falciparum no Brasil. Em 
contrapartida, o tratamento para $P$. vivax é de duração mais longa e a doença geralmente se manifesta de forma benigna, levando o paciente a não aderir por completo ao tratamento. A partir daí ocorrem as recaídas, aumentando as fontes de infecção e a quantidade de casos de malária por $P$. vivax.

Soma-se a esse quadro o aparecimento no Brasil de cepas de $P$. vivax mais virulentas, capazes de causar casos graves de malária (Kalmar e cols., 1998) e de cepas multi-resistentes aos antimaláricos tais como cloroquina e mefloquina (Alecrim e cols., 1999).

\subsubsection{No Estado de São Paulo}

O Estado de São Paulo não é considerado área com transmissão ativa de malária, sendo registrados poucos casos autóctones anualmente, em regiões de Mata Atlântica com plantas da família Bromeliaceae, que funcionam como criadouros de anofelinos do subgênero Kerteszia. A malária associada a estes vetores, sempre causada por $P$. vivax ou $P$. malariae, apresenta quadro bem específico com parasitemias baixas, sintomas moderados e transmissão isolada.

Os casos importados representam quase a totalidade de casos registrados no estado. Apesar do aumento de casos de malária no Brasil, a Superintendência de Controle de Endemias (SUCEN), órgão responsável pelo diagnóstico, tratamento e controle do vetor da doença no estado, vem registrando decréscimo no número de casos. Em 1999, foram registrados 292 casos de malária, sendo 75,3\% diagnosticados como $P$. vivax, 20,2\% P. falciparum e 4,5\% P. vivax associado a $P$. falciparum (fonte SUCEN). 
Já na capital do estado, o Laboratório de Malária registrou 105 casos em 2000, sendo 65,7\% P. vivax, 28,6\% P. falciparum, 2,8\% P. malariae e 2,8\% $P$. vivax associado a P. falciparum. Muitos casos são importados de outros países endêmicos $(21 \%)$, entretanto, os estados brasileiros de Pará e Rondônia foram responsáveis por quase a metade dos casos (fonte SUCEN).

Infelizmente, alguns profissionais de saúde do Estado de São Paulo, assim como de outras áreas não endêmicas para malária, não estão habituados a suspeitar, diagnosticar e tratar casos desta doença. O atraso na formulação da hipótese diagnóstica de malária e freqüentemente a suspeita de outras infecções, podem causar uma piora no quadro clínico, fazendo com que a porcentagem de casos graves seja mais elevada nessas regiões.

\subsection{Aspectos Clínicos e Laboratoriais da Malária Grave}

Malária grave designa uma infeção com manifestações e complicações que são potencialmente fatais no homem (Warrel, 1987), causando 15 a $20 \%$ de mortalidade apesar das drogas antimaláricas efetivas e da assistência médica correta (WHO, 1990). Anualmente, 5 a 10 milhões de indivíduos infectados desenvolvem complicações durante a infecção, manifestadas como coma (malária cerebral), acidose metabólica, hipoglicemia, anemia severa, insuficiência renal e edema pulmonar (White e Ho, 1992), cuja freqüência pode variar conforme o nível de transmissão de malária na área (Tabela 1). 
Tabela 1. Principais manifestações de malária grave observadas e grupo etário mais atingido, em áreas de diferentes níveis de transmissão de malária.

\begin{tabular}{l|l|l}
\hline TRANSMISSÃO & $\begin{array}{l}\text { PRINCIPAL MANIFESTAÇÃO DE MALÁRIA } \\
\text { GRAVE }\end{array}$ & GRUPO ETÁRIO \\
\hline ALTA & ANEMIA & CRIANÇAS JOVENS \\
\hline INTERMEDIÁRIA & MALÁRIA CEREBRAL E ACIDOSE METABÓLICA & $\begin{array}{l}\text { CRIANÇAS DE TODAS } \\
\text { AS IDADES }\end{array}$ \\
\hline \multirow{2}{*}{ BAIXA } & INSUFICIÊNCIA RENAL E EDEMA PULMONAR & ADULTOS \\
\cline { 2 - 3 } & ANEMIA E HIPOGLICEMIA & CRIANÇAS \\
\cline { 2 - 3 } & MALÁRIA CEREBRAL E ACIDOSE METABÓLICA & TODOS \\
\hline
\end{tabular}

(WHO, 1990; Luxemburger e cols., 1996; Snow e cols., 1997).

Em muitas partes do mundo, disfunção cerebral é a manifestação grave mais comum da malária falciparum e a principal causa de morte em adultos com malária grave. Devido à característica histopatológica comum de obstrução das veias e capilares do cérebro com eritrócitos contendo trofozoítas maduros e esquizontes, o coma desenvolve-se rapidamente após a convulsão generalizada conduzindo a uma letalidade de 4 a 50\%. Na Tailândia e Vietnã, metade dos casos de malária falciparum grave têm malária cerebral (Tran e cols., 1996). Entretanto em outros locais, como Papua Nova Guiné, esse número cai para 17\% (Lalloo e cols., 1996). Esse dado para o Brasil não está disponível, mas tendo em vista as publicações existentes, pode-se notar que a malária falciparum grave, neste país, apresenta quase que exclusivamente complicações renais e respiratórias (Corbett e cols., 1989; Duarte e cols., 1985; Boulos, 1992).

Edema pulmonar agudo também é uma complicação fatal comum, apresentando edema intersticial com células endoteliais aumentadas e monócitos estreitando o lumem capilar. O interstício edematoso também contém macrófagos com endócitos e pigmento malárico (Duarte e cols., 1985). 
Outra complicação importante na malária grave é a insuficiência renal aguda, definida como um aumento na creatinina sérica acima de $3 \mathrm{mg} / \mathrm{dL}$ ou um aumento na uréia sangüínea acima de 40 mg\%. Pacientes com insuficiência renal aguda sem envolvimento de múltiplos órgãos têm um bom prognóstico se a diálise peritoneal for realizada. No Vietnã, metade dos pacientes com malária grave apresentava evidência bioquímica de envolvimento renal (creatinina sérica $>2 \mathrm{mg} / \mathrm{dL}$ ), entretanto somente $30 \%$ preenchiam os critérios da WHO para insuficiência renal aguda e metade deles necessitaram de diálise. Edema pulmonar é comum em pacientes com insuficiência renal (50\%), cuja mortalidade pode chegar a 45\% (WHO, 2000).

Anemia é uma conseqüência inevitável da malária grave, sendo definida por $\mathrm{Hb}<7 \mathrm{~g} / \mathrm{dL}, \mathrm{Ht}<20 \%$. Icterícia (bilirrubina total no soro $>3 \mathrm{mg} / \mathrm{dL}$ ) é comum em pacientes com insuficiência renal aguda e em parasitemias acima de $100.000 / \mathrm{mm}^{3}$ (WHO, 2000).

Um aspecto laboratorial importante da malária grave é o grau de neutrófilos (mas não de monócitos) contendo pigmento malárico que, em áreas hipoendêmicas, tem sido utilizado para predizer a gravidade da infecção, com sensibilidade e especificidade maior que 73\% (Nguyen e cols., 1995). Em áreas hiperendêmicas não há correlação entre neutrófilos ou mesmo monócitos com pigmento e malária grave (Metzger e cols., 1995).

Níveis séricos de procalcitonina (PCT) têm sido determinados em pacientes com malária (Davis e cols., 1994; Al-Nawas e Shah, 1997). Em pacientes graves, concentrações de PCT antes do tratamento foram encontradas diretamente proporcionais às parasitemias (Hollenstein e cols., 1998). Além das concentrações mais baixas encontradas em pacientes semi-imunes, em relação a não imunes, as 
mais altas concentrações foram obtidas em pacientes com malária grave, sendo que 6 dos 7 pacientes com níveis de PCT >25ng/ml morreram (Chiwakata e cols., 2001). A PCT já é conhecida como marcador de sepsis, onde são encontrados valores $>100 \mathrm{ng} / \mathrm{ml}$ (Assicot e cols., 1993). Em indivíduos saudáveis a PCT é indetectável $(<0.1 \mathrm{ng} / \mathrm{ml})$. Entretanto, além de infecções bacterianas, fúngicas e parasitárias, outros estímulos são responsáveis pela elevação da PCT, como queimaduras, traumas e pancreatites (Nylen e cols., 1998). Tanto a origem como o papel da PCT na sepsis são desconhecidos, mas acredita-se que sua produção ocorra nas células do sistema monócito-macrófago (Oberhoffer e cols., 1999), mediando uma resposta secundária que aumenta a resposta inflamatória (Whang e cols., 1999).

Por fim, precisamos ter em mente que a malária é uma doença sistêmica,

onde os diferentes

sistemas afetados

refletem a infecção

dos eritrócitos.

Portanto, não se pode

esperar que um

único órgão ou

sistema seja afetado,

mas muitos, com

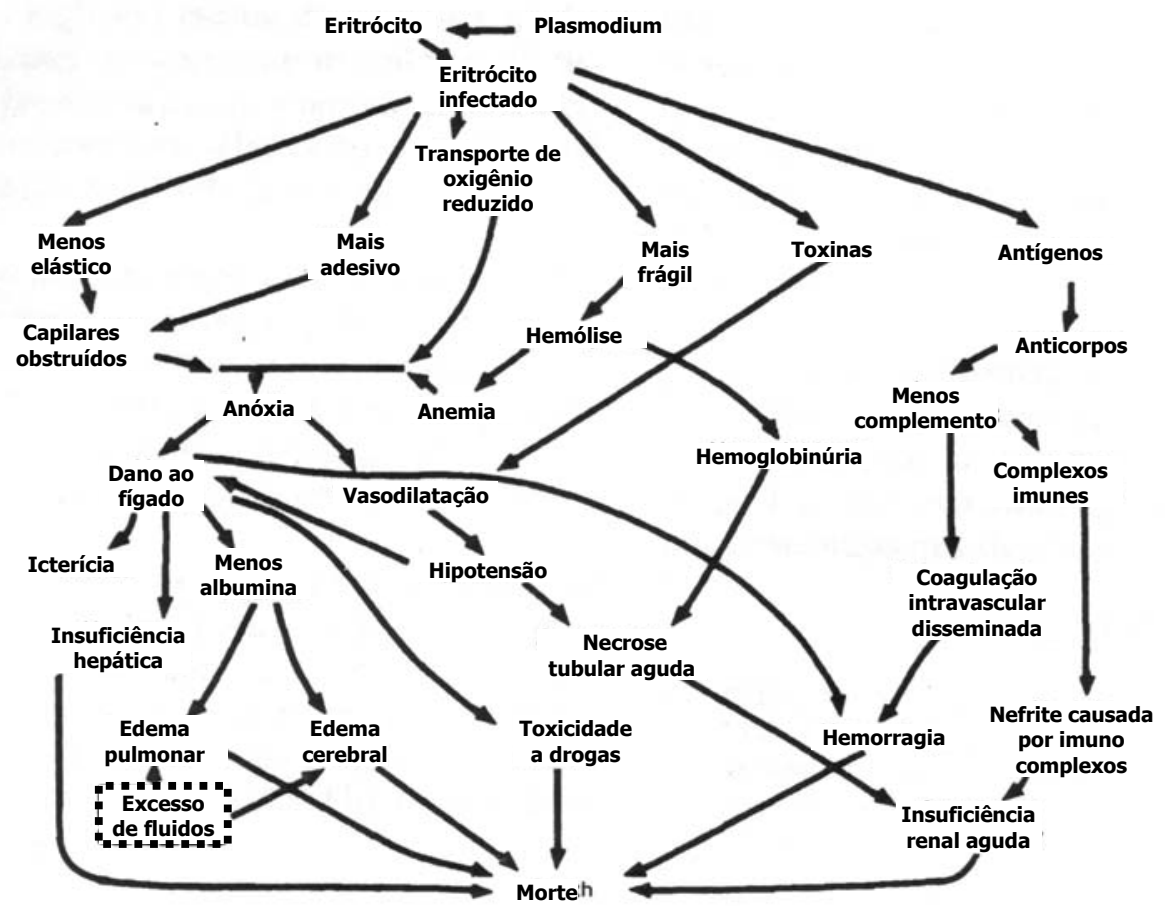

os respectivos sinais

e sintomas (Figura 4).

Figura 4. Inter-relações existentes entre os fenômenos da malária falciparum grave (modificado de Boulos, 1992). 
A malária grave, portanto, é uma síndrome complexa, determinada por fatores tanto do hospedeiro como do parasita. Dentre os fatores do parasita que podem ser citados como fenótipos de virulência devemos ressaltar a capacidade de citoaderência, "rosetting" e variação antigênica, além da indução de diversas citocinas.

\subsection{Aspectos Moleculares da Malária Grave}

\subsubsection{Seqüestramento e Citoaderência}

O ciclo eritrocítico do $P$. falciparum apresenta uma particularidade em relação a outros plasmódios que parasitam o homem. Trofozoítas maduros e esquizontes são seqüestrados da circulação periférica (Bignami e Bastianelli, 1889), devido à adesão dos eritrócitos infectados a células endoteliais (Miller, 1969). Alterações na superfície dos eritrócitos infectados, denominadas "knobs", são os sítios de adesão ao endotélio e a outros eritrócitos (Luse e Miller, 1971)(Figura 5). Essa habilidade de adesão do parasita Ihe permite escapar do clareamento pelo baço e fornece uma melhor maturação no ambiente venoso microaerofílico.

Entretanto, vale a pena ressaltar que eritrócitos infectados com trofozoítas maduros de $P$. vivax, $P$. ovale e $P$. malariae são capazes de passar pelo baço.

Figura 5. Ciclo eritrocítico do Plasmodium falciparum (modificado de Bolad e Berzins, 2000).

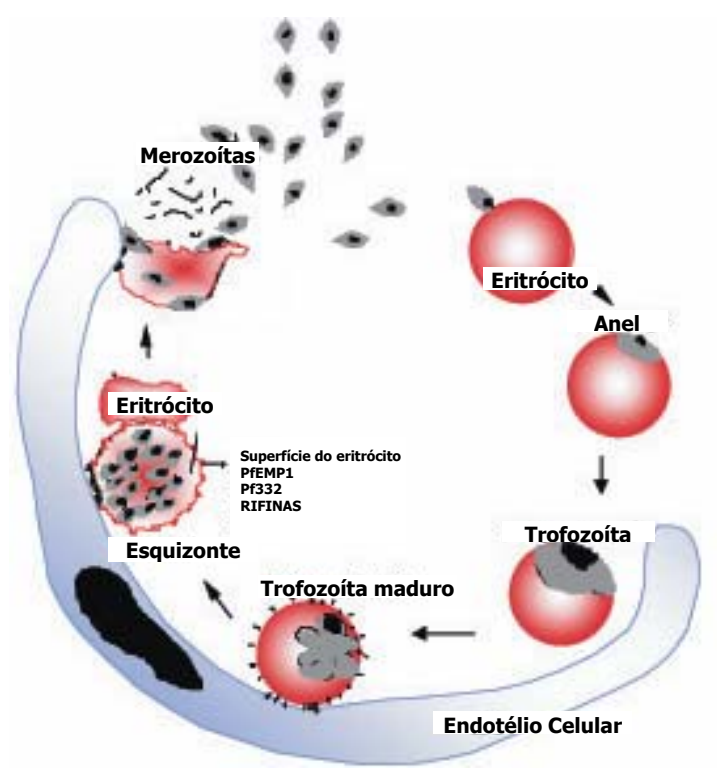


Apesar da maioria dos estudos focarem $P$. falciparum, seqüestramento também foi observado na malária de roedores e primatas (Jacobs e Warren, 1967; Smith e cols., 1982; Gilks e cols., 1990; Aikawa e cols., 1992; Fujioka e cols., 1994).

Interessante notar que, desafiando o conceito geral em relação à biologia dos estágios eritrocíticos de $P$. falciparum, a análise de sua distribuição nos capilares de cérebro de 50 pacientes revelou que todos os seus estágios de desenvolvimento são seqüestrados durante uma malária grave (Silamut e cols., 1999). Realmente, eritrócitos infectados com trofozoítas jovens, podem aderir especificamente às células endoteliais de cérebro e pulmão. Essa adesão ocorre através de duas proteínas do parasita recém identificadas (RSP-1 e RSP-2) que são exportadas para a superfície do eritrócito infectado e desaparecem rapidamente após o início da adesão por PfEMP1 (ver 1.4.3.1) (Pouvelle e cols., 2000).

A adesão ao endotélio, ou citoaderência, tem papel importante na patogenicidade da doença (Miller e cols., 1994), causando oclusão de pequenos vasos e contribuindo para falência de muitos órgãos (Howard e Gilladoga, 1989; Patnaik e cols., 1994). Citoaderência é um termo que pode também ser utilizado genericamente para designar, além de adesão ao endotélio, adesão de hemácias parasitadas a outras hemácias infectadas (autoaglutinação) ou mesmo a hemácias não infectadas ("rosetting").

\subsubsection{Receptores do hospedeiro envolvidos em citoaderência}

Várias moléculas já foram identificadas como receptores endoteliais por sua habilidade em aderir a eritrócitos parasitados em ensaios in vitro (Figura 6 e Tabela 2). 


\section{Figura 6.}

Representação esquemática das moléculas implicadas em citoaderência. Linhas pontilhadas significam interações ainda não confirmadas (modificado de Cooke e cols., 2000).

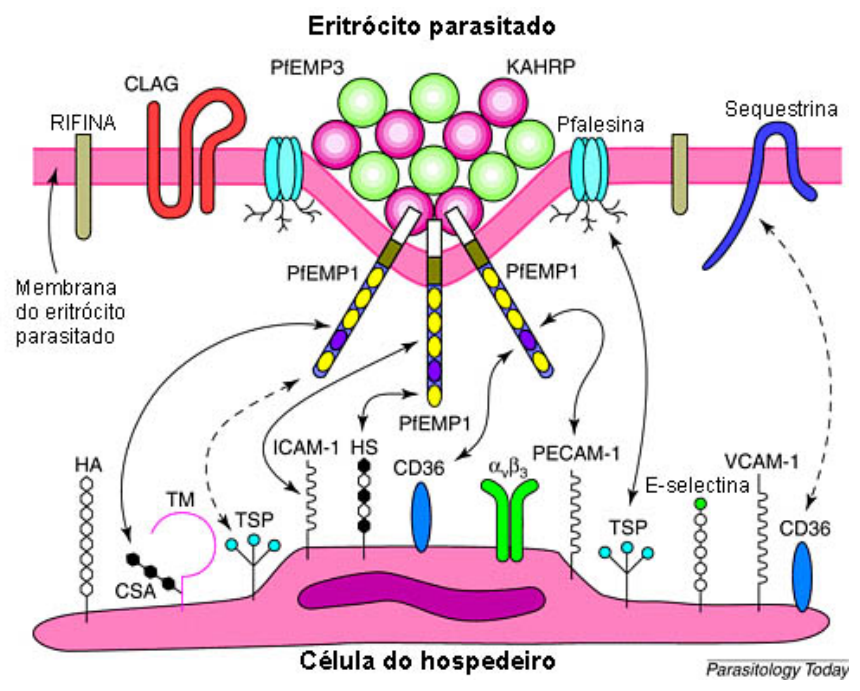

Trombospondina (TSP) foi a primeira molécula descrita como receptor de citoaderência (Roberts e cols., 1985), sendo posteriormente demonstrada se ligar a Proteína de Membrana do Eritrócito 1 (PfEMP1)(Baruch e cols., 1996), que será discutida no item 1.4.3.1. Entretanto, o domínio da PfEMP1 responsável por essa adesão ainda não foi precisamente mapeado.

CD36 foi a segunda molécula a ser implicada em citoaderência (Barnwell e cols., 1989), sendo encontrada em monócitos, células endoteliais, plaquetas e eritroblastos. A ligação à PfEMP1 é promovida pelo domínio CIDR (Baruch e cols., 1997; Smith e cols., 1998; Baruch e cols., 1999). Foi demonstrado que um subfragmento recombinante da CIDR, de 179 resíduos, que compreende a região de ligação a CD36, inibe e reverte a adesão dos eritrócitos infectados a esse receptor em 4 diferentes linhagens de parasitas (Cooke e cols., 1998). Interessantemente, macacos imunizados com esse subfragmento foram protegidos em desafios com parasitas homólogos (Duffy e cols., 2001). 
Tabela 2. Combinações receptor-ligante implicadas em citoaderência.

\begin{tabular}{|c|c|c|c|}
\hline $\begin{array}{l}\text { Receptor do } \\
\text { hospedeiro }\end{array}$ & $\begin{array}{l}\text { Ligante do } \\
\text { parasita }\end{array}$ & Observações & Referências \\
\hline TSP & PfEMP1 & $\begin{array}{l}\text { Baixa afinidade de ligação } \\
\text { em condições de fluxo }\end{array}$ & $\begin{array}{l}\text { (Cooke e cols., 1994; Baruch } \\
\text { e cols., 1996) }\end{array}$ \\
\hline CD36 & $\begin{array}{l}\text { PfEMP1 } \\
\text { (CIDR1) }\end{array}$ & $\begin{array}{l}\text { O fenótipo de ligação mais } \\
\text { comum dos parasitas }\end{array}$ & $\begin{array}{l}\text { (Oquendo e cols., 1989; } \\
\text { Baruch e cols., 1995, 1996, } \\
1997 \text { e 1999; Smith e cols., } \\
1998)\end{array}$ \\
\hline $\begin{array}{l}\text { CD54 } \\
\text { (ICAM-1) }\end{array}$ & $\begin{array}{l}\text { PfEMP1 } \\
\text { (DBL2) }\end{array}$ & $\begin{array}{lr}\begin{array}{l}\text { Receptor membro } \\
\text { superfamília } \\
\text { imunoglobulinas }\end{array} & \text { das } \\
\end{array}$ & $\begin{array}{l}\text { (Berendt e cols., } 1989 \text { e } \\
\text { 1992; Baruch e cols., 1996; } \\
\text { Smith e cols., 2000a) }\end{array}$ \\
\hline $\begin{array}{l}\text { CD62E } \\
\text { (E-selectina) } \\
\text { (ELAM-1) }\end{array}$ & $?$ & Alvo incomum de ligação & (Ockenhouse e cols., 1992) \\
\hline P-selectina & PfEMP1 ? & Ligação dependente de $\mathrm{Ca}^{2+}$ & (Ho e cols., 1998) \\
\hline $\begin{array}{l}\text { CD106 } \\
\text { (VCAM-1) }\end{array}$ & $?$ & $\begin{array}{lr}\text { Receptor membro } & \text { da } \\
\text { superfamília } & \text { das } \\
\text { imunoglobulinas/ } & \text { Alvo } \\
\text { incomum de ligação } & \\
\end{array}$ & $\begin{array}{l}\text { (Ockenhouse e cols., 1992; } \\
\text { Newbold e cols., 1997a e } \\
\text { 1997b) }\end{array}$ \\
\hline CSA & $\begin{array}{l}\text { PfEMP1 } \\
\text { (DBL3) } \\
\text { (CIDR1) }\end{array}$ & $\begin{array}{l}\text { Ligação importante na } \\
\text { malária durante a gestação }\end{array}$ & $\begin{array}{l}\text { (Rogerson e cols., 1995; Fried } \\
\text { e Duffy, 1996; Buffet e cols., } \\
\text { 1999; Reeder e cols., 1999) }\end{array}$ \\
\hline $\mathrm{HA}$ & $?$ & $\begin{array}{l}\text { Receptor que media adesão } \\
\text { à placenta }\end{array}$ & (Beeson e cols., 2000) \\
\hline $\begin{array}{l}\text { CD31 } \\
\text { (PECAM-1) }\end{array}$ & $\begin{array}{l}\text { PfEMP1 } \\
\text { (DBL2) } \\
\text { (CIDR1) }\end{array}$ & Alvo incomum de ligação & (Treutiger e cols., 1997) \\
\hline HS & $\begin{array}{l}\text { PfEMP1 } \\
\text { (DBL1) }\end{array}$ & $\begin{array}{l}\text { Receptor presente nas } \\
\text { células endoteliais e aorta }\end{array}$ & (Barragan e cols., 2000b) \\
\hline CD36 & Sequestrina & Interação ainda discutível & (Ockenhouse e cols., 1991) \\
\hline CD36 e TSP & Pfalesina & $\begin{array}{l}\text { Ligante são fragmentos de } \\
\text { uma Banda } 3 \text { modificada }\end{array}$ & $\begin{array}{l}\text { (Crandall e cols., 1993 e } \\
\text { 1994; Eda e cols., 1999) }\end{array}$ \\
\hline
\end{tabular}

ICAM-1, "intercellular adhesion molecule 1", é uma molécula endotelial que também age como receptor para eritrócitos parasitados (Berendt e cols., 1989). Recentemente foi demonstrado que o domínio DBL2 $\beta$ da PfEMP1 juntamente com o domínio C2, liga-se a ICAM1 (Smith e cols., 2000a).

E-selectina (ELAM-1, "endothelial leukocyte adhesion molecule 1") e VCAM-1 ("vascular cell adhesion molecule") já foram identificados como receptores 
endoteliais que mediam citoaderência (Ockenhouse e cols., 1992). Ambos não são constitutivamente expressos nas células endoteliais mas podem ser induzidos por IL-1 e TNF- $\alpha$. O ligante do parasita responsável por essa adesão ainda não foi identificado.

Interação de eritrócitos infectados com P-selectina ocorre pelo domínio lectina e é dependente de $\mathrm{Ca}^{2+}$. O resíduo de ligação no eritrócito infectado é um ácido siálico, sensível à tripsina, sugerindo que parte da PfEMP1 que interage com CD36 e ICAM-1, e não CSA que é resistente à tripsina, pode estar atuando como ligante (Ho e cols., 1998).

Após a demonstração de que sulfato de condroitina (CSA), um glicosaminoglicano, media citoaderência (Rogerson e cols., 1995), essa molécula foi reconhecida como sendo a principal para ligação à placenta (Fried e Duffy, 1996). CSA pode se ligar ao domínio DBL3 da PfEMP1 (Buffet e cols., 1999) ou ao domínio CIDR (Reeder e cols., 1999).

Ácido hialurônico (HA) é um outro receptor, recentemente descoberto, que tal como CSA, media adesão de eritrócitos infectados à placenta, porém o ligante do parasita responsável por esta adesão ainda não foi identificado (Beeson e cols., 2000).

PECAM-1, "platelet-endothelial cell adhesion molecule 1", também tem uma função em citoaderência em isolados de campo, utilizando como ligante a PfEMP1 (Treutiger e cols., 1997).

HS ("heparan sulphate") tem sido confirmado como receptor do hospedeiro, mediando citoaderência às células endoteliais e aorta via PfEMP1 (Barragan e cols., 2000b). 
O receptor alpha(v) beta3 é uma integrina e está envolvido em muitos processos patológicos e fisiológicos de aderência, mas sua função na citoaderência durante uma infecção malárica é pouco investigada. Entretanto, a habilidade de eritrócitos infectados com $P$. falciparum de aderir a alpha(v) beta3 em células endoteliais mostrou-se 7-270 vezes maior que para eritrócitos não infectados, sendo essa ligação inibida por anticorpos anti-alpha(v) (Siano e cols., 1998).

Alguns receptores como CD36 e TSP parecem se ligar à maioria, senão todos, os parasitas de pacientes infectados (Hasler e cols., 1990). De fato, em estudos de campo, CD36 é o receptor quantitativamente mais importante, porém, $80 \%$ dos isolados aderem a ICAM-1 (rev. em Newbold, 1999). Para isolados que aderem a ambos os receptores, o grau de adesão a CD36 é no mínimo 10 vezes maior que a ICAM-1. Adesão mínima ou nenhuma foi encontrada para E-selectiva, VCAM-1 ou CSA, na maioria dos isolados. Resultados semelhantes foram obtidos nos ensaios de citoaderência in vitro utilizando isolados brasileiros (Nogueira, 2000). A citoaderência a TSP e CD36 é diretamente proporcional à parasitemia (Ho e cols., 1991), que por sua vez é utilizada como critério de gravidade. Apesar de CSA ter sido associado a complicações na malária de gestantes (Fried e Duffy, 1996) e ICAM-1 ter importante papel na malária cerebral (Berendt e cols., 1989; Fernandez-Reyes e cols., 1997), alguns autores falharam na tentativa de correlacionar ligação a um determinado receptor e síndromes específicas causadas pela malária (Marsh e cols., 1988; Ho e cols., 1991).

Interação dos eritrócitos infectados com diferentes receptores já foi demonstrada (Cooke e cols., 1994), onde CD36 conduz à imobilização e ICAM-1 promove o rolamento. Portanto, diferentes receptores podem agir sinergicamente 
para determinar o padrão final de adesão (McCormick e cols., 1997). Da mesma forma porém, do lado do parasita, foi recentemente demonstrado que a PfEMP1 possui uma região considerada uma estrutura terminal semi-conservada mediando ligação a múltiplos e independentes receptores do hospedeiro (Su e cols., 1995; Chen e cols., 2000b).

\subsubsection{Ligantes do parasita envolvidos em citoaderência}

Além da PfEMP1, que será discutida no item 1.4.3.1, outras proteínas codificadas pelo parasita podem estar localizadas na superfície dos eritrócitos infectados, participando dos eventos de citoaderência (Figura 6 e Tabela 2).

Com a utilização de anticorpos que mimetizam a adesão a CD36, uma proteína de 270 kDa, denominada sequestrina, foi identificada (Ockenhouse e cols., 1991). A hipótese formulada pelos autores aponta CD36 como receptor e sequestrina como um ligante complementar envolvido na adesão dos eritrócitos infectados ao endotélio celular do hospedeiro. Infelizmente, até hoje essa interação ainda não foi confirmada.

Pfalesina, uma forma da proteína Banda 3 que foi modificada pelo parasita, também foi considerada como receptor do hospedeiro em fenômenos de citoaderência a CD36 e TSP. A ligação de eritrócitos infectados com P. falciparum a trombospondina ocorre pelo domínio T3, sendo mediado pela seqüência peptídica HPLQKTY da Banda 3, que está exposta na superfície do eritrócito infectado (Eda e cols., 1999). 
Os genes clag ("cytoadherence-linked asexual gene") são uma família multigênica com 9 genes localizados em vários cromossomos (Holt e cols., 1999). Clag9 tem aproximadamente $7 \mathrm{~kb}$, supostamente 9 exons, localiza-se no cromossomo 9, é transcrito em parasitas maduros e traduzido para uma proteína de 220 kDa. A precisa localização celular desta proteína ainda não foi determinada, entretanto, através da predição de estrutura, quatro domínios transmembrana foram encontrados, sugerindo localização na membrana, podendo ser exposta em eritrócitos parasitados. Outras evidências como imunofluorescência, o fato de que a inativação do gene clag9 inibe adesão de eritrócitos parasitados a CD36 (Trenholme e cols., 2000) e transfecção com a tecnologia "antisense" (Gardiner e cols., 2000), confirmam essa hipótese.

Pf60 é uma família multigênica (Carcy e cols., 1994), com estimados 140 genes, cujo primeiro gene foi caracterizado recentemente (Bischoff e cols., 2000). O 6.1 é um gene de cópia única, expresso constitutivamente por todos os parasitas maduros e codifica uma proteína localizada no núcleo. A única ligação com o fenômeno de citoaderência é que o exon 7, C-terminal, apresenta alta homologia com o exon II de genes var (Bonnefoy e cols., 1997). Entretanto o domínio Nterminal não tem homologia com qualquer proteína descrita.

Anticorpos monoclonais contra Pf332 inibem citoaderência in vitro de uma maneira independente da cepa do parasita (Iqbal e cols., 1993). Entretanto anticorpos policlonais contra a Pf332 inibem crescimento do parasita mas não citoaderência, fazendo com que a participação da Pf332 neste fenômeno seja ainda obscura (Ahlborg e cols., 1995). 


\subsubsection{Autoaglutinação e "Rosetting"}

A autoaglutinação de eritrócitos infectados é um fenômeno mediado por PfEMP1 (Fernandez e cols., 1998) mais comum em crianças africanas com doença grave (Roberts e cols., 2000), porém pouco estudado.

O termo "rosetting" designa a

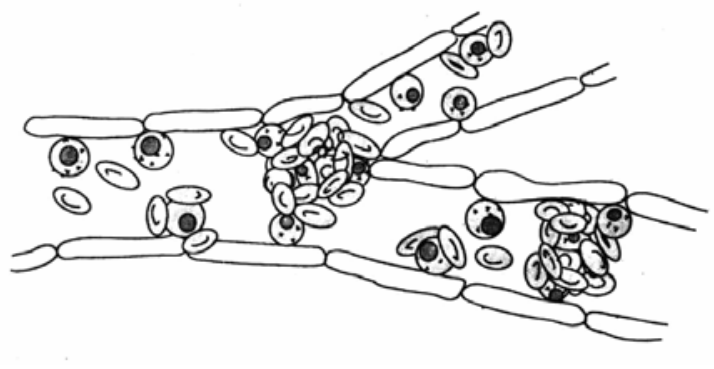

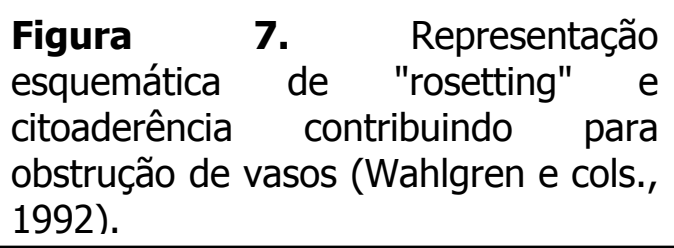

formação de rosetas devido a adesão de eritrócitos infectados com formas maduras assexuadas do parasita a hemácias não infectadas (David e cols., 1988). As rosetas normalmente aparecem com alguns eritrócitos não infectados ligados a um ou dois infectados, porém mais de 10 eritrócitos não infectados já foram encontrados aderidos a um único eritrócito infectado.

Embora "rosetting" tenha sido descrito em outras espécies de Plasmodium que sofrem seqüestramento, tais como $P$. chabaudi, $P$. fragile e $P$. coatney $i$ (Udomsangpetch e cols., 1991), foi também encontrado em outras, como P. vivax, P. ovale e P. malariae, cujas formas maduras continuam seu desenvolvimento na circulação periférica e normalmente não causam doença grave (Udomsangpetch e cols., 1995; Angus e cols., 1996; Lowe e cols., 1998). Na malária causada por $P$. falciparum o fenótipo de "rosetting" parece aumentar a obstrução microvascular do fluxo sangüíneo (Kaul e cols., 1991) e, segundo a maioria dos estudos (MacPherson e cols., 1985; Aikawa, 1988; Carlson e cols., 1990 e 1994; Carlson, 1993; Pongponratn e cols., 1991; Treutiger e cols., 1992; Ringwald e cols., 1993; Reeder e 
cols., 1994; Rowe e cols., 1995; Newbold e cols., 1997a, Kun e cols., 1998; Heddini e cols., 2001), mas não todos (al-Yaman e cols., 1995; Traore e cols., 2000), é comum em pacientes com malária grave ou complicada (Figura 7).

Possivelmente o "rosetting" permite que o parasita invada eritrócitos não infectados mais rapidamente (Wahlgren e cols., 1992), embora isso não tenha sido demonstrado (Clough e cols., 1998b). Além disso, o "rosetting" pode esconder a célula infectada e protegê-la da fagocitose, um dos principais mecanismos da imunidade anti-parasitária (Bouharoun-Tayoun e cols., 1995).

O fenômeno de "rosetting" tem ampla distribuição, existindo em todas as principais áreas de malária do mundo, com descrição em isolados de países endêmicos para malária na América Latina, Ásia e África (Wahlgren e cols., 1990). A estabilidade do fenótipo de "rosetting" durante cultivo in vitro varia de parasita para parasita, mas a taxa de "rosetting" freqüentemente diminui após cultivo prolongado (Wahlgren e cols., 1994).

\subsubsection{Receptores do hospedeiro envolvidos em "rosetting"}

Existem várias combinações de ligação entre diferentes receptores do hospedeiro e ligantes do parasita capazes de levar à formação de rosetas (Tabela 3).

Oligossacarídeos do grupo sangüíneo ABO foram os primeiros receptores do hospedeiro identificados no processo em "rosetting", principalmente os antígenos do

grupo sangüíneo A (Carlson e Wahlgren, 1992; Barragan e cols., 2000a). A ligação provavelmente acontece através da PfEMP1, entretanto esses antígenos parecem influenciar somente no tamanho das rosetas ao invés da freqüência de "rosetting". 
Tabela 3. Combinações receptor-ligante implicadas em "rosetting".

\begin{tabular}{|c|c|c|c|}
\hline $\begin{array}{l}\text { Receptor do } \\
\text { hospedeiro }\end{array}$ & $\begin{array}{l}\text { Ligante do } \\
\text { parasita }\end{array}$ & Observações & Referências \\
\hline $\begin{array}{l}\text { Antígenos } \\
\mathrm{ABO}\end{array}$ & $\begin{array}{l}\text { PfEMP1 } \\
\text { (DBL1) }\end{array}$ & $(\mathrm{BgA})$ & $\begin{array}{l}\text { (Carlson e Wahlgren, 1992; } \\
\text { Chotivanich e cols., 1998; } \\
\text { Barragan e cols., 2000a) }\end{array}$ \\
\hline CD36 & PfEMP1 & $\begin{array}{l}\text { Níveis de CD36 nos } \\
\text { eritrócitos maduros é baixo }\end{array}$ & $\begin{array}{l}\text { (Handunnetti e cols., 1992; } \\
\text { Wahlgren e cols., 1992) }\end{array}$ \\
\hline IgM & $\begin{array}{l}\text { PfEMP1 } \\
\text { (CIDR1) }\end{array}$ & & $\begin{array}{l}\text { (Scholander e cols., 1996; } \\
\text { Clough e cols., 1998a; } \\
\text { Treutiger e cols., 1999) }\end{array}$ \\
\hline $\begin{array}{l}\text { CD35 } \\
\text { (CR1) }\end{array}$ & $\begin{array}{l}\text { PfEMP1 } \\
\text { (DBL1) }\end{array}$ & $\begin{array}{l}\text { Polimorfismo de CD35 em } \\
\text { africanos }\end{array}$ & (Rowe e cols., 1997 e 2000) \\
\hline GAG & $\begin{array}{l}\text { PfEMP1 } \\
\text { (DBL-1) }\end{array}$ & $\begin{array}{l}\begin{array}{l}\text { Sugerido ser } \\
\text { eritrócitos }\end{array} \\
\text { ers }\end{array}$ & (Chen e cols., 1998a) \\
\hline$?$ & $\begin{array}{l}\text { Rosetinas } \\
\text { (Rifinas) }\end{array}$ & Pouco definidas & $\begin{array}{l}\text { Weber, 1988; Helmby } \\
\text { cols., 1993; Fernandez e } \\
\text { cols., 1999) }\end{array}$ \\
\hline
\end{tabular}

(modificado de Coppel e cols., 1998).

Outro receptor que pode estar envolvido no mecanismo de "rosetting" utilizando como ligante a PfEMP1 é CD36 (Handunnetti e cols., 1992), entretanto, como está presente em níveis baixos nos eritrócitos maduros, somente raramente participa deste fenômeno (Wahlgren e cols., 1992).

Imunoglobulinas em soros normais, com destaque para IgM, também têm uma função no "rosetting" de algumas linhagens de parasitas via PfEMP1 (Scholander e cols., 1996; Clough e cols., 1998a; Treutiger e cols., 1999), possivelmente estabilizando a interação entre os eritrócitos infectados e os não infectados (Treutiger e cols., 1999).

Receptor de complemento (CR1 ou CD35 ou receptor de C3b/C4b) é uma molécula imunoregulatória que está expressa na superfície dos eritrócitos, em alguns leucócitos da circulação periférica, em podócitos glomerulares e em células dendríticas foliculares (Ahearn e Fearon, 1989). CR1 se liga aos componentes C3b e 
C4b ativados por complemento e portanto participa de várias funções como clareamento de complexos imunes da circulação, aumento da fagocitose e regulação da ativação de complemento. CR1 é composto de vários domínios repetitivos denominados "short consensus repeats" (SCRs), de 60 aa com 4 cisteínas conservadas e vários outros resíduos conservados (Hourcade e cols., 1989). O domínio extracelular do variante alélico mais comum de CR1 é composto de 30 SCRs. Os primeiros 28 são arranjados em repetições em tandem em grupos homólogos de 7, onde cada grupo forma um "long homologous repeat" (LHR). Os sítios de ligação em CR1 para C3b e C4b foram mapeados, sendo que os SCRs 8-12 e SCRs 15-18 ligam-se preferencialmente a C3b, enquanto os SCRs 1-4 ligam-se preferencialmente a C4b (Figura 8)(Klickstein e cols., 1988; Krych e cols., 1991; Kalli e cols., 1991). Esse receptor é necessário para a formação de rosetas de eritrócitos não infectados com algumas cepas de parasitas adaptadas em laboratório e esta ligação ocorre por meio da PfEMP1 (Rowe e cols., 1997). Em isolados de campo, a região de CR1 necessária para o "rosetting" foi identificada onde também ocorre o sítio de ligação para C3b, que poderia ser um intermediário desta ligação (Rowe e cols., 2000). O único domínio da PfEMP1 até o momento envolvido no mecanismo de "rosetting" é o DBL1 $\alpha$, que media adesão às hemácias não infectadas via receptor de complemento (CR1) (Rowe e cols., 1997 e 2000) ou via HS (Chen e cols., 1998a).

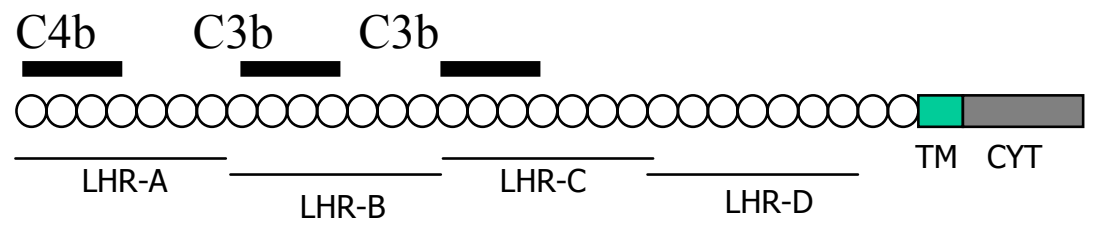

Figura 8. Diagrama do variante alélico de CR1 mais comum. Cada domínio SCR está representado por um círculo e o arranjo dos SCRs em grupos homólogos de sete para formar LHRs é mostrado. TM é a região transmembrana e CYT a cauda citoplasmática. Os sítios de ligação preferencial para C3b e C4b estão indicados. 
Glicosaminoglicanos (GAG), como o HS dos eritrócitos, são receptores do hospedeiro que foram identificados na formação de rosetas (Chen e cols., 1998a). Em 2000, foi demonstrado que uma região da PfEMP1 solúvel (DBL1 $\alpha)$ necessita de um fragmento mínimo de heparina de 12-mer (aproximadamente $4 \mathrm{kDa}$ ) para a adesão. Este fragmento é capaz de separar rosetas formadas naturalmente (Barragan e cols., 2000b).

\subsubsection{Ligantes do parasita envolvidos em "rosetting"}

Outras moléculas, além da PfEMP1, poderiam contribuir para o "rosetting" de parasitas. Um exemplo são as proteínas polimórficas de 20 a $40 \mathrm{kDa}$, as rifinas ou rosetinas (Helmby e cols., 1993). Estas proteínas são também codificadas por uma família multigênica, composta de 200 membros, denominada rif, "repetitive interspersed family" (Weber, 1988). Os genes rif são compostos por 2 exons, sendo o primeiro curto e o segundo com 1,3 kb. Esses genes estão associados com os genes var em regiões subteloméricas (Kyes e cols., 1999), são transcritos nos estágios assexuados do parasita e os produtos são exportados para a superfície do eritrócito infectado, onde podem ser detectados de 14 a 16 horas após a invasão. Muitas rifinas podem ser expressas na superfície de eritrócitos com apenas um parasita, conferindo grande variabilidade antigênica. Porém sua função em citoaderência ou "rosetting" ainda não foi bem estabelecida, bem como o receptor do hospedeiro que media a adesão.

Os genes stevor ("subtelomeric variant open reading frame"), anteriormente reportados como $7 h 8$, estão relacionados aos genes rife pertencem também a uma 
família multigênica, com 34 membros (Limpaiboon e cols., 1990). Ambos os genes estão presentes próximos aos telômeros de todos os cromossomos. Os genes stevor têm 2 exons. O exon 1 é curto, codifica um codon de iniciação e um domínio transmembrana. O exon $2(\sim 1 \mathrm{~kb})$ codifica $30 \mathrm{kDa}$ da proteína e inclui dois segmentos transmembrana (Cheng e cols., 1998). Embora as seqüências stevore rif sejam similares em tamanho e estrutura, os stevor formam uma família distinta, mais conservada e de menor número de cópias.

\subsubsection{Variação Antigênica}

A maior parte do ciclo de vida do Plasmodium no hospedeiro vertebrado ocorre nos eritrócitos e é necessária para a infecção dos mosquitos e sobrevivência do parasita. Como os eritrócitos não se diferenciam, não apresentam mecanismo interno de síntese ou transporte de proteínas e não expressam moléculas MHC classe I ou II na sua superfície, seriam um ambiente ideal para o parasita, que ficaria escondido do sistema imune do hospedeiro. Entretanto, o parasita sintetiza proteínas que atravessam a sua membrana plasmática, a membrana do vacúolo parasitóforo e se estabelecem na superfície do eritrócito. No caso de $P$. falciparum, após 18 horas da invasão, esses antígenos mediam adesão a vários receptores do endotélio do hospedeiro, impedindo que as hemácias infectadas passem através do baço, onde seriam destruídas. Entretanto, essas proteínas tornam o parasita visível ao sistema imune do hospedeiro, que necessita variar as proteínas exportadas para a superfície da hemácia para evitar o reconhecimento pelo sistema imune, além de variar a especificidade de adesão, para que diferentes proteínas possam se ligar a 
diferentes receptores (rev. em Newbold, 1999). Estudos in vitro com clones de $P$. falciparum verificaram que a taxa de troca antigênica de um determinado variante seria em torno de 2\% por geração (Biggs e cols., 1991; Roberts e cols., 1992).

Muita divergência existe em relação à função primária dos antígenos variantes. Como muitos trabalhos sugerem que resposta de anticorpos a antígenos variantes são parte de uma resposta imune protetora contra a malária (Brown e Hills, 1974; Gilks e cols., 1990; Marsh e cols., 1989; Bull e cols., 1998), alguns autores acreditam que citoaderência é sua função primordial e variação antigênica, uma adaptação para evitar o ataque imune (Borst e cols., 1995). Inversamente, outros autores acreditam que a função principal das proteínas variantes é gerar uma resposta imune que regula o crescimento do parasita enquanto que a citoaderência evita que parasitas que falham neste objetivo, sejam destruídos pelo baço (Newbold, 1999; Saul, 1999). Como justificativa discute-se que uma única malária falciparum é suficiente para gerar anticorpos contra antígenos variantes de superfície, enquanto que a maioria das proteínas do parasita são pouco imunogênicas, e portanto, a função primária das proteínas de superfície seria a de antígenos. Além disso, a resposta imune contra os antígenos de superfície é capaz de destruir eritrócitos infectados e as modificações nas especificidades antigênicas ocorrem a uma taxa comparável a taxa pela qual a resposta imune é gerada.

A variação antigênica foi primeiro descrita em $P$. knowlesi, através da observação da resposta imune em infeções crônicas de primatas (Brown e Brown, 1965). Porém, esse fenômeno tem sido detectado em outras espécies de plasmódios de símios, como P. fragile (Handunnetti e cols., 1987), espécies que parasitam roedores, como $P$. chabaudi (McLean e cols., 1982) ou mesmo espécies que 
parasitam o homem, como P. vivax (Mendis e cols., 1988; del Portillo e cols., 2001). P. falciparum também produz mudanças antigênicas na superfície do eritrócito infectado (Langreth e Reese, 1979) e anticorpos contra o parasita bloqueiam adesão de eritrócitos infectados a outras células de uma maneira cepaespecifica (Udeinya e cols., 1983). Howard e cols. identificaram, em 1983, o antígeno variante de $P$. knowlesi que conduz à variação antigênica na superfície de eritrócitos infectados. Logo em seguida, o mesmo grupo identificou um antígeno homológo para P. falciparum, cepa-específico, com 280 KDa, posteriormente denominado "Plasmodium falciparum Erythrocyte Membrane Protein 1" (PfEMP1)(Leech e cols., 1984)(Figura 6).

\subsubsection{Proteína de Membrana do Eritrócito 1 (PfEMP1) e Reconhecimento Imune}

A PfEMP1 é codificada por genes var (Baruch e cols, 1995; Smith e cols, 1995; Su e cols 1995). Mudanças na expressão destes genes estão relacionadas com mudanças nos fenótipos antigênicos e de citoaderência. Esses genes se apresentam em múltiplas cópias formando uma família gênica com aproximadamente 50 membros, localizados nas regiões subteloméricas dos 14 cromossomos (no mínimo 1 em cada telômero), em grupos internos nos cromossomos 4, 7, 8 e 12 e em qualquer orientação (Rubio e cols., 1996; Thompson e cols., 1997; Fischer e cols., 1997). A localização telomérica não é um pré-requisito para a expressão dos genes var, mas é importante para a geração de diversidade, juntamente com eventos de mutação, inserção e deleção (Hernandez-Rivas e cols., 1997; Ward e cols., 1999; 
Taylor e cols., 2000). Recombinação ectópica freqüente foi demonstrada em genes var e ocorre entre regiões subteloméricas de cromossomos heterólogos, facilitando a conversão gênica (Freitas-Junior e cols., 2000).

Apesar de somente um gene var ser expresso em parasitas maduros, diferentes genes são transcritos simultaneamente de muitos cromossomos em uma célula infectada por um trofozoíta jovem. Entretanto, neste estágio, são detectadas as extremidades $5^{\prime}$ dos vários transcritos e apenas um transcrito completo. Portanto, aparentemente, uma transcrição incompleta ocorre em muitos genes var no estágio de anel (Rowe e cols., 1997; Scherf e cols., 1998; Chen e cols., 1998b), embora alguns autores levantem a possibilidade de transcrição completa de muitos genes e degradação seletiva e rápida, de 3' para 5', dos produtos não destinados para expressão (Borst e cols., 1995; Taylor e cols., 2000).

Além de transcrição relaxada com controle ao nível de início da transcrição, a expressão dos genes var pode ser regulada por mecanismos epigenéticos associados com modificações na estrutura do DNA ou metilação. Recentemente foi descrito o primeiro gene de histona desacetilase em P. falciparum (Joshi e cols., 1999), possibilitando a ocorrência deste último mecanismo.

Promotores de genes var são pouco estudados, mas a análise de regiões 5' que flanqueiam esses genes identificou duas seqüências conservadas, uma específica para as cópias internas dos cromossomos e uma distinta, específica para as cópias subteloméricas (Deitsch e cols., 1999; Voss e cols., 2000). Recentemente foi estudada a participação dos introns no controle da transcrição. Estes são conservados e contêm uma estrutura similar a origens de replicação anteriormente descritas em leveduras. Inclusão deste intron em plasmídeos com um promotor de 
var levou ao silenciamento completo e específico do gene, estabelecido durante a fase de síntese de DNA (fase S) (Deitsch e cols., 2001).

Apesar de tanta polêmica nos mecanismos de regulação da expressão de genes var, é certo que eles são ativados in situ, onde cópias são desativadas/ativadas tanto em regiões subteloméricas como internas, e não precisam de um rearranjo de DNA programado, embora uma recombinação espontânea já tenha sido descrita (Deitsch e cols., 1999; rev. em Craig e Scherf, 2001).

Com o objetivo de desafiar a hipótese de que somente um transcrito completo pode ser detectado por parasita, análise de parasitas selecionados para um determinado receptor demonstrou que múltiplos genes var podem ser expressos em uma população fenotipicamente homogênea. Diferentemente de outros trabalhos, vários transcritos inteiros de genes var foram detectados na população de trofozoítas maduros (Noviyanti e cols., 2001). Da mesma forma, anticorpo monoclonal contra a região ATS foi capaz de detectar várias bandas em extratos destes parasitas, sugerindo que diferentes PfEMP1, mediando o mesmo fenótipo de adesão, foram expressas em diferentes células ou ainda, que diferentes PfEMP1 foram expressas na mesma célula. Infelizmente, para confirmar esta última hipótese seria necessária a análise de células individuais. Uma PfEMP1 dominante sempre foi observada nos extratos, provavelmente determinando o fenótipo de adesão. Assim, o aumento da expressão de um gene não dominante pode levar a uma mudança do fenótipo de adesão e conseqüente alteração da patogenia da doença.

Os genes var são organizados em dois exons (Su e cols., 1995; rev. em Smith e cols., 2001), com um tamanho total de 6 a 13 kb, separados por um intron de 1 
kb. O Exon $2(1,6 \mathrm{~kb})$ codifica um segmento terminal acídico (ATS), intracelular, envolvido no ancoramento da PfEMP1 a proteínas do hospedeiro (espectrina e actina do citoesqueleto do eritrócito) ou do parasita (KAHRP, "knob-associated histidine-rich protein"), situadas no "knob" (Oh e cols., 2000)(Figura 6). O Exon 1 (4-10 kb) codifica a região da molécula que fica exposta na superfície do eritrócito infectado e uma região transmembrana. A região extracelular apresenta de 2 a 7 domínios polimórficos, denominados DBLs ("duffy binding like domains"), e uma ou duas regiões polimórficas ricas em cisteínas (CIDR, "cysteine rich interdomain region"), exclusivas para $P$. falciparum (Figura 9). Já os DBLs são similares a elementos descritos em antígenos (EBAs, "erythrocyte binding antigens") envolvidos na invasão do eritrócito e ligação às suas proteínas, tais como Duffy e glicoforina A (Adams e cols., 1992; Sim e cols., 1994). Os DBLs tanto na PfEMP1 quanto em EBA apresentam 10 cisteínas conservadas que são distribuídas em 10 blocos. Os DBLs e CIDRs são identificados pela posição do domínio no gene (DBL1-7; CIDR1 ou 2) e a letra grega indica os grupos de homologia (DBLs $\alpha, \beta, \gamma$, $\delta$ e $\varepsilon$; CIDRs $\alpha, \beta$ e $\gamma)$ (Figura 10).

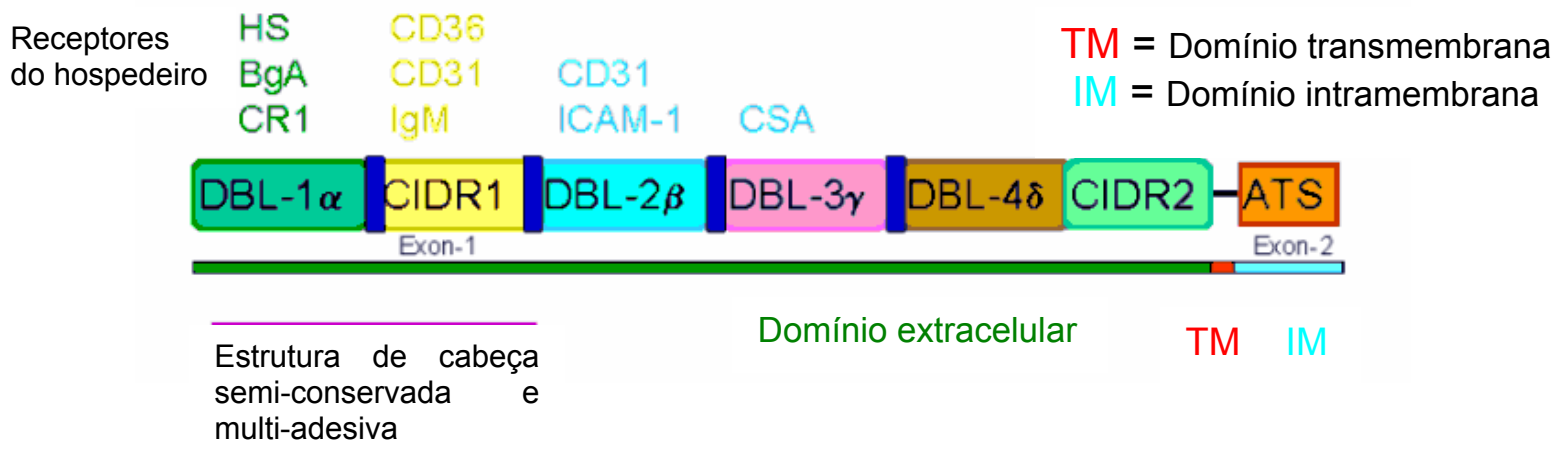

Figura 9. Representação esquemática da estrutura da PfEMP1 mostrando os receptores do hospedeiro e respectivos domínios que promovem ligação a estes receptores (http://sites.huji.ac.il/malaria/maps/ PfEMP1.html). 


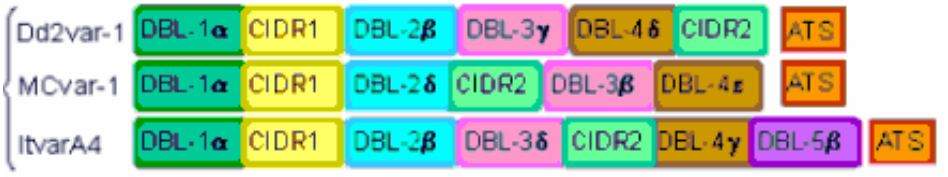

Figura 10. Organização dos domínios de 3 genes var (http://sites.huji.ac.il/malaria/maps/ PfEMP1.html).

Os domínios DBL2 ou CIDR podem se ligar a PECAM-1 em isolados de campo (Treutiger e cols., 1997). A região DBL1-CIDR da PfEMP1 tem sido considerada uma estrutura terminal semi-conservada mediando ligação a múltiplos e independentes receptores do hospedeiro (Su e cols., 1995; Chen e cols., 2000b). DBL-1 liga-se especificamente a HS ("heparan sulphate") das células endoteliais e aorta (Barragan e cols., 2000b).

Recentemente, foram analisadas 20 seqüências de genes var disponíveis no GenBank (Smith e cols., 2000b). A estrutura e organização de domínios das 20 PfEMP1 foram determinadas. Os autores foram capazes de verificar associações de domínios como $\mathrm{DBL} \alpha \mathrm{CIDR} \alpha, \mathrm{DBL} \beta C 2, \mathrm{DBL} \delta \mathrm{CIDR} \beta$, podendo conferir funções de modelagem, transporte ou atividade de adesão. Foram também identificadas duas novas regiões conservadas com características de domínios, localizadas na parte extracelular da molécula. A primeira é um segmento N-terminal (NTS), teoricamente globular, que, a partir do resíduo metionina iniciador, pode ter de 75 a 107 aa. Essa região não apresenta homologia com qualquer seqüência nos bancos de dados, mas tem provavelmente uma $\alpha$-hélice central. A segunda, de 140 a 217 aa, foi designada como C2 e não está presente em todas as seqüências analisadas mas, como a região 
NTS, é supostamente globular, tem uma estrutura de $\alpha$-hélice e uma seqüência singular (Figura 11).

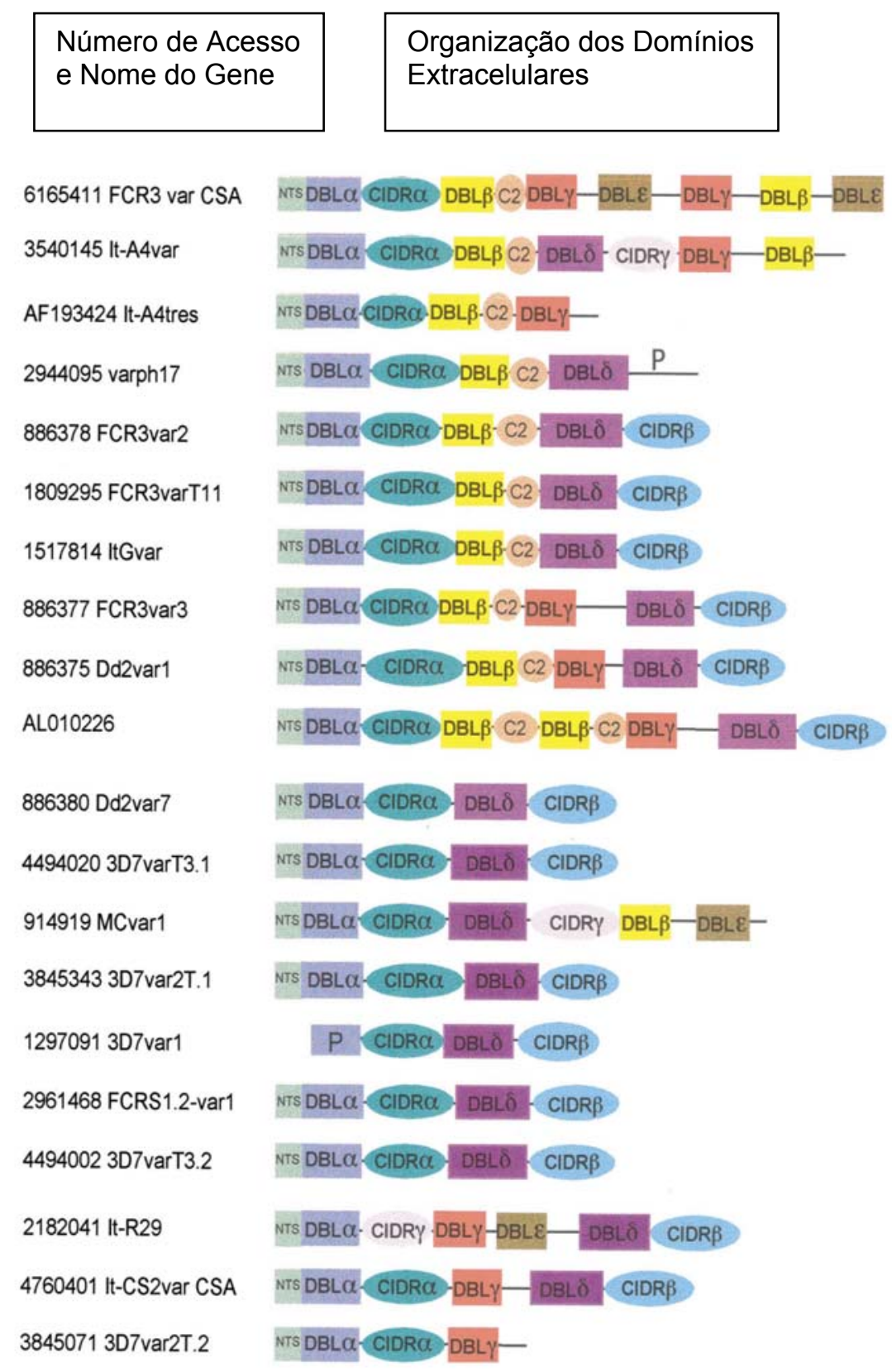

Figura 11. Representação esquemática da organização dos domínios extracelulares de 20 PfEMP1 (Smith e cols., 2000b). A letra $\mathrm{P}$ designa seqüências incompletas.

Anticorpos contra PfEMP1 podem fornecer proteção contra malária através da interferência em um ou mais processos de citoaderência controlados por esta 
proteína (David e cols., 1983). A presença de anticorpos anti-PfEMP1 está significativamente relacionada ao aparecimento de imunidade clínica, apontando a PfEMP1 como uma possível candidata ao desenvolvimento de uma vacina contra a malária (Reeder e Brown, 1996; Bull e cols., 1998; Barragan e cols., 1998; Giha e cols., 1999; Bull e cols., 1999; Giha e cols., 2000). Como a resposta imune é variante-específica, indivíduos com baixa exposição a $P$. falciparum mostram um reconhecimento limitado da superfície do eritrócito parasitado (Marsh e Howard, 1986; Bull e cols., 1998). Entretanto, soros de adultos residentes em área endêmica podem aglutinar eritrócitos parasitados com diferentes cepas e isolados (Aguiar e cols., 1992; Reeder e cols., 1994).

O reconhecimento de cada variante por um grupo diferente de anticorpos do soro, indica que a PfEMP1 não apresenta epítopos antigênicos que reagem cruzado, mostrando epítopos imunodominantes variante-específicos (Newbold e cols., 1992). Apesar do domínio CIDR1 ser relativamente conservado, ele não induz altos títulos de anticorpos durante a infecção (Baruch e cols., 1996; Baruch e cols., 1997). Porém, anticorpos monoclonais produzidos contra diferentes regiões da CIDR1 da PfEMP1 reagiram com várias cepas de $P$. falciparum, que estavam expressando diferentes variantes de PfEMP1, mostrando a presença de epítopos que reagem cruzado na superfície de eritrócitos infectados (Gamain e cols., 2001), como havia sido sugerido anteriormente (Marsh e Howard, 1986). De fato, um anticorpo monoclonal foi capaz de reconhecer $90 \%$ das cepas testadas, somente falhando em reagir com aquelas que não se ligam a CD36.

Níveis de anticorpos contra três peptídeos sintéticos derivados de regiões da PfEMP1 altamente conservadas (dois do DBL1 $\alpha$ e um do Exon 2), que representam 
5 seqüências de duas cepas (FCR3 e Malayan Camp), foram medidos em população residente de área endêmica para malária (Staalso e cols., 1998). A resposta de anticorpos contra estes peptídeos aumentou com a idade e foi maior em indivíduos assintomáticos. O peptídeo mais conservado do DBL1 $\alpha$ foi reconhecido por $70 \%$ dos positivos. Esse mesmo peptídeo foi reconhecido por anticorpos IgG de $50 \%$ das crianças residentes de área hiperendêmica com transmissão sazonal, porém não foi encontrada correlação com proteção e dados do mesmo grupo ainda não publicados indicam que essa região do DBL1 não fica acessível para os anticorpos (Dodoo e cols., 2001).

Estudos clínicos têm sugerido que os indivíduos tornam-se rapidamente imunes à malária grave não-cerebral, mas não à malária leve ou assintomática (Gupta e cols., 1999). Além disso, eritrócitos infectados provenientes de isolados que causam infecção grave são mais freqüentemente reconhecidos que aqueles que causam doença leve (Bull e cols., 1999). Se isso ocorre porque o repertório variante destes isolados é restrito ou se eles têm características comuns que permitem o desenvolvimento de anticorpos que reagem cruzado, ainda não foi determinado.

Algumas estratégias vêm sendo utilizadas para desenvolvimento de vacinas baseadas em PfEMP1, com o objetivo de reduzir a mortalidade. Dentre elas estão uma vacina para malária em gestantes, baseada no $\mathrm{DBL} \gamma$ e uma vacina geral para a malária, baseada no DBL1 $\alpha$ ou no CIDR1 $\alpha$. As duas vacinas seriam complementadas com uma vacina que incluiria epítopos de células $\mathrm{T}$ para elevar a resposta de anticorpos contra novos variantes do parasita (rev. em Duffy e cols., 2001). 


\subsubsection{Citocinas}

Muitos autores têm apontado para a importância das citocinas, principalmente TNF- $\alpha$ ("tumor necrosis factor alpha") e IFN- $\gamma$ ("gamma interferon"), na malária grave (Miller e cols., 1994; Jakobsen e cols., 1995; Hommel, 1996; rev. em Chen e cols., 2000a). Após infecção por $P$. falciparum, TNF- $\alpha$ é produzido por muitas linhas celulares, como monócitos e macrófagos (a principal fonte de TNF- $\alpha$ ), linfócitos, granulócitos, plaquetas e células endoteliais (Wahlgren e cols., 1995). Produtos do parasita estimulam as células do hospedeiro, causando uma excessiva produção de citocinas, que por sua vez, causam efeitos adversos na progressão da doença. Essas toxinas são moléculas derivadas do parasita que são secretadas ou liberadas nos estágios de trofozoítas e esquizontes e são contidas entre proteínas ancoradas por GPI ("glycosylphosphatidylinositol")(Pichyangkul e cols., 1997). A MSP1 ("merozoite surface protein") é ancorada por GPI e induz a produção de TNF- $\alpha$ e IL-1 (interleucina 1), provavelmente devido aos fragmentos $\mathrm{N}$-terminais que são liberados durante o processo de invasão (Schofield e Hackett, 1993). Produtos do metabolismo do parasita, como a hemozoína, também são tóxicos e induzem a produção de IL-1 (Pichyangkul e cols., 1994). Quantidades moderadas de citocinas tais como TNF- $\alpha$, IFN- $\gamma$ e IL-1 são necessárias para o hospedeiro reagir contra organismos invasores, mas uma superprodução pode ser prejudicial. Níveis altos de TNF- $\alpha$ e IFN- $\gamma$ são encontrados com mais freqüência em pacientes com malária grave (Kwiatkowski, 1990). Pacientes que morreram de malária cerebral além de apresentarem grandes quantidades de TNF- $\alpha$, IFN- $\gamma$ e IL-1 no cérebro, apresentam expressão elevada de mRNAs de citocinas relevantes em vários órgãos afetados 
(Udomsangpetch e cols., 1997). Desconhece-se a razão para esse acúmulo de citocinas, mas acredita-se que elas não sejam protetoras, e sim contribuam para a patogênese da doença. Desse modo, as citocinas aumentam e redistribuem a expressão de receptores endoteliais (ICAM-1 e PECAM-1), causam distúrbios físicos no hospedeiro (febre alta) e aumentam a produção de óxido nítrico com conseqüente dano no local do seqüestramento (Green e cols., 1994; Anstey e cols., 1996). TNF- $\alpha$ tem papel importante no desenvolvimento de anemia, através da indução de mecanismos de deseritropoese e eritrofagocitose (Roodman e cols., 1987; Clark e Chaudhri, 1988). TNF- $\alpha$ está também envolvido no desenvolvimento de malária cerebral, acidose láctica, hipoglicemia, insuficiência renal e edema pulmonar (rev. em Odeh, 2001). A razão entre os níveis séricos de IL-10 e TNF- $\alpha$ menor que 1 é um fator de risco para malária cerebral e anemia grave (May e cols., 2000). Apesar de parecer crucial a reversão dos efeitos desta citocina para conter a malária grave, administração de anticorpos anti TNF- $\alpha$ em crianças em coma não afetou o resultado da doença, embora a febre tenha sido eliminada (Kwiatkowski e cols., 1993). Possivelmente, anticorpos anti TNF- $\alpha$ agem retendo esta citocina na circulação, o que prolonga seu efeito no endotélio vascular (van Hensbroek e cols., 1996). A modulação da resposta de TNF- $\alpha$, juntamente com a administração de drogas antimaláricas representa uma nova abordagem para o tratamento da malária grave. 
2. OBJETIVOS 


\subsection{Objetivo Geral}

A variação na seqüência primária da PfEMP1 é responsável por diferenças nas características de adesão do parasita e pode afetar o tropismo dos eritrócitos infectados pelos tecidos e, consequentemente, o efeito da malária e o prognóstico da doença. Este estudo visou, portanto, estudar o repertório do domínio DBL1 $\alpha$ dos genes var de isolados de Plasmodium falciparum obtidos de pacientes infectados na Região Amazônica Brasileira e determinar se existe alguma associacão de seqüências DBL1 $\alpha$ expressas e malária grave no Brasil. Vale a pena ressaltar, que o domínio DBL1a é o único até o momento envolvido no mecanismo de "rosetting", fenômeno diretamente relacionado à malária grave.

\subsection{Objetivos Específicos}

2.2.1. Estudar o repertório genômico de um segmento de aproximadamente 200 bp localizado no domínio DBL1 $\alpha$ dos genes var de isolados de Plasmodium falciparum obtidos de pacientes sem malária grave infectados nos Estados de Mato Grosso e Rondônia.

2.2.2. Estudar o repertório expresso de um segmento de aproximadamente 400 bp do domínio DBL1 $\alpha$ dos genes var de isolados de Plasmodium falciparum obtidos de pacientes com e sem malária grave, infectados nos Estados de Mato Grosso, Rondônia e Pará e amadurecidos em cultivo contínuo. 
2.2.3. Analisar a presença de seqüências de transcritos var $\mathrm{DBL} 1 \alpha$ de pacientes graves no repertório genômico de isolados obtidos de pacientes sem malária grave infectados nos Estados de Mato Grosso, Rondônia, Pará e Acre.

2.2.4. Analisar, através de imunofluorescência, o padrão de ligação a eritrócitos de uma proteína DBL1 $\alpha-H i s$, cuja seqüência é preferencialmente expressa em paciente com malária grave. 
3. PACIENTES, MATERIAL E MÉTODOS 


\subsection{Pacientes}

\subsubsection{Graves}

Neste estudo foram utilizadas 6 amostras de sangue infectado por $P$. falciparum, provenientes de pacientes com malária grave, internados em diferentes hospitais da cidade de São Paulo (Instituto de Infectologia Emílio Ribas, Hospital da Polícia Militar, Hospital Universitário da Universidade de São Paulo e Hospital das Clínicas da Faculdade de Medicina da Universidade de São Paulo). Os pacientes foram diagnosticados no Laboratório de Malária da SUCEN entre 1987 e 1993 e todos apresentavam parasitemia $>2 \%$ de anéis de $P$. falciparum na circulação periférica (Tabela 1 do Anexo 2). Os dados laboratoriais e epidemiológicos dos pacientes foram fornecidos pela SUCEN e encontram-se no Anexo 3 (G33=913/87, $\mathbf{G 2 3}=481 / 87, \mathbf{G 3 4}=511 / 89, \mathbf{G 2}=019 / 93, \mathbf{G 2 9}=665 / 88, \mathbf{G 3}=072 / 92)$. Os dados laboratoriais e bioquímicos dos pacientes foram fornecidos pelos hospitais e resumidos na Tabela 2 do Anexo 2. Todos os pacientes foram considerados graves de acordo com os critérios da Organização Mundial de Saúde (WHO, 2000).

Antes da administração do tratamento e mediante o consentimento pósinformado do paciente, o sangue foi coletado por punção venosa em tubo heparinizado e uma alíquota da papa de hemácias foi imediatamente dispensada em tubo com glycerolyte para congelamento em Nitrogênio líquido (Diggs e cols., 1975). 


\subsubsection{Não Graves}

Neste estudo foram utilizadas 80 amostras de sangue infectado por $P$. falciparum provenientes de pacientes sem qualquer indício de gravidade. As amostras procedentes do Mato Grosso (Peixoto de Azevedo) foram coletadas em 1997, as do Pará (Itaituba e Redenção) entre 1987 e 1997, as de Rondônia (Porto Velho) em 1997 e as do Acre (Plácido de Castro, Senador Guiomar e Rio Branco) em 1999.

Para os estudos de genes expressos em parasitas amadurecidos em cultura foram utilizados 4 isolados (Tabela 1 do Anexo 2). Os dados laboratoriais e epidemiológicos foram fornecidos pela SUCEN e encontram-se no Anexo 3 (NG1=161/88, NG2=72/92, NG3=291/90 e NG4=343/90).

O sangue foi coletado por punção venosa em tubo heparinizado, logo após a realização do diagnóstico, mediante consentimento pós-informado do paciente. Uma alíquota de sangue total ou papa de hemácias foi imediatamente dispensada em tubo com glycerolyte (Diggs e cols., 1975) e congelada em Nitrogênio líquido. Algumas amostras utilizadas na extração de DNA foram estocadas a $-20^{\circ} \mathrm{C}$, sem adição de criopreservativo.

\subsection{Descongelamento, cultivo e purificação de parasitas maduros}

Para os estudos de expressão dos genes var em parasitas maduros, as hemácias infectadas com anéis obtidas dos pacientes foram descongeladas (Diggs e cols., 1975) e instaladas em cultura (Trager e Jensen, 1976). O crescimento dos parasitas foi monitorado por esfregaços e gotas espessas coradas por Giemsa. Os 
parasitas de pacientes graves foram amadurecidos em cultivo apenas até alcançarem o estágio de trofozoítas maduros e esquizontes. Os parasitas de pacientes não graves, que normalmente apresentavam baixas parasitemias, foram mantidos em cultivo por 3 ciclos. Os estágios maduros apresentando "knobs" foram purificados como descrito (Pasvol e cols., 1978) e utilizados imediatamente para extração de RNA.

\subsection{Extração do DNA genômico}

A extração do DNA genômico das amostras provenientes de pacientes sem malária grave foi realizada como descrito (Ferreira e cols., 1998). Uma alíquota de $300 \mu \mathrm{l}$ da amostra de sangue foi tratada com $30 \mu \mathrm{l}$ de uma solução de saponina a 1,5\% em PBS, durante 5 minutos à temperatura ambiente. Um $\mathrm{ml}$ de PBS foi adicionado para lavagem por centrifugação a 12.500 x g por 15 minutos a $4^{\circ} \mathrm{C}$. A lavagem foi repetida até a completa remoção da hemoglobina. O precipitado foi ressuspendido em $200 \mu \mathrm{l}$ de tampão de extração de DNA (10 mM Tris-HCl pH 8,0, 5 mM EDTA pH 8,0, $100 \mathrm{mM} \mathrm{NaCl}$, 0,5\% SDS, $200 \mu \mathrm{g} / \mathrm{ml}$ Proteinase K) e incubado durante a noite a $50^{\circ} \mathrm{C}$. No dia seguinte, o material foi extraído com fenol, fenol/clorofórmio (1:1) e clorofórmio/álcool isoamílico (24:1). Após obtenção da fase aquosa, a amostra foi precipitada durante a noite com $20 \mu \mathrm{l}$ de $3 \mathrm{M}$ acetato de sódio (pH 5,2) e $500 \mu$ l de etanol absoluto gelado. O precipitado, obtido por centrifugação como acima, foi lavado com etanol $75 \%$, seco a $37^{\circ} \mathrm{C}$, ressuspendido em $30 \mu \mathrm{l}$ de TE (1 mM EDTA, 10 mM Tris- $\mathrm{HCl}$ pH 7,4) e estocado a $4^{\circ} \mathrm{C}$.

\subsection{Extração de RNA}

A extração de RNA foi realizada como descrito (Kyes e cols., 2000). As células infectadas com parasitas maduros foram ressuspendidas em $250 \mu$ meio RPMI, rapidamente lisadas em $750 \mu$ de TRIZOL LS (Life Technologies) pré-aquecido 
$\left(37^{\circ} \mathrm{C}\right)$, incubadas por $5 \mathrm{~min}$ a $37^{\circ} \mathrm{C}$ e congeladas. Para completar a extração de RNA, as amostras foram descongeladas a temperatura ambiente e $200 \mu \mathrm{l}$ de clorofórmio foram adicionados. Após forte homogeneização, as amostras foram incubadas por $10 \mathrm{~min}$. a temperatura ambiente e centrifugadas a $12.000 \mathrm{x} \mathrm{g}$, a $4^{\circ} \mathrm{C}$, por $15 \mathrm{~min}$. A fase aquosa foi transferida a outro tubo e $500 \mu \mathrm{l}$ de isopropanol foram adicionados. As amostras foram centrifugadas após incubação a $4^{\circ} \mathrm{C}$ durante a noite. O sobrenadante foi removido e o precipitado de RNA foi lavado em etanol $75 \%$, seco, ressuspendido em $15 \mu$ l de formamida, doseado em GeneQuant (Pharmacia) e estocado a $-70^{\circ} \mathrm{C}$.

\subsection{Tratamento com DNase e Síntese de cDNA}

Um $\mu \mathrm{g}$ de RNA foi tratado 3x com DNase I (Life Technologies) por 15 min. a temperatura ambiente. A reação foi interrompida com adição de EDTA (concentração final $2,5 \mathrm{mM}$ ) e inativada a $65^{\circ} \mathrm{C}$ por $10 \mathrm{~min}$. A fita de cDNA foi sintetizada ("First-Strand cDNA Synthesis Kit", Amersham Pharmacia Biotech), utilizando hexadeoxinucleotídeos aleatórios. Como controle de contaminação com DNA, amostras foram processadas sem adição de transcriptase reversa. Após inativação a $90^{\circ} \mathrm{C}$ por 5 min., as amostras foram submetidas a PCR.

\subsection{Amplificação de DNA}

Dois protocolos para amplificação de seqüências da região N-terminal do DBL1 de genes var foram utilizados. O primeiro (Kyes e cols., 1997) foi utilizado para amplificar um fragmento de 200 bp (Anexo 1), enquanto o segundo (Taylor e cols., 2000) foi utilizado para amplificar um fragmento de 400 bp (Anexo 2). 0 primeiro protocolo foi realizado exatamente como descrito. Para o segundo protocolo, foram utilizados tubos de $0,5 \mathrm{ml}$, volume de $25 \mu \mathrm{l}$ e as seguintes concentrações finais: $10 \mathrm{mM}$ Tris $\mathrm{pH} 8,3,50 \mathrm{mM} \mathrm{KCl}, 1$ a $2 \mathrm{mM} \mathrm{MgCl}, 200 \mu \mathrm{M}$ 
dNTPs, $1 \mu \mathrm{M}$ dos oligonucleotídeos $\alpha \mathrm{AF}$ [5' GCACG(A/C)AGTTTTGC 3'] e $\alpha B R$ [5' GCCCATTC(G/C)TCGAACCA 3'] e 0.5 U Platinum ${ }^{\mathrm{TM}}$ Taq Polymerase (Gibco BRL). Uma alíquota de $2 \mu \mathrm{l}$ de DNA genômico ou CDNA foi utilizada nas reações que foram realizadas em aparelho GeneAmp PCR System 2400 (Applied Biosystems) nas seguintes condições: um ciclo inicial de $95^{\circ} \mathrm{C} / 5 \mathrm{~min} ., 42^{\circ} \mathrm{C} / 1 \mathrm{~min} ., 60^{\circ} \mathrm{C} / 1 \mathrm{~min}$. , seguido por 29 ciclos de $95^{\circ} \mathrm{C} / 1 \mathrm{~min}$., $42^{\circ} \mathrm{C} / 1 \mathrm{~min}$., $60^{\circ} \mathrm{C} / 1 \mathrm{~min}$. e mais um ciclo de extensão a $72^{\circ} \mathrm{C}$ por $10 \mathrm{~min}$. No momento de preparo das reações, controles negativos (sem presença de DNA) foram adicionados entre as amostras positivas para monitorar eventuais contaminações durante a manipulação das reações.

\subsection{Gel de Agarose e Purificação dos Fragmentos}

Os produtos amplificados por PCR ou RT-PCR foram analisados por eletroforese em gel de agarose tipo II a 1\% e tampão TAE na presença de brometo de etídeo (Sambrook e cols., 1989). O gel foi fotografado e os fragmentos foram purificados com sílica conforme descrito (Boyle e Lew, 1995).

\subsection{Clonagem}

Os fragmentos purificados foram ligados ao vetor pGEM-T Easy de 2,7 kb (Promega). A ligação foi realizada por 1 hora à temperatura ambiente e em seguida mantida a $4^{\circ} \mathrm{C}$ durante a noite, conforme orientações do fabricante, para aumentar a eficiência de ligação. Células competentes (E. coli cepa sure), obtidas como descrito (Sambrook e cols., 1989), foram transformadas por eletroporação (200 ohms, $25 \mu \mathrm{F}$ e 2,5 kV em cubetas de 0,2 cm) com $1 \mu \mathrm{l}$ da ligação. Para seleção dos transformantes, as células foram plaqueadas em placas LB-ágar-amp-tet, suplementadas com $80 \mu \mathrm{g} / \mathrm{ml}$ de X-Gal (5-bromo-4-chloro-3-indolyl- $\beta$-D-galactoside) e $0,5 \mathrm{mM}$ de IPTG (isopropyl $\beta$-D-thiogalactoside), e incubadas a $37^{\circ} \mathrm{C}$ por 16 horas. As colônias transformantes (brancas) foram crescidas por 16 horas a $37^{\circ} \mathrm{C}$ em LB- 
amp-tet, para extração do DNA plasmidial (Sambrook e cols., 1989). Uma alíquota de $3 \mu \mathrm{l}$ de cada extração foi digerida por uma hora a $37^{\circ} \mathrm{C}$ com $1 \mathrm{U}$ de Eco RI (Gibco) (que flanqueia os sítios de clonagem) utilizando Tampão React 3 (Gibco) em um volume final de $15 \mu \mathrm{l}$. O volume total da digestão foi analisado em gel de

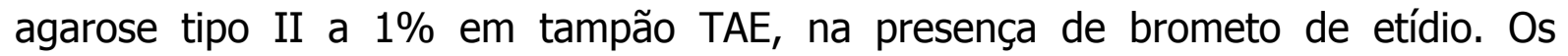
plasmídeos que continham inserto do tamanho previsto foram selecionados para preparo das membranas. Os fragmentos clonados utilizados como sonda foram digeridos dos plasmídeos como descrito acima e purificados em gel de agarose e sílica.

Para sequenciamento dos clones, os plasmídeos foram extraídos com "Wisard Plus SV Minipreps DNA Purification System" (Promega) e sequenciados por GATC $\mathrm{GmbH}$.

\subsection{Análise das Seqüências}

As seqüências obtidas no Anexo 1 foram traduzidas a aminoácidos através do programa EditSeq do pacote DNAstar e submetidas a BLASTP versão 2.1.3 (Altschul e cols., 1997). Alinhamentos foram realizados utilizando ClustalW versão 1.8 (Higgins e cols., 1996). Árvores filogenéticas foram criadas com ClustalX excluindo os "gaps" para 1000 "bootstraps" utilizando o método NJ (Neighbour Joining) (Saitou and Nei, 1987). Análise filogenética foi realizada do domínio DBL-1 de 146 var genes obtidos no GenBank. As árvores foram geradas de todas as seqüências utilizando o pacote Phylip (Felsenstein, J. 1993. PHYLIP, Phylogeny Inference Package, versão 3.5c, distribuído pelo autor: Departamento de Genética, Universidade de Washington, Seatle). Análise de bootstrap de 100 réplicas foi realizada com o programa Seqboot deste pacote. Árvores sem raiz foram construídas pelo método de Máxima Parsimônia do Protdist e finalmente calculando a melhor árvore destes dados. 
As seqüências obtidas no Anexo 2 foram traduzidas a aminoácidos através do programa EditSeq do pacote DNAstar e submetidas a BLASTP versão 2.1.3 (Altschul e cols., 1997). Alinhamentos foram realizados utilizando ClustalX versão 1.81 (Thompson e cols., 1997). Árvore de máxima verossimilhança foi construída utilizando o modelo GTR+I+G, selecionado pelo programa Modeltest versão 3.06 (Posada e Crandall, 1998). O método de "Quartet puzzling" foi utilizado para escolher a melhor árvore de verossimilhança (Strimmer e von Haeseler, 1996). Todas as análises foram realizadas com a versão 4.06 do PAUP*(Swofford, 1998).

\subsection{Southern Blot}

\subsubsection{Preparo de Sondas Radioativas}

A marcação de fragmentos de RT-PCR foi realizada por "random primer" com $\alpha^{33} \mathrm{P}$ dCTP utilizando "Multiprime DNA Labelling System" (Amersham Pharmacia Biotech), conforme instruções do fabricante, sendo o precipitado ressuspendido em $97 \mu$ de TE e $3 \mu$ de $10 \mathrm{~N} \mathrm{NaOH}$.

A marcação do oligonucleotídeo T7 foi realizada com T4 polinucleotídeo quinase (PNK)(New England, Biolabs). Uma alíquota de $2 \mu$ do oligo na

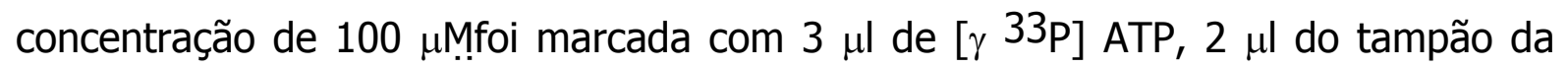
enzima 10x e $1 \mu \mathrm{l}$ PNK, em volume final de $20 \mu \mathrm{l}$, por 1 hora a $37^{\circ} \mathrm{C}$. A amostra foi precipitada com $2 \mu \mathrm{l}$ de 0,5 M EDTA pH 8,0, $37 \mu \mathrm{l}$ TE, $40 \mu$ l de DNA transportador e $300 \mu \mathrm{l}$ de etanol/acetato de amônio por 1 hora a $-20^{\circ} \mathrm{C}$. A amostra foi centrifugada a $12.000 \times \mathrm{g}$ por 6 minutos a temperatura ambiente e ressuspendida em $100 \mu \mathrm{l}$ de água.

\subsubsection{Preparo, Hibridação e Lavagem das Membranas}


DNA plasmidial dos clones obtidos no item 3.8 foi adicionado em duplicatas a membranas Hybond $\mathrm{N}+$ (Amersham) com a ajuda de um robô Flexys (Genomic Solutions, USA) utilizando uma cabeça de 96 pinos. As membranas foram denaturadas durante 3 min. com 1,5 M NaCl e 0,5 N NaOH, neutralizadas 2 x por 3 min. com 1,5 M NaCl, 0,5 M Tris $\mathrm{HCl}$ pH 7,2, 1 mM EDTA pH 8,0, lavadas em 2 x SSC $(0,3$ M cloreto de sódio, 0,03 M citrato de sódio pH 7,0) por 5 minutos, secas a temperatura ambiente sobre papel de filtro e fixadas em UV Stratalinker 2400 (Stratagene).

Para hibridação com o oligo T7, as membranas foram lavadas em 2 x SSC e pré-hibridizadas em 6 × SSC, $5 \times$ Denhardt's, 0,5\% SDS, $100 \mu \mathrm{g} / \mathrm{ml}$ de DNA de esperma de salmão por 2 horas a $37^{\circ} \mathrm{C}$ em forno PersonalHyb (Stratagene). A solução foi então trocada e a membrana foi hibridada por 16 horas a $370^{\circ} \mathrm{C}$ com a sonda radioativa. As lavagens das membranas foram realizadas em 0,5\% SDS, 6 x $\mathrm{SSC}$ a $37^{\circ} \mathrm{C}$ por 15 min. e então com a mesma solução a $42^{\circ} \mathrm{C}$ por 5 minutos.

Para hibridação com fragmentos de RT-PCR, as membranas foram lavadas em 2 x SSC por 5 min. e pré-hibridizadas em 0,5 M fosfato de sódio ( $\mathrm{pH} 7,2$ ), 7\% SDS (Smith e cols., 1995), com 1 mM EDTA e $100 \mu \mathrm{g} / \mathrm{ml}$ de DNA de esperma de salmão a $50^{\circ} \mathrm{C}$ por 2 horas em forno PersonalHyb (Stratagene). A solução foi então trocada e as membranas foram hibridadas por 16 horas a $37^{\circ} \mathrm{C}$, com a sonda radioativa. As lavagens das membranas foram realizadas em 2 x SSC a temperatura ambiente por 10 minutos e em $0,1 \times \mathrm{SSC} / 0,1 \%$ SDS a $65^{\circ} \mathrm{C}$ por 30 minutos. As membranas foram expostas a $-70^{\circ} \mathrm{C}$ em filme Kodak Diagnostic Film X-OMAT-AR XK1.

\subsection{PCR Multiplex}

Amostras de DNA genômico foram obtidas dos parasitas de 5 pacientes com malária grave antes do amadurecimento, como descrito no item 3.3. Análise por PCR Multiplex foi realizada com oligonucleotídeos para os genes CSP, MSP1 e MSP2 (Wooden e cols., 1992). Como controle de infecção com diferentes cepas de $P$. 
falciparum foi utilizado um DNA genômico de isolado da Tanzânia que apresentava múltiplos alelos de MSP1 e MSP2. Os produtos foram resolvidos em gel de agarose $2 \%$ corado com brometo de etídeo. 0 gel foi fotografado, transferido a membrana Hybond $\mathrm{N}+$, que foi hibridada com oligonucleotídeos específicos marcados com $[\gamma$ 32P] ATP. As lavagens foram realizadas em $0,5 \%$ SDS, 6 x SSC a $37^{\circ} \mathrm{C}$ por $15 \mathrm{~min}$. E então com a mesma solução a $50^{\circ} \mathrm{C}$ por 5 minutos.

\subsection{Expressão de Proteínas}

Para expressão da proteína referente ao fragmento de $~ 400$ bp da região Nterminal do DBL1 $\alpha$ da PfEMP1, o fragmento Eco RI purificado do vetor pGEM-T foi clonado em vetor pRSET-C (Invitrogen) em sítio de Eco RI, que mantém a fase de leitura e adiciona uma cauda com 7 histidinas à proteína. Após confirmação por seqüenciamento, o plasmídeo recombinante foi utilizado para transformação de células competentes ( $E$. coli cepa BL21). A expressão da proteína foi induzida com $0,1 \mathrm{mM}$ de IPTG por 2 horas a $37^{\circ} \mathrm{C}$. As células foram rompidas por 10 ciclos de sonicação a 40 watts por 10 segundos, com intervalos de 10 segundos. Após centrifugação $(10.000 \mathrm{~g})$, uma alíquota do precipitado e uma alíquota do sobrenadante foram submetidas a SDS-PAGE para verificação da presença da proteína. O precipitado foi ressuspendido em "Start Buffer" (Amersham Pharmacia Biotech) (10 mM de Imidazol, $20 \mathrm{mM}$ de fosfato de sódio, 0,5 M de $\mathrm{NaCl}$ ) gelado com 8 M Uréia. A amostra foi mantida em agitador por 1 hora a temperatura ambiente. Após centrifugação, o sobrenadante foi coletado, filtrado em filtro 0,45 $\mu \mathrm{m}$ para remover debris celulares e $\mathrm{o} \mathrm{pH}$ foi checado para 7,5. A proteína foi purificada com kit HisTrap conforme instruções do fabricante, utilizando o protocolo básico de purificação (Amersham Pharmacia Biotech). 


\subsection{Imunofluorescência}

Esfregaço foi preparado com hemácias A+ lavadas 3x em PBS. As hemácias foram fixadas com acetona e uma alíquota de $15 \mu \mathrm{l}$ de DBL1 $\alpha$-His $(0,08 \mathrm{mg} / \mathrm{ml})$ foi adicionada ao pocinho. Como controle negativo foi utilizada uma proteína não relacionada (Meta1-His de Leishmania $0,45 \mathrm{mg} / \mathrm{ml}$ ). Como controle positivo foi utilizado anticorpo policlonal anti hemácias (diluição 1:100), produzido em camundongo. Para detecção das proteínas com cauda de histidina foi utilizado anticorpo monoclonal $\mathrm{IgG}_{2}$ Anti-His (diluição 1:100), produzido em camundongo, capaz de detectar seis resíduos de histidina (Amersham Pharmacia Biotech). Anticorpo anti-IgG de camundongo, conjugado à fluoresceína foi utilizado na diluição de 1:100. A lâmina foi observada em objetiva de imersão com aumento de 1000x. 
4. RESULTADOS E DISCUSSÃO 


\subsection{Análise do repertório de seqüências DBL1 $\alpha$ de genes var de isolados de campo de P. falciparum dos Estados de Mato Grosso e Rondônia, Brasil}

\section{ANEXO 1: Plasmodium falciparum: DBL-1 Var Sequence Analysis in Field Isolates from Central Brazil}

A malária grave na Região Amazônica Brasileira, apesar de rara, conduz principalmente a casos de insuficiência renal e respiratória e raramente à malária cerebral (Boulos, 1992; Duarte e cols., 1985). A expressão de genes var (Su e cols., 1995; Baruch e cols., 1995; Smith e cols., 1995) na superfície de eritrócitos infectados está diretamente associada aos fenômenos de variação antigênica e citoaderência, principais responsáveis pela patologia da malária falciparum (rev. em Newbold, 1999). O domínio "Duffy Binding Like" mais N-terminal (DBL-1) dos genes var tornou-se alvo de muitos estudos epidemiológicos e moleculares desde que oligonucleotídeos degenerados foram capazes de amplificar diferentes seqüências de clones de laboratório e isolados de campo (Kyes e cols., 1997; Ward e cols., 1999, Taylor e cols., 2000). Portanto, iniciamos estudos para gerar um banco de seqüências DBL-1 $\alpha$ var de isolados de P. falciparum da Amazônia Brasileira para futuros estudos de expressão.

Iniciamos o estudo com isolados oriundos de Peixoto de Azevedo, no Estado do Mato Grosso (MT), onde parasitas foram coletados de 20 pacientes (MT01-20). Em paralelo foram utilizados também 24 isolados de Porto Velho, no Estado de Rondônia (RO01-25). Após extração de DNA genômico (Ferreira e cols., 1998), a região $\mathrm{N}$-terminal do $\mathrm{DBL}-1 \alpha$ de genes var de $P$. falciparum foi amplificada por PCR 
(Kyes e cols., 1997). Fragmentos de 200 bp foram obtidos em cada isolado, clonados e seqüenciados. Duzentas seqüências (10 de cada isolado), correspondestes aos 70 aminoácidos mais N-terminais do domínio DBL-1 $\alpha$ da seqüência var-1 (Su e cols., 1995), foram geradas e confirmadas por BLAST (Altschul e cols., 1997) representar seqüências var. Quarenta e quatro diferentes seqüências de aminoácidos foram obtidas (GenBank AF172771-172814) mostrando a mesma estrutura de DBL-1 $\alpha$ descrita em outros isolados (Figura $1 A$ do Anexo 1 ). Cinqüenta seqüências foram obtidas dos isolados de Rondônia, representando 15 diferentes seqüências de aminoácidos. Porém, somente 3 seqüências não haviam sido encontradas nas amostras de Mato Grosso (Figura 12). Após alinhamento das 44 seqüências e a maioria das seqüências disponíveis no GenBank, 8 resíduos e várias cisteínas foram altamente conservados (Figura 13). 


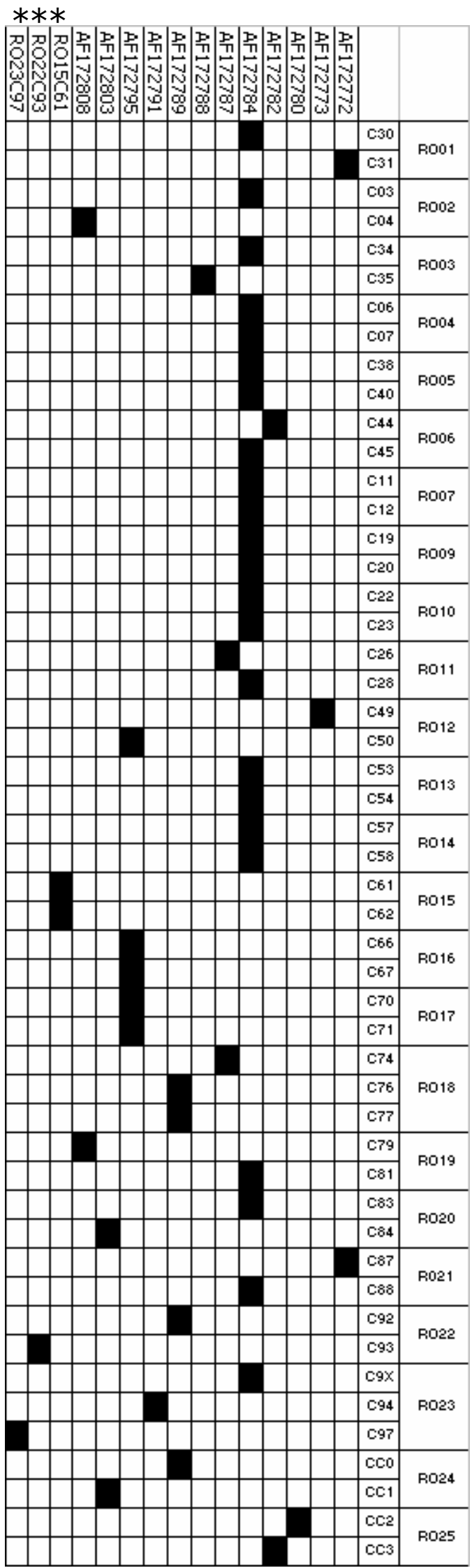

Figura 12. Diferentes seqüências de aminoácidos obtidas com os 50 clones após PCR do domínio DBL1 $\alpha$ de genes var de gDNA de 24 isolados de $P$. falciparum de Rondônia. AF, número de acesso do GenBank para as seqüências obtidas de isolados de Mato Grosso. *Seqüências não encontradas nos isolados de Mato Grosso e não depositadas no GenBank. 


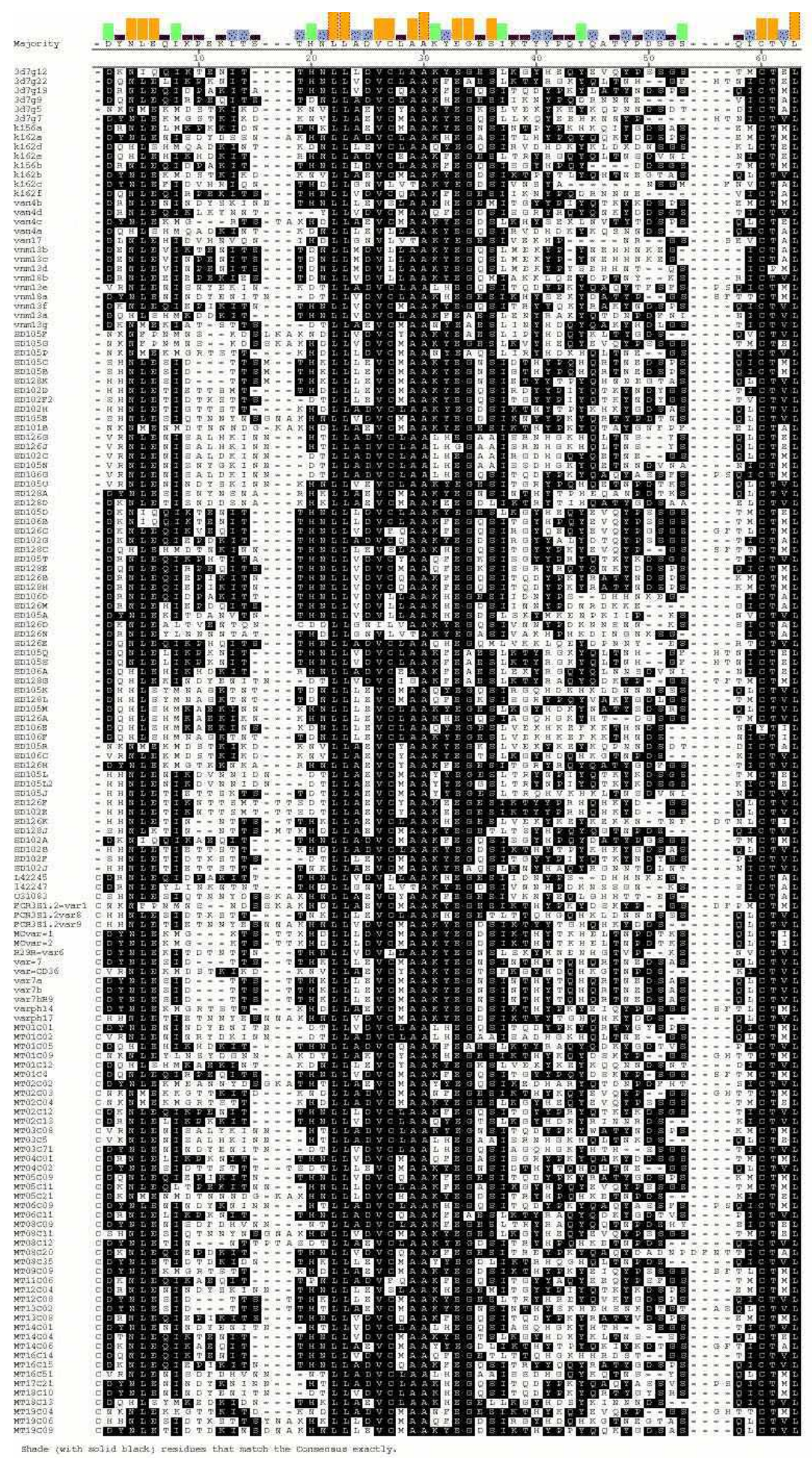

Figura 13. Alinhamento das 102 seqüências var encontradas no GenBank e 44 seqüências var de $P$. falciparum obtido diretamente de 20 pacientes de Mato Grosso, Região Amazônica Brasileira. O alinhamento foi realizado utilizando clustalw (versão 1.8)(Higgins e cols., 1996) e algumas edições manuais. DNAstar foi utilizado para a visualização gráfica. 
Análise da porcentagem de identidade revelou que algumas seqüências brasileiras foram mais similares a seqüências de isolados de origem geográfica distinta. Além disso, dendogramas gerados de todas as seqüências demonstraram que as seqüências DBL-1 var do Mato Grosso não agruparam mais freqüentemente com seqüências obtidas de isolados da mesma região geográfica (Figura 14 e 15). Portanto, esses resultados confirmam e expandem as observações de outros autores (Kyes e cols., 1997; Ward e cols., 1999), ou seja, similaridade de seqüências DBL$1 \alpha$ var não pode predizer origem geográfica. 
Figura 14. Cálculo filogenético com clustalw excluindo "gaps" e correção para múltiplas substituições (Higgins e cols., 1996) para 1000 réplicas de bootstrap utilizando 0 método de NJ (Neighbour Joining) (Saitou e Nei, 1987). As seqüências brasileiras estão indicadas $(\star)$.

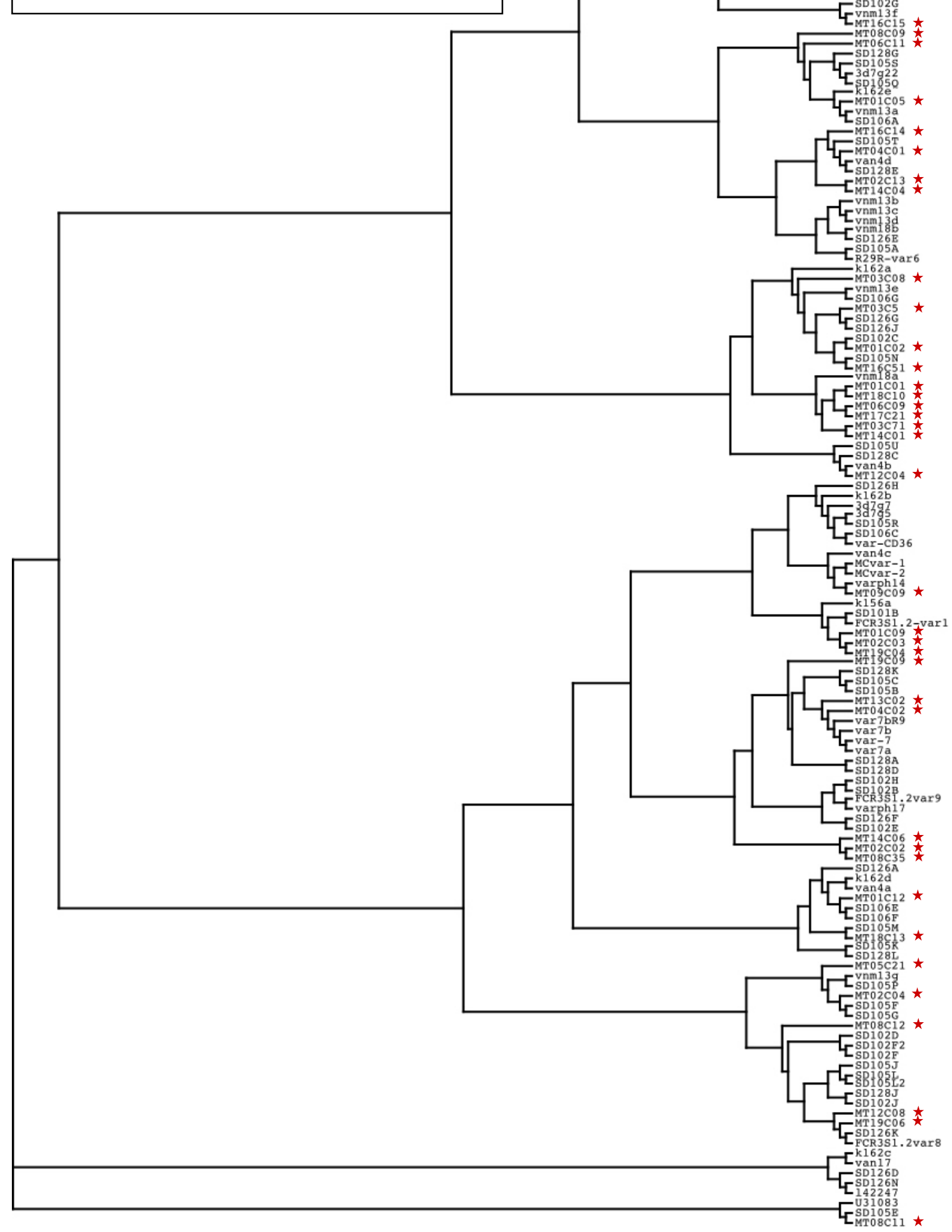




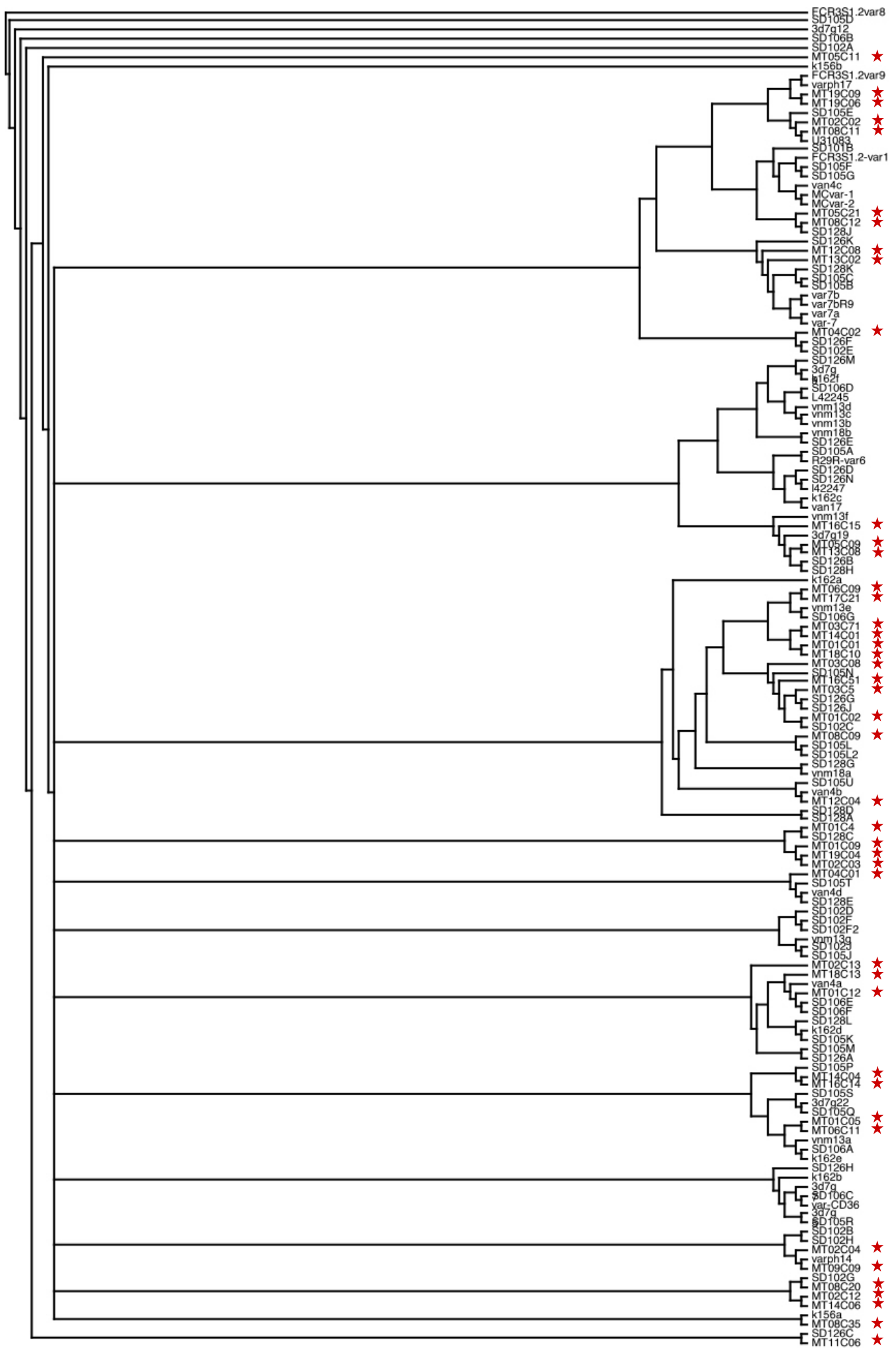

Figura 15. Análise filogenética do domínio DBL-1 de 146 genes var. Árvores foram geradas de todas as seqüências com pacote Phylip (Felsenstein, J. 1993. PHYLIP, Phylogeny Inference Package, versão 3.5c, distribuído pelo autor: Departamento de Genética, Universidade de Washington, Seatle). Análise de bootstrap de 100 réplicas foi realizada com o programa seqboot deste pacote. Árvores sem raiz foram construídas pelo método de máxima parsimônia do protdist e finalmente a melhor árvore consenso foi calculada destes dados. As seqüências brasileiras estão indicadas $(\star)$. 
De 3 a 9 diferentes seqüências foram detectadas por paciente e nenhum dos pacientes abrigava parasitas apresentando todas as mesmas seqüências de parasitas de outro paciente (Figura $1 B$ do Anexo 1). Em contraste ao observado no Sudão (Ward e cols., 1999), onde 37 diferentes seqüências de aminoácidos foram amplificadas de 5 pacientes (média de 7,4 seqüências diferentes/paciente), em 20 pacientes brasileiros foram obtidas apenas 44 diferentes seqüências de aminoácidos (média de 2,2 seqüências diferentes/paciente). Mesmo que o número de cepas circulantes por paciente fosse 1, o que é improvável em isolados de campo (Druilhe e cols., 1998), esperaríamos encontrar mais seqüências DBL-1 $\alpha$. Estes resultados claramente indicam que este par de oligonucleotídeos tem especificidade limitada e sugere que um número menor de clones circulantes está presente em cada paciente do Mato Grosso em relação ao Sudão. Um novo par de oligonucleotídeos, capaz de amplificar por PCR a maioria dos genes var de clones de laboratório (Taylor e cols., 2000), será utilizado nos mesmos isolados em estudos futuros.

Este é o primeiro trabalho de seqüências $\mathrm{DBL}-1$ var de $P$. falciparum de isolados brasileiros obtidos diretamente de pacientes. Vários estudos têm sido realizados para demonstrar que os domínios DBL das proteínas PfEMP1 são capazes de se ligar a diferentes receptores endoteliais (Rowe e cols., 1997; Chen e cols., 1998a; Buffet e cols., 1999; Smith e cols., 2000). Esta especificidade diferencial de adesão conduz ao seqüestramento em vários órgãos. Informação mundial de seqüências DBL-1 $\alpha$ de DNA genômico está rapidamente sendo acumulada (Kyes e cols., 1997; Ward e cols., 1999; Taylor et al, 2000) na tentativa de determinar se existem seqüências particulares de DBL-1 $\alpha$ preferencialmente expressas nas diferentes patologias da malária falciparum grave. 


\subsection{Análise de seqüências DBL1 $\alpha$ de genes var expressos em isolados de campo de $P$. falciparum obtidos de pacientes com malária grave infectados na Região Amazônica Brasileira}

\section{ANEXO 2: Association of severe non-cerebral Plasmodium falciparum malaria in Brazil with expressed PfEMP1 DBL1 $\alpha$ sequences lacking cysteine residues}

Infecções por $P$. falciparum são caracterizadas por remoção da circulação periférica de eritrócitos infectados com parasitas maduros. Este seqüestramento ocorre por adesão dos eritrócitos infectados aos receptores endoteliais do hospedeiro na microvasculatura de muitos órgãos. Este fenótipo, denominado citoaderência, causa retenção e acúmulo de eritrócitos infectados conduzindo à oclusão de microvasos e alterações patológicas associadas à malária grave (Miller e cols., 1994). A citoaderência é conferida por PfEMP1, uma proteína codificada por genes var (Su e cols., 1995), que apresenta na sua região N-terminal, altamente polimórfica, muitos ligantes para diferentes receptores endoteliais (rev. em Cooke e cols., 2000). A adesão de eritrócitos infectados a não infectados, um fenômeno denominado "rosetting" (Handunnetti e cols., 1989), também contribui para a patologia associada a infecções por P. falciparum (MacPherson e cols., 1985; Aikawa, 1988; Carlson e cols., 1990; Pongponratn e cols., 1991; Treutiger e cols., 1992; Rowe e cols., 1995; Newbold e cols., 1997a) e muitas linhas de evidência têm demonstrado que o DBL1 $\alpha$ da PfEMP1 media "rosetting" (Rowe e cols., 1997; Chen e cols., 1998a e 2000b; Barragan e cols., 2000b). 
O entendimento dos mecanismos moleculares implicados na malária falciparum grave pode conduzir a novas e adequadas estratégias de controle. Trabalho recente associou malária grave de pacientes da Guiana Francesa a determinadas seqüências DBL $\delta$ de genes var, indicando que isolados de indivíduos com diferentes manifestações clínicas podem ser caracterizados por repertórios PfEMP1 específicos (Ariey e cols., 2001). Nós, portanto, analisamos as seqüências DBL1 $\alpha$ de genes var expressos em parasitas obtidos de pacientes com malária grave da Região Amazônica Brasileira, para determinar se existem seqüências DBL1 $\alpha$ específicas predominantemente expressas nesses parasitas.

Foram utilizadas para o estudo, 6 amostras de pacientes com malária grave,

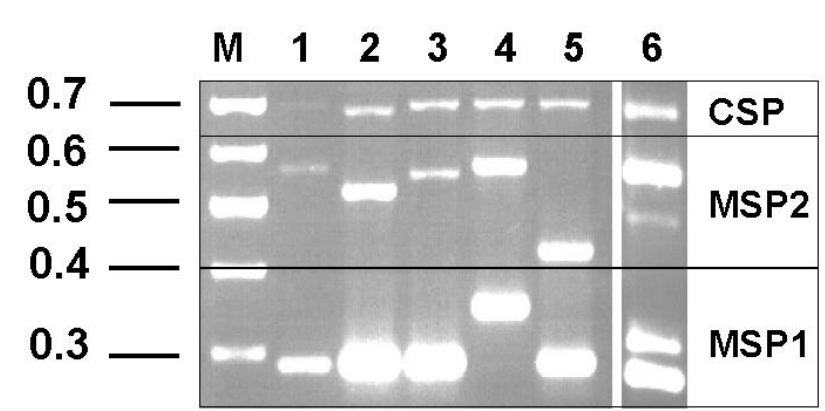

Figura 16. PCR multiplex. cuja maioria (amostras 1 a 5 ) aparentemente apresentava infecção clonal (Figura 16), diferentemente de um isolado da Tanzânia (amostra 6). Entretanto, cinqüenta e sete seqüências DBL1 $\alpha$ foram obtidas por

RT-PCR de parasitas maduros (Figura 17 e Tabela 4), representando 25 diferentes seqüências de aminoácidos, sendo 2 já descritas (GenBank AF221773 e AJ133811) e 23 novas (GenBank AF368922 a AF368944). Alinhamento de todas as 25 seqüências mostrou que 8 podiam ser agrupadas devido a deleções de 1-2 cisteínas (Figura 18 e Figura 1 do Anexo 2). Significativamente, esse grupo compreendeu todas as seqüências mais abundantemente expressas em cada paciente, como demonstrado pela porcentagem de clones idênticos sequenciados em cada amostra. 


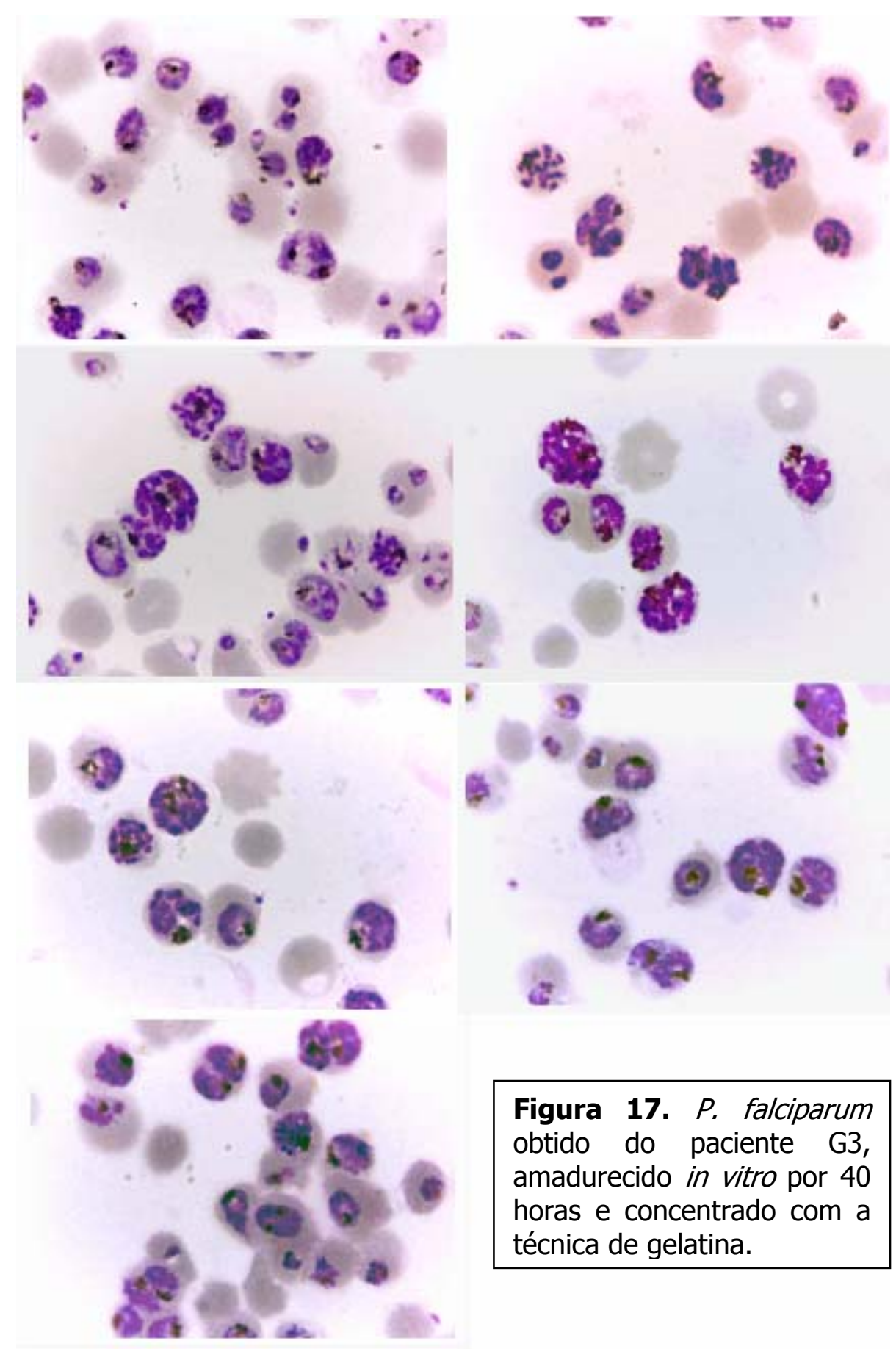

Tabela 4. Parasitemias e estágios dos parasitas em cada isolado utilizado.

\begin{tabular}{|c|c|c|c|c|c|c|c|c|c|c|}
\hline & G33 & G23 & G34 & G2 & G29 & G3 & NG1 & NG2 & NG3 & NG4 \\
\hline $\begin{array}{l}\text { Após } \\
\text { cultivo } \\
*\end{array}$ & $\begin{array}{l}5,4 \% \\
89 T \\
11 \mathrm{~A}\end{array}$ & \begin{tabular}{|l}
$0,8 \%$ \\
$75 T$ \\
$25 \mathrm{~A}$
\end{tabular} & $\begin{array}{l}0,3 \% \\
33 \mathrm{E}, 67 \mathrm{~T}\end{array}$ & $\begin{array}{l}2,3 \% \\
44 \mathrm{E}, 39 \mathrm{~T} \\
17 \mathrm{~A}\end{array}$ & \begin{tabular}{|l}
$1,2 \%$ \\
$42 \mathrm{E}, 33 \mathrm{~T}$ \\
$25 \mathrm{~A}$
\end{tabular} & ND & \begin{tabular}{|l|}
$N D$ \\
\end{tabular} & ND & \begin{tabular}{|l|}
$3,8 \%$ \\
$50 \mathrm{E}, 47 \mathrm{~T}$ \\
$3 \mathrm{~A}$
\end{tabular} & $\begin{array}{l}7 \% \\
13 \mathrm{E}, 70 \mathrm{~T} \\
17 \mathrm{~A}\end{array}$ \\
\hline $\begin{array}{l}\text { Após } \\
\text { Plasmagel } \\
\#\end{array}$ & \begin{tabular}{|l|}
$53 \%$ \\
$98 \mathrm{~T}$ \\
$2 \mathrm{~A}$ \\
\end{tabular} & \begin{tabular}{|l|}
$66 \%$ \\
$99 T$ \\
$1 \mathrm{~A}$
\end{tabular} & NR & \begin{tabular}{|l}
$55 \%$ \\
$56 \mathrm{E}, 43 \mathrm{~T}$ \\
$1 \mathrm{~A}$
\end{tabular} & \begin{tabular}{|l}
$45 \%$ \\
$53 \mathrm{E}, 45 \mathrm{~T}$ \\
$2 \mathrm{~A}$
\end{tabular} & \begin{tabular}{|l}
$65 \%$ \\
$83 \mathrm{~T}, 15 \mathrm{E}$ \\
$2 \mathrm{~A}$
\end{tabular} & \begin{tabular}{|l|}
$27 \%$ \\
$81 \mathrm{~T}, 19 \mathrm{E}$
\end{tabular} & \begin{tabular}{|l|}
$58 \%$ \\
$81 T, 18 \mathrm{E}$ \\
$1 \mathrm{~A}$
\end{tabular} & NR & \begin{tabular}{|l|}
$52 \%$ \\
$80 \mathrm{~T}, 18 \mathrm{E}$ \\
$2 \mathrm{~A}$
\end{tabular} \\
\hline
\end{tabular}

*Parasitemia em 1000 hemácias, \#Parasitemia em 300 hemácias,

$\mathrm{A}=$ anel, $\mathrm{T}=$ trofozoíta maduro, $\mathrm{E}=$ esquizonte,

$\mathrm{NR}=$ não realizado, $\mathrm{ND}=$ não determinado 


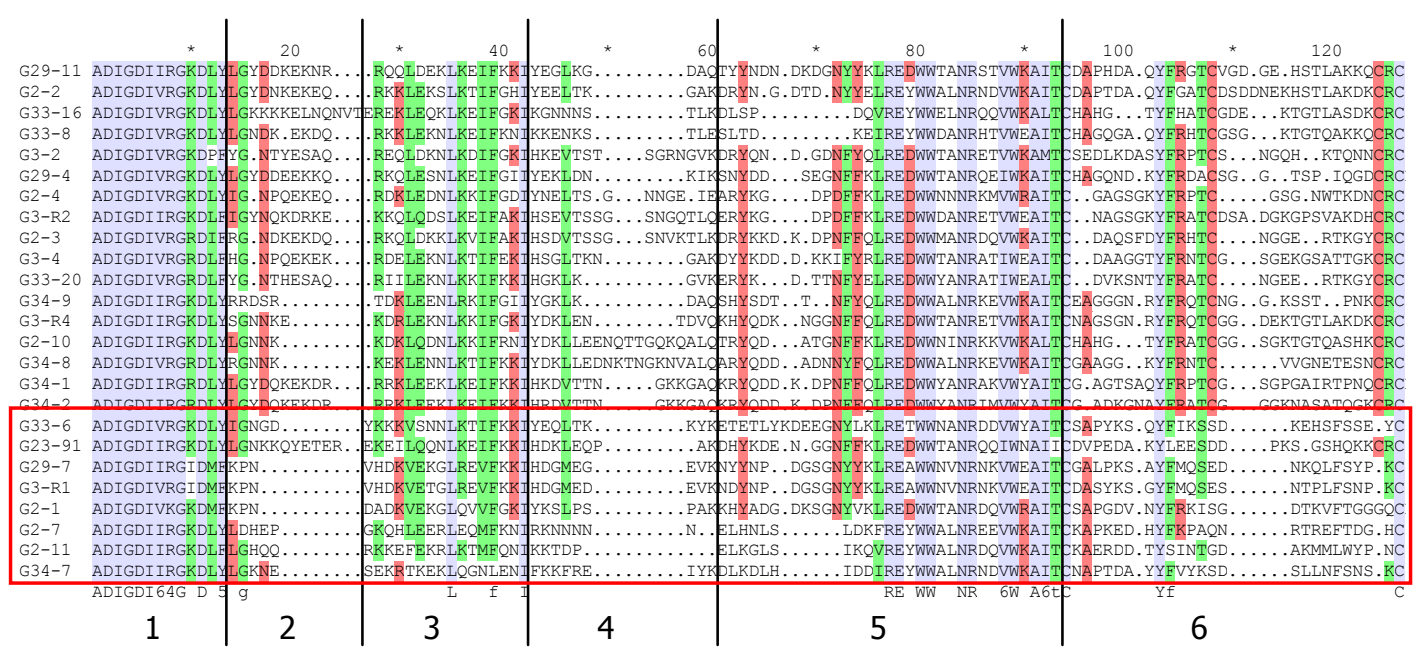

1
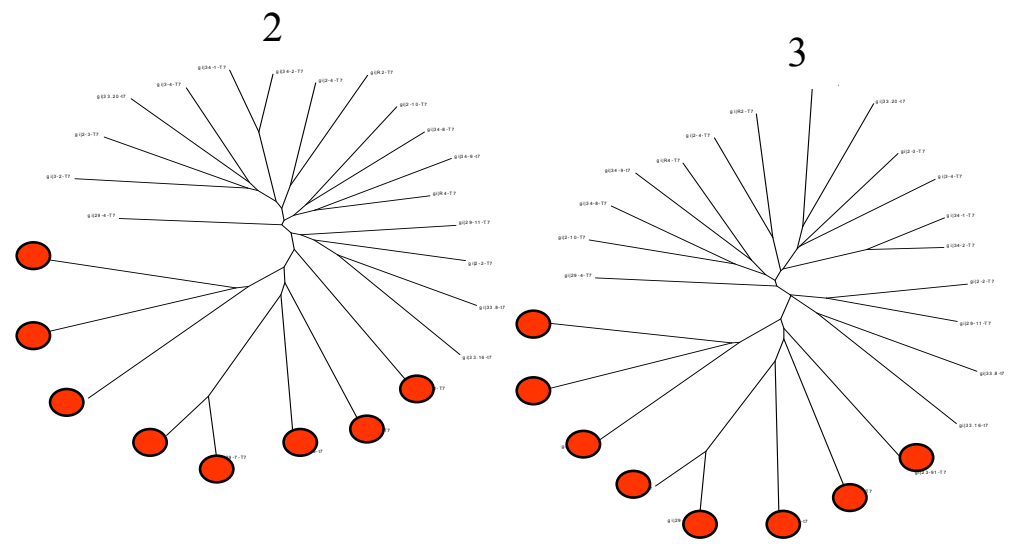

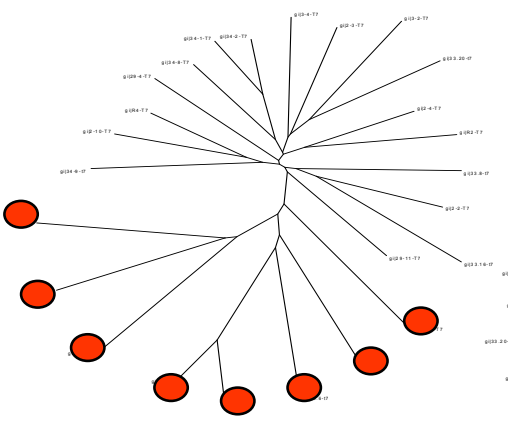

4

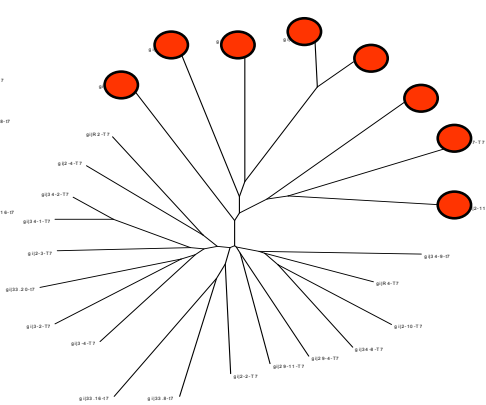

5

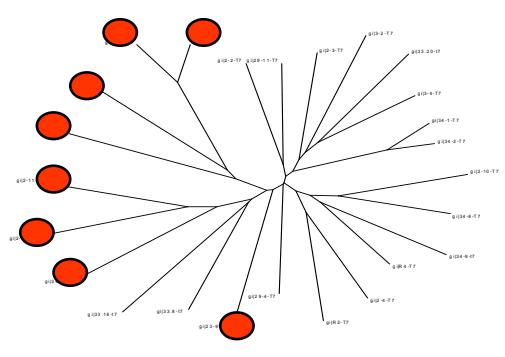

6

Figura 18. A. Alinhamento das diferentes seqüências de aminoácidos do domínio DBL1 $\alpha$, obtidas dos parasitas de pacientes graves. Dentro do retângulo vermelho estão representadas as seqüências preferencialmente expressas de cada isolado. B. Diferentes árvores sem raiz construídas após deleções de diferentes regiões do alinhamento (A. 1 a 6) e as posições das seqüências preferencialmente expressas ( ). A Oleção da região 6 do alinhamento foi a única responsável pelo desagrupamento dessas seqüências. 
Nós então investigamos se essas seqüências também eram expressas em parasitas de pacientes com malária não grave. Cinqüenta e quatro seqüências DBL1 $\alpha$ var foram obtidas de parasitas de 4 pacientes (Tabela 1 do Anexo 2), representando 21 diferentes seqüências de aminoácidos. Apenas uma já havia sido descrita (GenBank AF275864). As outras 20 seqüências foram depositadas no GenBank (AF368945 a AF368950 e AF416572 a AF416585). Importante notar que nesta análise foi incluída uma amostra de um paciente com malária não grave que trata-se de uma recrudescência proveniente de uma infecção grave.

Em análise filogenética do domínio DBL1 $\alpha$ de diferentes genes var expressos no Brasil (25 de grave e 21 de malária não grave) juntamente com 21 seqüências do Sudão obtidas do GenBank, as mesmas seqüências de parasitas de pacientes graves que haviam sido agrupadas permaneceram juntas (Figura 1 do Anexo 2).

Nós então investigamos se as seqüências DBL1 $\alpha$ var mais predominantemente expressas em parasitas de pacientes com malária grave estavam amplamente presentes no repertório de genes var de pacientes com malária não grave da Amazônia Brasileira. Filtros de alta densidade foram preparados com 320 clones representando seqüências DBL1 $\alpha$ var de DNA genômico de parasitas obtidos de 80 pacientes sem malária grave de 4 diferentes estados da Amazônia Brasileira. Os resultados de hibridização com seqüências preferencialmente expressas em parasitas de diferentes pacientes com malária grave demonstraram que, apesar destas seqüências serem raramente expressas nos parasitas de pacientes sem malária grave, são abundantes no genoma destes parasitas (Figura 2 do Anexo 2).

Como "rosetting" tem sido associado a malária grave e é mediado por DBL1 $\alpha$, nós investigamos se um domínio $\mathrm{DBL} 1 \alpha$ da seqüência mais abundante de um 
paciente com malária grave pode se ligar a eritrócitos. Portanto, uma proteína (AF368922) foi expressa com uma cauda de histidina e utilizada em análise por imunofluorescência (IFA), similarmente ao que já havia sido feito para demonstrar que a PfEMP1 é um ligante de "rosetting" (Chen e cols., 1998a). Esse seqüência foi escolhida por apresentar $72 \%$ de identidade com a seqüência (2182041) do clone ItR29, identificada como ligante de "rosetting" para o receptor CR1 dos eritrócitos (Rowe e cols., 1997). A IFA com a proteína DBL1 $\alpha-H i s$ apresentou uma coloração de

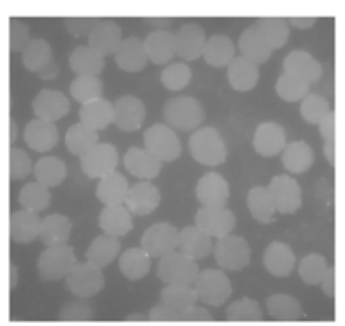
PBS

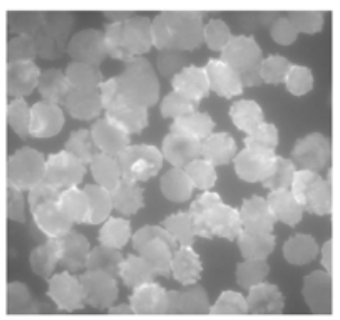

Anti A

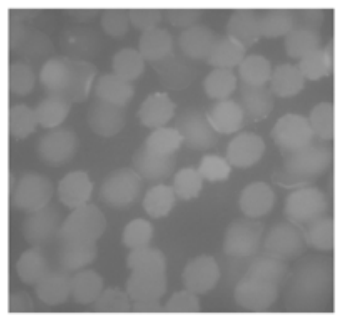

Anti B

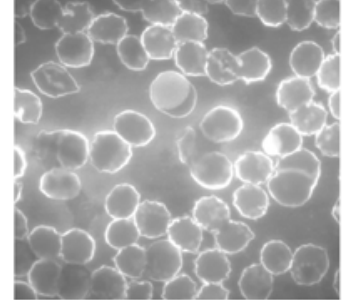

Anti RBC

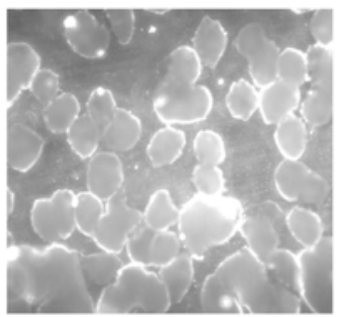

DBL1alfa/His

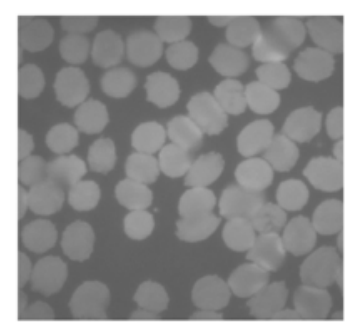

Meta1/His

superfície em todos os eritrócitos não infectados.

Este resultado mostrou-se específico para DBL1 $\alpha$, visto

Figura 19. Imunofluorescência utilizando monocamadas de eritrócitos A+ e diferentes anticorpos/proteínas.

que uma proteína não relacionada também com cauda de histidina não apresentou qualquer sinal (Figura 19 e Figura 3 do Anexo 2). 
Este é o primeiro trabalho reportando associação de malária grave em pacientes brasileiros e determinadas seqüências $\mathrm{DBL} 1 \alpha$. Os resultados e conclusões obtidos deste estudo foram baseados em material de parasitas de 6 pacientes diagnosticados com malária grave. Para identificar estes pacientes, nós examinamos a história clínica de 1599 pacientes com malária falciparum, atendidos no Laboratório de Malária da SUCEN, de 1987 a 2000. Porém, fomos capazes de identificar somente seis pacientes com malária grave, segundos os critérios da WHO (WHO, 2000). Além disso, nós também demonstramos níveis séricos de PCT mais elevados nestes pacientes (Figura 20). Este novo parâmetro foi mostrado se correlacionar com a severidade da doença e o risco de mortalidade (Chiwakata e cols., 2001).

A

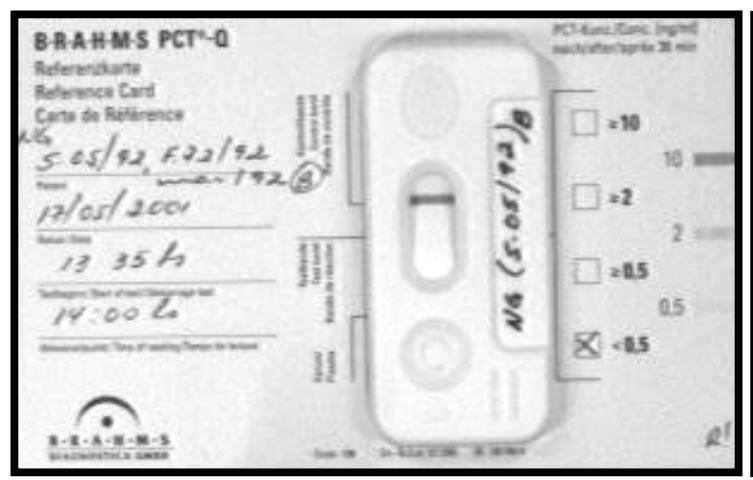

B

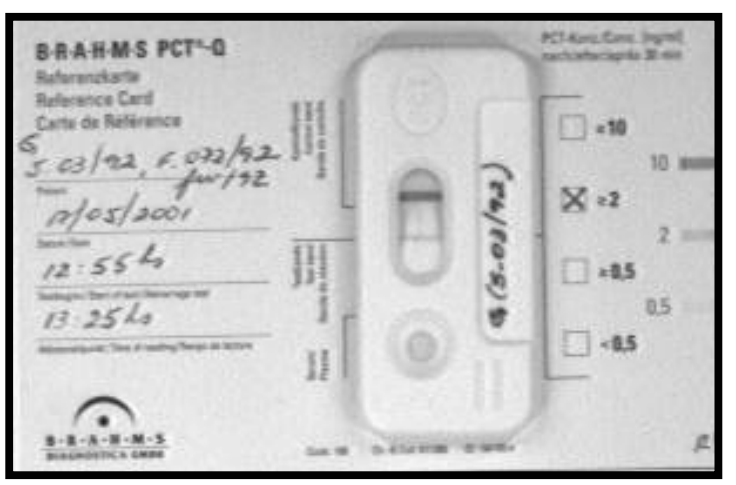

Figura 20. Teste imunocromatográfico para dosagem de procalcitonina (PCT) em soro humano. A. Teste negativo (realizado com o paciente NG2). B. Teste positivo (realizado com o paciente G3). 
Infecções maláricas não são clonais, mesmo em regiões de baixa endemicidade. Portanto, não foi surpreendente encontrar diferentes seqüências DBL1 $\alpha$ var expressas nos parasitas obtidos de todos os pacientes (Figura 21A e 21B) . Notavelmente, entretanto, houve seqüências DBL1 $\alpha$ predominantemente expressas nos parasitas obtidos de todos os 6 pacientes com malária grave. Além disso, estas seqüências mostraram uma região com deleções de 1-2 cisteinas. Porém, as seqüências predominantemente expressas em parasitas de pacientes sem malária grave não apresentaram essas deleções. De fato o mesmo paciente no momento de sua infecção grave apresentava parasitas expressando principalmente seqüências DBL1 $\alpha$ com deleção de 2 cisteínas e 20 dias depois, durante uma recrudescência, causando infecção não grave, as seqüências DBL1 $\alpha$ predominantemente expressas apresentavam todas as 4 cisteínas. Este resultado nos leva a especular que um dobramento diferente destes domínios confere às populações de parasitas que os expressam, diferentes graus de virulência e reforçam a importância da conformação da PfEMP1 na patologia associada a malária. 


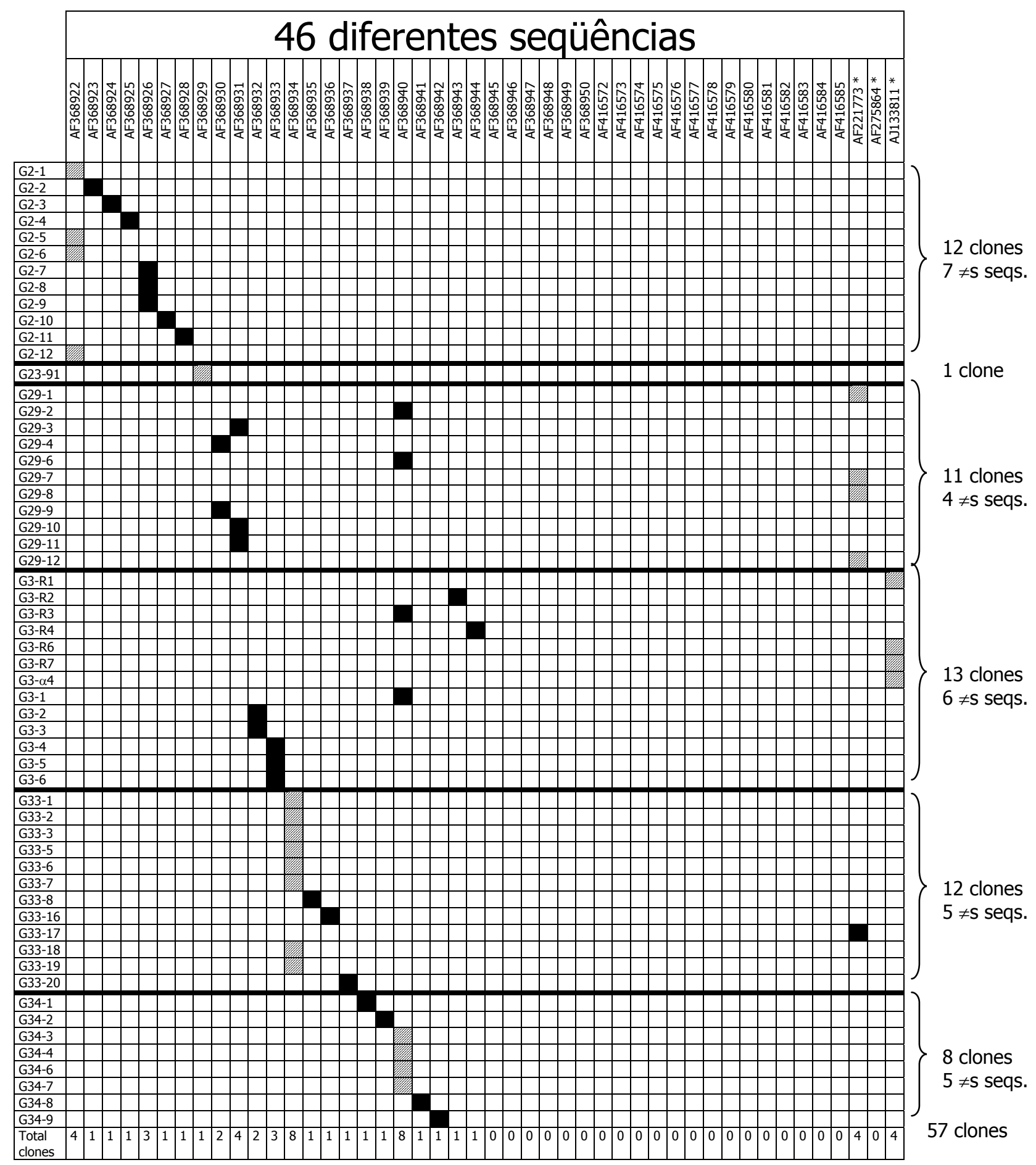

Figura 21A. Números de Acesso do GenBank para as seqüências dos 57 clones obtidos da região DBL1 $\alpha$ de genes var de isolados de $P$. falciparum de pacientes com malária grave. Nos quadrados hachurados em diagonal são representadas as seqüências preferencialmente expressas em cada paciente. *Seqüências já reportadas no GenBank. 




Figura 21B. Números de Acesso do GenBank para as seqüências dos 54 clones obtidos da região DBL1 $\alpha$ de genes var de isolados de $P$. falciparum de pacientes com malária não grave. Nos quadrados hachurados em diagonal são representadas as seqüências preferencialmente expressas em cada paciente. *Seqüências já reportadas no GenBank. 
Aqui nós demonstramos que o domínio $\mathrm{DBL} 1 \alpha$ representando a seqüência mais abundantemente expressa de um dos pacientes com malária grave, quando expresso em bactéria, se liga a eritrócitos. Este resultado, portanto, sugere uma associação de "rosetting" com malária grave não cerebral, presente nos pacientes brasileiros. Infelizmente, não existem dados de "rosetting" no Brasil e claramente mais estudos são necessários para validar esta associação.

Os resultados aqui descritos, juntamente com aqueles encontrados na Guiana Francesa (Ariey e cols., 2001), indicam que existem realmente associações de malária grave com seqüências PfEMP1 específicas. Entretanto, além da família multigênica var, existem várias outras famílias multigênicas, tais como rif, stevor, clag e pf60, envolvidas em virulência (rev. em Kyes e cols., 2001). Atualmente, metodologias em larga escala podem ser desenvolvidas para comparar o repertório genômico e expresso dos genes de virulência daqueles parasitas que causam manifestações clínicas específicas. Esses dados ajudariam a elucidar os mecanismos moleculares envolvidos nas diferentes apresentações da malária grave e possibilitariam a criação de alternativas às estratégias de erradicação e controle da malária atualmente utilizadas. 
5. CONCLUSÕES 
5.1. Os isolados brasileiros apresentam domínios $\mathrm{DBL} 1 \alpha$ de genes var com estrutura muito semelhante àquela obtida em isolados de outros países, com várias cisteínas e outros resíduos conservados.

5.2. Existem isolados brasileiros com domínios $\mathrm{DBL} 1 \alpha$ de genes var idênticos aos encontrados em isolados de países muito distantes e sem qualquer fluxo de parasitas com o Brasil.

5.3. Alguns domínios DBL1 $\alpha$ de genes var de isolados brasileiros apresentaram maior similaridade com isolados de origem geográfica distinta e portanto, similaridade entre essas seqüências não pode predizer origem geográfica.

5.4. O repertório genômico do domínio $\mathrm{DBL} 1 \alpha$ dos genes var de isolados de Plasmodium falciparum de Mato Grosso e Rondônia é muito semelhante, porém, os oligonucleotídeos $\alpha 5$ e $\alpha A R$ também apresentam especificidade limitada para os isolados brasileiros.

5.5. Resultados preliminares sugerem que pacientes brasileiros com malária grave também apresentam níveis elevados de procalcitonina, apesar de mais baixos que os encontrados em regiões de alta endemicidade.

5.6. Várias seqüências do domínio $\mathrm{DBL} 1 \alpha$ dos genes var são expressas em parasitas maduros de isolados brasileiros de Plasmodium falciparum. 
5.7. Seqüências expressas em alguns isolados brasileiros também apresentam 100\% de identidade com seqüências de isolados de países longínquos.

5.8. As seqüências preferencialmente expressas em parasitas de pacientes com malária grave do Brasil apresentam deleções de uma ou duas cisteínas. Parasitas de pacientes com malária não grave também apresentaram essas seqüências, porém elas foram raramente expressas, apesar de freqüentes no genoma desses parasitas.

5.9. Uma seqüência com deleção de duas cisteínas, preferencialmente expressa em parasitas de um dos pacientes com malária grave do Brasil se liga a eritrócitos. 
6. REFERÊNCIAS BIBLIOGRÁFICAS 
Adams, J. H., Sim, B. K., Dolan, S. A., Fang, X., Kaslow, D. C. \& Miller, L. H. (1992). "A family of erythrocyte binding proteins of malaria parasites." Proc Natl Acad Sci U S A, 89(15), 7085-9.

Aguiar, J. C., Albrecht, G. R., Cegielski, P., Greenwood, B. M., Jensen, J. B., Lallinger, G., Martinez, A., McGregor, I. A., Minjas, J. N., Neequaye, J. e cols. (1992). "Agglutination of Plasmodium falciparuminfected erythrocytes from east and west African isolates by human sera from distant geographic regions." Am J Trop Med Hyg, 47(5), 621-32.

Ahearn, J. M. \& Fearon, D. T. (1989). "Structure and function of the complement receptors, CR1 (CD35) and CR2 (CD21)." Adv Immunol, 46, 183-219.

Ahlborg, N., Iqbal, J., Hansson, M., Uhlen, M., Mattei, D., Perlmann, P., Stahl, S. \& Berzins, K. (1995). "Immunogens containing sequences from antigen Pf332 induce Plasmodium falciparum-reactive antibodies which inhibit parasite growth but not cytoadherence." Parasite Immunol, 17(7), 341-52.

Aikawa, M. (1988). "Human cerebral malaria." Am J Trop Med Hyg, 39(1), 3-10.

Aikawa, M., Brown, A., Smith, C.D., Tegoshi, T., Howard, R.J., Hasler, T.H., Ito, Y., Perry, G., Collins, W.E. \& Webster, K. (1992) "A primate model for human cerebral malaria: Plasmodium coatneyiinfected rhesus monkeys". Am J Trop Med Hyg, 46(4), 391-7.

Alecrim, M.G., Alecrim, W. \& Macedo, V. (1999). "Plasmodium vivax resistance to chloroquine (R2) and mefloquine (R3) in Brazilian Amazon region." Rev Soc Bras Med Trop, 32(1), 67-8.

Al-Nawas, B. \& Shah, P. (1997). "Procalcitonin in acute malaria." Eur J Med Res, 2(5), 206-8.

Altschul, S. F., Madden, T. L., Schaffer, A. A., Zhang, J., Zhang, Z., Miller, W. \& Lipman, D. J. (1997). "Gapped BLAST and PSI-BLAST: a new generation of protein database search programs." Nucleic Acids Res, 25(17), 3389-402.

al-Yaman, F., Genton, B., Mokela, D., Raiko, A., Kati, S., Rogerson, S., Reeder, J. \& Alpers, M. (1995). "Human cerebral malaria: lack of significant association between erythrocyte rosetting and disease severity." Trans R Soc Trop Med Hyg, 89(1), 55-8.

Angus, B. J., Thanikkul, K., Silamut, K., White, N. J. \& Udomsangpetch, R. (1996). "Short report: Rosette formation in Plasmodium ovale infection." Am J Trop Med Hyg, 55(5), 560-1.

Anstey, N. M., Weinberg, J. B., Hassanali, M. Y., Mwaikambo, E. D., Manyenga, D., Misukonis, M. A., Arnelle, D. R., Hollis, D., McDonald, M. I. \& Granger, D. L. (1996). "Nitric oxide in Tanzanian children with malaria: inverse relationship between malaria severity and nitric oxide production/nitric oxide synthase type 2 expression." J Exp Med, 184(2), 557-67.

Ariey, F., Hommel, D., Le Scanf, C., Duchemin, J. B., Peneau, C., Hulin, A., Sarthou, J. L., Reynes, J. M., Fandeur, T. \& Mercereau-Puijalon, O. (2001). "Association of severe malaria with a specific Plasmodium falciparum genotype in French Guiana." J Infect Dis, 184(2), 237-41.

Assicot, M., Gendrel, D., Carsin, H., Raymond, J., Guilbaud, J. \& Bohuon, C. (1993). "High serum procalcitonin concentrations in patients with sepsis and infection." Lancet, 341(8844), 515-8.

Barnwell, J. W., Asch, A. S., Nachman, R. L., Yamaya, M., Aikawa, M. \& Ingravallo, P. (1989). "A human 88-kD membrane glycoprotein (CD36) functions in vitro as a receptor for a cytoadherence ligand on Plasmodium falciparum-infected erythrocytes." J Clin Invest, 84(3), 765-72.

Barragan, A., Fernandez, V., Chen, Q., von Euler, A., Wahlgren, M. \& Spillmann, D. (2000b). "The duffy-binding-like domain 1 of Plasmodium falciparum erythrocyte membrane protein 1 (PfEMP1) is a heparan sulfate ligand that requires 12 mers for binding." Blood, 95(11), 3594-9.

Barragan, A., Kremsner, P. G., Wahlgren, M. \& Carlson, J. (2000a). "Blood group A antigen is a coreceptor in Plasmodium falciparum rosetting." Infect Immun, 68(5), 2971-5.

Barragan, A., Kremsner, P. G., Weiss, W., Wahlgren, M. \& Carlson, J. (1998). "Age-related buildup of humoral immunity against epitopes for rosette formation and agglutination in African areas of malaria endemicity." Infect Immun, 66(10), 4783-7.

Baruch, D. I., Gormely, J. A., Ma, C., Howard, R. J. \& Pasloske, B. L. (1996). "Plasmodium falciparum erythrocyte membrane protein 1 is a parasitized erythrocyte receptor for adherence to CD36, 
thrombospondin, and intercellular adhesion molecule 1." Proc Natl Acad Sci U S A, 93(8), 3497-502.

Baruch, D. I., Ma, X. C., Pasloske, B., Howard, R. J. \& Miller, L. H. (1999). "CD36 peptides that block cytoadherence define the CD36 binding region for Plasmodium falciparum-infected erythrocytes." Blood, 94(6), 2121-7.

Baruch, D. I., Ma, X. C., Singh, H. B., Bi, X., Pasloske, B. L. \& Howard, R. J. (1997). "Identification of a region of PfEMP1 that mediates adherence of Plasmodium falciparum infected erythrocytes to CD36: conserved function with variant sequence." Blood, 90(9), 3766-75.

Baruch, D. I., Pasloske, B. L., Singh, H. B., Bi, X., Ma, X. C., Feldman, M., Taraschi, T. F. \& Howard, R. J. (1995). "Cloning the $P$. falciparum gene encoding PfEMP1, a malarial variant antigen and adherence receptor on the surface of parasitized human erythrocytes." Cell, 82(1), 77-87.

Beeson, J. G., Rogerson, S. J., Cooke, B. M., Reeder, J. C., Chai, W., Lawson, A. M., Molyneux, M. E. \& Brown, G. V. (2000). "Adhesion of Plasmodium falciparum-infected erythrocytes to hyaluronic acid in placental malaria." Nat Med, 6(1), 86-90.

Berendt, A. R., McDowall, A., Craig, A. G., Bates, P. A., Sternberg, M. J., Marsh, K., Newbold, C. I. \& Hogg, N. (1992). "The binding site on ICAM-1 for Plasmodium falciparum-infected erythrocytes overlaps, but is distinct from, the LFA-1-binding site." Cell, 68(1), 71-81.

Berendt, A. R., Simmons, D. L., Tansey, J., Newbold, C. I. \& Marsh, K. (1989). "Intercellular adhesion molecule-1 is an endothelial cell adhesion receptor for Plasmodium falciparum." Nature, 341(6237), 57-9.

Biggs, B. A., Gooze, L., Wycherley, K., Wollish, W., Southwell, B., Leech, J. H. \& Brown, G. V. (1991). "Antigenic variation in Plasmodium falciparum." Proc Natl Acad Sci U S A, 88(20), 9171-4.

Bignami, A. \& Bastianelli, A. (1889). "Observation of estivo-autumnal malaria." Riforma Medica, 6, 1334-5.

Bischoff, E., Guillotte, M., Mercereau-Puijalon, O. \& Bonnefoy, S. (2000). "A member of the Plasmodium falciparum Pf60 multigene family codes for a nuclear protein expressed by readthrough of an internal stop codon." Mol Microbiol, 35(5), 1005-16.

Bolad, A. \& Berzins, K. (2000). "Antigenic diversity of Plasmodium falciparum and antibody-mediated parasite neutralization." Scand J Immunol, 52(3), 233-9.

Bonnefoy, S., Bischoff, E., Guillotte, M. \& Mercereau-Puijalon, O. (1997). "Evidence for distinct prototype sequences within the Plasmodium falciparum Pf60 multigene family." Mol Biochem Parasitol, 87(1), 1-11.

Borst, P., Bitter, W., McCulloch, R., Van Leeuwen, F. \& Rudenko, G. (1995). "Antigenic variation in malaria." Cell, 82(1), 1-4.

Bouharoun-Tayoun, H., Oeuvray, C., Lunel, F. \& Druilhe, P. (1995). "Mechanisms underlying the monocyte-mediated antibody-dependent killing of Plasmodium falciparum asexual blood stages." J Exp Med, 182(2), 409-18.

Boulos, M. (1992). "Clinical picture of severe malaria." Rev Inst Med Trop Sao Paulo, 34 Suppl 9, S412.

Boyle, J. S. \& Lew, A. M. (1995). "An inexpensive alternative to glassmilk for DNA purification." Trends Genet, 11(1), 8.

Breman, J. G. (2001). "The ears of the hippopotamus: manifestations, determinants, and estimates of the malaria burden." Am J Trop Med Hyg, 64(1-2 Suppl), 1-11.

Brown, K. N. \& Brown, I. N. (1965). "Immunity to malaria: antigenic variation in chronic infections of Plasmodium knowlesi." Nature, 208(17), 1286-8.

Brown, K. N. \& Hills, L. A. (1974). "Antigenic variation and immunity to Plasmodium knowlesi: antibodies which induce antigenic variation and antibodies which destroy parasites." Trans $R$ Soc Trop Med Hyg, 68(2), 139-42.

Bruce-Chwatt, L. J. (1985). Essential malariology, Wiley, New York. 
Buffet, P. A., Gamain, B., Scheidig, C., Baruch, D., Smith, J. D., Hernandez-Rivas, R., Pouvelle, B., Oishi, S., Fujii, N., Fusai, T., Parzy, D., Miller, L. H., Gysin, J. \& Scherf, A. (1999). "Plasmodium falciparum domain mediating adhesion to chondroitin sulfate $A$ : a receptor for human placental infection." Proc Natl Acad Sci U S A, 96(22), 12743-8.

Bull, P. C., Lowe, B. S., Kortok, M. \& Marsh, K. (1999). "Antibody recognition of Plasmodium falciparum erythrocyte surface antigens in Kenya: evidence for rare and prevalent variants." Infect Immun, 67(2), 733-9.

Bull, P. C., Lowe, B. S., Kortok, M., Molyneux, C. S., Newbold, C. I. \& Marsh, K. (1998). "Parasite antigens on the infected red cell surface are targets for naturally acquired immunity to malaria." Nat Med, 4(3), 358-60.

Carcy, B., Bonnefoy, S., Guillotte, M., Le Scanf, C., Grellier, P., Schrevel, J., Fandeur, T. \& MercereauPuijalon, O. (1994). "A large multigene family expressed during the erythrocytic schizogony of Plasmodium falciparum." Mol Biochem Parasitol, 68(2), 221-33.

Carlson, J. \& Wahlgren, M. (1992). "Plasmodium falciparum erythrocyte rosetting is mediated by promiscuous lectin-like interactions." J Exp Med, 176(5), 1311-7.

Carlson, J. (1993). "Erythrocyte rosetting in Plasmodium falciparum malaria--with special reference to the pathogenesis of cerebral malaria." Scand J Infect Dis Suppl, 86, 1-79.

Carlson, J., Helmby, H., Hill, A. V., Brewster, D., Greenwood, B. M. \& Wahlgren, M. (1990). "Human cerebral malaria: association with erythrocyte rosetting and lack of anti-rosetting antibodies." Lancet, 336(8729), 1457-60.

Carlson, J., Nash, G. B., Gabutti, V., al-Yaman, F. \& Wahlgren, M. (1994). "Natural protection against severe Plasmodium falciparum malaria due to impaired rosette formation." Blood, 84(11), 3909-14.

Chen, Q., Barragan, A., Fernandez, V., Sundstrom, A., Schlichtherle, M., Sahlen, A., Carlson, J., Datta, S. \& Wahlgren, M. (1998a). "Identification of Plasmodium falciparum erythrocyte membrane protein 1 (PfEMP1) as the rosetting ligand of the malaria parasite P. falciparum." J Exp Med, 187(1), 15-23.

Chen, Q., Fernandez, V., Sundstrom, A., Schlichtherle, M., Datta, S., Hagblom, P. \& Wahlgren, M. (1998b). "Developmental selection of var gene expression in Plasmodium falciparum." Nature, 394(6691), 392-5.

Chen, Q., Heddini, A., Barragan, A., Fernandez, V., Pearce, S. F. \& Wahlgren, M. (2000b). "The semiconserved head structure of Plasmodium falciparum erythrocyte membrane protein 1 mediates binding to multiple independent host receptors." J Exp Med, 192(1), 1-10.

Chen, Q., Schlichtherle, M. \& Wahlgren, M. (2000a). "Molecular aspects of severe malaria." Clin Microbiol Rev, 13(3), 439-50.

Cheng, Q., Cloonan, N., Fischer, K., Thompson, J., Waine, G., Lanzer, M. \& Saul, A. (1998). "stevor and rif are Plasmodium falciparum multicopy gene families which potentially encode variant antigens." Mol Biochem Parasitol, 97(1-2), 161-76.

Chiwakata, C. B., Manegold, C., Bonicke, L., Waase, I., Julch, C. \& Dietrich, M. (2001). "Procalcitonin as a parameter of disease severity and risk of mortality in patients with Plasmodium falciparum malaria." J Infect Dis, 183(7), 1161-4.

Chotivanich, K. T., Udomsangpetch, R., Pipitaporn, B., Angus, B., Suputtamongkol, Y., Pukrittayakamee, S. \& White, N. J. (1998). "Rosetting characteristics of uninfected erythrocytes from healthy individuals and malaria patients." Ann Trop Med Parasitol, 92(1), 45-56.

Clark, I. A. \& Chaudhri, G. (1988). "Tumour necrosis factor may contribute to the anaemia of malaria by causing dyserythropoiesis and erythrophagocytosis." Br J Haematol, 70(1), 99-103.

Clough, B., Atilola, F. A. \& Pasvoi, G. (1998b). "The role of rosetting in the multiplication of Plasmodium falciparum: rosette formation neither enhances nor targets parasite invasion into uninfected red cells." Br J Haematol, 100(1), 99-104.

Clough, B., Atilola, F. A., Black, J. \& Pasvol, G. (1998a). "Plasmodium falciparum: the importance of IgM in the rosetting of parasite-infected erythrocytes." Exp Parasitol, 89(1), 129-32. 
Cooke, B. M., Berendt, A. R., Craig, A. G., MacGregor, J., Newbold, C. I. \& Nash, G. B. (1994). "Rolling and stationary cytoadhesion of red blood cells parasitized by Plasmodium falciparum: separate roles for ICAM-1, CD36 and thrombospondin." Br J Haematol, 87(1), 162-70.

Cooke, B. M., Nicoll, C. L., Baruch, D. I. \& Coppel, R. L. (1998). "A recombinant peptide based on PfEMP-1 blocks and reverses adhesion of malaria-infected red blood cells to CD36 under flow." Mol Microbiol, 30(1), 83-90.

Cooke, B., Coppel, R. \& Wahlgren, M. (2000). "Falciparum malaria: sticking up, standing out and outstanding." Parasitol Today, 16(10), 416-20.

Coppel, R. L., Brown, G. V. \& Nussenzweig, V. (1998). "Adhesive proteins of the malaria parasite." Curr Opin Microbiol, 1(4), 472-81.

Corbett, C. E., Duarte, M. I., Lancellotti, C. L., Silva, M. A. \& Andrade Junior, H. F. (1989). "Cytoadherence in human falciparum malaria as a cause of respiratory distress." J Trop Med Hyg, 92(2), 112-20.

Craig, A. \& Scherf, A. (2001). "Molecules on the surface of the Plasmodium falciparum infected erythrocyte and their role in malaria pathogenesis and immune evasion." Mol Biochem Parasitol, $115(2), 129-43$.

Crandall, I., Collins, W. E., Gysin, J. \& Sherman, I. W. (1993). "Synthetic peptides based on motifs present in human band 3 protein inhibit cytoadherence/sequestration of the malaria parasite Plasmodium falciparum." Proc Natl Acad Sci U S A, 90(10), 4703-7.

Crandall, I., Guthrie, N., Demers, D. \& Sherman, I. W. (1994). "Plasmodium falciparum: CD36 dependent cytoadherence or rosetting of infected erythrocytes is modulated by knobs." Cell Adhes Commun, 2(6), 503-10.

David, P. H., Handunnetti, S. M., Leech, J. H., Gamage, P. \& Mendis, K. N. (1988). "Rosetting: a new cytoadherence property of malaria-infected erythrocytes." Am J Trop Med Hyg, 38(2), 289-97.

David, P. H., Hommel, M., Miller, L. H., Udeinya, I. J. \& Oligino, L. D. (1983). "Parasite sequestration in Plasmodium falciparum malaria: spleen and antibody modulation of cytoadherence of infected erythrocytes." Proc Natl Acad Sci U S A, 80(16), 5075-9.

Davis, T. M., Assicot, M., Bohuon, C., St John, A., Li, G. Q. \& Anh, T. K. (1994). "Serum procalcitonin concentrations in acute malaria." Trans R Soc Trop Med Hyg, 88(6), 670-1.

Deitsch, K. W., Calderwood, M. S. \& Wellems, T. E. (2001). "Malaria. Cooperative silencing elements in vargenes." Nature, 412(6850), 875-6.

Deitsch, K. W., del Pinal, A. \& Wellems, T. E. (1999). "Intra-cluster recombination and var transcription switches in the antigenic variation of Plasmodium falciparum." Mol Biochem Parasitol, 101(1-2), 107-16.

del Portillo, H. A., Fernandez-Becerra, C., Bowman, S., Oliver, K., Preuss, M., Sanchez, C. P., Schneider, N. K., Villalobos, J. M., Rajandream, M. A., Harris, D., Pereira da Silva, L. H., Barrell, B. \& Lanzer, M. (2001). "A superfamily of variant genes encoded in the subtelomeric region of Plasmodium vivax." Nature, 410(6830), 839-42.

Diggs, C., Joseph, K., Flemmings, B., Snodgrass, R. \& Hines, F. (1975). "Protein synthesis in vitro by cryopreserved Plasmodium falciparum." Am J Trop Med Hyg, 24(5), 760-3.

Dodoo, D., Staalsoe, T., Giha, H., Kurtzhals, J. A., Akanmori, B. D., Koram, K., Dunyo, S., Nkrumah, F. K., Hviid, L. \& Theander, T. G. (2001). "Antibodies to variant antigens on the surfaces of infected erythrocytes are associated with protection from malaria in Ghanaian children." Infect Immun, 69(6), 3713-8.

Druilhe, P., Daubersies, P., Patarapotikul, J., Gentil, C., Chene, L., Chongsuphajaisiddhi, T., Mellouk, S. \& Langsley, G. (1998). "A primary malarial infection is composed of a very wide range of genetically diverse but related parasites." J Clin Invest, 101(9), 2008-16.

Duarte, M. I., Corbett, C. E., Boulos, M. \& Amato Neto, V. (1985). "Ultrastructure of the lung in falciparum malaria." Am J Trop Med Hyg, 34(1), 31-5. 
Duffy, P. E., Craig, A. G. \& Baruch, D. I. (2001). "Variant proteins on the surface of malaria-infected erythrocytes--developing vaccines." Trends Parasitol, 17(8), 354-6.

Eda, S., Lawler, J. \& Sherman, I. W. (1999). "Plasmodium falciparum-infected erythrocyte adhesion to the type 3 repeat domain of thrombospondin-1 is mediated by a modified band 3 protein." Mol Biochem Parasitol, 100(2), 195-205.

Fernandez, V., Hommel, M., Chen, Q., Hagblom, P. \& Wahlgren, M. (1999). "Small, clonally variant antigens expressed on the surface of the Plasmodium falciparum-infected erythrocyte are encoded by the rif gene family and are the target of human immune responses." J Exp Med, 190(10), 1393-404.

Fernandez, V., Treutiger, C. J., Nash, G. B. \& Wahlgren, M. (1998). "Multiple adhesive phenotypes linked to rosetting binding of erythrocytes in Plasmodium falciparum malaria." Infect Immun, 66(6), 2969-75.

Fernandez-Reyes, D., Craig, A. G., Kyes, S. A., Peshu, N., Snow, R. W., Berendt, A. R., Marsh, K. \& Newbold, C. I. (1997). "A high frequency African coding polymorphism in the N-terminal domain of ICAM-1 predisposing to cerebral malaria in Kenya." Hum Mol Genet, 6(8), 1357-60.

Ferreira, M. U., Liu, Q., Kaneko, O., Kimura, M., Tanabe, K., Kimura, E. A., Katzin, A. M., Isomura, S. \& Kawamoto, F. (1998). "Allelic diversity at the merozoite surface protein-1 locus of Plasmodium falciparum in clinical isolates from the southwestern Brazilian Amazon." Am J Trop Med Hyg, 59(3), 474-80.

Fischer, K., Horrocks, P., Preuss, M., Wiesner, J., Wunsch, S., Camargo, A. A. \& Lanzer, M. (1997). "Expression of var genes located within polymorphic subtelomeric domains of Plasmodium falciparum chromosomes." Mol Cell Biol, 17(7), 3679-86.

Freitas-Junior, L. H., Bottius, E., Pirrit, L. A., Deitsch, K. W., Scheidig, C., Guinet, F., Nehrbass, U., Wellems, T. E. \& Scherf, A. (2000). "Frequent ectopic recombination of virulence factor genes in telomeric chromosome clusters of $P$. falciparum." Nature, 407(6807), 1018-22.

Fried, M. \& Duffy, P. E. (1996). "Adherence of Plasmodium falciparum to chondroitin sulfate A in the human placenta." Science, 272(5267), 1502-4.

Fujioka, H., Millet, P., Maeno, Y., Nakazawa, S., Ito, Y., Howard, R.J., Collins, W.E. \& Aikawa, M. (1994) "A nonhuman primate model for human cerebral malaria: rhesus monkeys experimentally infected with Plasmodium fragile". Exp Parasitol, 78(4), 371-6.

Gamain, B., Miller, L. H. \& Baruch, D. I. (2001). "The surface variant antigens of Plasmodium falciparum contain cross-reactive epitopes." Proc Natl Acad Sci U S A, 98(5), 2664-9.

Gardiner, D. L., Holt, D. C., Thomas, E. A., Kemp, D. J. \& Trenholme, K. R. (2000). "Inhibition of Plasmodium falciparum clag9 gene function by antisense RNA." Mol Biochem Parasitol, 110(1), 33-41.

Giha, H. A., Staalsoe, T., Dodoo, D., Elhassan, I. M., Roper, C., Satti, G. M., Arnot, D. E., Theander, T. G. \& Hviid, L. (1999). "Nine-year longitudinal study of antibodies to variant antigens on the surface of Plasmodium falciparum-infected erythrocytes." Infect Immun, 67(8), 4092-8.

Giha, H. A., Staalsoe, T., Dodoo, D., Roper, C., Satti, G. M., Arnot, D. E., Hviid, L. \& Theander, T. G. (2000). "Antibodies to variable Plasmodium falciparum-infected erythrocyte surface antigens are associated with protection from novel malaria infections." Immunol Lett, 71(2), 117-26.

Gilks, C. F., Walliker, D. \& Newbold, C. I. (1990). "Relationships between sequestration, antigenic variation and chronic parasitism in Plasmodium chabaudi chabaudi--a rodent malaria model." Parasite Immunol, 12(1), 45-64.

Green, S. J., Scheller, L. F., Marletta, M. A., Seguin, M. C., Klotz, F. W., Slayter, M., Nelson, B. J. \& Nacy, C. A. (1994). "Nitric oxide: cytokine-regulation of nitric oxide in host resistance to intracellular pathogens." Immunol Lett, 43(1-2), 87-94.

Gupta, S., Snow, R. W., Donnelly, C. A., Marsh, K. \& Newbold, C. (1999). "Immunity to non-cerebral severe malaria is acquired after one or two infections." Nat Med, 5(3), 340-3.

Handunnetti, S. M., Mendis, K. N. \& David, P. H. (1987). "Antigenic variation of cloned Plasmodium fragile in its natural host Macaca sinica. Sequential appearance of successive variant antigenic types." 
J Exp Med, 165(5), 1269-83.

Handunnetti, S. M., van Schravendijk, M. R., Hasler, T., Barnwell, J. W., Greenwalt, D. E. \& Howard, R. J. (1992). "Involvement of CD36 on erythrocytes as a rosetting receptor for Plasmodium falciparum-infected erythrocytes." Blood, 80(8), 2097-104.

Handunnetti, S.M., David, P.H., Perera, K.L. \& Mendis, K.N. (1989) "Uninfected erythrocytes form rosettes around Plasmodium falciparum infected erythrocytes". Am J Trop Med Hyg, 40(2), 115-8.

Hasler, T., Handunnetti, S. M., Aguiar, J. C., van Schravendijk, M. R., Greenwood, B. M., Lallinger, G., Cegielski, P. \& Howard, R. J. (1990). "In vitro rosetting, cytoadherence, and microagglutination properties of Plasmodium falciparum-infected erythrocytes from Gambian and Tanzanian patients." Blood, 76(9), 1845-52.

Heddini, A., Pettersson, F., Kai, O., Shafi, J., Obiero, J., Chen, Q., Barragan, A., Wahlgren, M. \& Marsh, K. (2001). "Fresh isolates from children with severe Plasmodium falciparum malaria bind to multiple receptors." Infect Immun, 69(9), 5849-56.

Helmby, H., Cavelier, L., Pettersson, U. \& Wahlgren, M. (1993). "Rosetting Plasmodium falciparuminfected erythrocytes express unique strain-specific antigens on their surface." Infect Immun, 61(1), 284-8.

Hernandez-Rivas, R., Mattei, D., Sterkers, Y., Peterson, D. S., Wellems, T. E. \& Scherf, A. (1997). "Expressed var genes are found in Plasmodium falciparum subtelomeric regions." Mol Cell Biol, 17(2), 604-11.

Higgins, D. G., Thompson, J. D. \& Gibson, T. J. (1996). "Using CLUSTAL for multiple sequence alignments." Methods Enzymol, 266, 383-402.

Ho, M., Schollaardt, T., Niu, X., Looareesuwan, S., Patel, K. D. \& Kubes, P. (1998). "Characterization of Plasmodium falciparum-infected erythrocyte and P- selectin interaction under flow conditions." Blood, 91(12), 4803-9.

Ho, M., Singh, B., Looareesuwan, S., Davis, T. M., Bunnag, D. \& White, N. J. (1991). "Clinical correlates of in vitro Plasmodium falciparum cytoadherence." Infect Immun, 59(3), 873-8.

Hollenstein, U., Looareesuwan, S., Aichelburg, A., Thalhammer, F., Stoiser, B., Amradee, S., Chullawichit, S., El Menyawi, I. \& Burgmann, H. (1998). "Serum procalcitonin levels in severe Plasmodium falciparum malaria." Am J Trop Med Hyg, 59(6), 860-3.

Holt, D. C., Gardiner, D. L., Thomas, E. A., Mayo, M., Bourke, P. F., Sutherland, C. J., Carter, R., Myers, G., Kemp, D. J. \& Trenholme, K. R. (1999). "The cytoadherence linked asexual gene family of Plasmodium falciparum: are there roles other than cytoadherence?" Int J Parasitol, 29(6), 939-44.

Hommel, M. (1996). "[Physiopathology of symptoms of malaria. Role of cytokines, cytoadherence and premunition]." Presse Med, 25(2), 70-6.

Hourcade, D., Holers, V. M. \& Atkinson, J. P. (1989). "The regulators of complement activation (RCA) gene cluster." Adv Immunol, 45, 381-416.

Howard, R. J. \& Gilladoga, A. D. (1989). "Molecular studies related to the pathogenesis of cerebral malaria." Blood, 74(8), 2603-18.

Howard, R. J., Barnwell, J. W. \& Kao, V. (1983). "Antigenic variation of Plasmodium knowlesi malaria: identification of the variant antigen on infected erythrocytes." Proc Natl Acad Sci U S A, 80(13), 412933.

Iqbal, J., Perlmann, P. \& Berzins, K. (1993). "Plasmodium falciparum: analysis of the cytoadherence inhibition of the human monoclonal antibody 33G2 and of antibodies reactive with antigen Pf332." Exp Parasitol, 77(1), 79-87.

Jacobs, R. \& Warren, M. (1967) "Sequestration of schizonts in the deep tissues of mice infected with chloroquine-resistant Plasmodium berghel'. Trans R Soc Trop Med Hyg, 61(2), 273-5.

Jakobsen, P. H., Bate, C. A., Taverne, J. \& Playfair, J. H. (1995). "Malaria: toxins, cytokines and disease." Parasite Immunol, 17(5), 223-31. 
Joshi, M. B., Lin, D. T., Chiang, P. H., Goldman, N. D., Fujioka, H., Aikawa, M. \& Syin, C. (1999). "Molecular cloning and nuclear localization of a histone deacetylase homologue in Plasmodium falciparum." Mol Biochem Parasitol, 99(1), 11-9.

Kalli, K. R., Hsu, P. H., Bartow, T. J., Ahearn, J. M., Matsumoto, A. K., Klickstein, L. B. \& Fearon, D. T. (1991). "Mapping of the C3b-binding site of CR1 and construction of a (CR1)2- F(ab')2 chimeric complement inhibitor." J Exp Med, 174(6), 1451-60.

Kalmar, E. M. N., Cassetari, V., Machado, F. R., Alencar, F. E. C., Kirchgatter, K., Boulos, M. \& Tapajós, R. (1998). "Malária grave em paciente com infecção por Plasmodium vivax. relato de caso." Rev Soc Bras Med Trop, 31(supl I), 56.

Kaul, D. K., Roth, E. F., Jr., Nagel, R. L., Howard, R. J. \& Handunnetti, S. M. (1991). "Rosetting of Plasmodium falciparum-infected red blood cells with uninfected red blood cells enhances microvascular obstruction under flow conditions." Blood, 78(3), 812-9.

Klickstein, L. B., Bartow, T. J., Miletic, V., Rabson, L. D., Smith, J. A. \& Fearon, D. T. (1988). "Identification of distinct C3b and C4b recognition sites in the human C3b/C4b receptor (CR1, CD35) by deletion mutagenesis." J Exp Med, 168(5), 1699-717.

Krych, M., Hourcade, D. \& Atkinson, J. P. (1991). "Sites within the complement C3b/C4b receptor important for the specificity of ligand binding." Proc Natl Acad Sci U S A, 88(10), 4353-7.

Kun, J. F., Schmidt-Ott, R. J., Lehman, L. G., Lell, B., Luckner, D., Greve, B., Matousek, P. \& Kremsner, P. G. (1998). "Merozoite surface antigen 1 and 2 genotypes and rosetting of Plasmodium falciparum in severe and mild malaria in Lambarene, Gabon." Trans R Soc Trop Med Hyg, 92(1), 1104.

Kwiatkowski, D. (1990). "Tumour necrosis factor, fever and fatality in falciparum malaria." Immunol Lett, 25(1-3), 213-6.

Kwiatkowski, D., Molyneux, M. E., Stephens, S., Curtis, N., Klein, N., Pointaire, P., Smit, M., Allan, R., Brewster, D. R., Grau, G. E. e cols. (1993). "Anti-TNF therapy inhibits fever in cerebral malaria." $Q J$ Med, 86(2), 91-8.

Kyes, S. A., Rowe, J. A., Kriek, N. \& Newbold, C. I. (1999). "Rifins: a second family of clonally variant proteins expressed on the surface of red cells infected with Plasmodium falciparum." Proc Natl Acad Sci U S A, 96(16), 9333-8.

Kyes, S., Horrocks, P. \& Newbold, C. (2001). "Antigenic variation at the infected red cell surface in malaria." Annu Rev Microbiol, 55, 673-707.

Kyes, S., Pinches, R. \& Newbold, C. (2000). "A simple RNA analysis method shows var and rif multigene family expression patterns in Plasmodium falciparum." Mol Biochem Parasitol, 105(2), 3115.

Kyes, S., Taylor, H., Craig, A., Marsh, K. \& Newbold, C. (1997). "Genomic representation of var gene sequences in Plasmodium falciparum field isolates from different geographic regions." Mol Biochem Parasitol, 87(2), 235-8.

Lalloo, D. G., Trevett, A. J., Paul, M., Korinhona, A., Laurenson, I. F., Mapao, J., Nwokolo, N., DangaChristian, B., Black, J., Saweri, A., Naraqi, S. \& Warrell, D. A. (1996). "Severe and complicated falciparum malaria in Melanesian adults in Papua New Guinea." Am J Trop Med Hyg, 55(2), 119-24.

Langreth, S. G. \& Reese, R. T. (1979). "Antigenicity of the infected-erythrocyte and merozoite surfaces in falciparum malaria." J Exp Med, 150(5), 1241-54.

Leech, J. H., Barnwell, J. W., Miller, L. H. \& Howard, R. J. (1984). "Identification of a strain-specific malarial antigen exposed on the surface of Plasmodium falciparum-infected erythrocytes." J Exp Med, $159(6), 1567-75$.

Limpaiboon, T., Taylor, D. W., Jones, G., Geysen, H. M. \& Saul, A. (1990). "Characterization of a Plasmodium falciparum epitope recognized by a monoclonal antibody with broad isolate and species specificity." Southeast Asian J Trop Med Public Health, 21(3), 388-96.

Lowe, B. S., Mosobo, M. \& Bull, P. C. (1998). "All four species of human malaria parasites form 
rosettes." Trans R Soc Trop Med Hyg, 92(5), 526.

Luse, S. A. \& Miller, L. H. (1971). "Plasmodium falciparum malaria. Ultrastructure of parasitized erythrocytes in cardiac vessels." Am J Trop Med Hyg, 20(5), 655-60.

Luxemburger, C., Thwai, K. L., White, N. J., Webster, H. K., Kyle, D. E., Maelankirri, L., Chongsuphajaisiddhi, T. \& Nosten, F. (1996). "The epidemiology of malaria in a Karen population on the western border of Thailand." Trans R Soc Trop Med Hyg, 90(2), 105-11.

MacPherson, G. G., Warrell, M. J., White, N. J., Looareesuwan, S. \& Warrell, D. A. (1985). "Human cerebral malaria. A quantitative ultrastructural analysis of parasitized erythrocyte sequestration." $\mathrm{Am} \mathrm{J}$ Pathol, 119(3), 385-401.

Marsh, K. \& Howard, R. J. (1986). "Antigens induced on erythrocytes by P. falciparum: expression of diverse and conserved determinants." Science, 231(4734), 150-3.

Marsh, K., Marsh, V. M., Brown, J., Whittle, H. C. \& Greenwood, B. M. (1988). "Plasmodium falciparum: the behavior of clinical isolates in an in vitro model of infected red blood cell sequestration." Exp Parasitol, 65(2), 202-8.

Marsh, K., Otoo, L., Hayes, R. J., Carson, D. C. \& Greenwood, B. M. (1989). "Antibodies to blood stage antigens of Plasmodium falciparum in rural Gambians and their relation to protection against infection." Trans R Soc Trop Med Hyg, 83(3), 293-303.

May, J., Lell, B., Luty, A. J., Meyer, C. G. \& Kremsner, P. G. (2000). "Plasma interleukin-10:Tumor necrosis factor (TNF)-alpha ratio is associated with TNF promoter variants and predicts malarial complications." J Infect Dis, 182(5), 1570-3.

McCormick, C. J., Craig, A., Roberts, D., Newbold, C. I. \& Berendt, A. R. (1997). "Intercellular adhesion molecule-1 and CD36 synergize to mediate adherence of Plasmodium falciparum-infected erythrocytes to cultured human microvascular endothelial cells." J Clin Invest, 100(10), 2521-9.

McLean, S. A., Pearson, C. D. \& Phillips, R. S. (1982). "Plasmodium chabaudi: antigenic variation during recrudescent parasitaemias in mice." Exp Parasitol, 54(3), 296-302.

Mendis, K. N., Ihalamulla, R. I. \& David, P. H. (1988). "Diversity of Plasmodium vivax-induced antigens on the surface of infected human erythrocytes." Am J Trop Med Hyg, 38(1), 42-6.

Metzger, W. G., Mordmuller, B. G. \& Kremsner, P. G. (1995). "Malaria pigment in leucocytes." Trans $R$ Soc Trop Med Hyg, 89(6), 637-8.

Miller, L. H. (1969). "Distribution of mature trophozoites and schizonts of Plasmodium falciparum in the organs of Aotus trivirgatus, the night monkey." Am J Trop Med Hyg, 18(6), 860-5.

Miller, L. H., Good, M. F. \& Milon, G. (1994). "Malaria pathogenesis." Science, 264(5167), 1878-83.

Mota, M. M., Pradel, G., Vanderberg, J. P., Hafalla, J. C., Frevert, U., Nussenzweig, R. S., Nussenzweig, V. \& Rodriguez, A. (2001). "Migration of Plasmodium sporozoites through cells before infection." Science, 291(5501), 141-4.

Newbold, C. I. (1999). "Antigenic variation in Plasmodium falciparum: mechanisms and consequences." Curr Opin Microbiol, 2(4), 420-5.

Newbold, C. I., Craig, A. G., Kyes, S., Berendt, A. R., Snow, R. W., Peshu, N. \& Marsh, K. (1997a). "PfEMP1, polymorphism and pathogenesis." Ann Trop Med Parasitol, 91(5), 551-7.

Newbold, C. I., Pinches, R., Roberts, D. J. \& Marsh, K. (1992). "Plasmodium falciparum: the human agglutinating antibody response to the infected red cell surface is predominantly variant specific." Exp Parasitol, 75(3), 281-92.

Newbold, C., Warn, P., Black, G., Berendt, A., Craig, A., Snow, B., Msobo, M., Peshu, N. \& Marsh, K. (1997b). "Receptor-specific adhesion and clinical disease in Plasmodium falciparum." Am J Trop Med Hyg, 57(4), 389-98.

Nguyen, P. H., Day, N., Pram, T. D., Ferguson, D. J. \& White, N. J. (1995). "Intraleucocytic malaria pigment and prognosis in severe malaria." Trans R Soc Trop Med Hyg, 89(2), 200-4.

Nogueira, P. A. (2000). "Repertório de genes var expressos e propriedades de citoaderência aos 
receptores de células endoteliais de isolados de "Plasmodium falciparum" da região de Rondônia," Doutorado, Universidade de São Paulo, São Paulo.

Noviyanti, R., Brown, G. V., Wickham, M. E., Duffy, M. F., Cowman, A. F. \& Reeder, J. C. (2001). "Multiple var gene transcripts are expressed in Plasmodium falciparum infected erythrocytes selected for adhesion." Mol Biochem Parasitol, 114(2), 227-37.

Nylen, E. S., Whang, K. T., Snider, R. H., Jr., Steinwald, P. M., White, J. C. \& Becker, K. L. (1998). "Mortality is increased by procalcitonin and decreased by an antiserum reactive to procalcitonin in experimental sepsis." Crit Care Med, 26(6), 1001-6.

Oberhoffer, M., Stonans, I., Russwurm, S., Stonane, E., Vogelsang, H., Junker, U., Jager, L. \& Reinhart, K. (1999). "Procalcitonin expression in human peripheral blood mononuclear cells and its modulation by lipopolysaccharides and sepsis-related cytokines in vitro." J Lab Clin Med, 134(1), 4955.

Ockenhouse, C. F., Klotz, F. W., Tandon, N. N. \& Jamieson, G. A. (1991). "Sequestrin, a CD36 recognition protein on Plasmodium falciparum malaria- infected erythrocytes identified by anti-idiotype antibodies." Proc Natl Acad Sci U S A, 88(8), 3175-9.

Ockenhouse, C. F., Tegoshi, T., Maeno, Y., Benjamin, C., Ho, M., Kan, K. E., Thway, Y., Win, K., Aikawa, M. \& Lobb, R. R. (1992). "Human vascular endothelial cell adhesion receptors for Plasmodium falciparum-infected erythrocytes: roles for endothelial leukocyte adhesion molecule 1 and vascular cell adhesion molecule 1." J Exp Med, 176(4), 1183-9.

Odeh, M. (2001). "The role of tumour necrosis factor-alpha in the pathogenesis of complicated falciparum malaria." Cytokine, 14(1), 11-8.

Oh, S. S., Voigt, S., Fisher, D., Yi, S. J., LeRoy, P. J., Derick, L. H., Liu, S. \& Chishti, A. H. (2000). "Plasmodium falciparum erythrocyte membrane protein 1 is anchored to the actin-spectrin junction and knob-associated histidine-rich protein in the erythrocyte skeleton." Mol Biochem Parasitol, 108(2), 237-47.

Oquendo, P., Hundt, E., Lawler, J. \& Seed, B. (1989). "CD36 directly mediates cytoadherence of Plasmodium falciparum parasitized erythrocytes." Cell, 58(1), 95-101.

Pasvol, G., Wilson, R. J., Smalley, M. E. \& Brown, J. (1978). "Separation of viable schizont-infected red cells of Plasmodium falciparum from human blood." Ann Trop Med Parasitol, 72(1), 87-8.

Patnaik, J. K., Das, B. S., Mishra, S. K., Mohanty, S., Satpathy, S. K. \& Mohanty, D. (1994). "Vascular clogging, mononuclear cell margination, and enhanced vascular permeability in the pathogenesis of human cerebral malaria." Am J Trop Med Hyg, 51(5), 642-7.

Pichyangkul, S., Saengkrai, P. \& Webster, H. K. (1994). "Plasmodium falciparum pigment induces monocytes to release high levels of tumor necrosis factor-alpha and interleukin-1 beta." Am J Trop Med Hyg, 51(4), 430-5.

Pichyangkul, S., Saengkrai, P., Yongvanitchit, K., Stewart, A. \& Heppner, D. G. (1997). "Activation of gammadelta $\mathrm{T}$ cells in malaria: interaction of cytokines and a schizont-associated Plasmodium falciparum antigen." J Infect Dis, 176(1), 233-41.

Pongponratn, E., Riganti, M., Punpoowong, B. \& Aikawa, M. (1991). "Microvascular sequestration of parasitized erythrocytes in human falciparum malaria: a pathological study." Am J Trop Med Hyg, 44(2), 168-75.

Posada, D. \& Crandall, K. A. (1998). "MODELTEST: testing the model of DNA substitution." Bioinformatics, 14(9), 817-8.

Pouvelle, B., Buffet, P. A., Lepolard, C., Scherf, A. \& Gysin, J. (2000). "Cytoadhesion of Plasmodium falciparum ring-stage-infected erythrocytes." Nat Med, 6(11), 1264-8.

Reeder, J. C. \& Brown, G. V. (1996). "Antigenic variation and immune evasion in Plasmodium falciparum malaria." Immunol Cell Biol, 74(6), 546-54.

Reeder, J. C., Cowman, A. F., Davern, K. M., Beeson, J. G., Thompson, J. K., Rogerson, S. J. \& Brown, G. V. (1999). "The adhesion of Plasmodium falciparum-infected erythrocytes to chondroitin sulfate A is 
mediated by P. falciparum erythrocyte membrane protein 1." Proc Natl Acad Sci U S A, 96(9), 5198202.

Reeder, J. C., Rogerson, S. J., al-Yaman, F., Anders, R. F., Coppel, R. L., Novakovic, S., Alpers, M. P. \& Brown, G. V. (1994). "Diversity of agglutinating phenotype, cytoadherence, and rosette-forming characteristics of Plasmodium falciparum isolates from Papua New Guinean children." Am J Trop Med Hyg, 51(1), 45-55.

Ringwald, P., Peyron, F., Lepers, J. P., Rabarison, P., Rakotomalala, C., Razanamparany, M., Rabodonirina, M., Roux, J. \& Le Bras, J. (1993). "Parasite virulence factors during falciparum malaria: rosetting, cytoadherence, and modulation of cytoadherence by cytokines." Infect Immun, 61(12), 5198-204.

Roberts, D. D., Sherwood, J. A., Spitalnik, S. L., Panton, L. J., Howard, R. J., Dixit, V. M., Frazier, W. A., Miller, L. H. \& Ginsburg, V. (1985). "Thrombospondin binds falciparum malaria parasitized erythrocytes and may mediate cytoadherence." Nature, 318(6041), 64-6.

Roberts, D. J., Craig, A. G., Berendt, A. R., Pinches, R., Nash, G., Marsh, K. \& Newbold, C. I. (1992). "Rapid switching to multiple antigenic and adhesive phenotypes in malaria." Nature, 357(6380), 68992.

Roberts, D. J., Pain, A., Kai, O., Kortok, M. \& Marsh, K. (2000). "Autoagglutination of malaria-infected red blood cells and malaria severity." Lancet, 355(9213), 1427-8.

Rogerson, S. J., Chaiyaroj, S. C., Ng, K., Reeder, J. C. \& Brown, G. V. (1995). "Chondroitin sulfate A is a cell surface receptor for Plasmodium falciparum-infected erythrocytes." J Exp Med, 182(1), 15-20.

Roodman, G. D., Bird, A., Hutzler, D. \& Montgomery, W. (1987). "Tumor necrosis factor-alpha and hematopoietic progenitors: effects of tumor necrosis factor on the growth of erythroid progenitors CFU-E and BFU-E and the hematopoietic cell lines K562, HL60, and HEL cells." Exp Hematol, 15(9), 928-35.

Rowe, A., Obeiro, J., Newbold, C. I. \& Marsh, K. (1995). "Plasmodium falciparum rosetting is associated with malaria severity in Kenya." Infect Immun, 63(6), 2323-6.

Rowe, J. A., Moulds, J. M., Newbold, C. I. \& Miller, L. H. (1997). "P. falciparum rosetting mediated by a parasite-variant erythrocyte membrane protein and complement-receptor 1." Nature, 388(6639), 292-5.

Rowe, J. A., Rogerson, S. J., Raza, A., Moulds, J. M., Kazatchkine, M. D., Marsh, K., Newbold, C. I., Atkinson, J. P. \& Miller, L. H. (2000). "Mapping of the Region of Complement Receptor (CR) 1 Required for Plasmodium falciparum Rosetting and Demonstration of the Importance of CR1 in Rosetting in Field Isolates." J Immunol, 165(11), 6341-6346.

Rubio, J. P., Thompson, J. K. \& Cowman, A. F. (1996). "The var genes of Plasmodium falciparum are located in the subtelomeric region of most chromosomes." Embo J, 15(15), 4069-77.

Saitou, N. \& Nei, M. (1987). "The neighbor-joining method: a new method for reconstructing phylogenetic trees." Mol Biol Evol, 4(4), 406-25.

Sambrook, J., Fritsch, E. F. \& Maniatis, T. (1989). Molecular cloning : a laboratory manual, Cold Spring Harbor Laboratory, Cold Spring Harbor, N.Y.

Saul, A. (1999). "The role of variant surface antigens on malaria-infected red blood cells." Parasitol Today, 15(11), 455-7.

Scherf, A., Hernandez-Rivas, R., Buffet, P., Bottius, E., Benatar, C., Pouvelle, B., Gysin, J. \& Lanzer, M. (1998). "Antigenic variation in malaria: in situ switching, relaxed and mutually exclusive transcription of var genes during intra-erythrocytic development in Plasmodium falciparum." Embo J, 17(18), 541826.

Schofield, L. \& Hackett, F. (1993). "Signal transduction in host cells by a glycosylphosphatidylinositol toxin of malaria parasites." J Exp Med, 177(1), 145-53.

Scholander, C., Treutiger, C. J., Hultenby, K. \& Wahlgren, M. (1996). "Novel fibrillar structure confers adhesive property to malaria-infected erythrocytes." Nat Med, 2(2), 204-8. 
Siano, J. P., Grady, K. K., Millet, P. \& Wick, T. M. (1998). "Short report: Plasmodium falciparum: cytoadherence to alpha(v)beta3 on human microvascular endothelial cells." Am J Trop Med Hyg, 59(1), 77-9.

Silamut, K., Phu, N. H., Whitty, C., Turner, G. D., Louwrier, K., Mai, N. T., Simpson, J. A., Hien, T. T. \& White, N. J. (1999). "A quantitative analysis of the microvascular sequestration of malaria parasites in the human brain." Am J Pathol, 155(2), 395-410.

Sim, B. K., Chitnis, C. E., Wasniowska, K., Hadley, T. J. \& Miller, L. H. (1994). "Receptor and ligand domains for invasion of erythrocytes by Plasmodium falciparum." Science, 264(5167), 1941-4.

Smith, J. D., Chitnis, C. E., Craig, A. G., Roberts, D. J., Hudson-Taylor, D. E., Peterson, D. S., Pinches, R., Newbold, C. I. \& Miller, L. H. (1995). "Switches in expression of Plasmodium falciparum var genes correlate with changes in antigenic and cytoadherent phenotypes of infected erythrocytes." Cell, 82(1), 101-10.

Smith, J. D., Craig, A. G., Kriek, N., Hudson-Taylor, D., Kyes, S., Fagen, T., Pinches, R., Baruch, D. I., Newbold, C. I. \& Miller, L. H. (2000a). "Identification of a Plasmodium falciparum intercellular adhesion molecule-1 binding domain: a parasite adhesion trait implicated in cerebral malaria." Proc Natl Acad Sci U S A, 97(4), 1766-71.

Smith, J. D., Gamain, B., Baruch, D. I. \& Kyes, S. (2001). "Decoding the language of var genes and Plasmodium falciparum sequestration." Trends in Parasitology, 17(11), 538-45.

Smith, J. D., Kyes, S., Craig, A. G., Fagan, T., Hudson-Taylor, D., Miller, L. H., Baruch, D. I. \& Newbold, C. I. (1998). "Analysis of adhesive domains from the A4VAR Plasmodium falciparum erythrocyte membrane protein-1 identifies a CD36 binding domain." Mol Biochem Parasitol, 97(1-2), $133-48$.

Smith, J. D., Subramanian, G., Gamain, B., Baruch, D. I. \& Miller, L. H. (2000b). "Classification of adhesive domains in the Plasmodium falciparum erythrocyte membrane protein 1 family." Mol Biochem Parasitol, 110(2), 293-310.

Smith, L.P., Hunter, K.W., Oldfield, E.C. \& Strickland, G.T. (1982) "Murine malaria: blood clearance and organ sequestration of Plasmodium yoelii-infected erythrocytes". Infect Immun, 38(1), 162-7.

Snow, R. W., Omumbo, J. A., Lowe, B., Molyneux, C. S., Obiero, J. O., Palmer, A., Weber, M. W., Pinder, M., Nahlen, B., Obonyo, C., Newbold, C., Gupta, S. \& Marsh, K. (1997). "Relation between severe malaria morbidity in children and level of Plasmodium falciparum transmission in Africa." Lancet, 349(9066), 1650-4.

Staalso, T., Khalil, E. A., Elhassan, I. M., Zijlstra, E. E., Elhassan, A. M., Giha, H. A., Theander, T. G. \& Jakobsen, P. H. (1998). "Antibody reactivity to conserved linear epitopes of Plasmodium falciparum erythrocyte membrane protein 1 (PfEMP1)." Immunol Lett, 60(2-3), 121-6.

Strimmer, K. \& von Haeseler, A. (1996). "Quartet Puzzling: A Quartet Maximum-Likelihood Method for Reconstructing Tree Topologies." Mol Biol Evol, 13(7), 964-9.

Su, X. Z., Heatwole, V. M., Wertheimer, S. P., Guinet, F., Herrfeldt, J. A., Peterson, D. S., Ravetch, J. A. \& Wellems, T. E. (1995). "The large diverse gene family var encodes proteins involved in cytoadherence and antigenic variation of Plasmodium falciparum-infected erythrocytes." Cell, 82(1), 89-100.

Swofford, D. L. (1998). "PAUP*. Phylogenetic Analysis Using Parsimony (*and Other Methods).", Suderland, Massachusetts.

Taylor, H. M., Kyes, S. A., Harris, D., Kriek, N. \& Newbold, C. I. (2000). "A study of var gene transcription in vitro using universal var gene primers." Mol Biochem Parasitol, 105(1), 13-23.

Thompson, J. D., Gibson, T. J., Plewniak, F., Jeanmougin, F. \& Higgins, D. G. (1997). "The CLUSTAL_X windows interface: flexible strategies for multiple sequence alignment aided by quality analysis tools." Nucleic Acids Res, 25(24), 4876-82.

Thompson, J. K., Rubio, J. P., Caruana, S., Brockman, A., Wickham, M. E. \& Cowman, A. F. (1997). "The chromosomal organization of the Plasmodium falciparum var gene family is conserved." Mol Biochem Parasitol, 87(1), 49-60. 
Trager, W. \& Jensen, J. B. (1976). "Human malaria parasites in continuous culture." Science, 193(4254), 673-5.

Tran, T. H., Day, N. P., Nguyen, H. P., Nguyen, T. H., Pham, P. L., Dinh, X. S., Ly, V. C., Ha, V., Waller, D., Peto, T. E. \& White, N. J. (1996). "A controlled trial of artemether or quinine in Vietnamese adults with severe falciparum malaria." N Engl J Med, 335(2), 76-83.

Traore, B., Muanza, K., Looareesuwan, S., Supavej, S., Khusmith, S., Danis, M., Viriyavejakul, P. \& Gay, F. (2000). "Cytoadherence characteristics of Plasmodium falciparum isolates in Thailand using an in vitro human lung endothelial cells model." Am J Trop Med Hyg, 62(1), 38-44.

Trenholme, K. R., Gardiner, D. L., Holt, D. C., Thomas, E. A., Cowman, A. F. \& Kemp, D. J. (2000). "clag9: A cytoadherence gene in Plasmodium falciparum essential for binding of parasitized erythrocytes to CD36." Proc Natl Acad Sci U S A, 97(8), 4029-33.

Treutiger, C. J., Heddini, A., Fernandez, V., Muller, W. A. \& Wahlgren, M. (1997). "PECAM-1/CD31, an endothelial receptor for binding Plasmodium falciparum- infected erythrocytes." Nat Med, 3(12), 14058.

Treutiger, C. J., Hedlund, I., Helmby, H., Carlson, J., Jepson, A., Twumasi, P., Kwiatkowski, D., Greenwood, B. M. \& Wahlgren, M. (1992). "Rosette formation in Plasmodium falciparum isolates and anti-rosette activity of sera from Gambians with cerebral or uncomplicated malaria." Am J Trop Med Hyg, 46(5), 503-10.

Treutiger, C. J., Scholander, C., Carlson, J., McAdam, K. P., Raynes, J. G., Falksveden, L. \& Wahlgren, M. (1999). "Rouleaux-forming serum proteins are involved in the rosetting of Plasmodium falciparuminfected erythrocytes." Exp Parasitol, 93(4), 215-24.

Udeinya, I. J., Miller, L. H., McGregor, I. A. \& Jensen, J. B. (1983). "Plasmodium falciparum strainspecific antibody blocks binding of infected erythrocytes to amelanotic melanoma cells." Nature, 303(5916), 429-31.

Udomsangpetch, R., Brown, A. E., Smith, C. D. \& Webster, H. K. (1991). "Rosette formation by Plasmodium coatneyi-infected red blood cells." Am J Trop Med Hyg, 44(4), 399-401.

Udomsangpetch, R., Chivapat, S., Viriyavejakul, P., Riganti, M., Wilairatana, P., Pongponratin, E. \& Looareesuwan, S. (1997). "Involvement of cytokines in the histopathology of cerebral malaria." $A m \mathrm{~J}$ Trop Med Hyg, 57(5), 501-6.

Udomsangpetch, R., Thanikkul, K., Pukrittayakamee, S. \& White, N. J. (1995). "Rosette formation by Plasmodium vivax." Trans R Soc Trop Med Hyg, 89(6), 635-7.

van Hensbroek, M. B., Palmer, A., Onyiorah, E., Schneider, G., Jaffar, S., Dolan, G., Memming, H., Frenkel, J., Enwere, G., Bennett, S., Kwiatkowski, D. \& Greenwood, B. (1996). "The effect of a monoclonal antibody to tumor necrosis factor on survival from childhood cerebral malaria." $J$ Infect Dis, 174(5), 1091-7.

Voss, T. S., Thompson, J. K., Waterkeyn, J., Felger, I., Weiss, N., Cowman, A. F. \& Beck, H. P. (2000). "Genomic distribution and functional characterisation of two distinct and conserved Plasmodium falciparum var gene 5' flanking sequences." Mol Biochem Parasitol, 107(1), 103-15.

Wahlgren, M., Abrams, J. S., Fernandez, V., Bejarano, M. T., Azuma, M., Torii, M., Aikawa, M. \& Howard, R. J. (1995). "Adhesion of Plasmodium falciparum-infected erythrocytes to human cells and secretion of cytokines (IL-1-beta, IL-1RA, IL-6, IL-8, IL-10, TGF beta, TNF alpha, G-CSF, GM-CSF." Scand J Immunol, 42(6), 626-36.

Wahlgren, M., Carlson, J., Helmby, H., Hedlund, I. \& Treutiger, C. J. (1992). "Molecular mechanisms and biological importance of Plasmodium falciparum erythrocyte rosetting." Mem Inst Oswaldo Cruz, 87(Suppl 3), 323-9.

Wahlgren, M., Carlson, J., Ruangjirachuporn, W., Conway, D., Helmby, H., Martinez, A., Patarroyo, M. E. \& Riley, E. (1990). "Geographical distribution of Plasmodium falciparum erythrocyte rosetting and frequency of rosetting antibodies in human sera." Am J Trop Med Hyg, 43(4), 333-8.

Wahlgren, M., Fernandez, V., Scholander, C. \& Carlson, J. (1994). "Rosetting." Parasitology Today, $10(2), 73-9$. 
Ward, C. P., Clottey, G. T., Dorris, M., Ji, D. D. \& Arnot, D. E. (1999). "Analysis of Plasmodium falciparum PfEMP-1/var genes suggests that recombination rearranges constrained sequences." $\mathrm{Mol}$ Biochem Parasitol, 102(1), 167-77.

Warrell, D. A. (1987). "Pathophysiology of severe falciparum malaria in man." Parasitology, 94(Suppl), S53-76.

Weber, J. L. (1988). "Interspersed repetitive DNA from Plasmodium falciparum." Mol Biochem Parasitol, 29(2-3), 117-24.

Whang, K. T., Vath, S. D., Becker, K. L., Snider, R. H., Nylen, E. S., Muller, B., Li, Q., Tamarkin, L. \& White, J. C. (1999). "Procalcitonin and proinflammatory cytokine in interactions in sepsis." Shock, 12(4), 268-73.

White, N. J. \& Ho, M. (1992). "The pathophysiology of malaria." Adv Parasitol, 31, 83-173.

WHO. (1990). "Severe and complicated malaria. World Health Organization, Division of Control of Tropical Diseases." Trans $R$ Soc Trop Med Hyg, 84(Suppl 2), 1-65.

WHO. (1996). "World malaria situation in 1993." Wkly Epidemiol Rec, 71(3), 17-22.

WHO. (1997). "World malaria situation in 1994. Part I-III." Wkly Epidemiol Rec, 72(36-38), 269-90.

WHO. (2000). "Severe falciparum malaria." Trans R Soc Trop Med Hyg, 94(supplement 1), 1-90.

Wooden, J., Gould, E. E., Paull, A. T. \& Sibley, C. H. (1992). "Plasmodium falciparum: a simple polymerase chain reaction method for differentiating strains." Exp Parasitol, 75(2), 207-12. 
7. ANEXO 1 


\title{
RESEARCH BRIEF \\ Plasmodium falciparum: DBL-1 Var Sequence Analysis in Field Isolates from Central Brazil ${ }^{1}$
}

\author{
Karin Kirchgatter, ${ }^{*} \uparrow$ Raphael Mosbach, $\ddagger$ and Hernando A. del Portillo*,2 \\ - Departamento de Parasitologia, Instituto de Cincias Blamedicas, Universidode de Sáo Pawio. \\ Prof Linew Prestes 1374, São Paulo, SP, 05508-900, Brazil; †Laboratório de Malária, \\ Divisáo de Programas Esperiais, Syperintendencia de Controle de Endemias (SUCEN). \\ Candeal Ancoverde 2878, Süo Pasalo, SP, 05408-603, Brazil; and \$Zentrum für Moleksiare Biologie, \\ Uniwersität Heideiberg, D-59I20 Heidelberg, INF 282, Germany
}

Kirchgatter, K., Mosbach, R., and del Portillo, H. A. 2000. Plasmodium falciparim: DBL-1 Var sequence analysis in field isolates from Central Brazil. Experimental Parasiology 95, 154-157. O 2000 madertic Preis

The Brazilian Amazon region is responsible for approximately 99\% of all malaria cases in Brazil waich last year acecunted for ca. 400,000, of which $23 \%$ were due to Plosmodiam falciparm (Brasil, 1999) Significantly, aside from a very fow isolated cases, severe malaria in this endemic region rarely lesds to cerebral malaria as opposed to other complications such as renal failure and lung edema (Boulos 1992; Duarte et al. 1985)

The $P$. falciparsm war gene family encodes predicted 200 - to 300 $-\mathrm{kDa}$ proteins with two different exons: a conserved transmembrane C-terminus and a highly polymorphic $\mathrm{N}$-terminus displaying variant numbers of Duffy binding-like (DBL) domains (Su et al. 1995; Baruch ef al. 1995; Smith et al. 1995). Expression of var geres on the surface of infected erythrocytes is directly associated with the phenomena of antigenic variation and cytoadherence to postcapillary venules and both phenomena are responsible for much of the pathophysiology of faleiparum malaria (rev. in Newbold 1999). The most N-terminal DBL

'The sequence data reponted herein have been submitted to GenBank and assigned the Accession Numbers AF172771-AF172814.

To whom correspondence should be addressed. Fax: (55-11) 3818.7417. E-msil: hesporti@lineu.icb.usp.br.
Somain (DBL-1) is becoming the target of several molocular epidemiological studies since degenerate primers are capable of amplifying different sequences from laboratory clones and wild isolates (Kyes of al. 1997; Ward et al. 1999, Taylor ef at. 2000). Acoordingly we have initiated studies to generate a DBL-1 ver secuence bank from $P$. falcjparum isolates of the Brazilian Amazon region for future expression studies.

Oar first study site is a municipality of the State of Mato Grosso (MT) in the southern part of the Amazon region called Peixoto de Azevedo. In the past few years this region has witnessed a significant decrease in human population mainly due to the migration of gold miners to neighboring states. Currently, there are approximately 27,000 people and 400 diagnosed malaria cases yearly of which $35 \%$ are due to $P$. falcipurum (Brasil 1999). Although epidemiological data on infected bites/person from this perticular Amazon region are not available, it can clearly be considered a hypoendemic area.

Blood stage parasites were obtained, after informed consent, from 20 adult infected males ( $\geq 18$ years) (MT01-20) before treatment administration. Total genomic DNA was extracted as described elsewhere (Ferreira er al. 1998) and used as a template in PCR reactions to amplify the 5 '-end of the $P$, falcipanm var DBL-1. Primers and conditions were as in Kyes et aL. (1997). As expected, a fragment of around 200 bp was amplified from each isolate and the possibility of this result being due to carrying-over contamination was excluded by performing negative controls from each isolate in parallel (not shown). The PCR fragments were cloned and minipreparations of plasmid DNA were sequenced using the ALFexpress AutoRead sequencing kit in an ALF Express DNA sequencer (Amersham Pharmacia Biotech, UK). Two hundred sequences (10 from esch isolate) corresponding to the $\mathrm{N}$ terminal 70 amino acids of the DBL-1 domain from the var-1 type 
secuence (Su $6 t$ al. 1995) were generated and confirmed to represent var sequences by BLAST tool version 2.0 (Altsctaul et al. 1997).

The deduced amino acid secuences revealed 44 different secuences (GenBank Accession Numbers AF172771-AF172814) displaying the same conserved structural franswork of the DBL-1 domain described in other isolates and clones (Fig. IA). Thus, the cysteine residues were conserved in all isolates with the exception of isolates MT11006 and
MT12C04 in which two other residues were observed $(\mathrm{C} 27 \rightarrow \mathrm{F}$ and $\mathrm{C} 27 \rightarrow 5$ ), respectively. Moreover, eight other residaes were totally conserved among the 44 sequences: L22, L23, V26, A29, A30, E33, T61, and L63, and these same amine acids, including the cysteine residues, were highly conserved when an alignment with most available sequences in GenBank was perforned (http://www:zmbh.uni-beidel berg.deledv/h.delportillo). Percentage of identity analysis revesled that

A

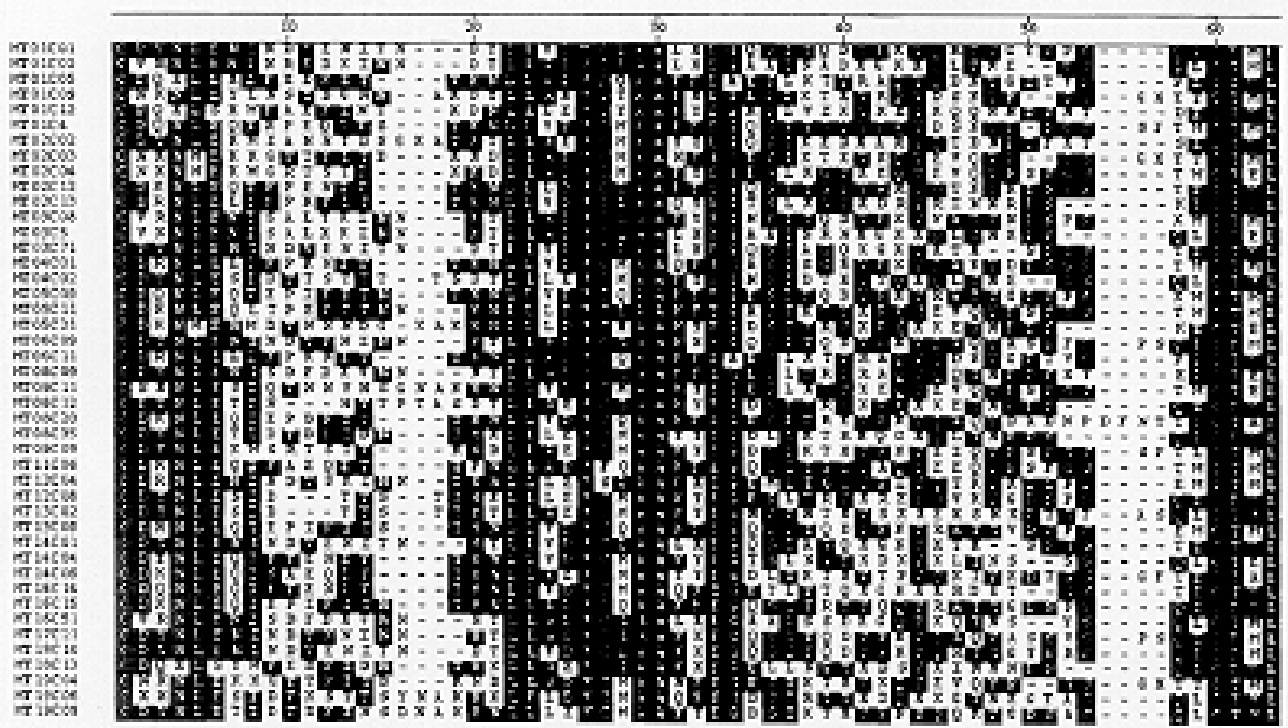

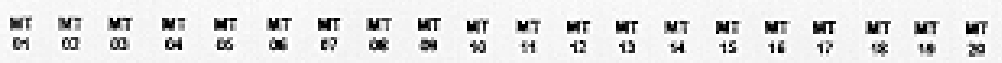

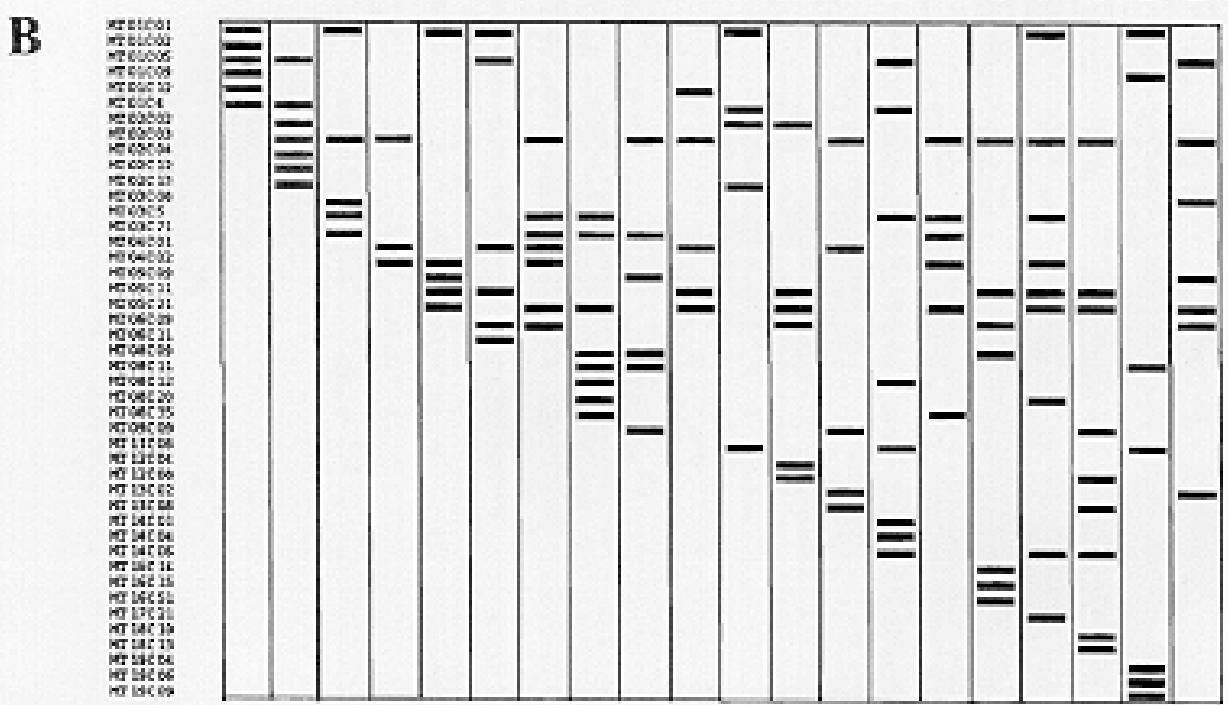

FIG. 1. A. Comparison of 44 var DBL-1 amino acid sequences from the Brazilian Amazon state of Mato Grosse (MT), Alignments were made using Clustalw version 1.8 with blosum matrices and some editing manuslly (Higgins ef al. 1996). The residues that match the consensus exactly are shaded with solid black. B. Schematic distribution of sequences reco,ded in each patient is represented by dark bars. 
there are Brazilian sequences with closer similarities among isolates from other geographical regions than among them. In fact, one particular sequetse, MT 12C04, was identical at the amino acid and racleotide levels to the sequence van4b (GenBank 294733) from Vanuatu whereas two Brazilian var sequences, MTDIC10 and MT01C14, were only $34 \%$ identical (not shown).

Dendograms gererated from all sequences femonstrated that the DBL-1 war sequences from the Mato Grosso state did not cluster to each other more frequently than they did with sequences obtained from isolates of other geographical regions or laboratory elones (http:/s www zmbleuni-heidelberg,de/edv/h,delportillo). Similar results were recorded upon generation of other dendograms using various algorithms and regions of DBL- 1 in searching for sequence similarities that could indicate their Brazilian geographical origin (nos shown). Together, these results further confirm and expand the observations of Kyes er al. (1997) and Ward ef al. (1999), that is, DBL-1 var sequences are not more elosely related to any particular sequence than they are to any other and therefore var gene sequenee similarity cannot predict geographical origin.

The genomic DNA used for amplification in this study was obeained from froesen peripheral bleod samples and never underwent in viro selection. Three to nine different sequenees were detected from each individual patient and none of the patients examined harbored all of the same seçuences (Fig. 1B). Yet, even if the number of circulating elones/isolate were 1 , it would have been expected to find more DBL1 sequences than observed. Indeed. of 10 sequences from each of 20 MT isolates, we were only able to determine 44 different amino acid sequences. This is in contrast to 37 different sexuerxes amplified from this same domain from five Sulanese patients (Ward et al. 1999); this gives an average of 7.4 different sequerces/patient in Sudan as opposed to 22 patient in Bracil. These results elearly indicate that this set of primers is of limited specificity and suggest that lower numbers of circulating clones per individual patient are present in Mato Grosso as opposed to Sudan. A new set of PCR primers capable of amplifying the majority of var genes in laboratory clones (Taylor et al. 2000) is. now being tested in these same isolates to establish new DBL-1 sequences from this Amazon region.

This is the first report on DBL-1 var sequences of $P$. falcipurum from Brazilian field isolates obtained directly from patients. DBL domains were originally deseribed in other malarial proteins such as the Dufly binding protein of $P$. wivax and shown to bind the Duffy blcod-group determinant in heterologous transfection assays (Chitnis and Miller 1994). Similar assays are now being used to demonstrate that the DBL domains from the PfEMPI proteins are also capable of binding to different endothelial receptors (Rowe er al. 1997; Chen ef al. 1998; Buffet et al. 1999; Smith et al. 2000). In tum, this differential birding specificity leads to sequestration in various organs. Worldwide DBL-1 geromic DNA sequence information is rapidly being aceumulated (GeneBank, Kyes et aI, 1997; Ward et al. 1999; Taylor et al. 2000, these data) to determine whether there are particular DBL-1 sequences preferentially expressed in the different pathologies of severe falcipanm malaria.

\section{ACKNOWLEDGMENTS}

We are grateful to all of the malaria patients who participated in this study, to the anonymous reviewers of the manuscript for helpful comments, and to Alister Craig for seientific discussions throughout this project. This project was Supported by the INCO-DC Programme (IC 18CT980364)

\section{REFERENCES}

Altschul, S. F., Madden, T. L., Schaffer, A. A, Zhang, J., Zhang, Z., Miller, W, and Lipman, D. J. 1997. Gapped BLAST and PSIBLAST: A new generation of protein database search programs, Nucieic Acids Reseaych 25, 3389-3402.

Baruch, D. I., Pasloske, B. L., Singh, H. B., Bi, X., Ma, X. C., Feldman, M., Tanaschi, T. F, and Howard, R. J. 1995. Cloning of the $P$. folciparam gene encoding PiEMPl, a malarial variant antigen and adherence receptar on the surface of parasitized human erythrocytes. Cell 82, 77-87.

Boulos, M. 199/. Tratamento da malária grave. Revista da Saciedede Brasileira de Medicina Thopical 25, S41-\$42.

Brasil. 1999. Dados Epidemiológicos de Malária. Ministério ḋ Saúde, Fundsç̃o Nacional de Saúté, Geréncia Téeniça de Malária, Brasilia.

Buffet, P. A., Gamain, B., Scheidig, C., Banuch, D, Smith, J. D., Hernardex-Rivas, R., Pouvelle, B., Oishi, S., Fujï, N., Fusai, T., Parzy, D., Miller, L. H., Gysin, J., and Scherf, A. 1999. Piacmodilum falciparum bomain mediating adhesion to chondroitin sulfate A: A rexeptor for human placental infection. Procecdings of the Natianal Academy of Sciences, USA 96, 12743-12748.

Chen, Q., Fernandex, V., Sundström, A, Schlichtherle, M., Datta, S., Hagblom, $P_{5}$ and Wahlgren, M. 1998. Developmental selection of var gene expression in Plesmodium falciparim. Nature 394, 392-395.

Clitnis, C. E., and Miller, L. H. 1994. Identification of the erythrocyte binding domains of Plasmodium vivax and Plosmodium knowiesi proteins involved in erythrocyte invasion. Journal of Experimental Medicine 180, 497-506.

Duarte, M. L. S., Corbett, C. E. P., Boulos, M., and Amato Nero, V. 1985. Ultrastructure of the lung in falciparum malaria. American Jownd of Tropical Medicine and Hygiene 34, 31-35.

Ferreira, M. U., Liu, Q-, Kaneko, O., Kimura, M., Tanabe, K, Kimura, E. A. S., Katzin, A. M., Isomura, S., and Kawamoto, F. 1998. Allelic diversity at the merozoite surface protein I bocus of Plasmodilum faiciparum in clinical isolates from the southwestem brazilian amazon. American Journal of Tropical Medicine and Hygiene 59, 474-480.

Higgins, D. G., Thompson, J. D., and Gibson, T. J. 1996, Using CLUSTAL for multiple sequence alignment. Method's in Enzymology 266, 383-402.

Kyes, S., Taylor, H., Craig, A., Marsh, K., and Newbold, C. 1997. Genomic representation of var gene sequences in Plasmodium falciparum field isolates from different geographic regions. Molecuiar and Biachenical Parasitolozy 87, 235-238.

Newbold, C. L. 1999. Antigenic variation in Plasmodiam falciparam: Muchanisms and consequenses. Current Opinion in Microbiology $2,420-425$. 
Rowc, J. A. Moulds, J. M., Newbold, C. I., and Miller, L. H. 1997. P. falcipanum rosetting mediated by a parasite-variant erythrocyte membrane protein and complement-receptor 1 . Nature $388,292-$ 295.

Smith, J. D., Chitnis, C. E., Craig, A. G., Roberts, D. J, HudsonThylor, D. E., Peterson, D. S., Pinches, R., Newbold, C. L., and Millet, L. H. 1995. Switches in expression of Plasmodium falciparwm var genes correlate with changes in antigenic and cytoadherent phenotypes of infected erythrocytes. Cell 82, 101-110.

Smith, J. D., Craig, A. G., Krick, N., Hudson-Taylor, D., Kyes, S, Fagen, T., Pinches, R., Baruch, D. L, Newbold, C. L., and Miller,

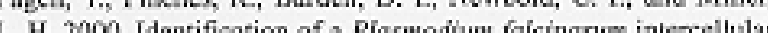
thesion.

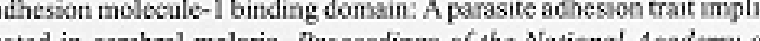
ated in cerebral malaria. Procectings of the National Academy of Sciences, USA 97, 1766-1771.
Su, X., Hestwole, V, M., Wertheimer, S. P., Guinel, F., Herrfeldt, J. A. Peterson, D. S., Ravetch, J. A, and Wellems, T, E. 1995. The lange diverse gene family ver encodes proteins involved in cylosdherence and antigenic variation of Plasmodiam falciparuminfected erythrocytes. Cell $82,89-100$.

Taylor, H. M., Kyes, S. A., Harris, D., Kriek, N., and Newbold, C. I. 2000. A study of var gene transcription in wiro using universal war gene primers. Molecular and Biochemical Parasifology 105, 13-23.

Ward, C. P., Clottcy, G. T., Dorris, M., Ji, D., and Amoc, D. E. 1999. Analysis of Plasmodium falciparum PIEMP-1/var genes suggests that recombination rearranges constrained sequences. Molecular and Biachemical Panasifology 102, 167-177.

Received 27 Deeember 1999; accepted with revision 18 April 2000 
8. ANEXO 2 


\title{
Association of severe non-cerebral Plasmodium falciparum malaria in Brazil with expressed PfEMP1 DBL1 $\alpha$ sequences lacking cysteine residues
}

\author{
Karin Kirchgatter ${ }^{1,2}$ and Hernando A. del Portillo ${ }^{1}$ \\ ${ }^{1}$ Departamento de Parasitologia, Instituto de Ciências Biomédicas, Universidade de São Paulo and ${ }^{2}$ Núcleo de \\ Estudos em Malária, Superintendência de Controle de Endemias (SUCEN), São Paulo-SP, Brazil
}

\begin{abstract}
Background: Cytoadherence and rosetting contribute to the development of severe Plasmodium falciparum malaria. In Brazil, severe falciparum malaria is mostly associated with renal or pulmonary complications and very rarely with cerebral malaria. The most N-terminal DBL $1 \alpha$ domain of PfEMP1, a protein encoded by the var multigene family mediates rosetting. We analyzed parasites of Brazilian patients with severe malaria to determine whether there were particular DBL $1 \alpha$ var sequences predominantly expressed in such patients.
\end{abstract}

Materials and Methods: DBL1 $\alpha$ var sequences were obtained from parasites of Brazilian patients with severe and mild malaria and analyzed through standard bioinformatic programs. 320 var DBL1 $\alpha$ sequences obtained from 80 Brazilian patients with mild malaria were spotted in high-density filters and hybridized to probes representing predominantly expressed sequences in parasites from patients with severe malaria. A DBL1 $\alpha$ domain was expressed in bacteria and used to demonstrate its binding capacity to erythrocytes by immunofluorescence.

Results: Forty-three different and unreported DBL1 $\alpha$ amino acid sequences were obtained. Sequences predominantly expressed in patients with severe malaria could be sub-grouped due to deletions of 1-2-cysteine residues. These sequences were commonly found in the var gene repertoire of parasites from patients with mild malaria and yet they were rarely expressed in these patients. A recombinant protein representing the most abundantly expressed sequence detected in one patient with severe malaria bound directly to uninfected erythrocytes.

Conclusion: This is the first report showing an association of severe non-cerebral malaria from Brazil with particular DBL $1 \alpha$ sequences.

\section{Introduction}

Plasmodium falciparum is the most virulent and devastating human malarial parasite and responsible for approximately 300 million annual clinical cases and 1 million deaths mostly in children below five years old. Falciparum infections are characterized by removal from the peripheral circulation of red blood cells infected with mature parasites. This sequestration occurs by adhesion of infected erythrocytes to host receptors in the microvasculature of several organs. This phenotype, termed cytoadherence, cause retention and accumulation of infected erythrocytes leading to occlusion of microvessels and acute pathologic changes associated with severe malaria (1).

Address correspondence and reprint requests to: H.A. del Portillo, Departamento de Parasitologia, Instituto de Ciências Biomédicas, Universidade de São Paulo, Av. Lineu Prestes 1374, São Paulo-SP, 05508-900 Brazil. Phone: +55-11-3818-7209; Fax: +55-11-3818-

7417; E-mail: hernando@icb.usp.br
Cytoadherence is conferred by the $P$. falciparum erythrocyte membrane protein 1 (PfEMP1), encoded by a multigene family termed var which has a two exon structure: a conserved acidic cytoplasmic tail (ATS) and a highly polymorphic N-terminus displaying variant numbers of Duffy binding like (DBL) domains (2). It is within the highly polymorphic $\mathrm{N}$-terminus that several ligands for different endothelial receptors have been mapped (rev. in 3).

In addition to cytoadherence, it is now widely accepted that the adhesion of infected erythrocytes to uninfected erythrocytes, a phenomenon called rosetting, further contributes to the pathology associated with falciparum infections (4). Indeed, rosetting has been associated with severe malaria since it is common in parasites from patients with malaria complications in many field studies $(5,6,7,8,9,10,11)$. Moreover, several lines of 
evidence have demonstrated that the most $\mathrm{N}$ terminal DBL1 $\alpha$ of PfEMP1 mediates rosetting $(12,13,14,15)$. Thus, PfEMP1 plays a major role in cytoadherence and rosetting and both phenomena are directly associated to severe falciparum malaria.

Severe falciparum malaria is a complex of different clinical manifestations leading mainly to cerebral, renal and pulmonary dysfunction. In many parts of the world, cerebral dysfunction is the more common severe manifestation causing death in $4-50 \%$ of the adults with severe malaria (16). In other regions such as Brazil however, severe falciparum malaria is mostly associated with renal and pulmonary complications and very rarely with cerebral malaria $(17,18,19)$. Interestingly, a recent report has associated severe malaria in patients from French Guyana and particular var DBL $\delta$ sequences indicating that isolates from individuals with different clinical syndromes could be characterized by particular PfEMP1 repertoires (20). Only one study is presently available on DBL1 $\alpha$ genomic sequences from Brazilian isolates (21). Here, we analyzed expressed var DBL1 $\alpha$ sequences of parasites obtained from patients with severe malaria in the Brazilian Amazon to determine whether there were particular DBL1 $\alpha$ sequences predominantly expressed in such patients.

\section{Materials and Methods}

Patients with Severe Malaria and $P$. falciparum samples

We investigated six patients diagnosed and treated between 1987 and 2000 in different Hospitals in the capital city of São Paulo, Brazil (Table 1).
All these patients were classified with severe falciparum malaria according to WHO parameters (16). Procalcitonin (PCT) serum levels, recently implicated as a new parameter to diagnose malaria severity (22), were determined using an immunochromatografic test (Brahms PCT-Q kit). After informed consent from all of them, blood samples were obtained and stored in liquid nitrogen. All patients had parasitemias $>2 \%$ of $P$. falciparum ring forms in the peripheral circulation and half presented peripheral schizonts further supporting the severity of their infections. Other laboratory data from these patients are reported in Table 2 .

Patients with Mild Malaria and P. falciparum samples

Eighty patients (20 from each different region as below) with mild malaria were also included in this study. Samples were collected through different years and from different regions of the Brazilian Amazon: Mato Grosso (1997), Pará (1987-1997), Rondônia (1997) and Acre (1999). In addition, isolates NG1 to NG4 obtained from four patients were used to determine expressed var DBL1 $\alpha$ sequences (Table 1). Blood samples were collected and stored as above.

\section{In vitro culture and purification of mature parasites}

Parasites were cultured in vitro (23) and parasite growth monitored by Giemsa staining of thin and thick blood films. Parasites obtained from blood of patients with severe malaria were matured for one cycle to trophozoites and schizonts whereas those from patients with mild malaria, with lower parasitemias (Table 1), were maintained in culture for up to three cycles. Mature parasites

\begin{tabular}{|c|c|c|c|c|c|c|}
\hline & Isolate & $\begin{array}{c}\text { Brazilian State of } \\
\text { Origin }\end{array}$ & $\begin{array}{c}\text { Previous Malaria } \\
\text { Attacks }\end{array}$ & $\begin{array}{c}\text { Days between symptoms } \\
\text { and treatment }\end{array}$ & Parasitaemia & $\begin{array}{l}\text { Serum Concentration } \\
\text { Range of PCT (ng/ml) }\end{array}$ \\
\hline \multirow{6}{*}{ 这 } & G33 & Rondônia & 0 & 5 & $>2 \% * *$ & $\geq 2$ \\
\hline & $\mathrm{G} 23$ & Rondônia & 0 & 5 & $>2 \%$ & $\geq 0.5$ \\
\hline & G34 & Pará & 1 & 10 & $>2 \% * *$ & Not determined \\
\hline & $\mathrm{G} 2$ & Mato Grosso & 0 & 14 & $>2 \%$ & $\geq 2$ \\
\hline & G29 & Rondônia & 0 & 9 & $>2 \% * *$ & Not determined \\
\hline & G3 & Mato Grosso & 3 & 3 & $>2 \%$ & $\geq 2$ \\
\hline \multirow{4}{*}{ 흘 } & NG1 & Rondônia & 1 & 4 & $0.9 \%$ & $<0.5$ \\
\hline & $\mathrm{NG} 2 *$ & Mato Grosso & 4 & Not determined & $0.5 \%$ & $<0.5$ \\
\hline & NG3 & Mato Grosso & 4 & Not determined & $0.4 \%$ & $<0.5$ \\
\hline & NG4 & Mato Grosso & 2 & 6 & $1 \%$ & $\geq 2$ \\
\hline
\end{tabular}

*Recrudescence of G3; ** With peripheral schizontaemia; PCT, procalcitonin 
Table 2. Laboratory data of the severe malaria patients upon Hospital admission.

\begin{tabular}{|c|c|c|c|c|c|c|}
\hline Isolate / Age (yrs) / Sex & $\mathbf{G 3 3} / 20 / \vec{b}$ & $\mathrm{G} 23 / 18 / 9$ & $\mathrm{G} 34 / 45 / 2$ & $62 / 37 / 9^{*}$ & $\mathrm{G} 29 / 41 / 3$ & $\mathrm{G} 3 / 18 / 8$ \\
\hline Admitted - discharged (dd/mm/yy) & $03-10 / 11 / 87$ & $22-29 / 06 / 87$ & $17-25 / 08 / 89$ & $13 / 01 / 93-03 / 02 / 93$ & $20 \cdot 28 / 09 / 88$ & $20-27 / 02 / 92$ \\
\hline pH $(7,35-7,45)$ & 7.361 & & & & 7.343 & 7.360 \\
\hline $\mathrm{pO}_{2}(80 \mathrm{~mm} \mathrm{Hg})$ & 71.5 & & & & $89.5^{9}$ & 74.6 \\
\hline $\mathrm{pCO}_{2}(40 \mathrm{~mm} \mathrm{Hg})$ & 25.9 & & & & 24.6 & 34.8 \\
\hline $\mathrm{HCO}_{3}(24 \mathrm{mEq} / 1)$ & 15.0 & & & & 13.4 & 19.5 \\
\hline Base Excess $(-2$ to $+2 \mathrm{mEq} / \mathrm{l})$ & -8.4 & & & & -10 & -4.7 \\
\hline Sat $\mathrm{O}_{2}(>96 \%)$ & & & & & 96 & 94.5 \\
\hline Creatinine $(0.4-1.4 \mathrm{mg} / \mathrm{dl})$ & 1.0 & 0.7 & 0.8 & 11.1 & 0.9 & 0.9 \\
\hline Urea $(10-50 \mathrm{mg} / \mathrm{dl})$ & 42 & 24 & 23 & 234 & 60 & 56 \\
\hline Leukocytes $\left(3,5-12.000 / \mathrm{mm}^{3}\right)$ & 6.300 & 9.600 & 6.900 & 6.600 & 5.200 & 6.600 \\
\hline Erythrocytes $\left(4,5-5,500,000 / \mathrm{mm}^{3}\right)$ & & 2.800 .000 & 3.800 .000 & 3.100 .000 & 2.800 .000 & \\
\hline Hemoglobin $\delta(>14 \mathrm{~g} / \mathrm{dl}) ;$ \& $(>12 \mathrm{~g} / \mathrm{dl})$ & 12.8 & 8.8 & 11.2 & 8.1 & 8.7 & 10.3 \\
\hline Hematocrit $(40-54 \%)$ & 41 & 25 & 35 & 25 & 25 & 33 \\
\hline Platelets $\left(100-500,000\left(\mathrm{~mm}^{3}\right)\right.$ & 22.500 & 56.000 & & & 64.000 & 29.000 \\
\hline Total serum bilirubin ( $<1.5 \mathrm{mg} / \mathrm{dl})$ & & & 2.7 & 3.6 & & 2.8 \\
\hline Direct serum bilirubin $(<0.5 \mathrm{mg} / \mathrm{dl})$ & & & 0.4 & 2.6 & & 1.1 \\
\hline
\end{tabular}

*Patient under peritoneal dialysis procedure; iW ith $\mathrm{O}_{2}$; 
obtained from all patients were purified as described elsewhere (24).

\section{DNA/RNA extractions and cDNA synthesis}

Genomic DNA was obtained as described in Ferreira et al. (25) and stored at $4^{\circ} \mathrm{C}$. Total RNA from mature parasites was extracted according to Kyes et al. (26) and stored at $70^{\circ} \mathrm{C}$. As needed, one microgram aliquots of total RNA were treated in three consecutive 15 min steps at room temperature with DNase I (Life Technologies) reaching a final volume of $20 \mu \mathrm{l}$. The reaction was stopped by adding EDTA to a final concentration of $2,5 \mathrm{mM}$ and incubation at $65^{\circ} \mathrm{C}$ for $10-\mathrm{min}$. One microliter aliquots were used in PCR reactions using var DBL1 $\alpha$-oligonucleotides (27); only samples that did not amplify were subsequently used in reverse transcription. cDNAs were prepared using the First-Strand cDNA Synthesis Kit (Amersham Pharmacia Biotech), and random hexadeoxynucleotides. Samples without reverse transcriptase were used in all reactions as yet another control of DNA contamination.

\section{PCR, cloning and sequencing}

Samples were amplified by PCR as previously described (27). PCR or RT-PCR fragments were resolved in 1-\% agarose gel, purified (28) and cloned into the pGEM-T Easy Vector (Promega). Sequence was contracted and obtained from GATC GmbH (Germany).

\section{Sequence analysis}

Sequences were translated to aminoacids by EditSeq Programme (DNAstar package) and submitted to BLASTP version 2.1.3 (29). Alignments were done using ClustalX version 1.81 (30). Maximum likelihood tree was constructed utilizing the $\mathrm{GTR}+\mathrm{I}+\mathrm{G}$ model, selected by Modeltest Program version 3.06 (31). The value of the gamma distribution with shape parameter $\alpha$ was 1.6315. Quartet puzzling method was used to choose the better likelihood tree (32). All these analyses were undertaken with 4.06 version of PAUP* (33).

Expression of a var DBL1 $\alpha$ domain as a Histagged bacterial protein

The var gene segment coding for the DBL1 $\alpha$ $\mathrm{N}$-terminal domain from the $P$. falciparum isolate G2 (clone 1) was subcloned into the pRSET-C Vector (Invitrogen). Authenticity of the recombinant plasmid was confirmed by DNA sequencing. After IPTG induction, the protein was expressed in E. coli strain BL21 at $37^{\circ} \mathrm{C}$ for 2 hours and purified using the basic protocol of the HisTrap Kit using $8 \mathrm{M}$ Urea and according to the manufacturer's instructions (Amersham Pharmacia Biotech).

\section{Immunofluorescence}

After washing three times in PBS, thin blood smears were prepared with $0.5 \%$ blood group $\mathrm{A} \mathrm{Rh}^{+}$erythrocytes. Erythrocytes were fixed with acetone and $15 \mu \mathrm{l}$ aliquots of two Histagged bacterial proteins, DBL1 $\alpha$-His and Meta1-His (an antigen from Leishmania used as a negative control) both at $80 \mu \mathrm{g} / \mathrm{ml}$ in PBS were dropped separately onto the smears and incubated for $30 \mathrm{~min}$ at room temperature. As a positive control, $15 \mu \mathrm{l}$ of an anti-human erythrocyte polyclonal mouse antibody were used. Slides were washed three times with PBS and binding was detected using an $\mathrm{IgG} 2$ monoclonal antibody against the His tag (Amersham Pharmacia Biotech) and ImmunoPure FITC conjugate goat anti-mouse IgG (Pierce).

\section{High-density filters and Southern hybridizations}

Plasmid DNA from 320 individual clones was spotted in duplicates onto $12 \mathrm{X} 8 \mathrm{~cm}$ nylon Hybond $\mathrm{N}+$ membranes (Amersham) by a robotic system (Flexys, Genomic Solutions, USA) using a 96 pins head. Gridding density was 2 identical sets of $(4 \times 4) \times 96$. RT-PCR fragments were labelled using random primer with $\left[\alpha^{33} \mathrm{P}\right]$ CTP using the Multiprime DNA Labelling System (Amersham Pharmacia Biotech) and T7 oligonucleotide was labelled with $\left[\gamma^{33} \mathrm{P}\right]$ ATP using T4 polynucleotide kinase. Membranes hybridized with $\mathrm{T} 7$ were washed in $6 \mathrm{XSSC} / 0.5 \% \mathrm{SDS}$ at $37^{\circ} \mathrm{C}$ for 15 min followed by another wash in the same solution at $5^{\circ} \mathrm{C}$ below $\mathrm{Tm}$ for $10 \mathrm{~min}$. Membranes hybridized with var probes were washed at 2XSSC for $10 \mathrm{~min}$ at room temperature followed by two washes at $0.1 \mathrm{XSSC} / 0.1 \% \mathrm{SDS}$ at $65^{\circ} \mathrm{C}$ for 15 minutes each. 


\section{Results}

P. falciparum DBL1 $\alpha$ var sequences expressed in patients with severe malaria revealed predominantly expressed sequences lacking 12 cysteine residues

57 DBL1 $\alpha$ var RT-PCR fragments amplified from total RNA of mature parasites obtained from six patients with severe malaria were cloned and sequenced. A total of 25 different deduced amino acid sequences were obtained and compared in blast analysis to available sequences at GenBank. Two sequences had $100 \%$ identity with sequences already deposited: G29-7 with a var gene from a Vanuatu isolate (AF221773) and G3-R1 with a var gene from FCR3 strain (AJ133811). The other 23 sequences were unreported (GenBank accession numbers AF368922 to AF368944). Alignment of all 25 sequences showed that 8 sequences could be sub-grouped due to deletions of 1-2 cysteine residues at their $\mathrm{C}$ termini (Fig. 1). These 8 sequences represent 3 sequences from patient $\mathrm{G} 2$ and one sequence from each severe patient (G3, G23, G29, G33 and G34). Significantly, these sequences were the most abundantly expressed in each patient as reflected by the large percentage $(>33 \%)$ of identical clones sequences from each sample. These data demonstrate that there are $P$. falciparum DBL1 $\alpha$ sequences lacking 1-2 cysteine residues that are predominantly expressed in the parasites obtained from all patients with severe malaria included in this study.

DBL1 $\alpha$ var sequences predominantly expressed in parasites obtained from severe malaria patients are rarely expressed in parasites from mild malaria patients

Having identified DBL1 $\alpha$ var sequences lacking 1-2 cysteine residues predominantly expressed in all patients with severe malaria from the Brazilian Amazon, we next examined DBL1 $\alpha$ var sequences expressed in parasites obtained from patients with mild malaria. 54 DBL1 $\alpha$ var sequences were obtained from parasites of four patients with mild malaria (Table 1). Twenty one different amino acids sequences were obtained from these patients. Sequence NG4-3 had 100\% identity with varH sequence obtained from the Brazilian ItG2 isolate (AF275864). The others 20 sequences were unreported and submitted to GenBank (accession numbers AF368945 to AF368950 and AF416572 to AF416585). It is important to recall that we included the same patient at the moment of having severe malaria (G3) and 20 days later at the moment of a recrudescence diagnosed as mild malaria (NG2).

\section{Phylogenetic Analysis of DBL1 $\alpha$ sequences}

Phylogenetic analysis of the DBL1 $\alpha$ domain from 46 different expressed var genes from Brazil (25 from severe and 21 from mild malaria) and 21 sequences from this same domain from Sudan obtained from GenBank was performed. Remarkably, the same sequences that had been sub-grouped in the analysis of DBL1 $\alpha$ sequences from patients with severe malaria remained sub-grouped. Two sequences expressed in parasites from patients with mild malaria and one sequence from Sudan also sub-grouped in this branch of the tree (Fig. 1).

$D B L 1 \alpha$ var sequences expressed in parasites obtained from patients with severe malaria are frequently present in the var repertoire of parasites obtained from patients with mild malaria

We then investigated whether the most predominantly expressed DBL1 $\alpha$ var sequences from patients with severe malaria were amply present in the var gene repertoire of patients with mild malaria in the Brazilian Amazon. To address this, high-density filters were spotted with 320 clones representing DBL1 $\alpha$ var sequences of parasites obtained from 80 patients with mild malaria and screened with different probes. First, we used a plasmid specific probe (T7) to verify if all the samples were spotted in approximately the same quantity (Fig. 2A). Second, we used single probes representing the most frequently expressed sequences from three individual patients and demonstrated that they are present in the genomic repertoire of many isolates from patients with mild malaria (Fig. 2B, 2C and 2D). Sequence analysis of several randomly chosen positive clones confirmed that they were identical to the sequence of the probe with which they reacted (not shown). 

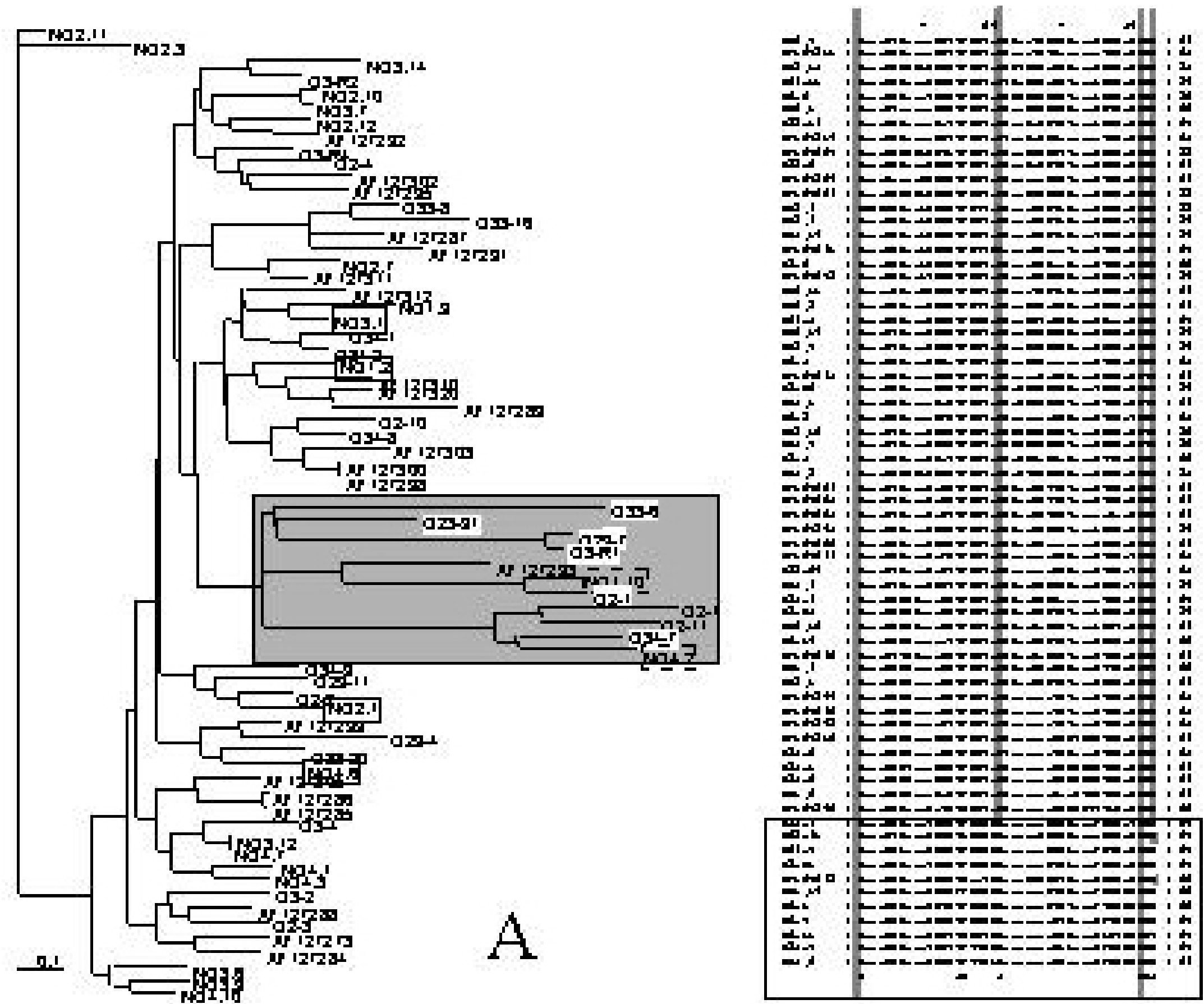

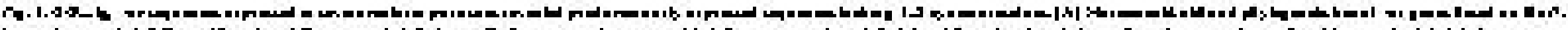

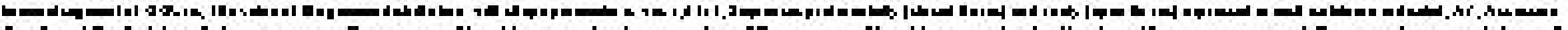

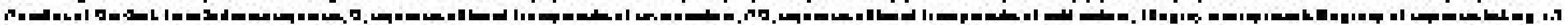

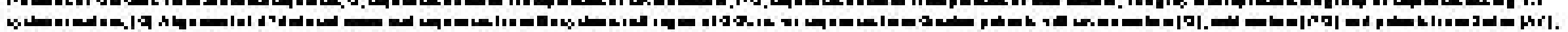

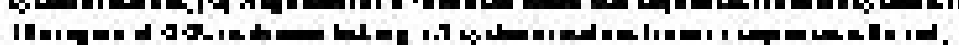




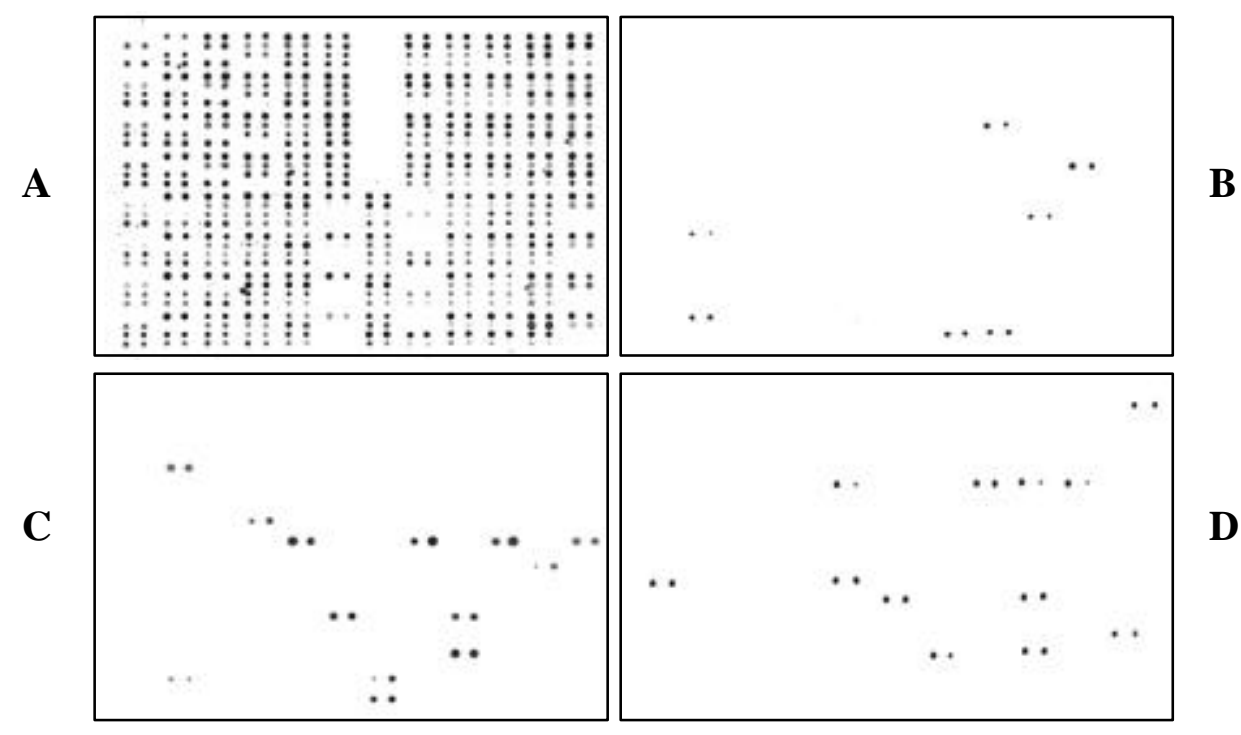

Fig. 2. DBL1 $\alpha$ var sequences expressed in severe malaria parasites are frequently present in the var gene repertoire of mild malaria parasites. High-density filters containing 320 DBL $1 \alpha$ var sequences obtained from parasites of patients with mild malaria were spotted in duplicates and hybridized with a plasmid-specific probe, T7 (A) or probes obtained from severe malaria parasites: (B) G29-7, (C) G33-6 or (D) G34-7. All spaces with no signal hybridization in A correspond to negative controls (water).

Similar results were obtained when filters were hybridized with complex RT-PCR probes from individual patients with severe malaria (not shown). These data demonstrated that the sequences preferentially expressed in parasites from patients with severe malaria are amply present in the genomes of parasites from patients with mild malaria; yet, they are rarely expressed in the latter.

\section{A DBL1 $\alpha$ domain expressed in bacteria binds directly to erythrocytes}

Rosetting have been associated with severe malaria and is unequivocally mediated by particular sequences of the PfEMP1 DBL1 $\alpha$ domain $(12,13,14,15)$. We thus investigated whether a DBL1 $\alpha$ domain from the most abundantly expressed sequence of a patient with severe malaria could bind to erythrocytes. To do so, the DBL1 $\alpha$ N-terminal domain from the $P$. falciparum isolate G2 (clone 1) (AF368922) was expressed with a 6x-histidine tail in E. coli and used in IFA analysis. Worth mentioning, a similar methodology had been previously used to demonstrate PfEMP1 as the rosetting ligand of $P$. falciparum (13). As positive and negative controls, a polyclonal mouse anti-human erythrocyte antibody and a non-related His-tagged protein from Leishmania were used, respectively. Similar to the positive control, the DBL1 $\alpha$-His gave a distinct surface staining with all uninfected erythrocytes (Fig. 3 A-B). In contrast, no staining was detected with an unrelated Leishmania Meta1-His protein (Fig. 3C).

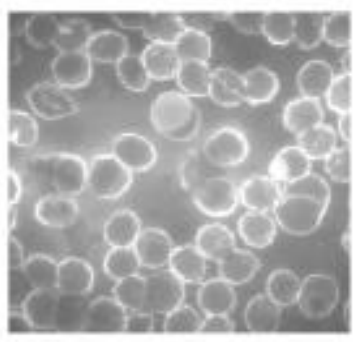

A

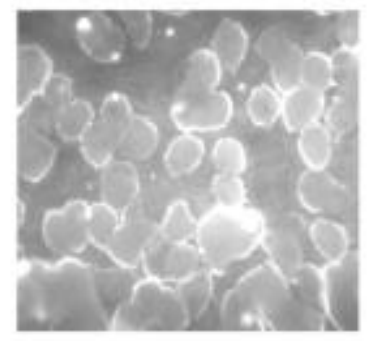

B

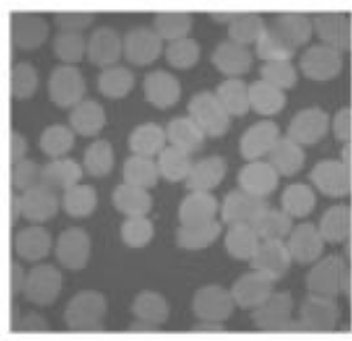

C

Fig. 3. A DBL1 $\alpha$ domain expressed in bacteria binds directly to erythrocytes. IFA analysis of uninfected erythrocytes using a polyclonal mouse anti-human erythrocyte antibody (A), recombinant protein DBL1 $\alpha$ (G2-1)His (B) or a non-related His-tagged protein from Leishmania (C). 


\section{Discussion}

An understanding of the molecular mechanisms underlying severe non-cerebral falciparum malaria should lead to rationale and novel control strategies. Towards this end, we analyzed expressed $P$. falciparum DBL1 $\alpha$ var sequences from patients with severe noncerebral malaria from the Brazilian Amazon.

Twenty-three different and previously unreported deduced amino acid sequences were obtained from parasites obtained of these patients. Significantly, all the patients with severe malaria harbored predominantly expressed PfEMP1 DBL1 $\alpha$ sequences displaying a region lacking 1-2 cysteine residues that sub-grouped them in clustal alignments. This sub-group was maintained when a similar analysis was performed using expressed sequences obtained from parasites of patients with mild malaria and sequences from this same var gene segment of isolates from Sudan available at GenBank. High-density filters representing genomic var DBL $1 \alpha$ sequences of parasites obtained from 80 patients with mild malaria from four different regions in the Brazilian Amazon, revealed that these sequences are widely distributed; yet, they are predominantly expressed in patients with severe non-cerebral malaria. This is the first report demonstrating an association of severe non-cerebral malaria in patients from Brazil and particular PfEMP1 DBL1 $\alpha$ sequences.

The results and conclusions withdraw from this study were based on parasite material obtained from six patients diagnosed with severe non-cerebral falciparum malaria. To identify these patients, we surveyed the clinical histories of 1599 patients with falciparum malaria kept at the Núcleo de Estudos em Malária da Superintendência de Controle de Endemias do Estado de São Paulo, Brasil (SUCEN) from 1987-2000. This laboratory is responsible for the diagnosis and treatment of all reported malaria cases in the city of São Paulo, a Brazilian non-endemic region. Most telling, it holds the highest number of clinical records of patients with severe malaria in Brazil. In spite of this logistics, we were able to identify only six patients with the criteria determined by WHO to diagnose severe malaria. In addition to these criteria, we also demonstrated higher than normal PCT serum levels in four of these patients; this new parameter has been recently proposed to correlate with disease severity and risk of mortality in malaria (22). These numbers thus accurately reflect the scarcity of patients with severe malaria in Brazil and reinforce the biological value of the data obtained in this study.

It is now well established that there is relaxed transcription of most if not all var genes during ring stages. Thus, even with highly purified samples containing mostly trophozoite and schizonts used in the RNA extractions, we cannot exclude the possibility of minor contaminations with ring stages. Moreover, malarial infections are not clonal even in regions of low endemicity. Therefore it was not surprising to identify different var DBL1 $\alpha$ transcripts in parasites obtained from all the patients that participated of this study. Remarkably however, there were predominantly expressed PfEMP1 DBL1 $\alpha$ sequences in all parasites obtained from the six patients with severe malaria. Moreover, these sequences displayed a common region lacking 1-2 cysteine residues towards their C-termini that allowed them to be sub-grouped in dendogram analysis. To validate this result, we performed a similar analysis including expressed DBL1 $\alpha$ sequences of parasites from patients with mild malaria and DBL1 $\alpha$ sequences from this same gene segment from isolates of Sudan available at GenBank. Although the sequences of two clones from two patients with mild malaria lacked these cysteine residues, they represented only one out of 14 clones sequenced from each patient. Similarly, one sequence from Sudan also subgrouped in this analysis; unfortunately, we have no idea on the clinical status of this patient or whether this sequence is expressed. Regardless, these data demonstrate that patients with mild malaria predominantly expressed DBL1 $\alpha$ domains having all 4 cysteine residues in this region of the domain. In contrast, patients with severe non-cerebral malaria harbor parasite populations predominantly expressing DBL1 $\alpha$ domains lacking 1-2 cysteine residues. In fact, patient G3 at the moment of having severe malaria had predominant DBL1 $\alpha$ sequences lacking 2 cysteine residues whereas 20 days later at a recrudescence with mild malaria the 
predominant DBL1 $\alpha$ sequences displayed 4 cysteine residues. It is thus tempting to speculate that a different folding of these domains confer the parasite populations expressing them different degrees of virulence and reinforce the importance of PfEMP1 domain folding in the pathology associated with malaria.

Two main phenomena have been associated with severe malaria: cytoadherence and rosetting. Of them, rosetting has been unequivocally demonstrated to be associated with particular sequences of the PfEMP1 DBL1 $\alpha$ domain $(12,13,14,15)$. Here, we demonstrated that a DBL1 $\alpha$ domain representing the most abundantly expressed PfEMP1 DBL1 $\alpha$ sequence from one of the patients with severe falciparum malaria expressed in bacteria, bind to erythrocytes. This result, thus, suggest an association of rosetting with severe non-cerebral falciparum malaria reported in these Brazilian patients. Unfortunately, there are no reports of rosetting from Brazil and clearly more studies are required to validate this association

A recent study has demonstrated the association of severe malaria with a particular var DBL $\delta$ sequences in patients from French Guiana (20). Together with the studies reported here, these data indicate that there are indeed associations of severe malaria with particular PfEMP1 sequences. However, in addition to the var multigene family, many other multigene families such as rif, stevor, clag and pf60, likely involved in virulence, have been discovered in P. falciparum (rev. in 34). High throughput methodologies can now be envisioned to discover and compare the repertoire of genomic and expressed virulent genes circulating in endemic regions with particular clinical syndromes of severe malaria. These data in turn should help in elucidating the molecular mechanisms underlying the different clinical manifestations to develop rationale alternative eradication control strategies.

\section{Acknowledgements}

We thank Dr. Alex Fiorini Carvalho and Dr. Luiz Fernando Lima Reis (Institute Ludwig) for facilitating the use of robotics to spot the filters. We thank Drs. Marcelo Urbano Ferreira and Crispim Cerutti Jr for some samples from patients with mild malaria, Dr. Emilia Kimura for the anti-human erythrocyte polyclonal mouse antibody and Dr. Silvia Reni Uliana for the Meta1-His protein. This work received support from the INCO-DC Programme (IC18CT98-0364).

\section{References}

1. Miller LH, Good MF, Milon G. (1994) Malaria pathogenesis. Science 264: 1878-1883.

2. Su XZ, Heatwole VM, Wertheimer SP, et al. (1995) The large diverse gene family var encodes proteins involved in cytoadherence and antigenic variation of Plasmodium falciparum-infected erythrocytes. Cell 82: 89100.

3. Cooke B, Coppel R, Wahlgren M. (2000) Falciparum malaria: sticking up, standing out and out-standing. Parasitol. Today 16: 416420.

4. Handunnetti SM, David PH, Perera KL, Mendis KN. (1989) Uninfected erythrocytes form "rosettes" around Plasmodium falciparum infected erythrocytes. Am. J. Trop. Med. Hyg. 40: 115-118.

5. MacPherson GG, Warrell MJ, White NJ, Looareesuwan S, Warrell DA. (1985) Human cerebral malaria. A quantitative ultrastructural analysis of parasitized erythrocyte sequestration. Am. J. Pathol. 119: 385-401.

6. Aikawa M. (1988) Human cerebral malaria. Am. J. Trop. Med. Hyg. 39: 3-10.

7. Carlson J, Helmby H, Hill AV, Brewster D, Greenwood BM, Wahlgren M. (1990) Human cerebral malaria: association with erythrocyte rosetting and lack of anti-rosetting antibodies. Lancet 336: 1457-1460.

8. Pongponratn E, Riganti M, Punpoowong B, Aikawa M. (1991) Microvascular sequestration of parasitized erythrocytes in human falciparum malaria: a pathological study. Am. J. Trop. Med. Hyg. 44: 168-175.

9. Treutiger CJ, Hedlund I, Helmby H, et al. (1992) Rosette formation in Plasmodium falciparum isolates and anti-rosette activity of sera from Gambians with cerebral or uncomplicated malaria. Am. J. Trop. Med. Hyg. 46: 503-510.

10. Rowe A, Obeiro J, Newbold CI, Marsh K. (1995) Plasmodium falciparum rosetting is associated with malaria severity in Kenya. Infect. Immun. 63: 2323-2326.

11. Newbold C, Warn P, Black G, et al. (1997) Receptor-specific adhesion and clinical disease in Plasmodium falciparum. Am. J. Trop. Med. 
Hyg. 57: 389-398.

12. Rowe JA, Moulds JM, Newbold CI, Miller LH. (1997) P. falciparum rosetting mediated by a parasite-variant erythrocyte membrane protein and complement-receptor 1. Nature 388: 292295.

13. Chen Q, Barragan A, Fernandez V, et al. (1998) Identification of Plasmodium falciparum erythrocyte membrane protein 1 (PfEMP1) as the rosetting ligand of the malaria parasite P. falciparum. J. Exp. Med. 187: 1523.

14. Chen Q, Heddini A, Barragan A, Fernandez V, Pearce SF, Wahlgren M. (2000) The semiconserved head structure of Plasmodium falciparum erythrocyte membrane protein 1 mediates binding to multiple independent host receptors. J. Exp. Med. 192: 1-10.

15. Barragan A, Fernandez V, Chen Q, von Euler A, Wahlgren M, Spillmann D. (2000) The duffy-binding-like domain 1 of Plasmodium falciparum erythrocyte membrane protein 1 (PfEMP1) is a heparan sulfate ligand that requires 12 mers for binding. Blood 95: 35943599.

16. WHO. (2000) Severe falciparum malaria. Trans. R. Soc. Trop. Med. Hyg. 94 Suppl 1: S1-S90.

17. Duarte MI, Corbett CE, Boulos M, Amato Neto V. (1985) Ultrastructure of the lung in falciparum malaria. Am. J. Trop. Med. Hyg. 34: 31-35.

18. Corbett CE, Duarte MI, Lancellotti CL, Silva MA, Andrade Junior HF. (1989) Cytoadherence in human falciparum malaria as a cause of respiratory distress. J. Trop. Med. Hyg. 92: 112-120.

19. Boulos M. (1992) Clinical picture of severe malaria. Rev. Inst. Med. Trop. Sao Paulo 34 Suppl 9: S41-S42.

20. Ariey F, Hommel D, Le Scanf C, et al. (2001) Association of severe malaria with a specific Plasmodium falciparum genotype in French Guiana. J. Infect. Dis. 184: 237-241.

21. Kirchgatter K, Mosbach R, del Portillo HA. (2000) Plasmodium falciparum: DBL-1 var sequence analysis in field isolates from central Brazil. Exp. Parasitol. 95: 154-157.

22. Chiwakata CB, Manegold C, Bonicke L, Waase I, Julch C, Dietrich M. (2001) Procalcitonin as a parameter of disease severity and risk of mortality in patients with
Plasmodium falciparum malaria. J. Infect. Dis. 183: 1161-1164.

23. Trager W, Jensen JB. (1976) Human malaria parasites in continuous culture. Science 193: 673-675.

24. Pasvol G, Wilson RJ, Smalley ME, Brown J. (1978) Separation of viable schizont-infected red cells of Plasmodium falciparum from human blood. Ann. Trop. Med. Parasitol. 72: 87-88.

25. Ferreira MU, Liu Q, Kaneko O, et al. (1998) Allelic diversity at the merozoite surface protein-1 locus of Plasmodium falciparum in clinical isolates from the southwestern Brazilian Amazon. Am. J. Trop. Med. Hyg. 59: 474-480.

26. Kyes S, Pinches R, Newbold C. (2000) A simple RNA analysis method shows var and rif multigene family expression patterns in Plasmodium falciparum. Mol. Biochem. Parasitol. 105: 311-315.

27. Taylor HM, Kyes SA, Harris D, Kriek N, Newbold CI. (2000) A study of var gene transcription in vitro using universal var gene primers. Mol. Biochem. Parasitol. 105: 13-23.

28. Boyle JS, Lew AM. (1995) An inexpensive alternative to glassmilk for DNA purification. Trends Genet. 11: 8.

29. Altschul SF, Madden TL, Schaffer AA, et al. (1997) Gapped BLAST and PSI-BLAST: a new generation of protein database search programs. Nucleic Acids Res. 25: 3389-3402.

30. Thompson JD, Gibson TJ, Plewniak F, Jeanmougin F, Higgins DG. (1997) The CLUSTAL_X windows interface: flexible strategies for multiple sequence alignment aided by quality analysis tools. Nucleic Acids Res. 25: 4876-4882.

31. Posada D, Crandall KA. (1998) MODELTEST: testing the model of DNA substitution. Bioinformatics 14: 817-818.

32. Strimmer K, von Haeseler A. (1996) Quartet Puzzling: A Quartet Maximum-Likelihood Method for Reconstructing Tree Topologies. Mol. Biol. Evol. 13: 964-969.

33. Swofford DL. (1998) PAUP*. Phylogenetic Analysis Using Parsimony (*and Other Methods). Version 4, Sunderland, Massachusetts.

34. Kyes S, Horrocks P, Newbold C. (2001) Antigenic variation at the infected red cell surface in malaria. Annu. Rev. Microbiol. 55: 673-707. 
9. ANEXO 3 


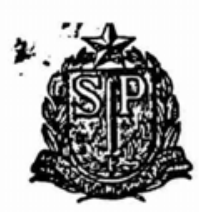

SECRETARIA DE ESTADO DA SAUDE

SUPERINTENDÊNCIA DE CONTROLE DE ENDEMIAS

S UCEN

FICHA No $913-87$

DIRETORIA DE COMBATE A VETORES

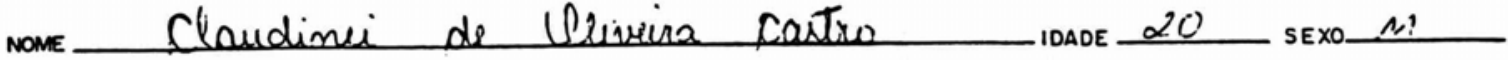

RESPONSÁvER

RESIDÊNCIA

CEP INV. EPIO. №

MUNICIPIO

TELEFONE

EXAME DE S A NGUE

PESQUISA E CONTAGEM DE PLASMÓ́IOS

\begin{tabular}{|c|c|c|c|c|c|c|c|}
\hline \multirow{3}{*}{ DATA } & \multicolumn{6}{|c|}{ FORMAS POR $\mathrm{mm}^{3}$} & \multirow{3}{*}{ MICROS COPISTA } \\
\hline & \multicolumn{2}{|c|}{ P. VIVAX } & \multicolumn{2}{|c|}{ P. FALCIPARUM } & \multicolumn{2}{|c|}{ P. MALARIAE } & \\
\hline & \begin{tabular}{|l|} 
F. ASSE XUADOS \\
\end{tabular} & GAMETCCROS & E,ASSEXuADOS & GAMETOCarTOS & E.ASSSXUADOS & Gamstocitos & \\
\hline 0311.72 & & & Imrontoss & is $(\mathrm{amm}$ & $a x_{2}+u=a$ & . & phlina \\
\hline $2^{\prime} \cdot 187$ & & & Incontais & is & - & & Déianse \\
\hline $06 . \overline{11.87}$ & & & 12.360 & & & & CHRISTINA \\
\hline $0911: 2$ & & & - & 240 & & & araices \\
\hline & & & & & & & \\
\hline & & & & & & & \\
\hline & & & & & & & \\
\hline & & & & & & & \\
\hline -......... & & & & & & & \\
\hline
\end{tabular}

ESQUEMA DE TRATAMENTO

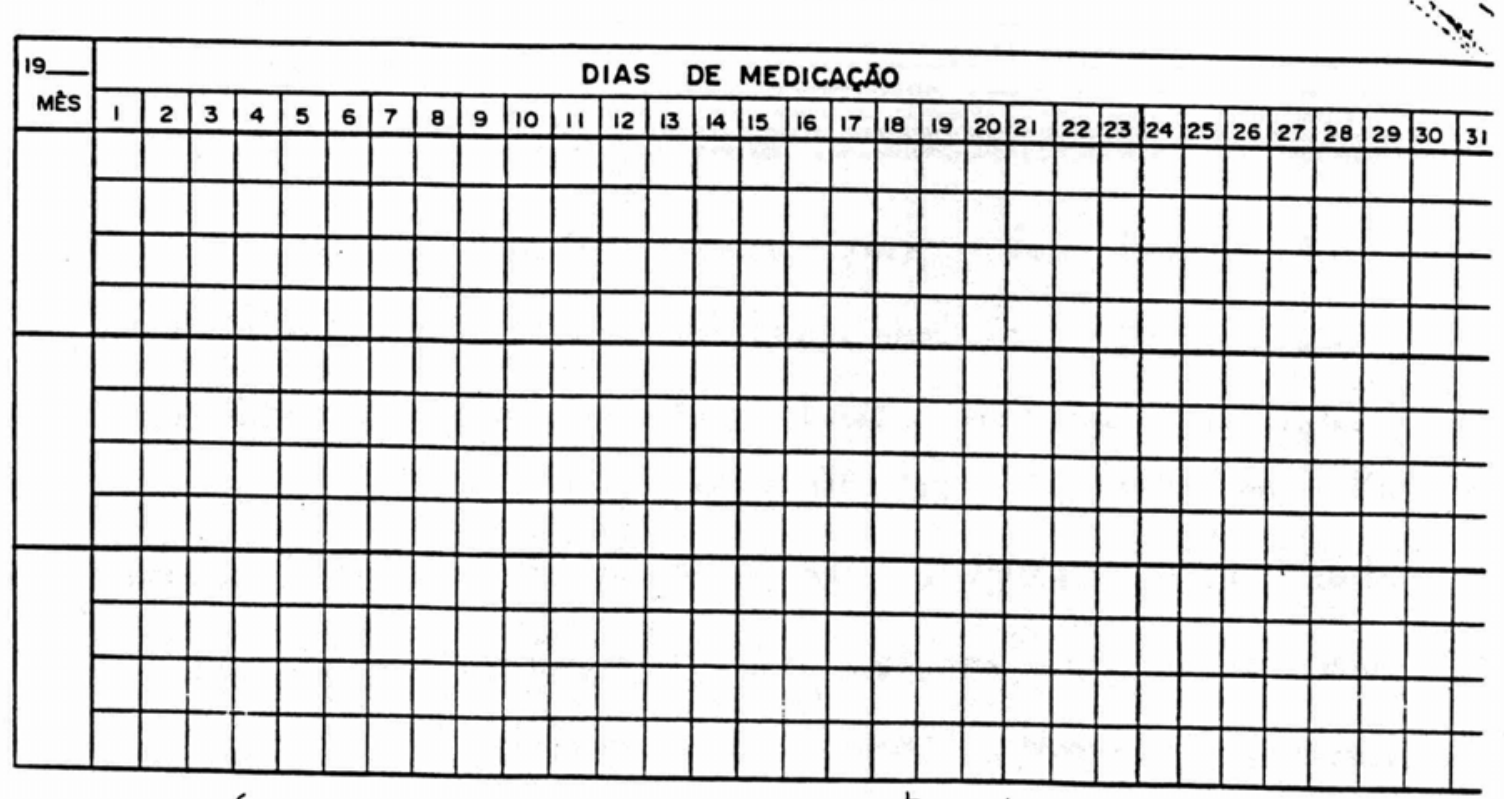

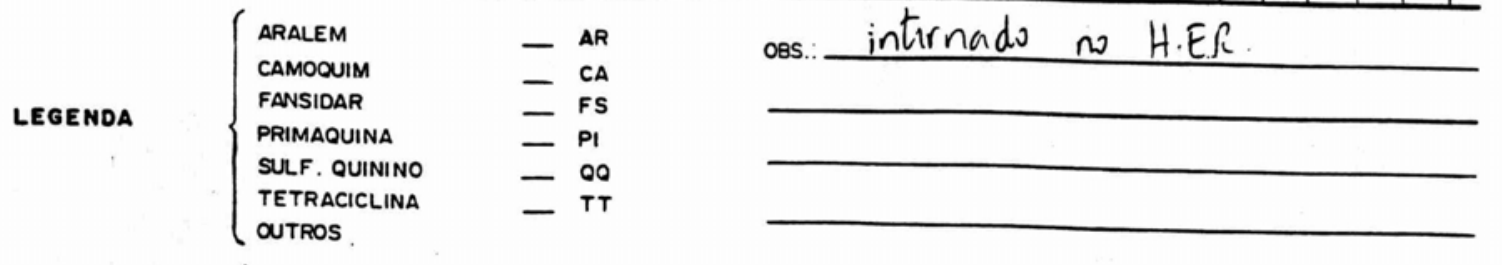




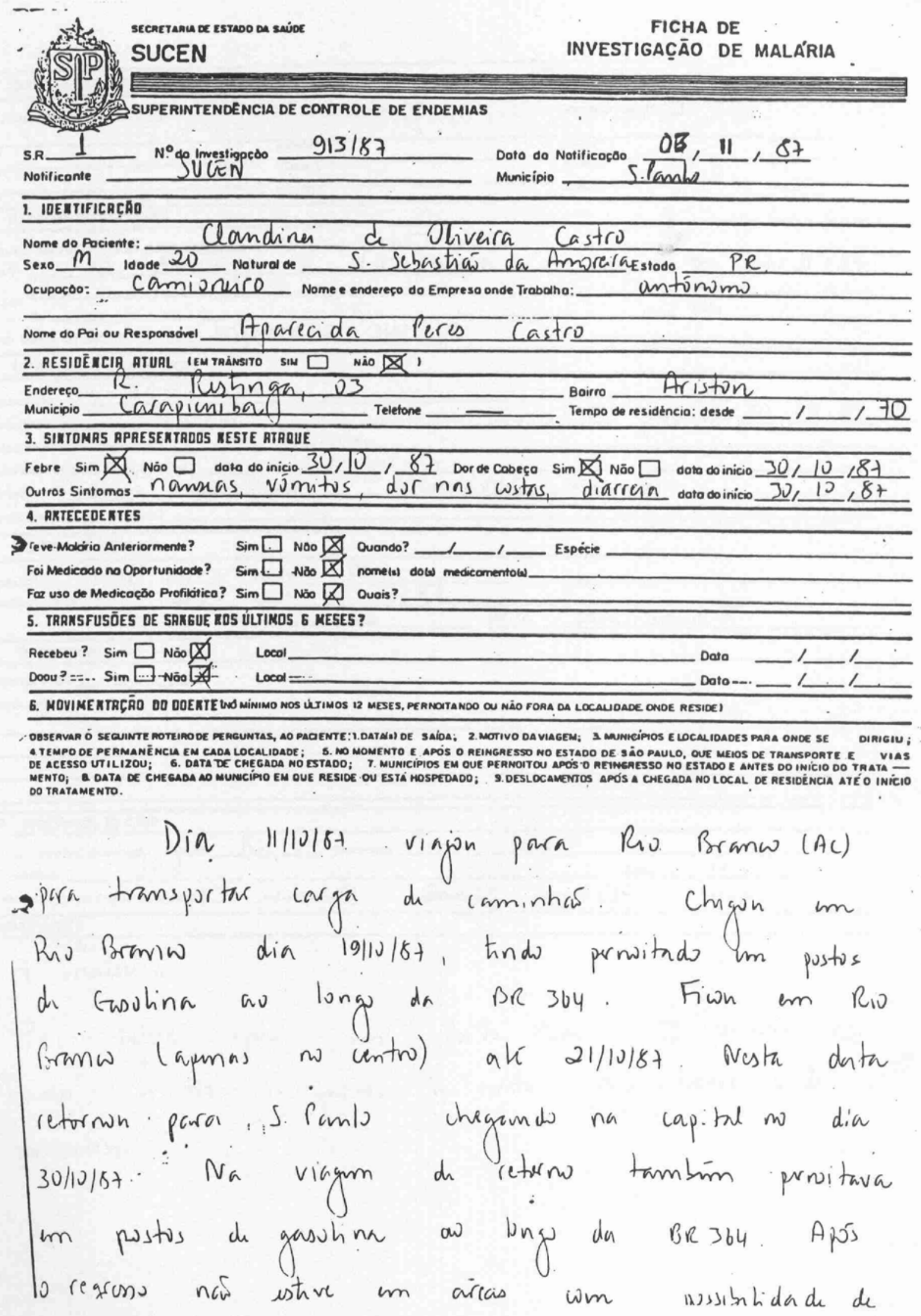




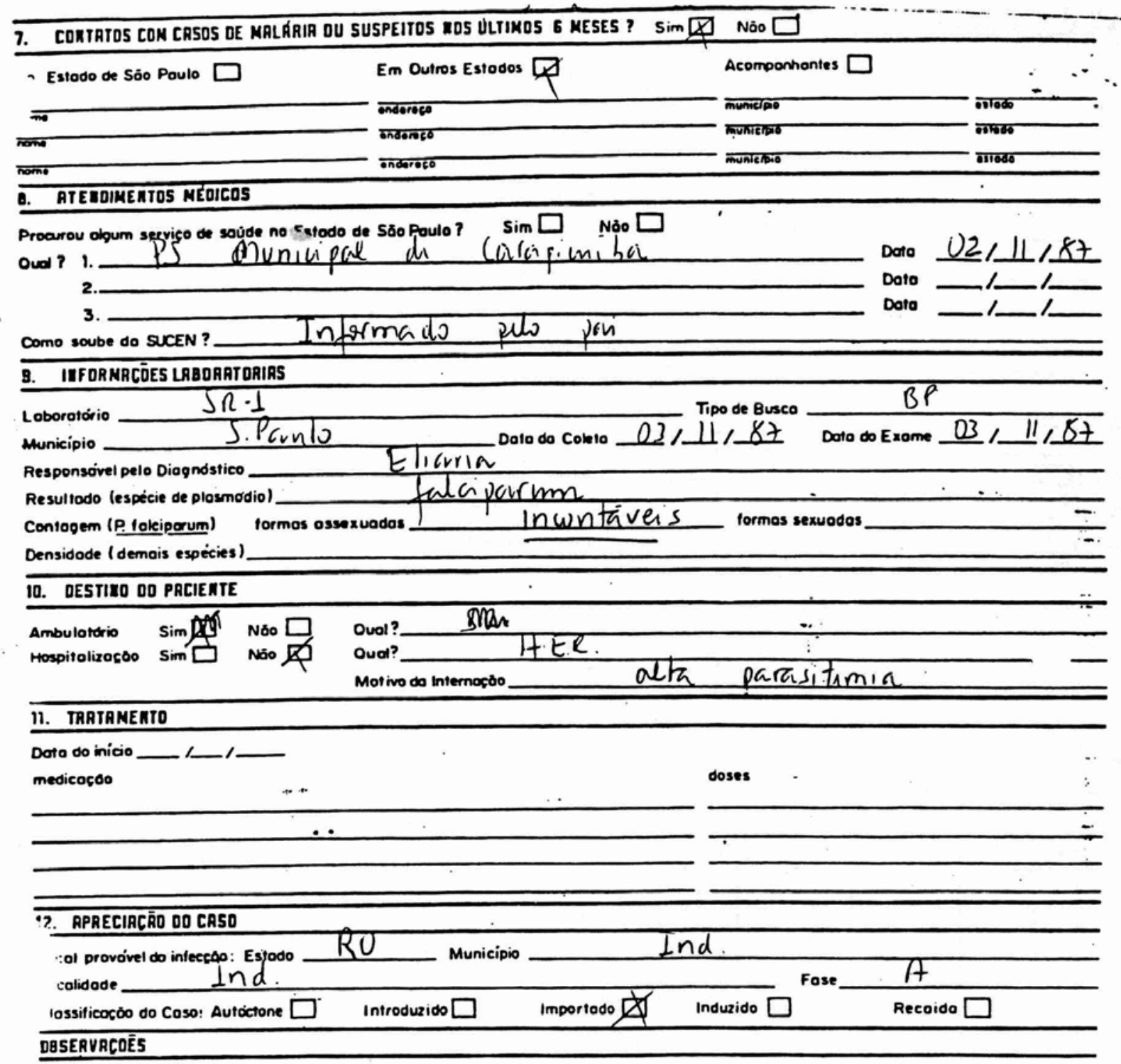

$$
\text { 1. malcúria }
$$

Pac. refere que un Porto Vecto a Ji parami (ros) havia moitos musgnitos, a noite ros locais onde pernoitin 
SECRETARIA DE ESTADO DA SAUDE

\section{SUPERINTENDÊNCIA DE CONTROLE DE ENDEMIAS}

S UCEN

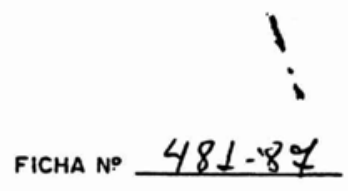

DIRETORIA DE COMBATE A VETORES

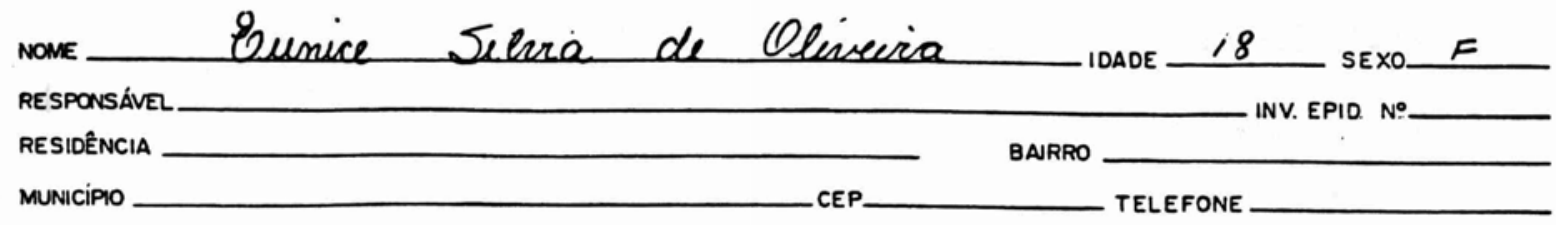

EXAME DE S A N G UE

PESOUISA E CONTAGEM de PLASMÓdIOS

\begin{tabular}{|c|c|c|c|c|c|c|c|}
\hline \multirow{3}{*}{ DATA } & \multicolumn{6}{|c|}{ FORMAS POR $\mathrm{mm}^{3}$} & \multirow{3}{*}{ MICROS COPISTA } \\
\hline & \multicolumn{2}{|c|}{ P. VIVAX } & \multicolumn{2}{|c|}{ P. FALCIPARUM } & \multicolumn{2}{|c|}{ P. MALARIAE } & \\
\hline & F. ASSEXVADOS & GAMETOCIOS & E.ASSEXWADOS & GAMETOCITOS & E.ASSEXUADOS & GMAETOGITOS & \\
\hline 22.06 .87 & & & Incentán & ens & & & Bhana \\
\hline 23.0687 & & & 26.880 & & & & Eliana \\
\hline $2,26.87$ & & & meg & 480 & & & Blsana \\
\hline 2906.87 & & & mog & 360 & & & Sleana \\
\hline & & & $\delta$ & & & & \\
\hline & & & & & & & \\
\hline & & & & & & & \\
\hline ewion & 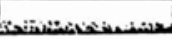 & & $\ldots$ & & & & \\
\hline
\end{tabular}

ESQUEMA DE TRATAMENTO

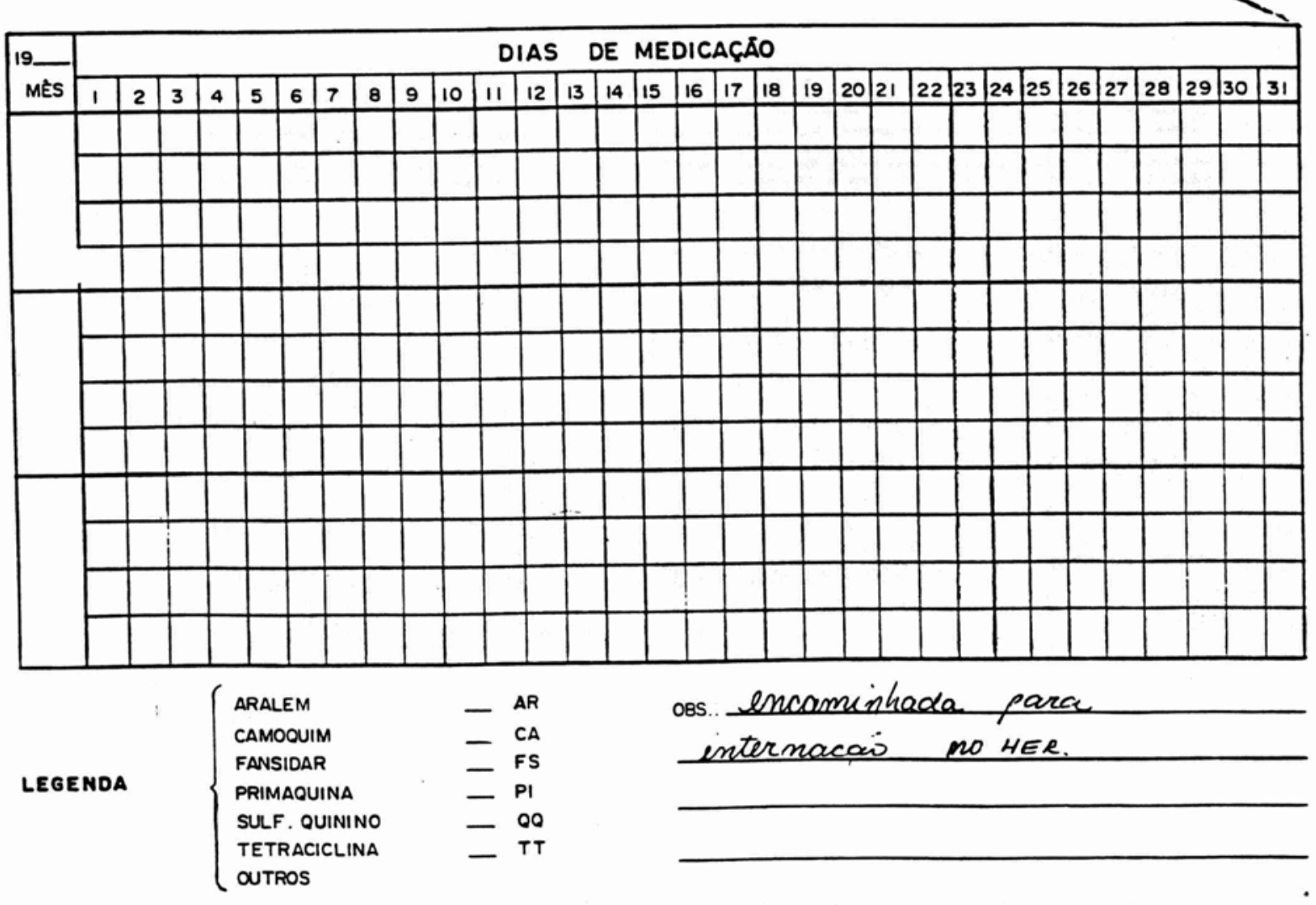




Nome do pocionte: Bunice selvia de Glineira

Sexo_f 1000019 Noturol on S.Paulo. Estodo SP

Ocuposoo: Dona de Casa Nome enderego da Empresa onde Trobsha:____ -

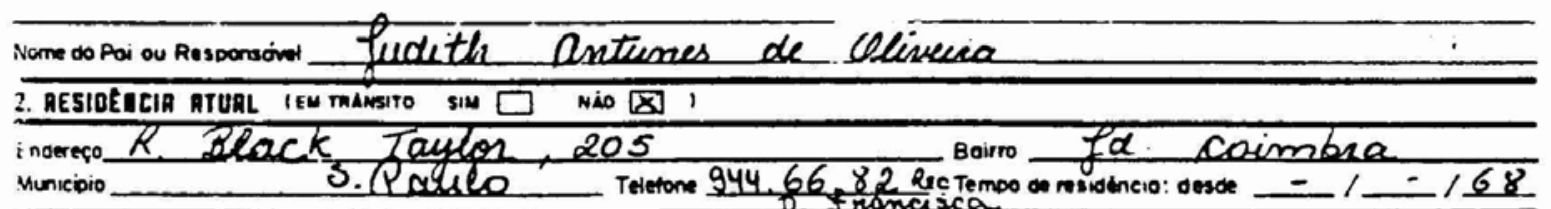

SIITOMA5 RPRESENTROOS IESTE TTRQUE

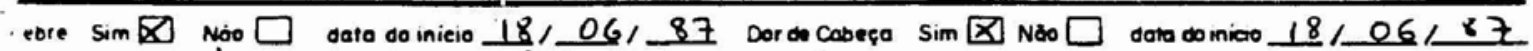
iutros sintomos dores no corpo, ind geral máuseas do dinico $18,06 / 87$

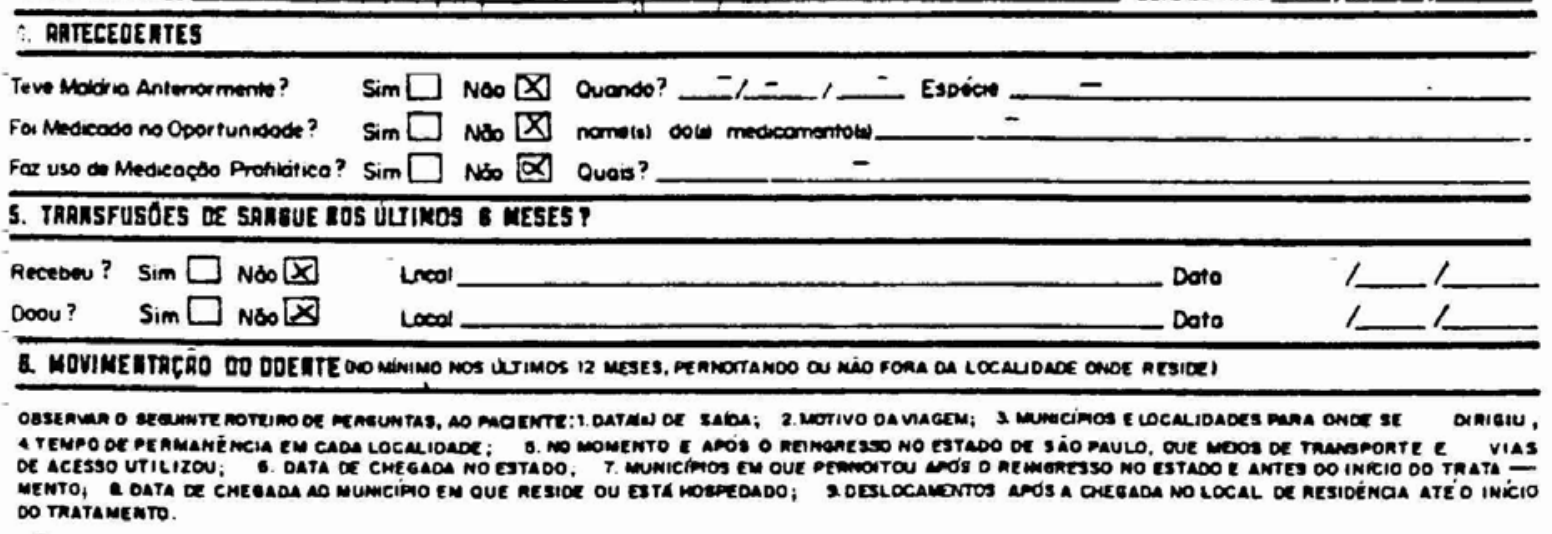

Reside em S.Paulo desce $1968 \mathrm{e}$ em 08.04 .87 viajou para Porto Nelho (Ro), no $\mathrm{km} 620 \mathrm{da}$ BR. 364, para visitar - marido lo fitho que la' residem, cheganao dia 11.04.87.

Permanecer maquela localidace ati dia 06.06 .87 quand retormou para S.Paulo, direto de ônibus, porque ceque reside, chegando dia 09.06.87.

Pesde que dugou nóo teve dulocamentos por areas com possibilidade de transmisaio. 


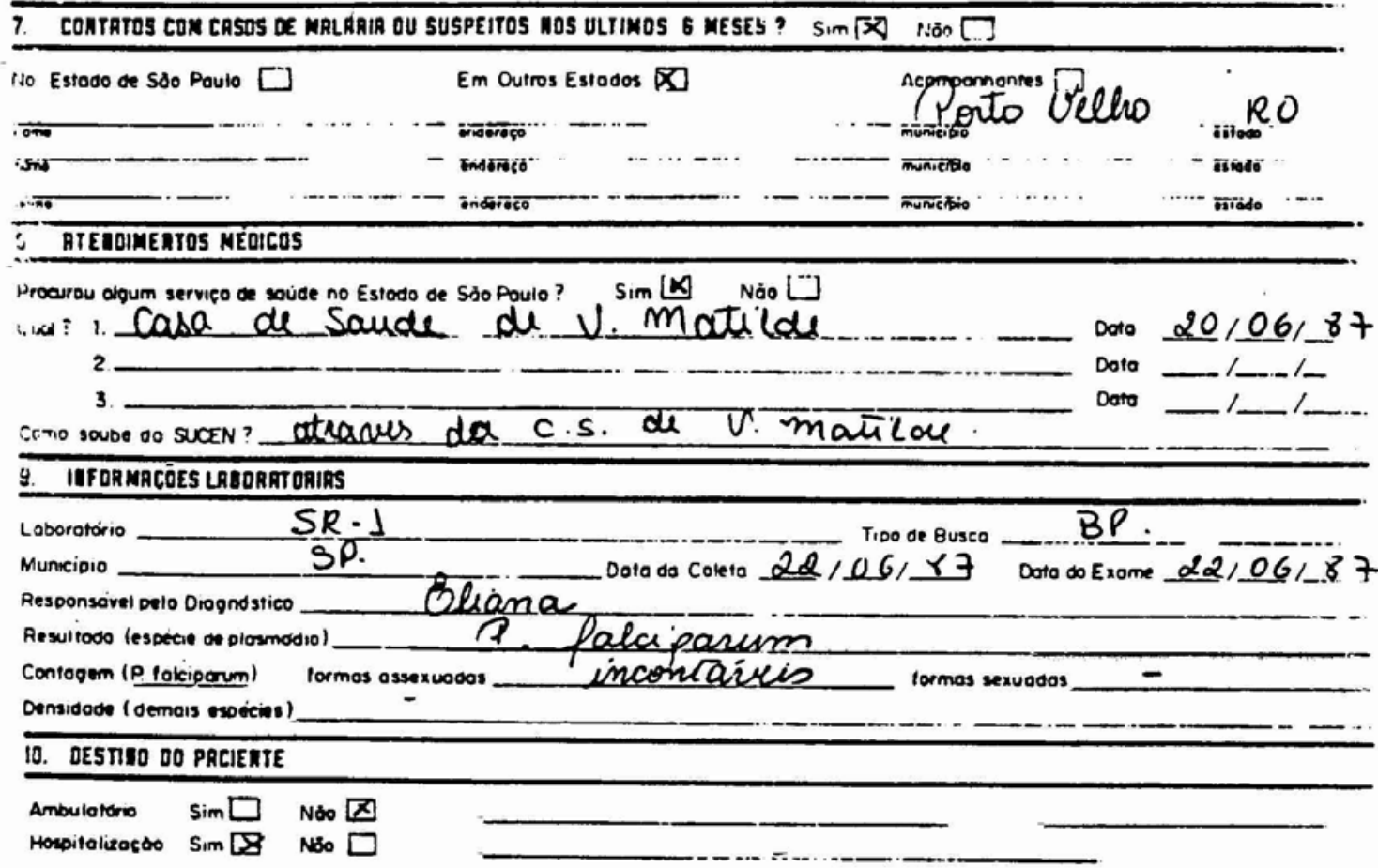

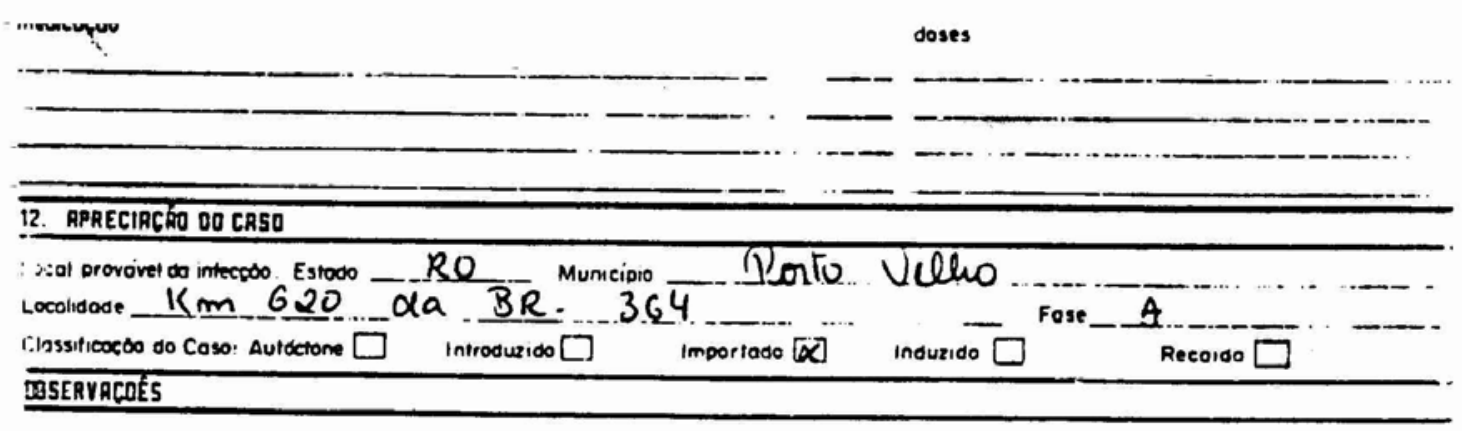

- 1a malairia

- Fa Vacinur en abril/87 em Villena (Ro)

Bliana Schnerder. - Tec lab Luit C. Barata


SECRETARIA DE ESTADO DA SAUDE

SUPERINTENDÊNCIA DE CONTROLE DE ENDEMIAS S UCEN

DIRETORIA DE COMBATE A VETORES

DEME

EXAME DE S A NG UE

pesouisa e contagem de pLASHódios

\begin{tabular}{|c|c|c|c|c|c|c|c|}
\hline \multirow{3}{*}{ DATA } & \multicolumn{6}{|c|}{ FORMAS POR $\mathrm{mm}^{3}$} & \multirow[b]{2}{*}{ MICROS COPISTA } \\
\hline & \multicolumn{2}{|c|}{ P. VIVAX } & \multicolumn{2}{|c|}{ P. FALCIPARUM } & \multicolumn{2}{|c|}{ P. MALARIAE } & \\
\hline & F. ASSEXUAOOS & SAM & F.ASSEXUADOS & GAMETocitos & E. ASSExunODS & GMuErocitos & 6 \\
\hline 89 & mig & meg & Incontávis & & & & in leana \\
\hline 24.8 .59 & net & meds & 42.720 & 480 & & & CHRISTINA \\
\hline 26.08 .89 & Mlg & meg & 3120 & 120 & & & Slebna \\
\hline 28.08 .89 & meta & meg & 480 & 120 & & & Golinasa \\
\hline 11.9 .89 & megl & -28 & mes & mes & & & CHRISTINA \\
\hline 2509.89 & meg & - & meg & - & & & thana \\
\hline $25 \cdot 10-89$ & mok & - & mest & - & & & CHRISTINA \\
\hline & & - & & & & & \\
\hline
\end{tabular}

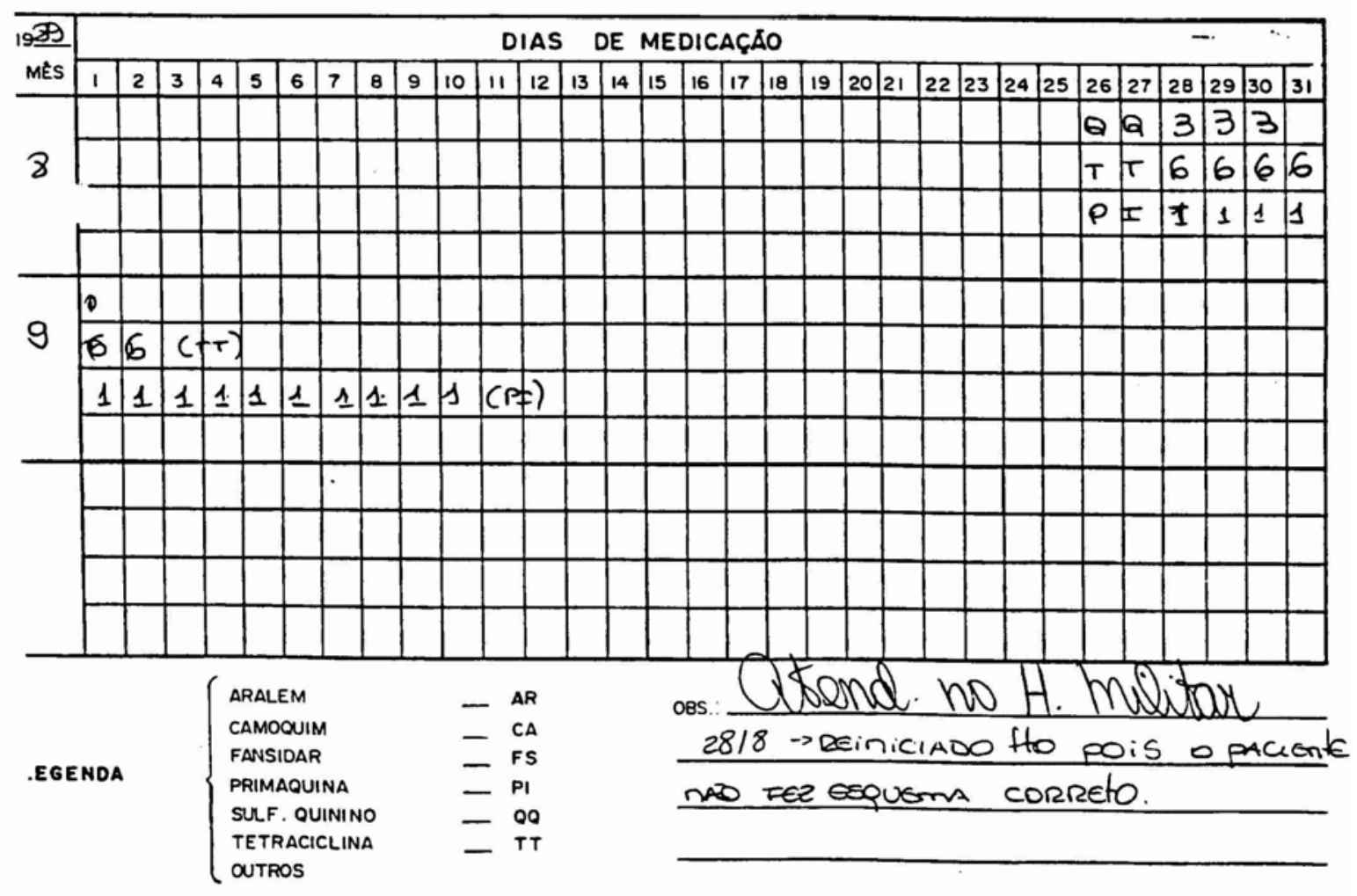


Sechetania de Estadoo on sacioe

SUCEN

SUPERINTEMOENCIA DE CONTROLE DE ENDEMIAS

FICHA DE INVESTIGAÇÃO DE MALATRIA

\section{I- IDENTIFICAÇĀO DA FICHA}

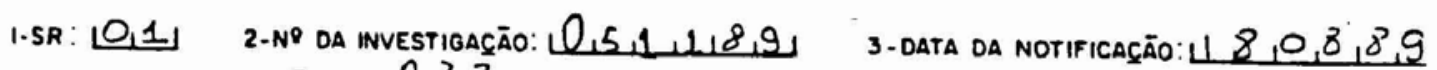
4. semana epidemiológica: $0,3,3$,

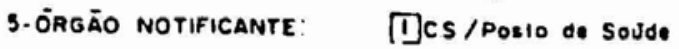
[2] Médico Porticular
XJPronto Socorro/Hospltol

I
6-TIPO DE BUSCA:
एबP
[2] BA Rolino
[3]BA FoCO

II-IDENTIFICACÃ̃o DO PACIENTE

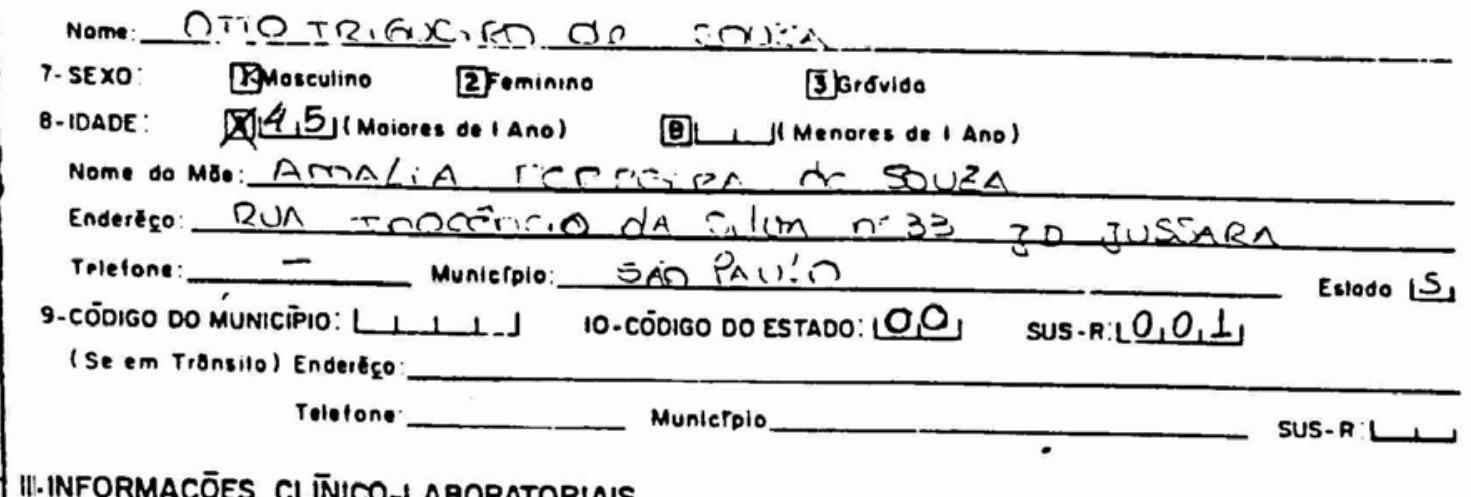

III. INFORMAC̄ŌES CLINIICO-LABORATORIAIS

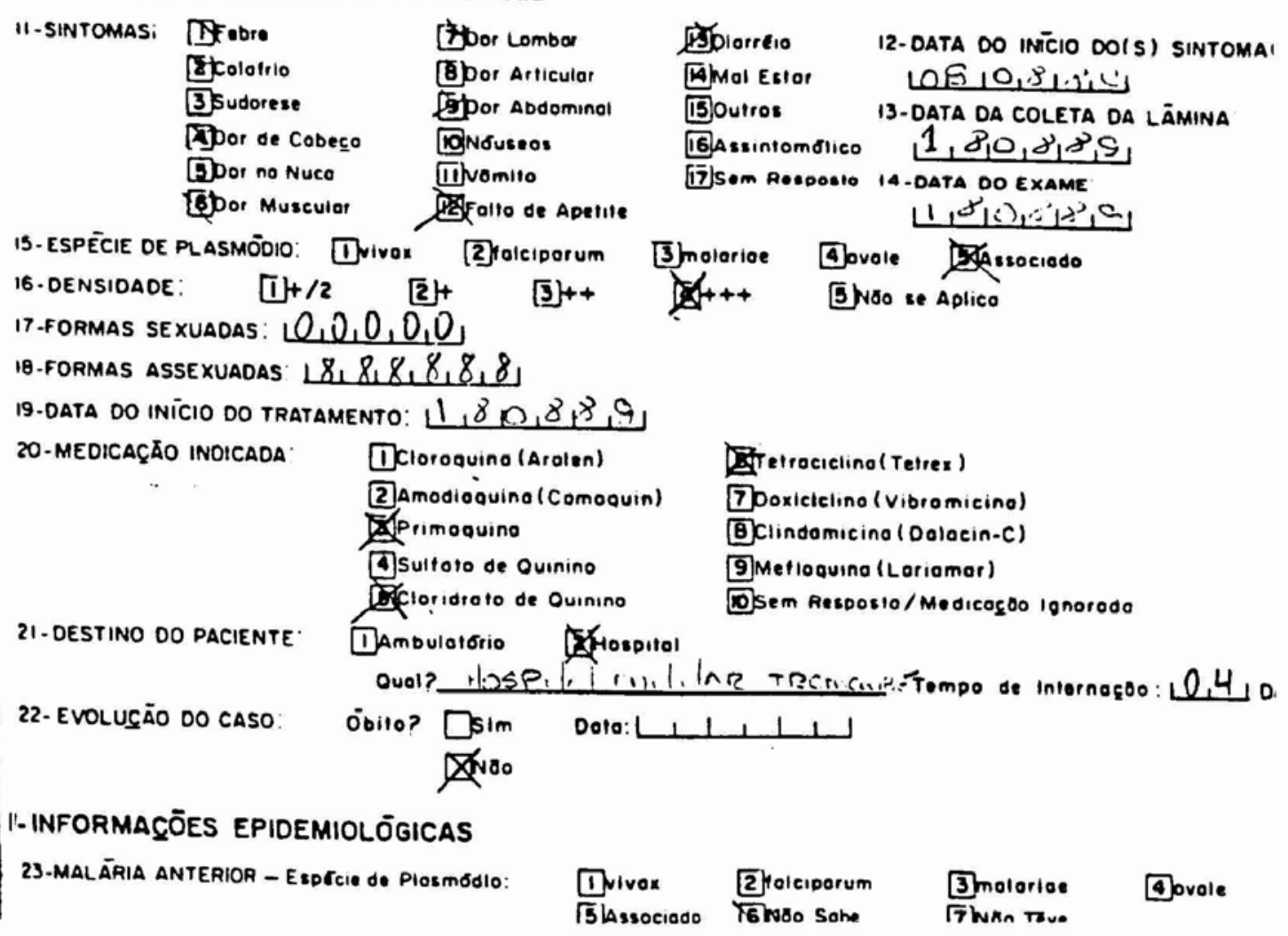


26-MEDIDAS PROFILATTICAS UTILIZADAS DURANTE O PERIODO DE EXPOSIC̄ĀO Quols?

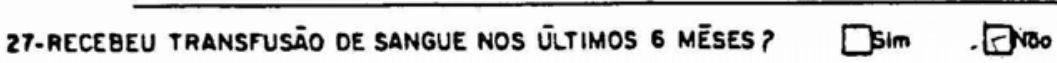
Ondo? " Doto: Doto:

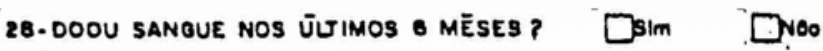
Onde?

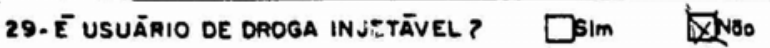

30-MOtivo do deslocamento para a ĀRea de EXPOsicao ä doEnça:
Serviço
[4] ozor
[2]A Procuro de Trabaino
3) ixor Rezidincio
ENAOO IO Aplice (N80 en Dostocou)
[6utro Motivo: 1

31-MOTIVO DO DESLOCAMENTO PARA O ESTADO DE SĀO PAULO:

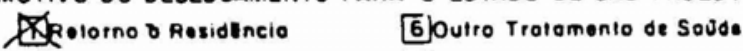

[2] Fixar Residineio

7.0zor

5. Sh Sorviço

ENoo se Aplico(NAO so Dosiocou)

4A Procuro de Trabaino

gOutro Molivo:

ETrotomento de Molorio

32-SETOR OU SUB-SETOR OE ATIVIDADE ECONŌMICA ONDE ESTĀ INSERIOA A OCUPAÇĀO DESEMPENHADA PELL PAO

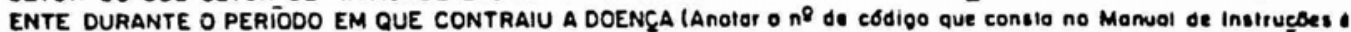
Preenchimentol.

Ocupoçdo merzGiJi:ir.vor

33-POSIÇĀO NA OĆUPAÇĀO: Tु robalnodor por Conto Próprio

\section{通improgiodo Temporório}

[SEmpregodo Permonanie

Codigo do Selor ou Sub-entor $\perp^{9}$

34-manteVE CONTATO COM SUSPEITOS de MALĀRIA NO ESTAdO de SĀo PAULO?
(1) $\sin \frac{1}{\text { nome enderkeco }}$

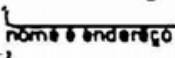
inme ender
[2] 通Noo Sobo

35.SERVICOS DE SAŨDE PROCURADOS NO ESTADO (Anteriorea a Notificocilo do Coso) ,

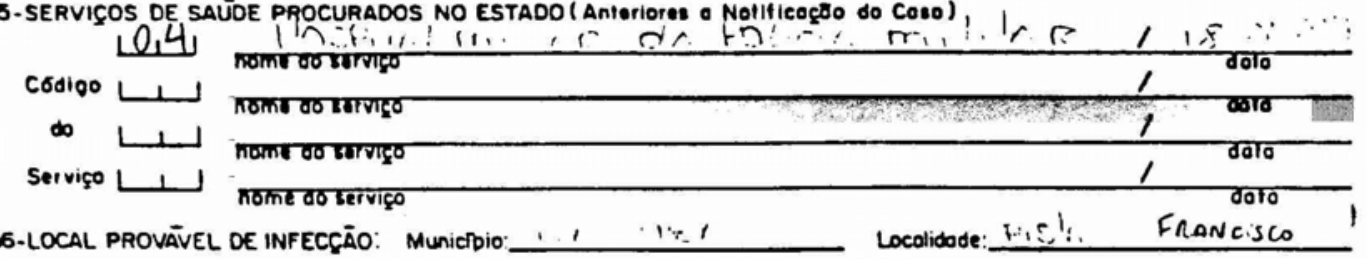

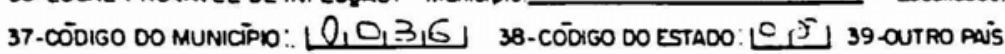

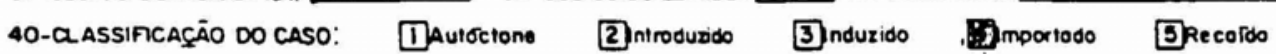

TEXTO: (Consuller o Monuol de Instruçoses de Preenchimento)

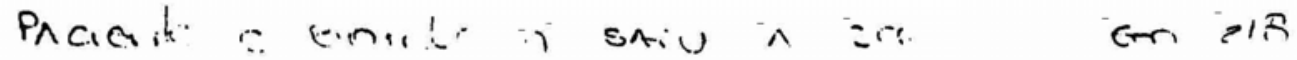

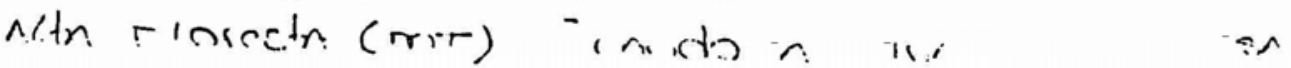

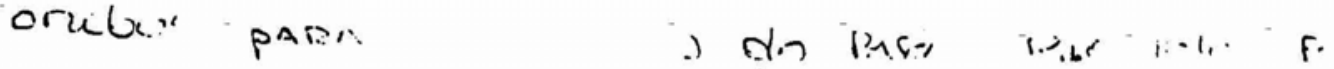

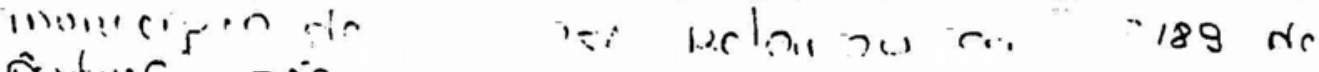

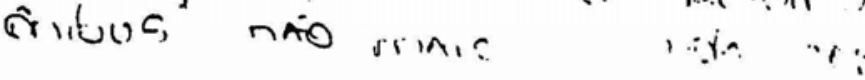

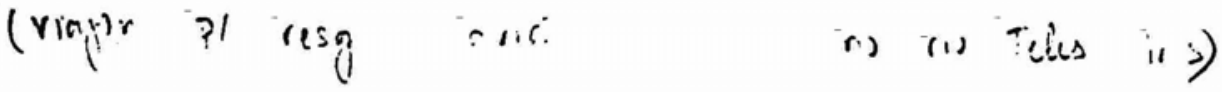




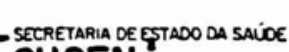
SUCEN

SUPERINTENOENCA DE CONTROL DEENOEMUNS

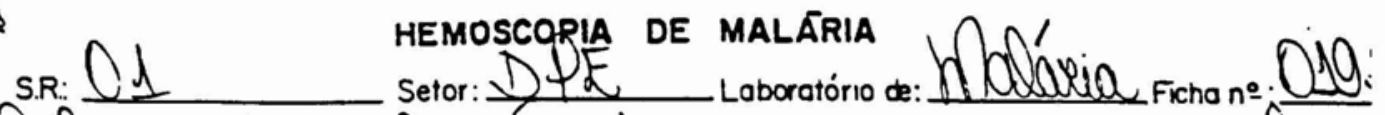

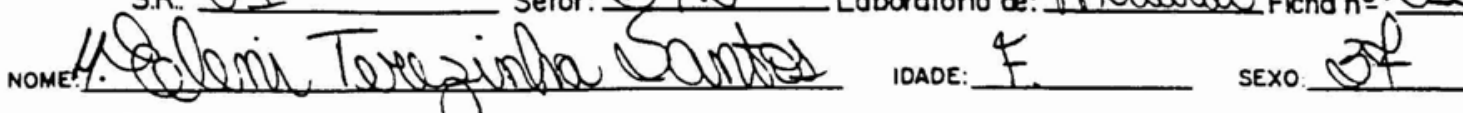
RESPONSĀVEL: U

RESIDËNCIA BAIRRO:

MUNICIPIO

CEP INV. EPID. NQ:

\section{PESOUISA E CONTAGEM DE PLASMŌDIOS} TELEFONE:

\begin{tabular}{|c|c|c|c|c|c|c|c|}
\hline \multirow{3}{*}{ DATA } & \multicolumn{6}{|c|}{ FORMAS POR $\mathrm{mm}^{3}$} & \multirow{3}{*}{ REALIZADO PO } \\
\hline & \multicolumn{2}{|c|}{ P. VIVAX } & \multicolumn{2}{|c|}{ P. FALCIPARUM } & \multicolumn{2}{|c|}{ OUTROS } & \\
\hline & FASSEXUAOAS & GAMETOCITOS & TS ASSEXYADAS & 1. GAMETACTOS & F ASSEXUADAS & GAMETOCITOS & \\
\hline & 1 & & Mastwas & Q1) 2 स्य & & & Sinvils \\
\hline & 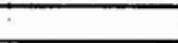 & 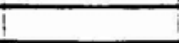 & 8 वी० & 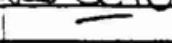 & 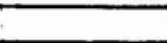 & & v \\
\hline 23 & 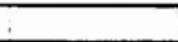 & $T$ & vol. & - & 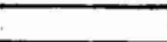 & - & colve \\
\hline प्री? & I & T & noa. & - & 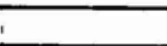 & & suted \\
\hline $28-1.93$ & + & I & meds & - & $t$ & & CHRISTINA \\
\hline $09-02.93$ & & t & meas & - & I & & ICHRISTINA \\
\hline $25-2-93$ & & i & nea & - & $i$ & & CARISTINA \\
\hline & & $T$ & 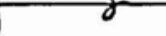 & & 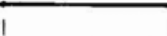 & & \\
\hline & i & T & & & T & & \\
\hline & + & T & & & † & & \\
\hline
\end{tabular}

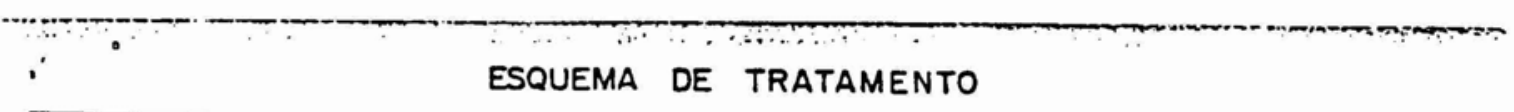

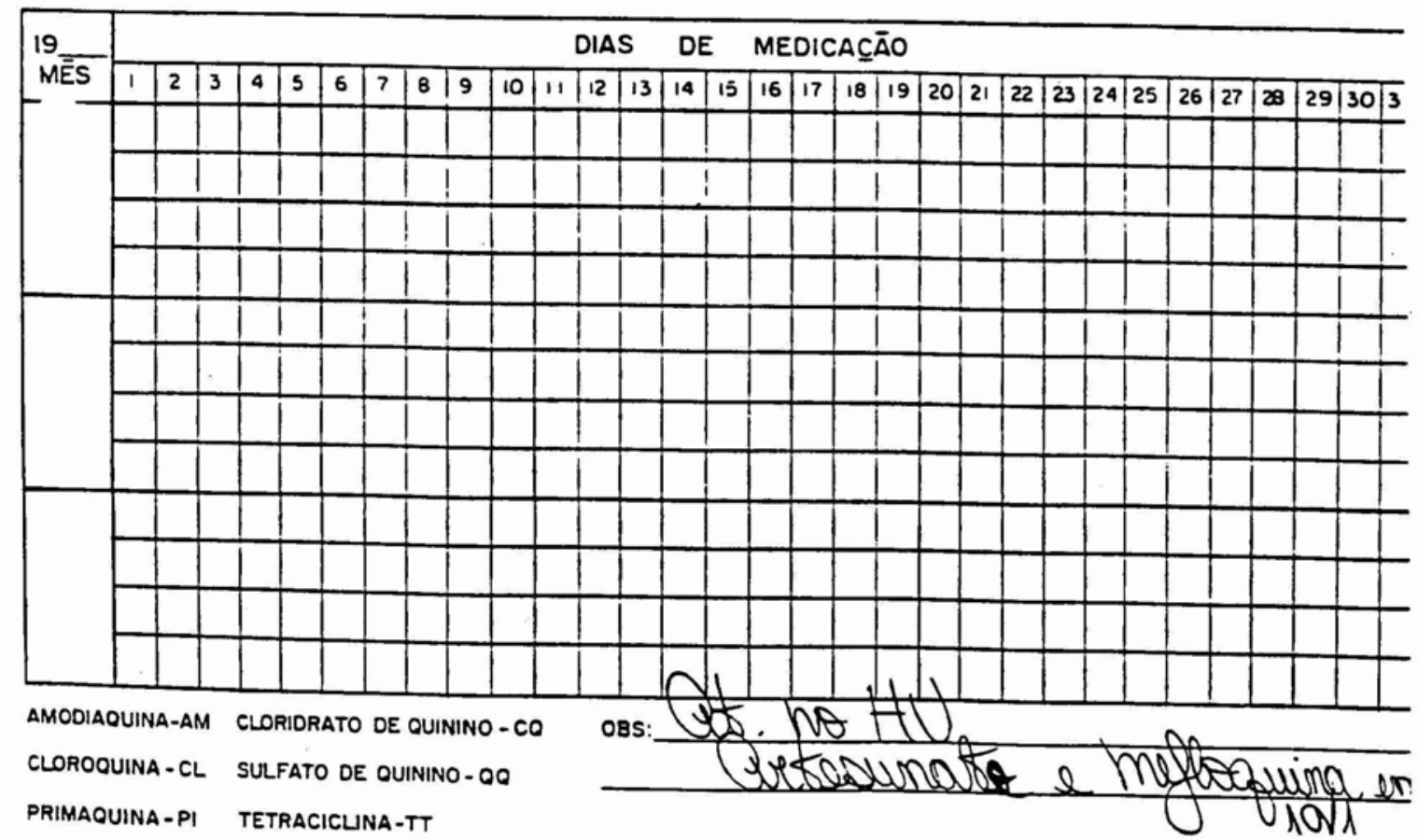




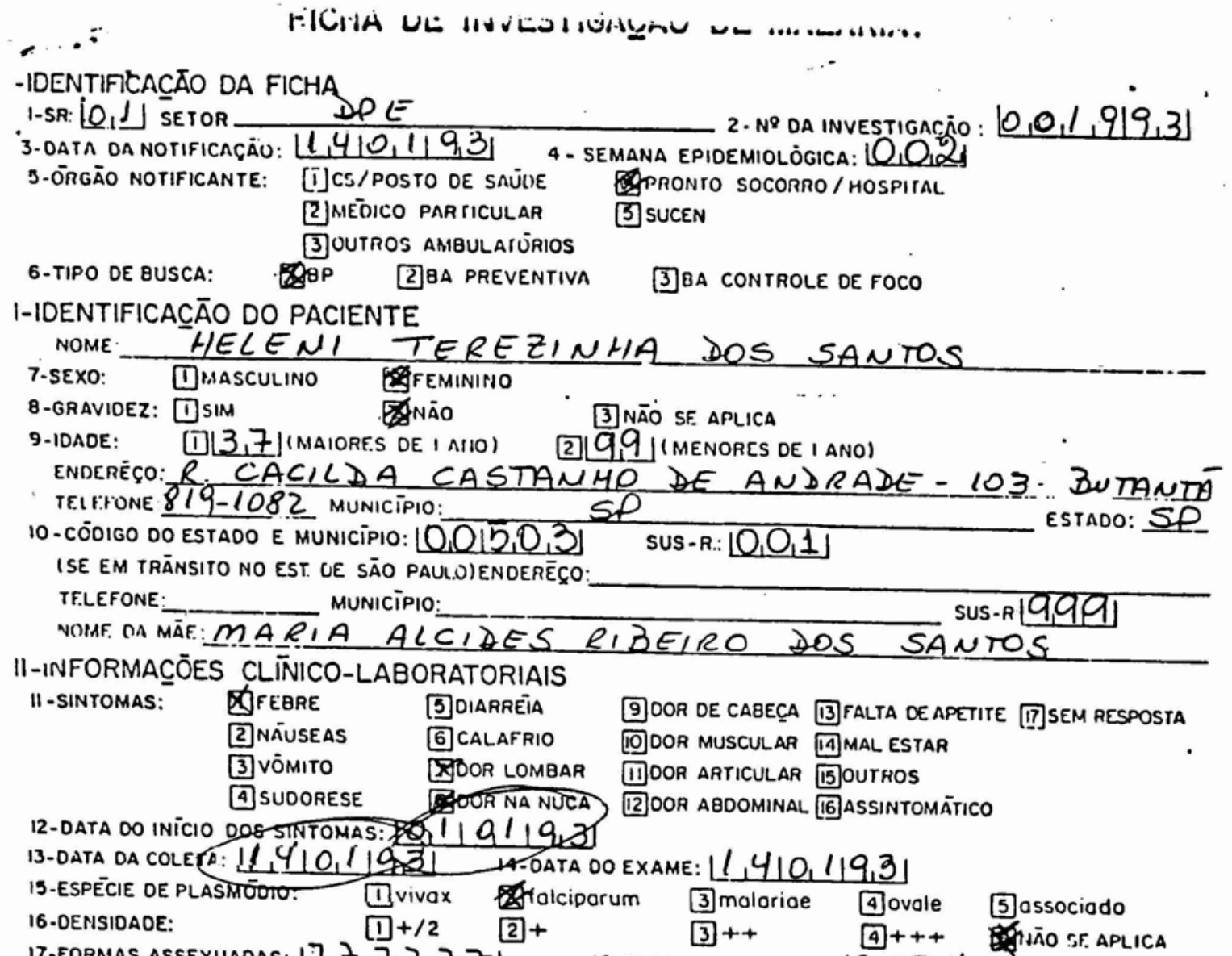
17-FORMAS ASSEXUADAS: $17,7,7,7,7,7,18$-FORMAS SEXUADAs: $10,0,2,4,0$ 19-0ATA DO INÍCIO DO tratamento: $1,410,119,3$ 20-MEDICAGĀO UTILIZADA:

\begin{tabular}{|c|c|c|}
\hline $\begin{array}{l}\text { 1]CLOROQUINA (ARAL.EN) } \\
\text { [2] AMOOIAQUINA (CAMOQUIN) } \\
\text { [3]PRIMAOUINA }\end{array}$ & $\begin{array}{l}\text { (4) SULFATO DE QUININO } \\
5 \text { CLORIDRATO DE QUININO } \\
\text { 6UETRACICLINA }\end{array}$ & $\begin{array}{l}\text { ODOXICICLINA (VIBRAMICINA) } \\
\text { DMEFLOOUINA (LARIAMAR) } \\
\text { DSEM RESPOSTA }\end{array}$ \\
\hline
\end{tabular}

21-DESTINO DOLINDAMICINA (OALACIN-C) MAOSPITAL QUAL? H. UNIVER SITARI D

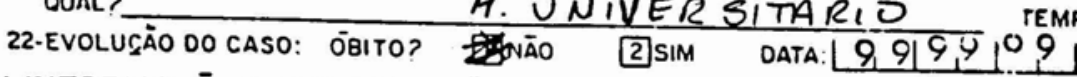
IV-INFORMAC̄ŌES EPIDEMIOLŌGICAS

23-MALĀRIA ANTERIOR - ESPËCIE DE PLASMŌDIO:

(1) 2 falcipar 3 malarioe 5 ASSOCIADO [ ]NĀO SABE 四NĀO TEVE JOUTROS ANTIMALÁRICOS: ARTESUNATO 24-HÄ OUANTO TEMPO? L D, OJMESES MEDICAMENTOS UTILIZADOS 25-DIAGNÜSTICO:

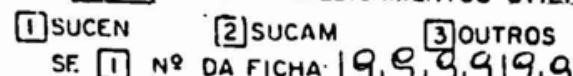

26-N DE MAL ĀRIAS ANTERIORES: 0,0

27.MEDIDAS PROFILĀTICAS UTILIZADAS DURANTE O PERIODO DE EXPOSIÇĀO: QUAIS?

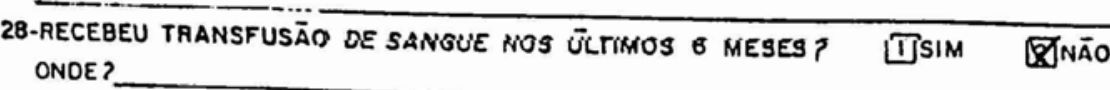

ONDE?

29-0OOU SANOUE nOS ÜLTIMOS 6 MESES? [1] SIM [ [JNAO ONOE?

30-E USUÄRIO DE DROOA NUETÄVEL? TISIM GUNAOO

DATA : $19,919,919,9$ DATA: $9,919,919,9$ DATA $19,919,919,9$ 
Análise de seqüências var de populações naturais de Plasmodium falciparum da Amazônia Brasileira

116

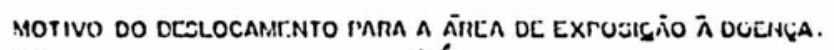

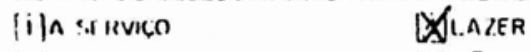

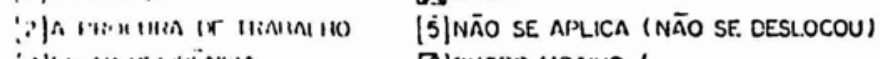

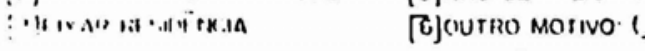

- SE TOR UU SUU-SETOR DE ATIVITADE ECONOMICA ONDE ESTÁ INSERIDA A OCU: ACTÃO OESETAPENHA.OA PELL PACIERIE OURANTE O PERIODO FM OUE CONTRAIU A DOENIGA (ANOTAR O N DE CODIGO OUE COHSTA NO MARUAL DE nCUNATC_....... $\angle A Z E R$

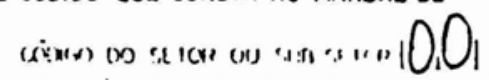

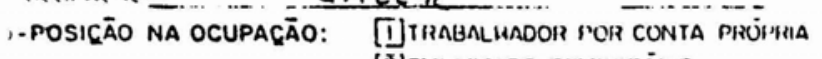

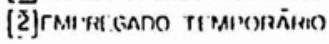

[i] phoryetinese

[3]]I MI 'RL GAUO DL HMANI NIL

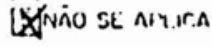

4-motivo do deslocamento paha U Estado de sāo paulo:

(X)

[ढ]OUTRO TRATAMENTO DE SAŨOE

'? FIXAR RESITEN.NCIA

[?]LAZER

[j] SLRVICOO

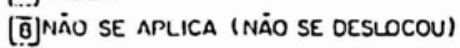

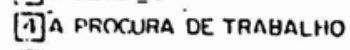

[9̈]Durro Morivo: 1

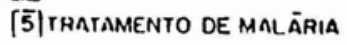

35. MANTEVE CONTATO COM SUSPEITOS DE MALĀRIA NO ESTAdO dE SĀo PAULO?

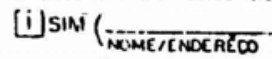

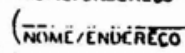

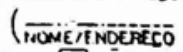

3 NÃO SABE

36-SERVICSO DE SAŨdE PROCURADOS NO ESTADO (ANTERIORES A NỌTIFICAÇAO DO CASO)

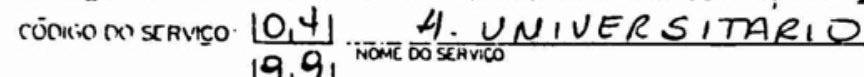
$10,9,0, ! 19,3 !$

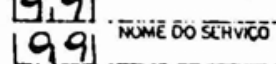
$19,919,919,91$

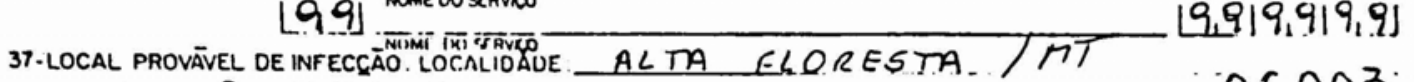
MUNICIFIO D MESMO

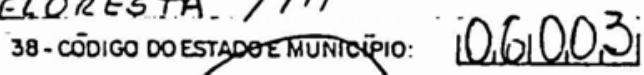
39- OUTRO PAIS:

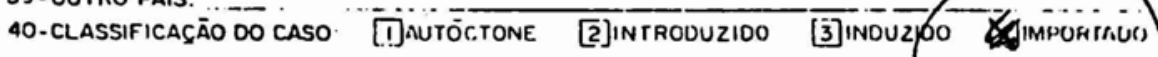
[5] FEE',sit: TEXTO: (CONSULTAR OMANUAL DE INSTRUḠ̄es DE PREENCHIMENTO).

Resicle en SD, en 16/12/92 viayon para 0 micipio de alta flevesta (MT) í passeio, en casa de pamen tes.

Dumawth o peivoclo enu que la: esterve, foi risitan duras fagendas de gado. Una proscima ab nio Bana ma I pento ore apiacos "Estância

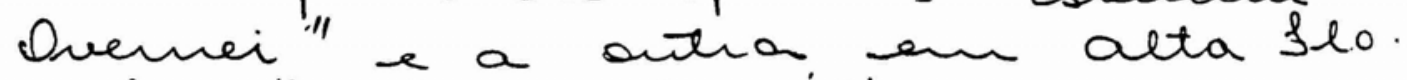
resta "Estância Amgilic a

Permamecin atí 0 ouron $04101 / 93$ retomamalo pal sas Pamlo.

Internan mo bosp inivensitáio

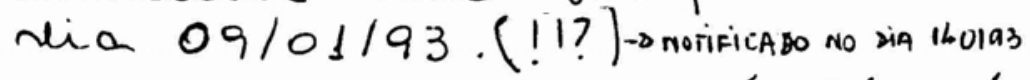

Funescigend 20101

Anexo 3 


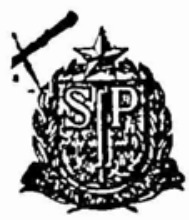

SECRETARIA DE ESTADO DA SAUDE

SUPERINTENDÊNCIA DE CONTROLE DE ENDEMIAS

S UCEN

FICHA N. $665-88$

DIRETORIA DE COMBATE A VETORES

IONE UBIRAJARA RIBEIRO DA SILUA IDADE 41 SEXOMASC. IESPONSÁVEL.

IESIDÊNCIA

BARRO

AUNICIPO

CEP INV. EPIQ N:

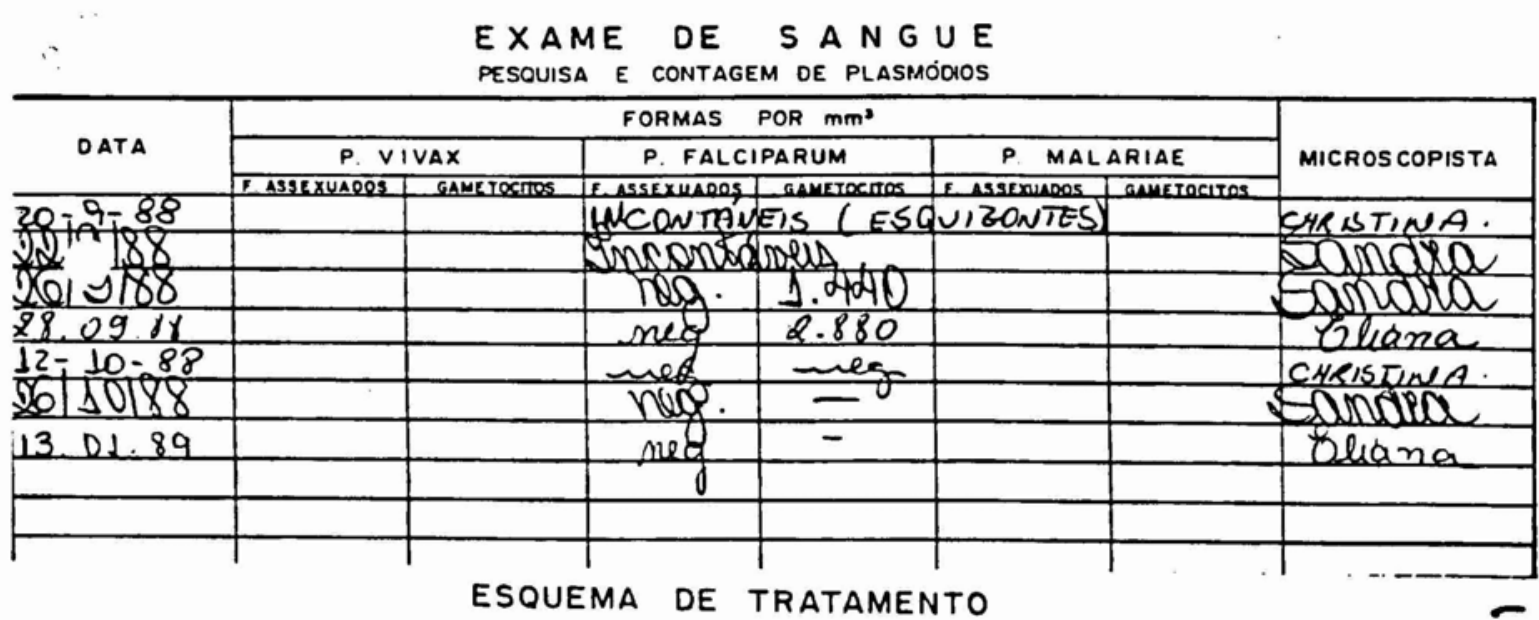

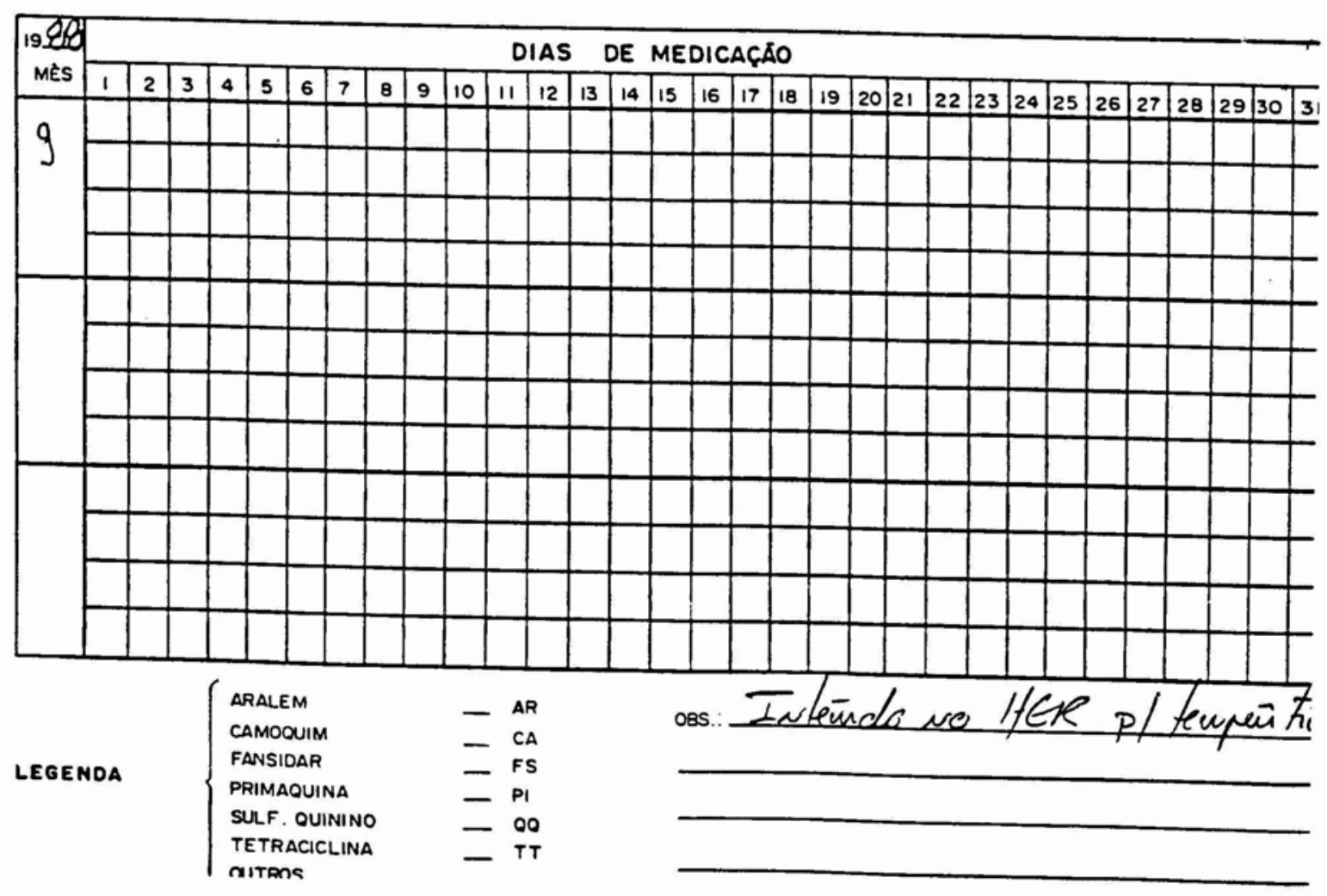


FICHA DE

INVESTIGAC̄ĀO DE MALÁRIA

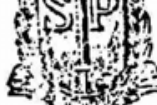

Sk... 1 SUPERTVTE SDE:ICIA DE COTTROLE DE EMCEMAS

Nositiconte SU, $\in$ N

\section{7. ?T.}

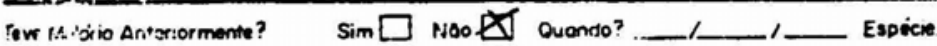

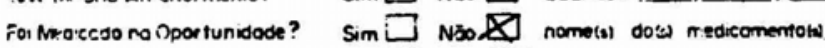

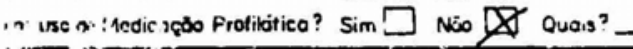

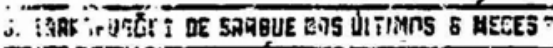

He abr." Sin. $\square$ Nód LCCEI

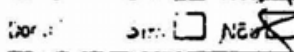

Locul dota do inici 12,9

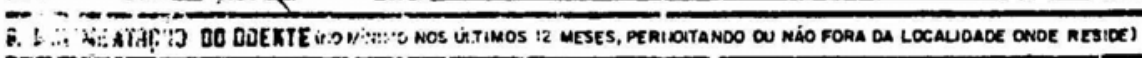

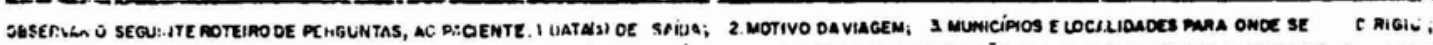

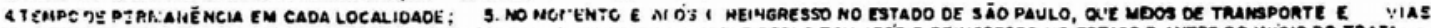

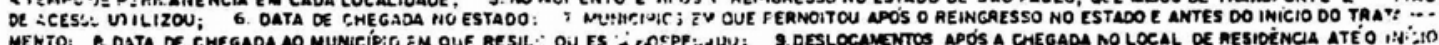

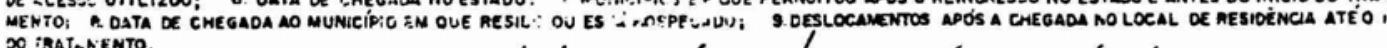

Sniu de S.Prendo en $14 / 8 / 88$ c/destivo A Gongrns' Minimu - RO ne ganuipo do Tpehado $P /$ ganuipar. In 12/9/88 ivicisi.c/

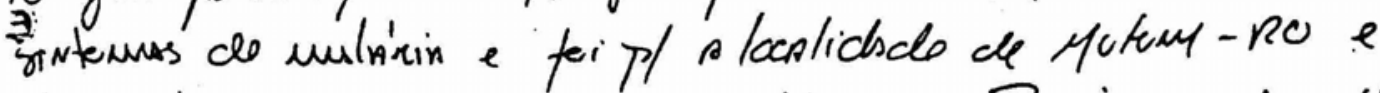

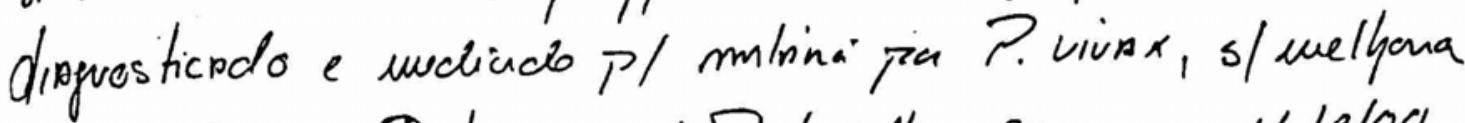
dos sinteruss. Deslocou-se p/ Panto velyo-Ro e em 16/9/88

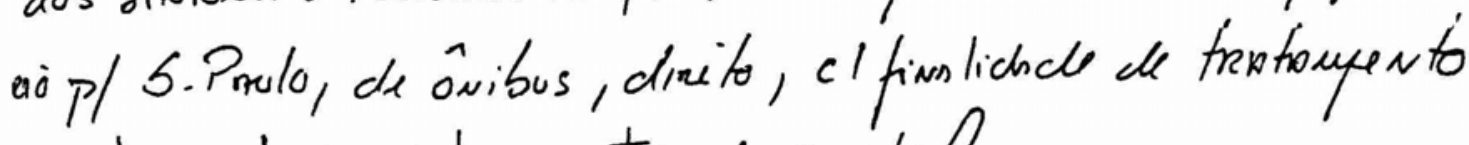
$N$ ré teve teve clesbesmentes ds cogitiol. 

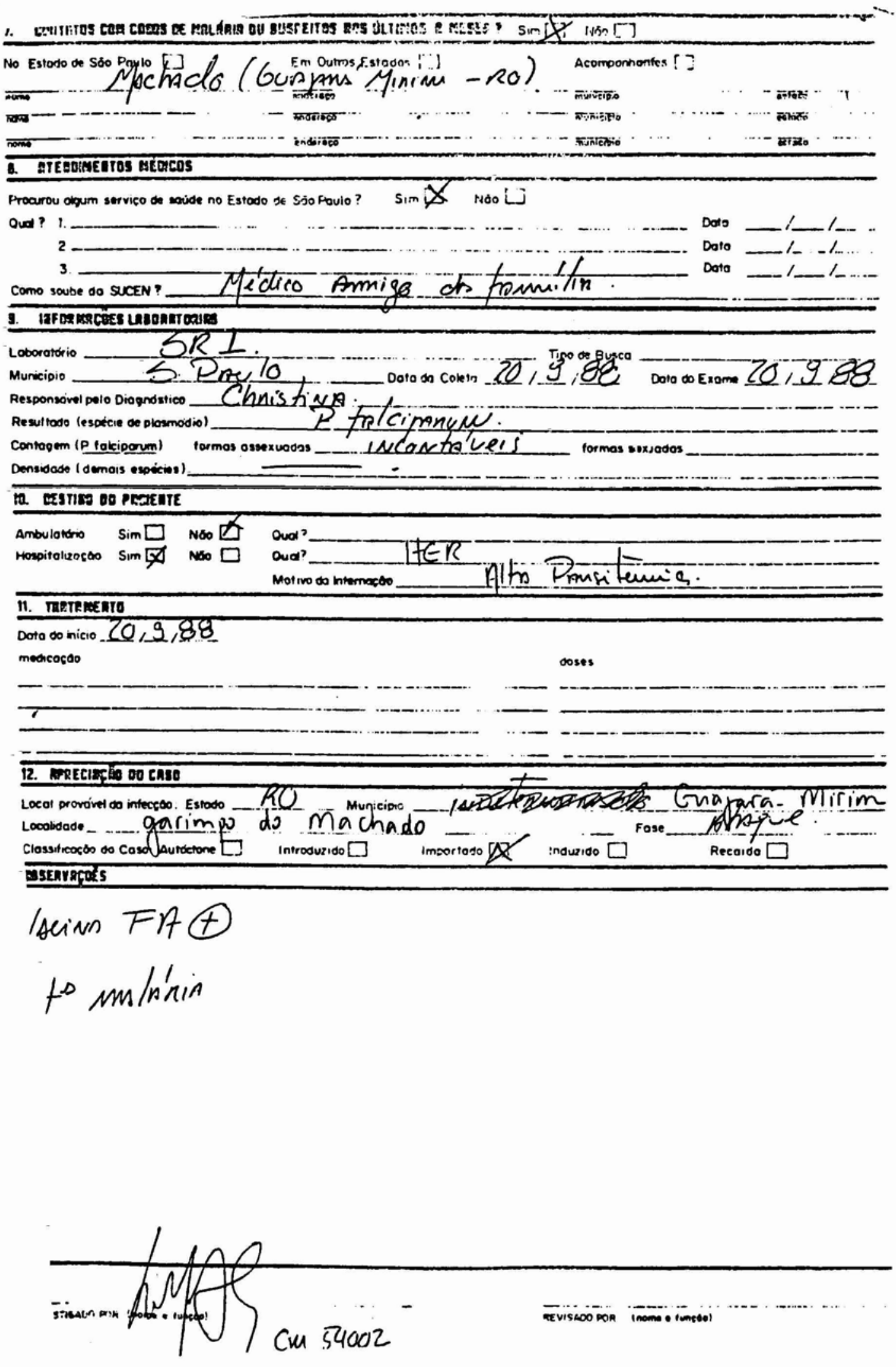


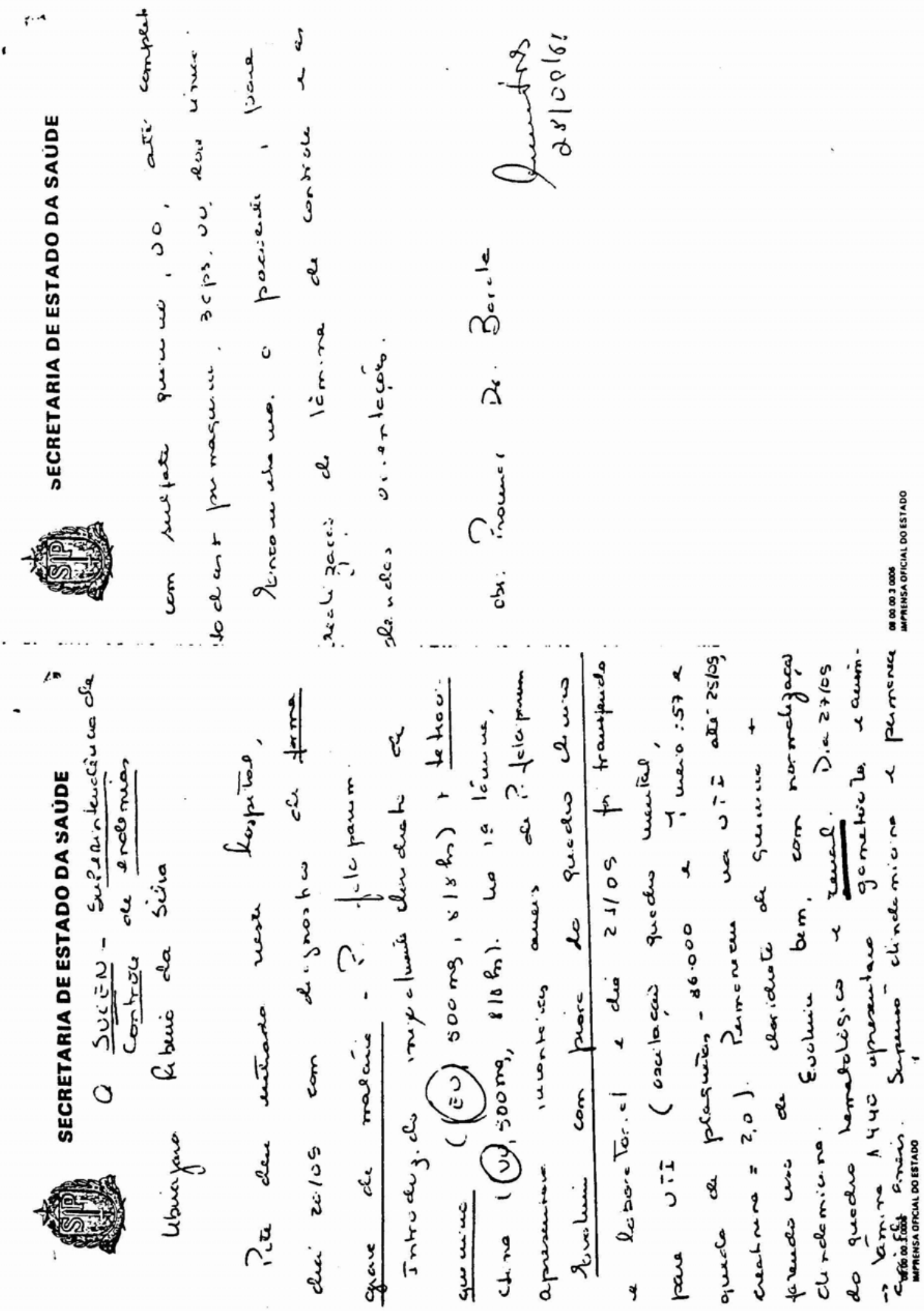


SECRETARIA de ESTAdo da SaIOE

SUCEN

SUPERWTENOENAAA DE CONTROLE DE ENDEMULS

\section{HEMOSCOPIA DE MALĀRIA}

S.R: $\mathrm{OA}$ setor: D.P.E.

Laboratório d: Malária Fichone: 7292

nome: Anderson Domingos Rinaldi idade: 18 a sexo: Maxe.

RESPONSĀVEL:

INV EPIO Ne.

RESIDĒNCIA:

BAIRRO

MUNICIPIO:

CEP.

TELEFONE:

PESQUISA E CONTAGEM DE PLASMŌDIOS

\begin{tabular}{|c|c|c|c|c|c|c|c|}
\hline \multirow{3}{*}{ DATA } & \multicolumn{6}{|c|}{ FORMAS POR $\mathrm{mm}^{3}$} & \multirow{3}{*}{ REALIZADO POR } \\
\hline & \multicolumn{2}{|c|}{ P. VIVAX } & \multicolumn{2}{|c|}{ P. FALCIPARUM } & \multicolumn{2}{|c|}{ OUTROS } & \\
\hline & F. ASSEXUADAS & GAMETOCITOS & F. ASSEXNADAS & GAMETOCITOS & F. ASSEXUADAS & GAMETÓCITOS & \\
\hline 200292 & & & INCONTAVEIS & - & & & ALARIPE \\
\hline $2 y-$ & & & mes & - & & & CHRISIINA \\
\hline $05 / 302$ & & & 100 & - & & & Samaiea \\
\hline $12-3.92$ & & & 24.760 & - & endercen & wia & CARISTINA \\
\hline $12=3-92$ & & & ne & - & & & CHIRISTINA \\
\hline रद अप & & & res. & $=$ & & & Samata \\
\hline $21-5-92$ & & & mes & 二 & & & DHRISTINA \\
\hline 01.02 .95 & 7 & t & $\gamma$ & & & & C4t25. \\
\hline 15.02 .93 & wes & 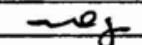 & - & - & & & CHRISTINA \\
\hline
\end{tabular}

ESQUEMA DE TRATAMENTO

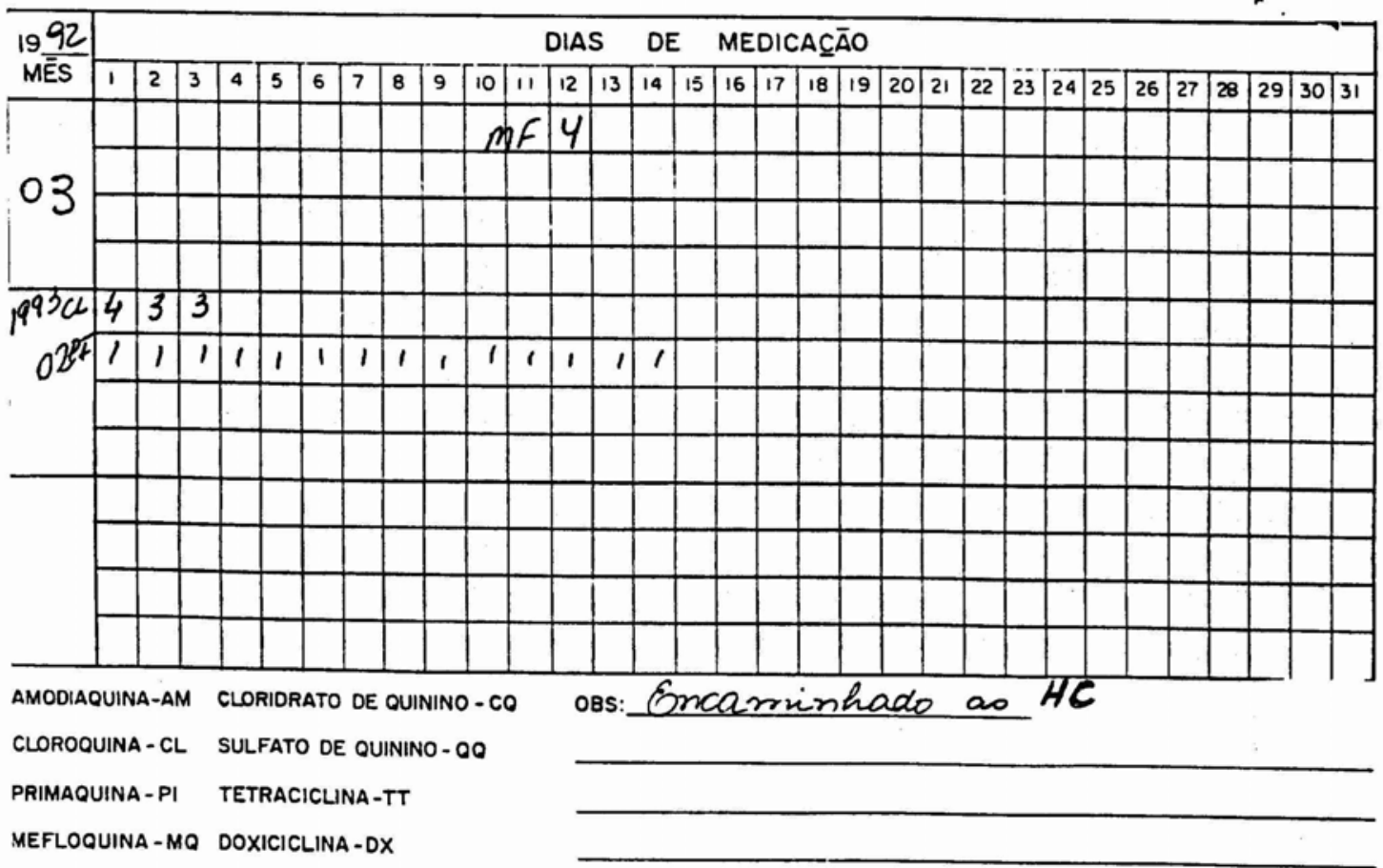


SECRETARIA OE ESTADO DA SAUVE

SUCENN

SUPEAWTENDENCA DE CONTROLE DE ENDEMINS

FICHA DE INVESTIGACATO DE MALARIA.

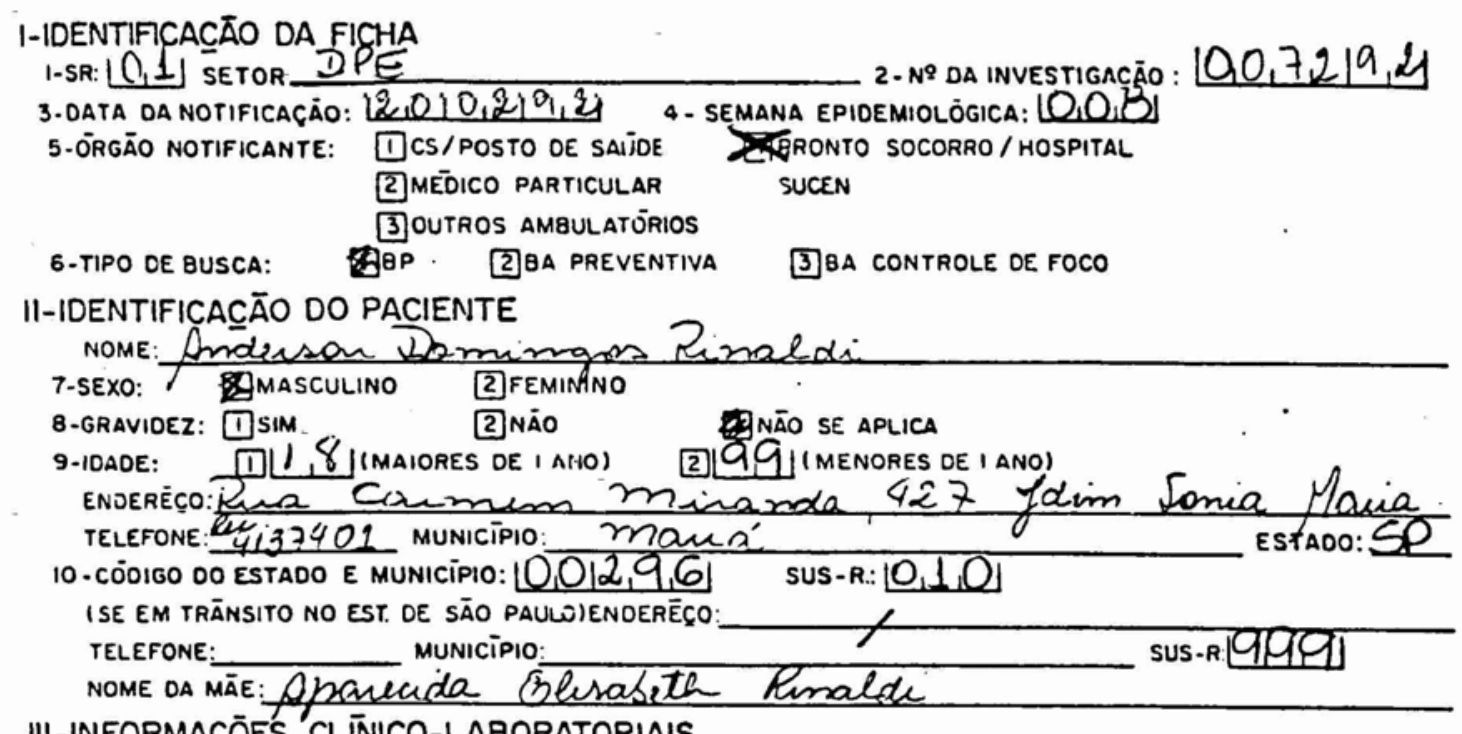

III-INFORMACŌES CLINICO-LABORATORIAIS

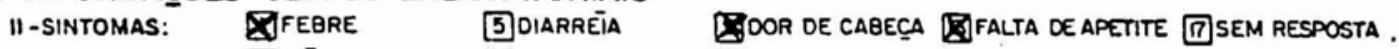

DNäuseas DCalafrio

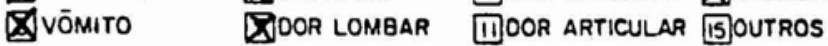

[SUDORESE BDOR NA NUCA 12 DOR ABDOMINAL 16 ASSINTOMĀTICO

12-DATA DO INICIO DOS SINTOMAS: $11810,219,21$

13-DATA DA Coleta: $12,010,219,21$ 14-DATA do exame: $12,010,2,9,2$,

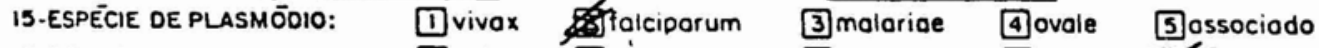

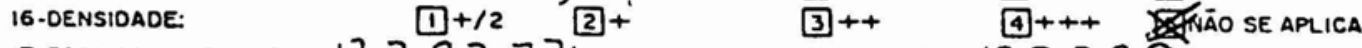

17-Formas ASSEXUAOAS: $17,7,7,7,7,71$ 18-formas seXUadas: $10,0,0,0,9$

19-0ATA dO INICIO DO TRATAMENTO: $[2,010,219,2$

20-MEDICACÄO UTILIZADA:

(1) CLOROOUINA (ARALEN) 4SULFATO DE OUININO

2. AMODIAQUINA (CAMOQUIN) 50LRIDRATO DE OUININO

3 PRIMAQUINA

5TIETRACICLINA

日DOXICICLINA (VIBRAMICINA)

9 MEFLOOUINA (LARIAMAR)

回SEM RESPOSTA

$\perp \perp$,

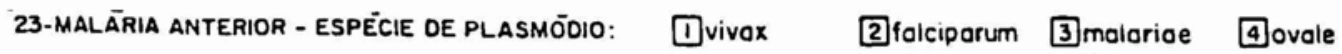

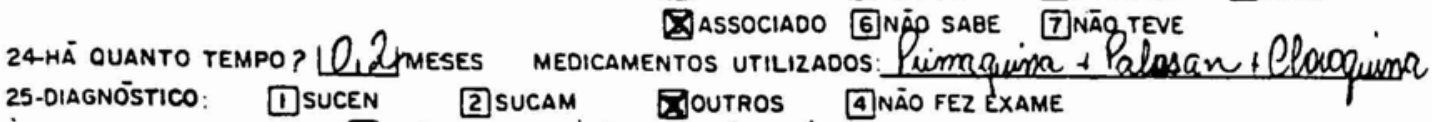

26-N? DE MALÁRIAS ANTERIORES: $\mid 0,3]$

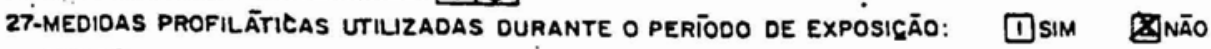
OUAIS? 28-Recebeu transfusāo de sangue nos ŪLTIMOS 6 meses? TISIM Gināo 
31-MOTIVO DO DEELOCAMENTO PARA A ÄREA DE EXPOSICQÃO Ā DOENÇA.
[i]A SERVIÇO
4. 4 LAZER
[2]A Frocura DE TRMBAUUIO
XTIXAR RESIOÉNCIA
[5] NN̄O SE APLICA (NĀO SE DESLOCOU)
[6]OUTRO MOIIVO: 1

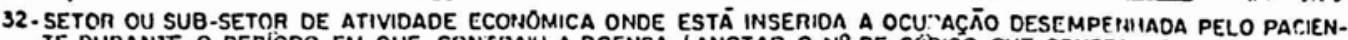
IE DURANIE O PERIDDO EM OUE CONTRAIU A DOENCA. IANOTAR O N DE CÓDIGO OUE CORSTA NO MARUUL OE
INSTRUCOES DE PAEENCHIMENTO).

OCu'Açio Govimpeiro

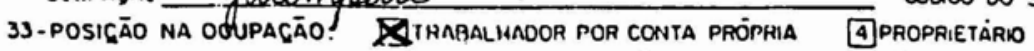

TMMTECGDO TEMTORÁRIO

5]NİO SE APUICA

[j]LMI MEGADO PE HMANENTE

34- MOTIVO dO DESLOCAMENTO PAHA O ESTAdO de SÄO PAULO:
(ī)RE.TORNO A RESIDËNCIA
6) OUIRO TRATAMENTO OE SAŨdE
[2] FIXAR RESIOE.NAII
[JLAZER

[3]Aं Scriviço

Da procuata oe trabalmo

[8]NİO SE ARLICA (NÄO SE DESLOCOU)

[5] TRATAMENTO de MALĀRIA

[G]ourro morivo: Hintos cases de maláia

35-MANTEVE CONTATO COM SUSPEITOS DE MALÄRIA NO ESTADO DE SĀO PAULO?

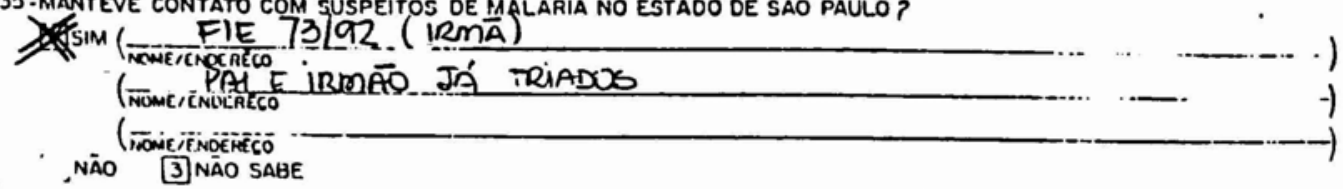

36-SERVICO DE SAŨDE PROCURADOS NO ESTADO (ANTERIORES A NOTIFICAÇAO DO CASO)

Cinivio Mistraço

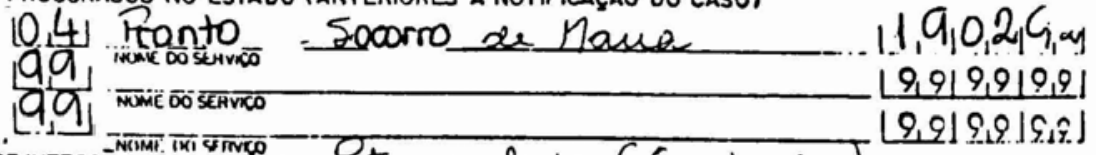

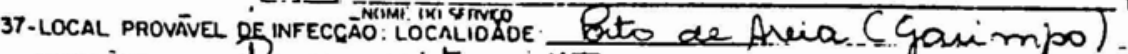

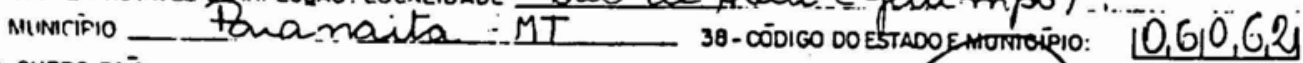

39. OUTRO PAIS

40-CLASSIFICAGÄO DO CASO "1]AUTÓCTONE [2]INTADDUzido [3]

TEXTO: (CONSULTAR O MANUAL DE INSTRUGŌES DE PREENCHIMENTO).

[s]ker.siun

Paciente relata ustar no pato grosso dusace 1988 t:1!

thando em agricultura, jerrdo que depair (paciente, jul." Lanos) inicioi traballha ra aúla de garimpo rw eifio an faramonta. Relata ter vindo mbora sir gois existia muitos casos de maláia e muif:

ouno

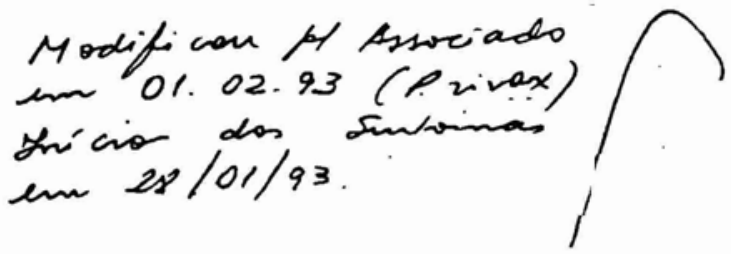




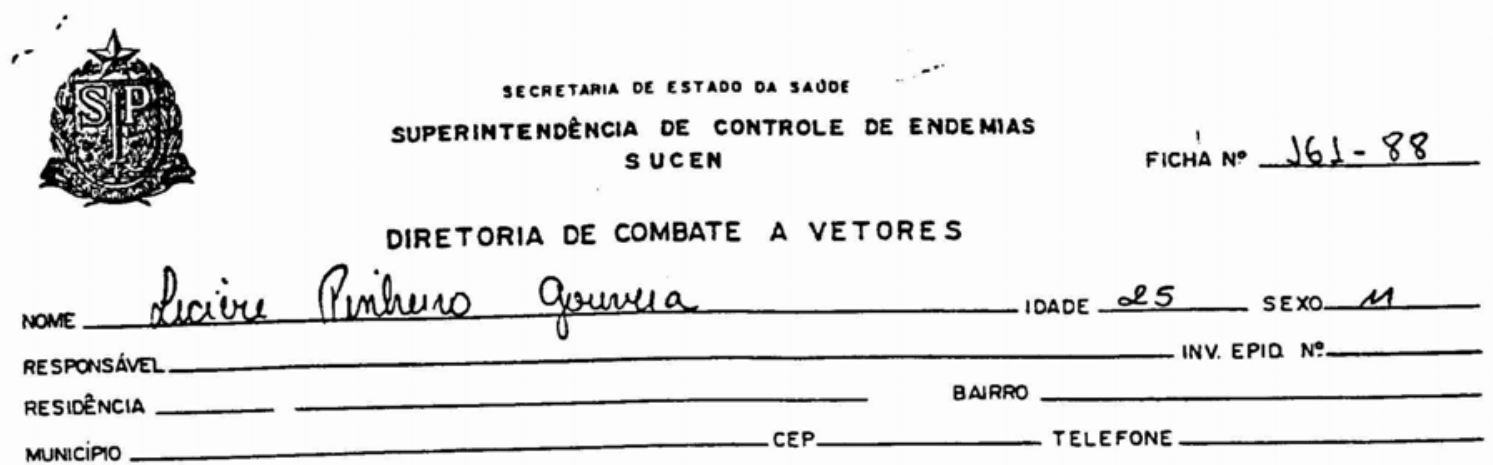

MUNICIPIO

EXAME DE S A NGUE

PESQUISA E CONTAGEM DE PLASMODOIOS

\begin{tabular}{|c|c|c|c|c|c|c|c|}
\hline \multirow{3}{*}{ DATA } & \multicolumn{6}{|c|}{ FORMAS POR $\mathrm{mm}^{3}$} & \multirow{3}{*}{ MICROS COPISTA } \\
\hline & \multicolumn{2}{|c|}{ P. VIVAX } & \multicolumn{2}{|c|}{ P. FALCIPARUM } & \multicolumn{2}{|c|}{ P MALARIAE } & \\
\hline & $F$ ASSEXUAOOS & GAMETOCHOS & IE.ASSESXUNOES & GAMETocitos & I. ASSEXuADOS & amstecitros & \\
\hline 0201288 & & & 43920 & - & & & tolsaina \\
\hline $04,0^{\prime} 28$ & & & 21520 & - & & & Chlenci \\
\hline 미 వ1 88 & & & reg. & 200 & & & \\
\hline & & & U & & & & \\
\hline & & & & & & & \\
\hline & & & & & & & \\
\hline & & & & & & & \\
\hline & & & & & & & \\
\hline & & & & & & & \\
\hline & & & & & & & \\
\hline
\end{tabular}

ESQUEMA DE TRATAMENTO

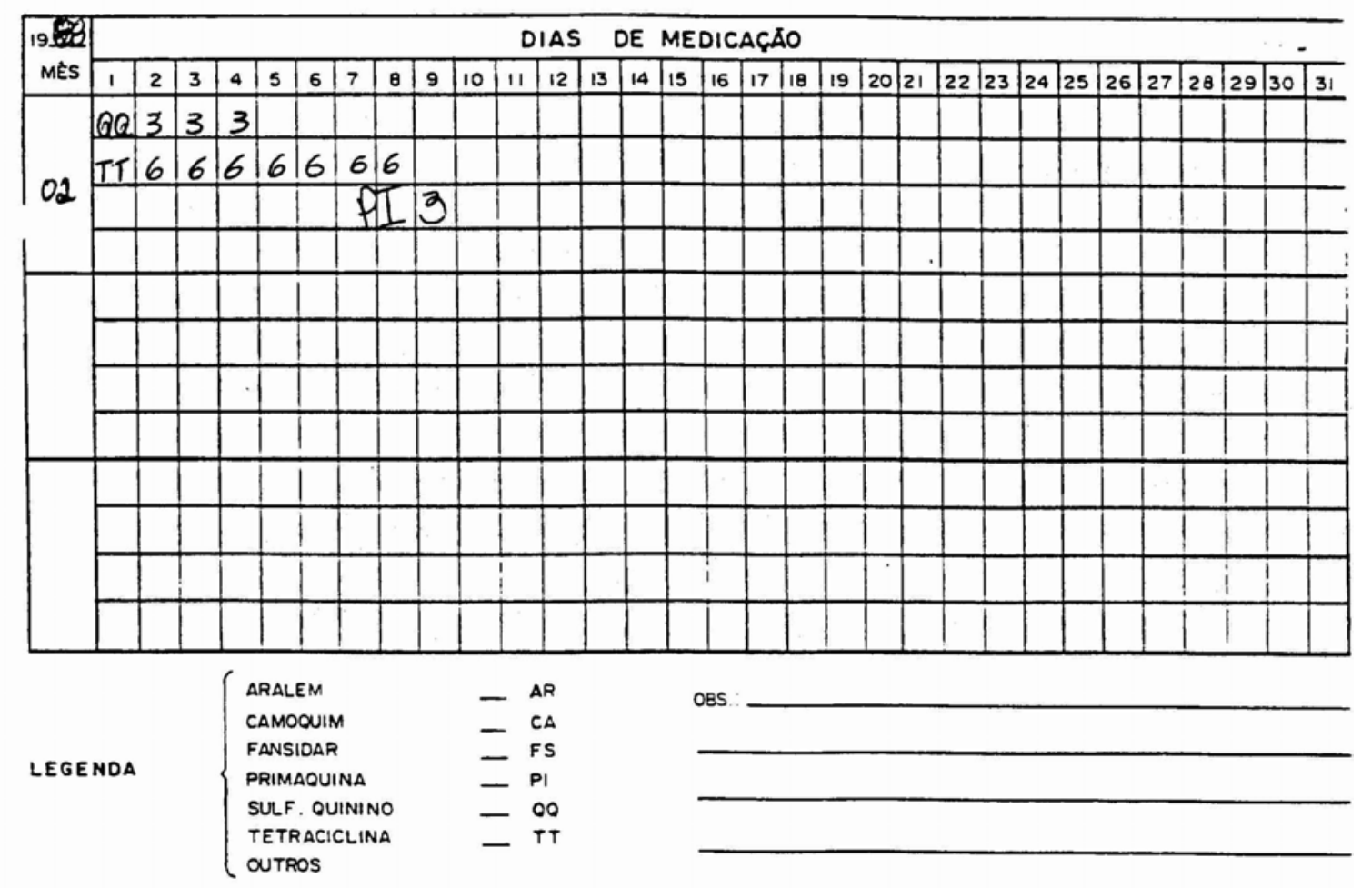




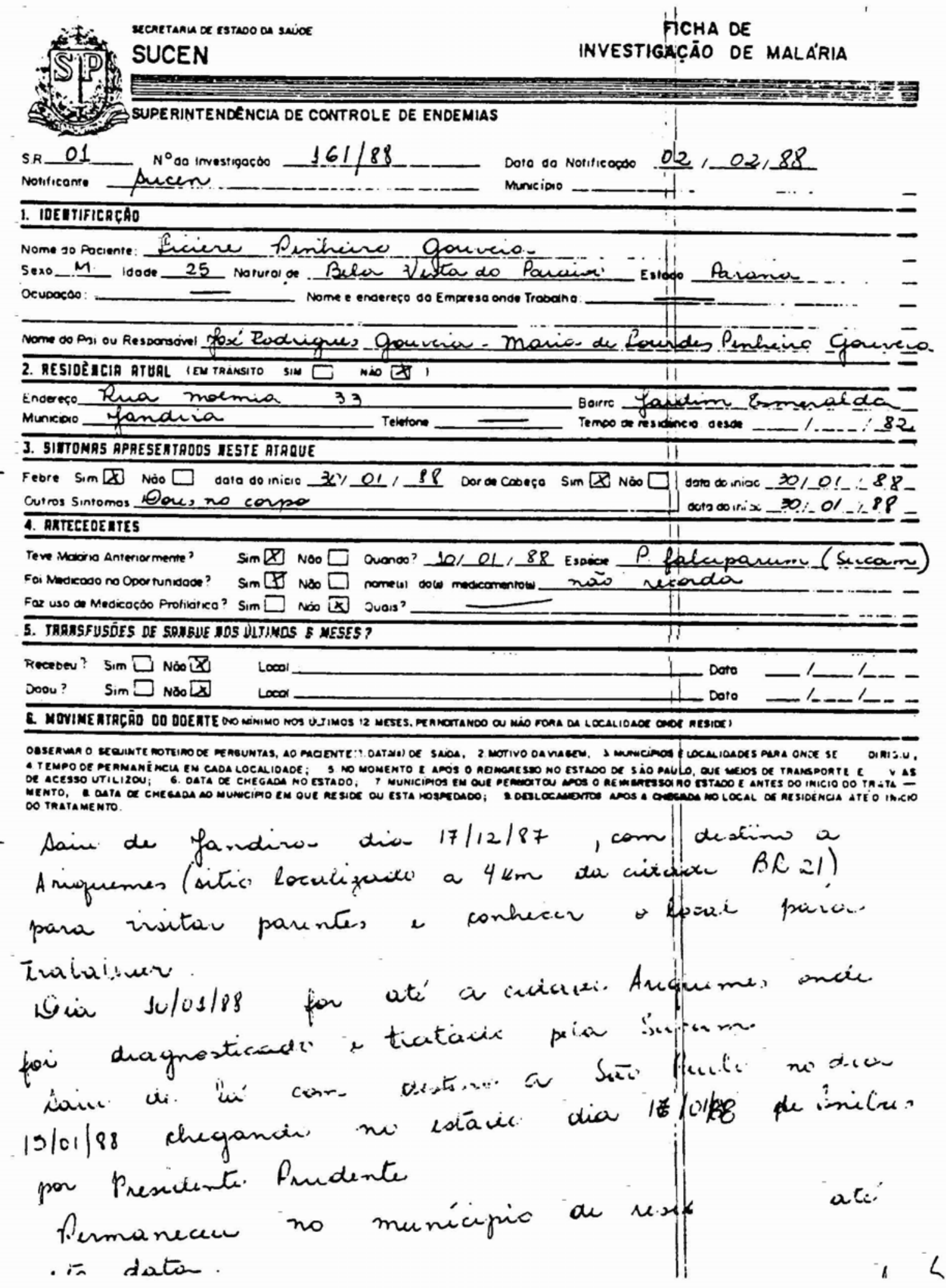




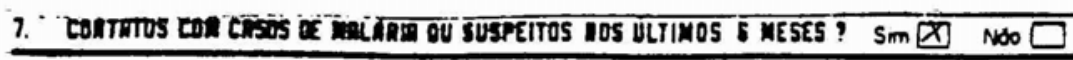

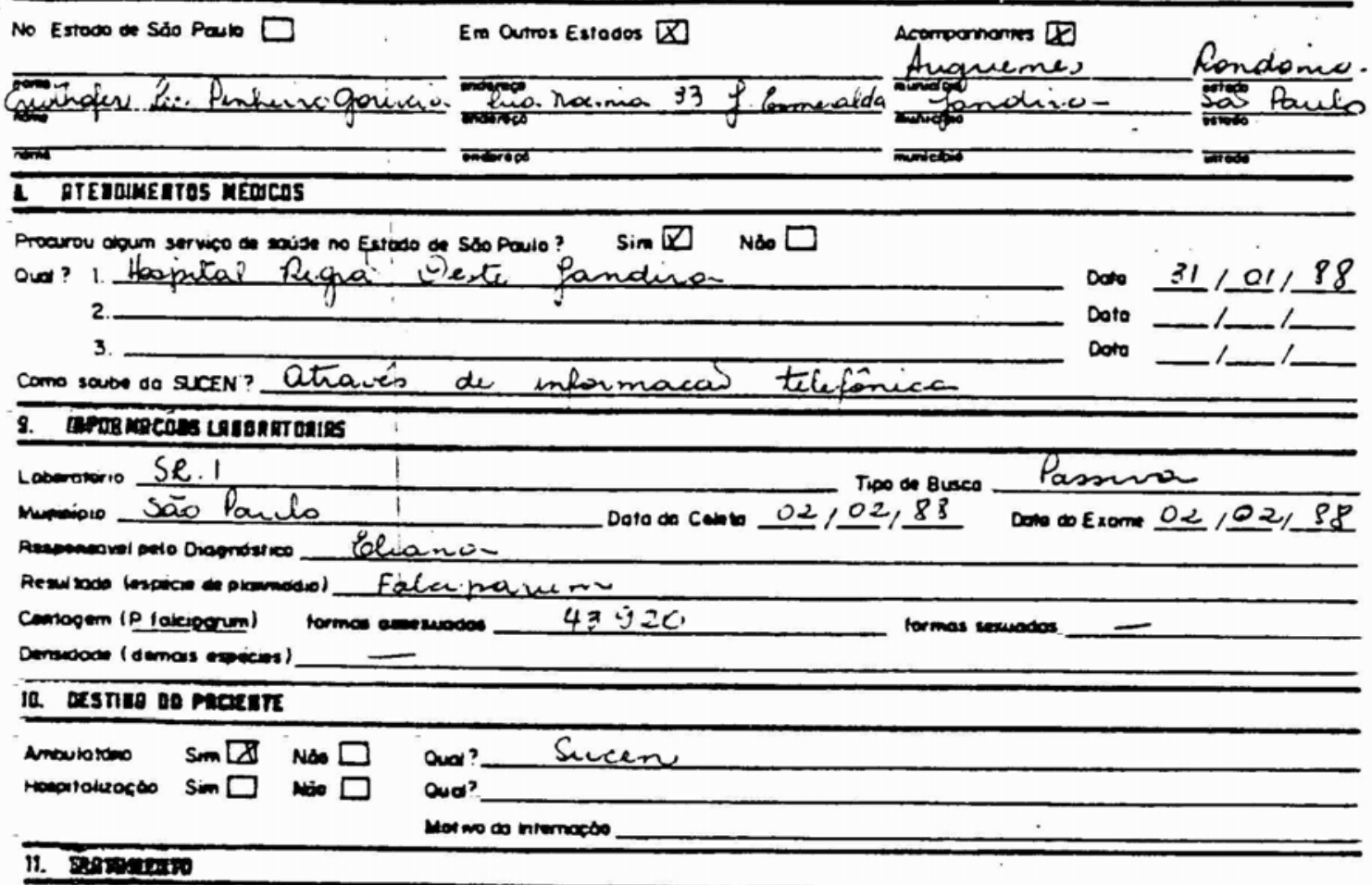

\section{Dow do nioo $02,102,88$}

mencoses.

doser

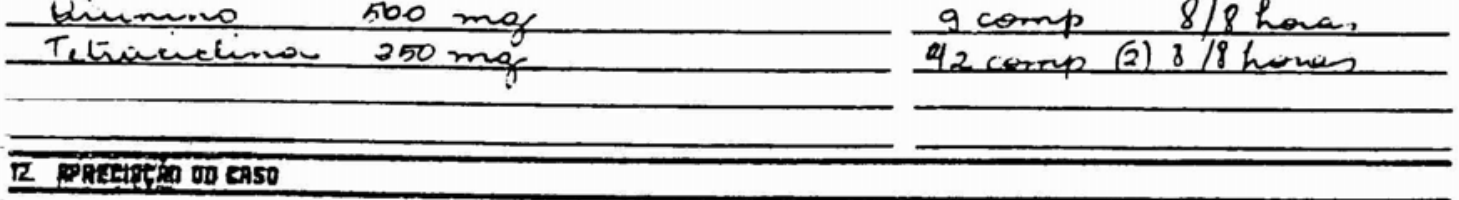

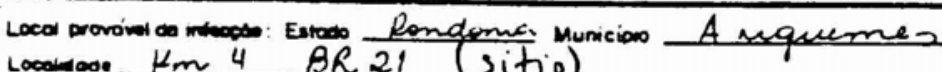

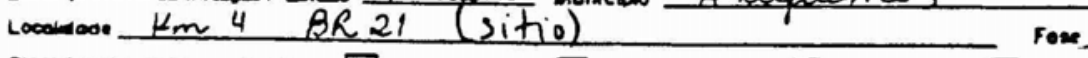

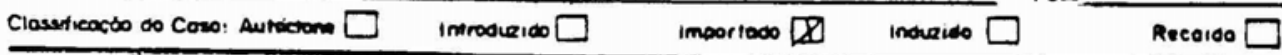

\section{Destavicotis}

- nar pretench witar para area endémeci-

- nã dacinucla contra fire amarelo

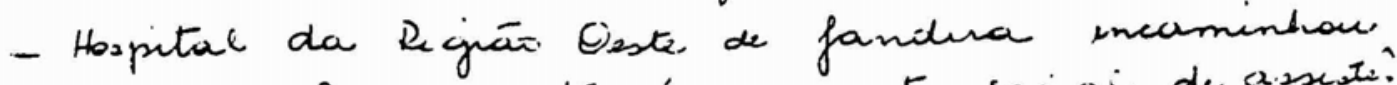

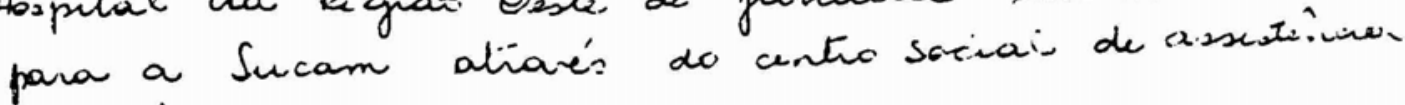
av-siciuces,

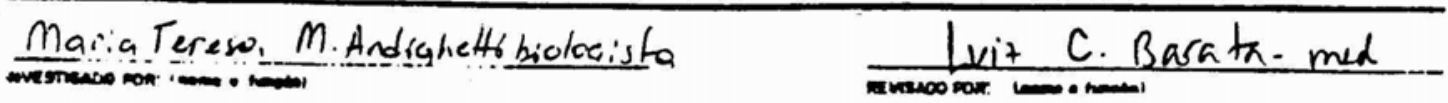




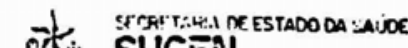

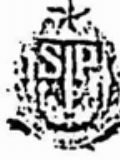

SUCEN

SUIEHINTENDENCUA DE CCIVTROLE DE EROEMINS

FICHA DE INVESTIGAC̄ÃO DE MALÂRIA.

-IDENTIFACACĀO DA FICHA

I-SR: 0,1$]$ SETOR SUCEN

3-DATA DA NOTIFICAÇĀO:

$0,410,519,0$

2- NQ DA INVESTIGACÃo: $0,2,9,1 \mid 9$, ol

5-ÖRGĀO NOTIFICANTE:

E.TS/POSTO de saũoe

2. MEDICO PARTICULAR

3 OUTROS AMBULATÓRIOS

6-TIPO DE BUSCA: ZRBPA PREVENTIVA ESA CONTROLE OE FOCO

II-IDENTIFICACĀO DO PACIENTE

NOME: JoSP ARIMATEIA OLIVRiRA

7-SEXO: ZMASCULINO 2]FEMININO

8-GRAVIDEZ: DSIM. [2]NĀO

9-IDADE: DI $2, O$ (MAIORES DE I ANO) Z9 91(MENORES DE I ANO)

ENOERËÇO: $R$ FRANLISCO ZANZINI N:SS CASA 12

TELEFONE: 9400066 MUNICIPIO: GUARUL hos

10-CÖDIGO DO ESTADO E MUNICIPIO: 10 (0) 1,9,0) SUS-R.: $10,1,5$

ISE EM TRĀNSITO NO EST. DE SĀO PAULO)ENDERĒçO:_ manmo

TELEFONE: $\quad$ MUNICIPIO: nussmo

NOME OA MĀE: RAIMVNDA Lopez do olivira

III-INFORMACŌES CLINIICO-LABORATORIAIS

II-SINTOMAS: QFEBRE SDIARREIA

[2]NÄUSEAS CALAFRIO

3 VÖMITO 7 DOR LOMBAR

¿SUDORESE DODOR NA NUCA

R-DATA DO INICLO DOS SINTOMAS: $10,210,419,0$

13-DATA DA COLETA: $10,416,519,01$ 14-DATA do exame: 10,4 in, 519,0
15-ESPËCIE DE PLASMŌDIO
Sivax
(2) folciporum
3 malarice 4 ovale
3 ++
$4++$
5 Ossociodo
16-DENSIDADE
(1) $+/ 2$
눈?

17-FORMAS ASSEXUADAS: $19,9,9,9,9,9$

19-DATA dO INICIO dO trataMENTO: $10,410,519,0$

ZOMEDICAGĀO UTILIZADA:

XILLROOUINA (ARALEN)

[2] AMODLAOUINA (CAMOOUIN)

区PRIMAOUINA

4 SULFATO DE QUININO

5 CLORIDRATO DE OUININO

Gtetraciclina

7) CLINDAMICINA (OALACIN-C)

21-DESTINO DO PACIENTE: 1 AMBULATÖRIO HOSPITAL QUAL? EMILIO RIBAS

Z2-EVOLUSÃO DO CASO: ÖBITO? WNĀO
N-INFORMACŌES EPIDEMIOLŌGICAS

23-MALĀRIA ANTERIOR - ESPËCIE DE PLASMŌDIO:

Divax

DDOXICICLINA (VIBRAMICINA)

9 MEFLOOUINA (LARIAMAR)

DSEM RESPOSTA

面OUTROS ANTIMALĀRICOS

TEMPO DE INTERNAÇĀO $Y$ ESTADO: 5 T

5 ASSOCIADO 6 NĀO SABE 7 NĀO TEVE

2O-DIAGNÖSTICO: 11 SUCEN

SE 11 N2 GICHA: $19,9,9999$

26-N DE MALĀRIAS ANTERIORES: 0,3

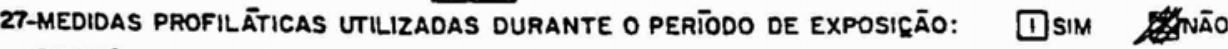
QUAIS?

28-Recebeu transfusāo de sangue nos ültimos 6 meses? 1 sim ONOE?

ONAE? 


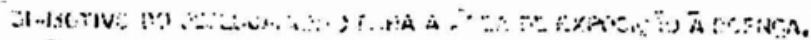

[ilis.

fij $\therefore \mathrm{int}$

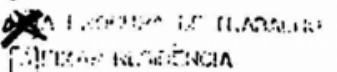

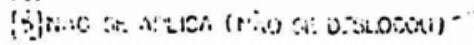

SSionitho nutrol 1

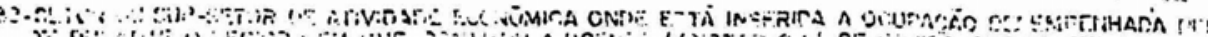

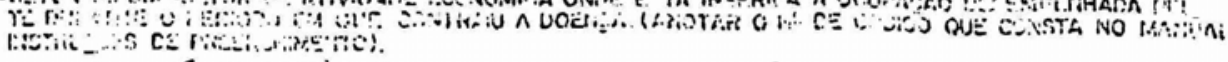

COUPA: :.... GARIM PEIRO

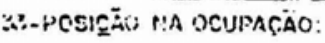

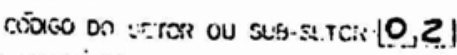

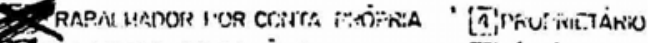

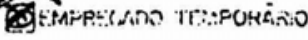

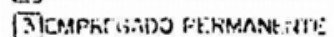

[G]ViAO SE APLICA

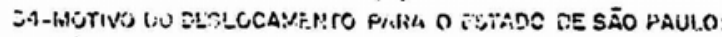

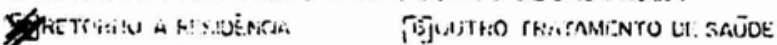

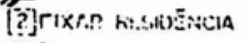

LijLATR:B

[3in sitivilu

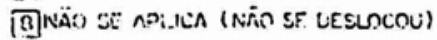

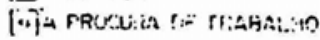

[อ]lovito muirs:

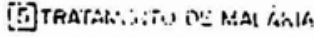

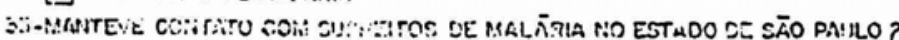

iiาsen

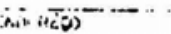

$-\cdots \cdots$

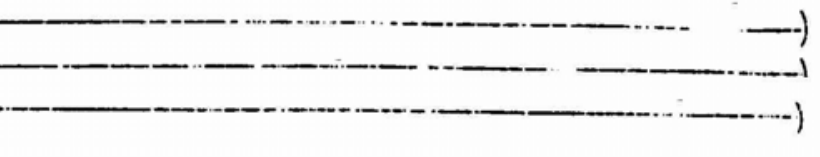

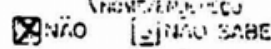

35-SERVICO DE SALIDE HROCUKL:DOS NO ESTACO (ANTERIORES A NOTIFICAẼ̃o DO CASO

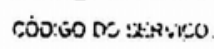

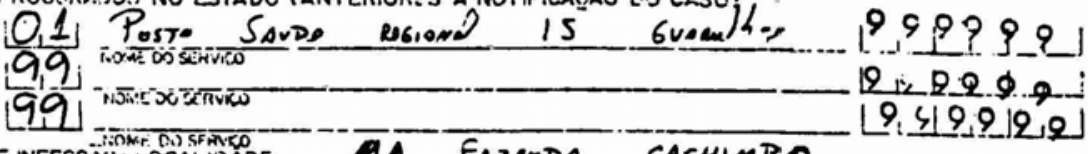

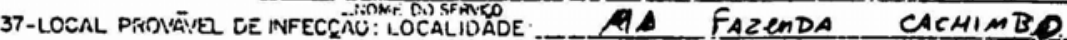

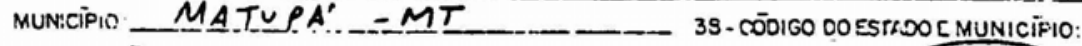

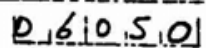

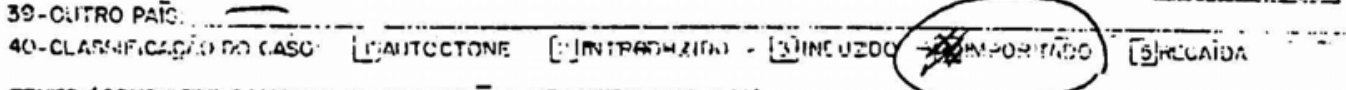

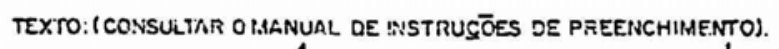

Paciente foi en Janieso/90 il atou flosesta (ut. ande fino 1 dia indo II MaTupa' and

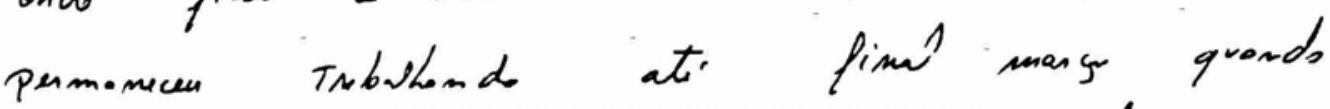
veio II S.P. Neste priodo refas Ten Tido 3 molainiss

$$
\text { Motupa' - Trobstare farente cachimpo }
$$




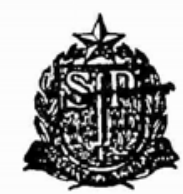

SECRETARIA OE ESTADO DA SAUDE

SUPERINTENDÊNCIA DE CONTROLE DE ENDEMIAS S UCEN

$343-90$

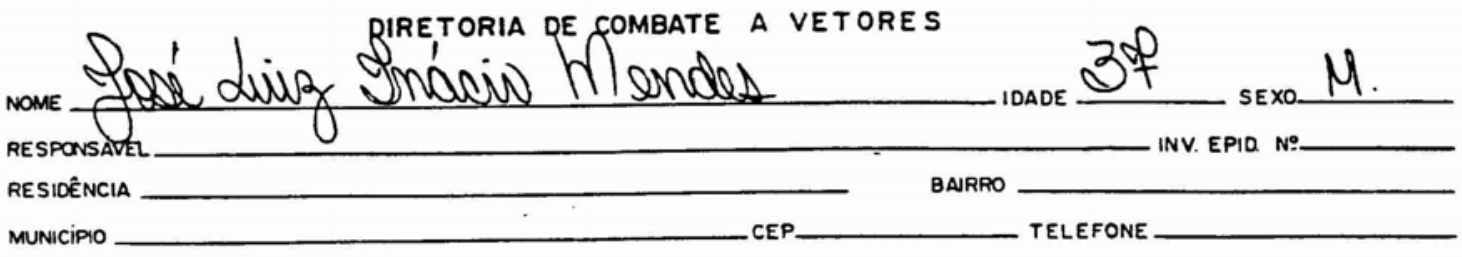

EXAME DE S A NG UE

PESQUISA E CONTAGEM DE PLASMODOIOS

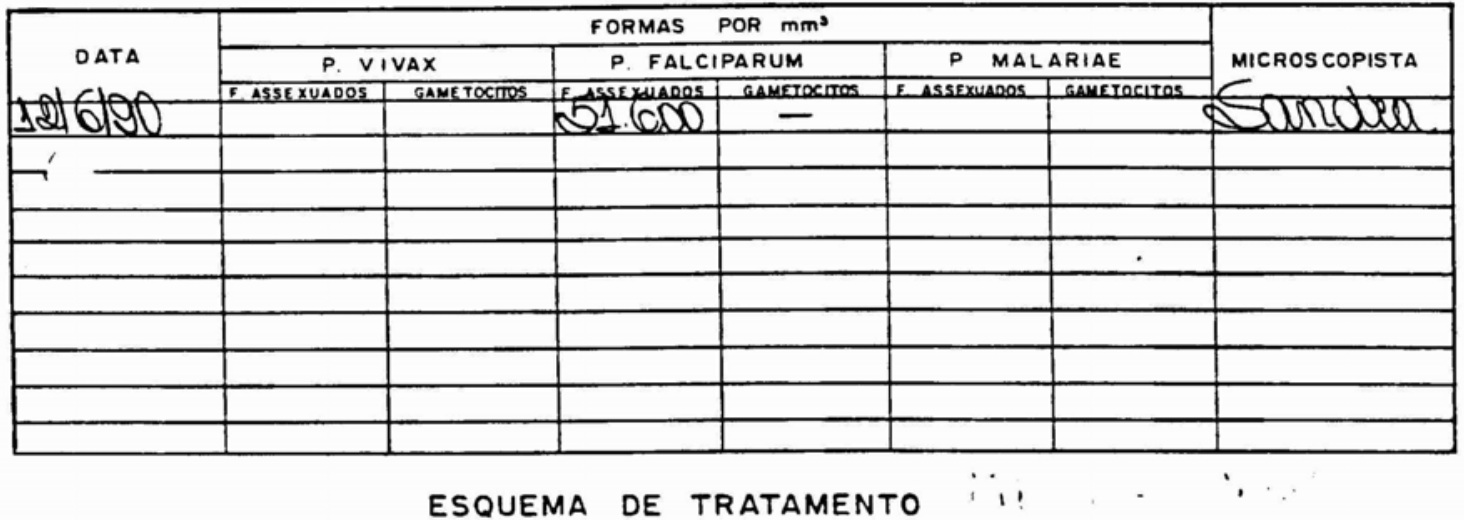

\begin{tabular}{|c|c|c|c|c|c|c|c|c|c|c|c|c|c|c|c|c|c|c|c|c|c|c|c|c|c|c|c|c|c|c|}
\hline \multirow{2}{*}{$\begin{array}{c}1990 \\
\text { MÈs }\end{array}$} & \multicolumn{30}{|c|}{ DIAS DE MEDICACGAOO } \\
\hline & 1 & 2 & 3 & 4 & 5 & 6 & 7 & 8 & 9 & 10 & 11 & 12 & 13 & 14 & 15 & 16 & 17 & 18 & 19 & 20 & 21 & $22: 2$ & $23 / 2$ & 42 & $5 \longdiv { 2 }$ & $6 \quad 6$ & 28 & 29 & 30 & 31 \\
\hline$T$ & & & & & & & & & & & $M d$ & & & & & & & & & & & & & & & & & & & \\
\hline & & & & & & & & & & & & & & & & & & & & & & & & & & & & & & \\
\hline N & & & & & & & & & & & & & & & & & & & & & & & & & & & & & & \\
\hline $\begin{array}{l}7 \\
0\end{array}$ & & & & & & & & & & & & & & & & & & & & & & & & & & & & & & \\
\hline & & & & & & & & & & & & & & & & & & & & & & & & & & & & & & \\
\hline & & & & & & & & & & & & & & & & & & & & & & & & & & & & & & \\
\hline & & & & & & & & & & & & & & & & & & & & & & & & & & & & & & \\
\hline & & & & & & & & & & & & & & & & & & & & & & & & & & & & & & \\
\hline & & & & & & & & & & & & & & & & & & & & & & & & & & & & & & \\
\hline & & & & & & & & & & & & & & & & & & & & & & & & & & & & & & \\
\hline & & & & & & & & & & & & & & & & & & & & & & & & & & & & & & \\
\hline & & & & & & & & & & & & & & & & & & & & & & & & & & & & & & \\
\hline
\end{tabular}

$\begin{cases}\text { ARALEM } & - \\ \text { CAMOQUIM } & \text { AR } \\ \text { FANSIDAR } & \text { CA } \\ \text { PRIMAQUINA } & =\text { FS } \\ \text { SULF. OUININO } & - \text { PI } \\ \text { TETRACICLINA } & - \text { TT }\end{cases}$




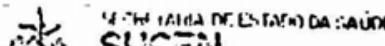

(ख) SUT:-iv

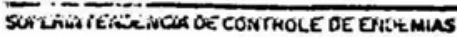

\section{FICHA DE INVESTIGACÃO DE MALARIA.}

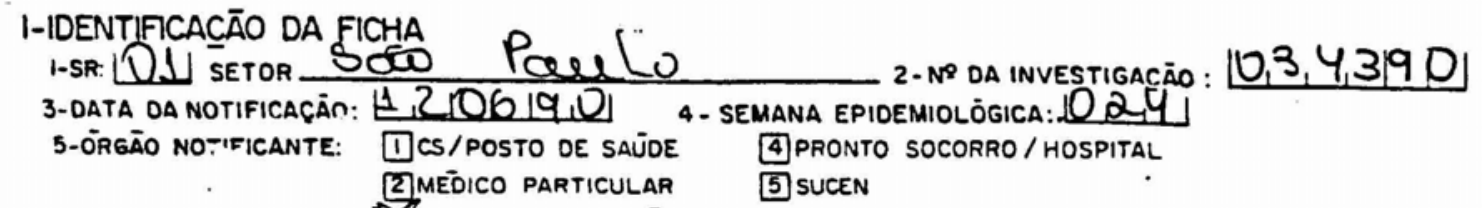

6-TIPO DE BUSCA: 2] BOA PREVENTIVA CONTROLE DE FOCO

II-IDENTIFICAC̄ĀO DO PACIENTE

NOME: Tese Lue Inacio mendes

7-SEXO:

8-GRAVIOEZ: 11 SIM 2NĀO

2) I IMENORES DE I ANO)

ENDERÉçO: Rua Vijconde de Ranaiba $n: 1316$ TELEFONE:2921022 MUNICIPIO: Sal POULJ

10-CÖDIGO DO ESTADO E MUNICIPIO: $10,015,0,31$ SUS-R: $0,0,1$

(SE EM TRĀNSITO NO EST. DE SĀO PAULO)ENDERẼÇO:

TELEFONE: MUNICIPIO:

NOME DA MÁE: Eliza da Silu Mende

III-INFORMACOOEES CLINICO-LABORATORIAIS

II-SINTOMAS: XFEBRE GIDIARREIA

JNĀUSEAS RALAFRIO

GVŌMITO ZOOR LOMBAR

SUDORESE NDOR NANUCA

R-DATA do INICIO DOS SINTOMAS: $10,710,6190$

DOOR DE CABECA GALTA DEAPETITE [1]SEM RESPOSTA

FDOR MUSCULAR [ATMAL ESTAR

GOOR ARTICULAR ISOUTROS

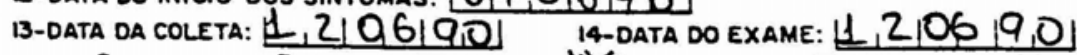

15-ESPËCIE DE PLASMŌDIO: 1 vivox 3 malarioe 4 lovale

16-DENSIDADE:

17-FORMAS ASSEXUADAS: $0,5 \pm, 6,0,0$

$3++$

$4+++$

19-OATA DO INICIO DO TRATAMENTO: $11,210619,0$

2O-MEDICACĀO UTILIZADA:

CLLOROQUINA (ARALEN)
2 AMODIAQUINA (CAMOOUIN)
3 PRIMAOUINA

4 SULFATO DE OUININO

5 CLORIDRATO DE OUININO

Gtetraciclina

7 CLINDAMICINA (DALACIN-C)

21-Destino dO PACIENTE:

90OXICICLINA (VIBRAMICINA)

MEFLOQUINA (LARIAMAR)

DI]SEM RESPOSTA

四OUTROS ANTIMALÉRICOS:TEMPO de INTERnaÇĀo 9 , das

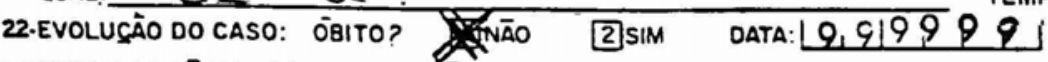

IV-INFORMACŌES EPIDEMIOLŌGICAS

23-MALĀRIA ANTERIOR - ESPËCIE DE PLASMŌDIO:

Orivox 3 falciporim 3 molarioe

5 ASSIOCIADO GNĀO SABE 7 NĀO TEVE.

4 ovale

24HÄ QUANTO TEMPO? $0, \perp$ MESES MEDICAMENTOS UTILIZADOS: $100+7$.

25-DIAGNÓSTICO: DSUCEN JUSUCAM JOUTROS FAOZ EXAME

26-N DE MALĀRIAS ANTERIORES: DA

27-MEDIDAS PROFILATTICAS UTILIZADAS DURANTE O PERIODO OE EXPOSICূĀO: DSIM QUAIS?

28-Recebeu transfusāo de sangue nos üLtimos 6 meses? DSIM ONDE? 
Análise de seqüências var de populações naturais de Plasmodium falciparum da Amazônia Brasileira

131

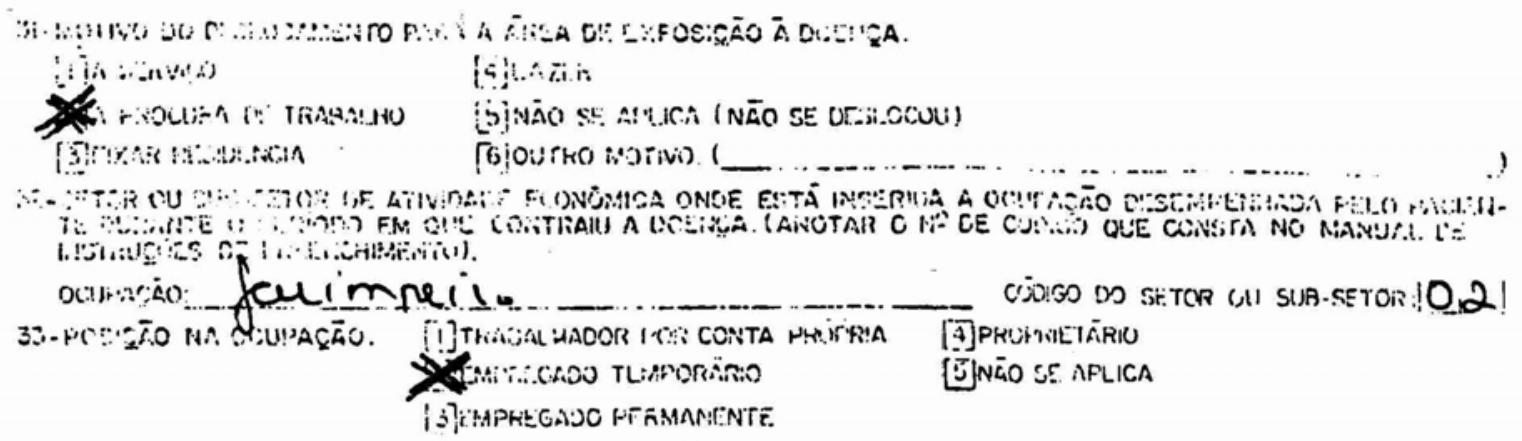

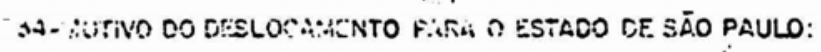

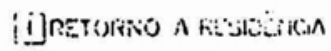

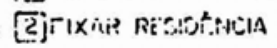

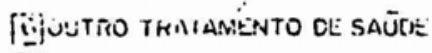

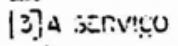

TITLAZER

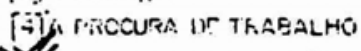

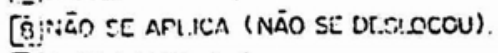

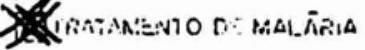

EOUTRO MOTIVO: (

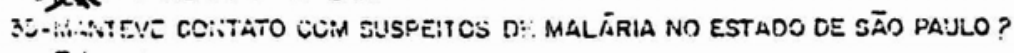

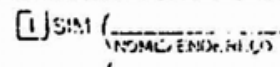

(

(n:orientinitici)

[3]

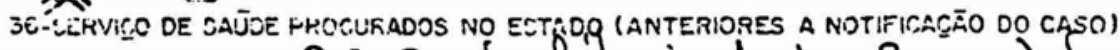

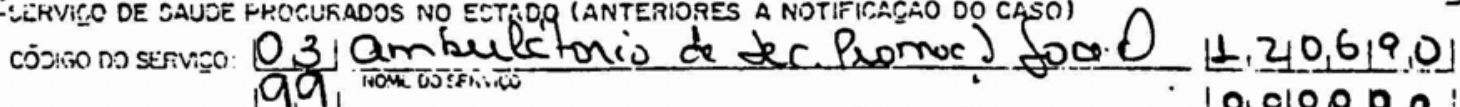

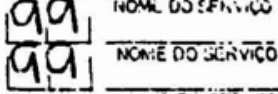

우이요요.

Q 9 9 9101.2

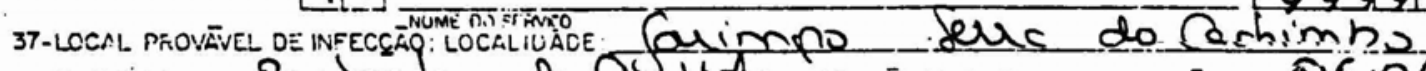

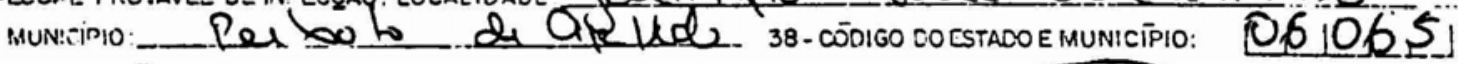

39-C:JTRE FAIS:

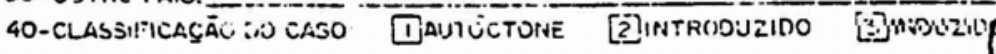

TEXTO: (CONSULTAK O MANJAL DE INSTRUSÖZS DE PREENCHIMENTO).

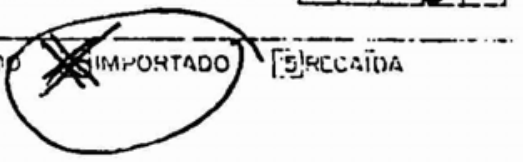

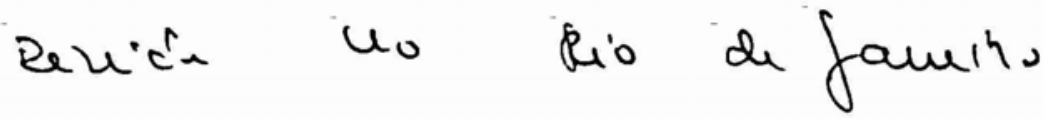

de marce 190 vicfou pl mato

onde permatucen

at $04 / 06 / 90$

nchellands us forimbs

de Senc

do Cochimho

vio pl

is paul,

de ourbur

Anexo 3 
10. ANEXO 4 


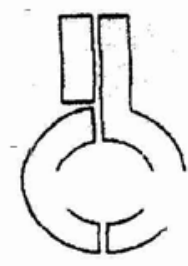

UNIVERSIDADE DE SÃO PAULO

INSTITUTO DE CIÉNCIAS BIOMEDICAS

Cidade Universitaria "Armando de Salles Oliveira"

Av. Prot. Lineu Prestes. 2415 - cep. 05508-900 São Paulo. SP - Brasil

Telefone :(55) (011) 8130900 - telefax : (55) (011) 8187438

Comissão de Ética

São Paulo. 22 de julho de 1998.

\section{REF.: PARECER 013/CEP}

Prezado Professor.

Em sua quarta reunião, realizada no dia 08 de julho p.p., a Comissão de Ética do Instituto de Ciências Biomédicas, atendendo sua solicitação, analisou o projeto sob sua responsabilidade intitulado "PLASMODIUM FACIPARUM : ANÁLISE DA EXPRESSĀO DE GENES VAR EM ISOLADOS DE CAMPO BRASILEIROS.

Após análise e discussão. a Comissão de Ética APROVOU o citado projeto. solicitando que seja reformulado o termo de anuência, o qual deve conter informações sobre o processo em linguagem simples, facilitando 0 entendimento por não especialistas.

Atenciosamente.

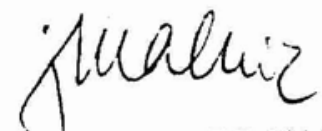

Prof. Dr. GERHARD MALNIC

Presidente em Exercicio da Comissão de Ética em Pesquisas com Seres Humanos - ICB

limo Sr.

Prof. Dr. HERNANDO A. DEL PORTILLO

Departamento de Parasitologia - ICB USP 